\title{
Circulating Tumor Cells a Real-Time Liquid Biopsy
}

Kiki Andree 

Circulating Tumor Cells

a Real-Time Liquid Biopsy

Kiki Andree 



\title{
CIRCULATING TUMOR CELLS A REAL-TIME LIQUID BIOPSY
}

\author{
PROEFSCHRIFT
}

ter verkrijging van

\begin{abstract}
de graad van doctor aan de Universiteit Twente,
op gezag van de rector magnificus,

prof.dr. T.T.M. Palstra,

volgens besluit van het College voor Promoties

in het openbaar te verdedigen

op donderdag 26 september 2019 om 16:45 uur
\end{abstract}

door

\section{Kiki Carlijn Andree}

geboren op 14 juni 1989

te Almelo, Nederland 
Dit proefschrift is goedgekeurd door:

Prof. dr. L.W.M.M. Terstappen, MD 


\section{PROMOTIE COMMISSIE:}

Prof. dr. J.L. Herek

Prof. dr. L.W.M.M. Terstappen, MD

Prof. dr. N.H. Stoecklein, MD

Prof. dr. J.W.M. Martens

Prof. dr. J.T. Zuilhof

Prof. dr. H.B.J. Karperien

Prof. dr. ir. P. Jonkheijm
Universiteit Twente (voorzitter / secretaris)

Universiteit Twente (promotor)

Heinrich-Heine Universiteit Düsseldorf

Erasmus Medisch Centrum

Wageningen Universiteit

Universiteit Twente

Universiteit Twente

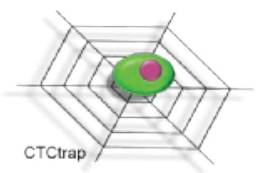

\section{CANCER

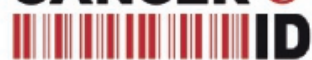

This work was financially supported by the EU FP-7 CTCTrap program \#305341, and the EU IMI CANCER-ID program \#115749-1.

Layout and design by Jules Verkade, persoonlijkproefschrift.nl.

Printed by Ipskamp Printing, proefschriften.net

ISBN: 978-90-365-4818-2

DOI: $10.3990 / 1.9789036548182$

(c) 2019 by K.C. Andree, Almelo, The Netherlands. All rights reserved. No parts of this thesis may be reproduced, stored in a retrieval system or transmitted in any form or by any means without permission of the author. Alle rechten voorbehouden. Niets uit deze uitgave mag worden vermenigvuldigd, in enige vorm of op enige wijze, zonder voorafgaande schriftelijke toestemming van de auteur. 

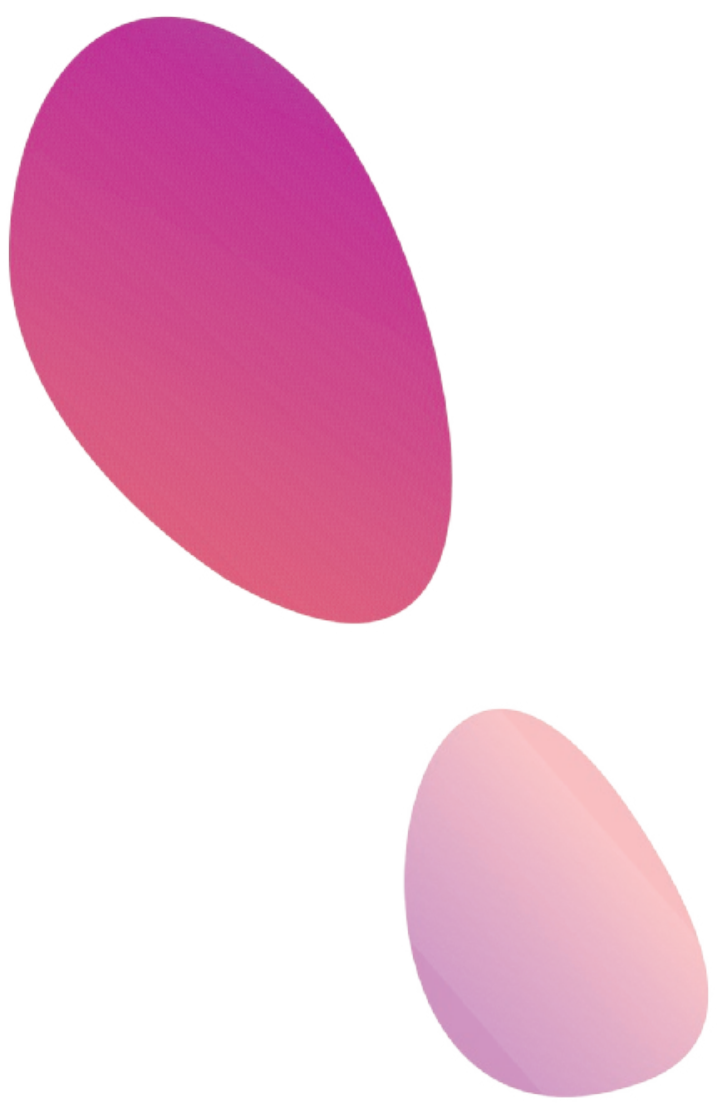
Introduction to this thesis 


\section{Introduction}

In 2018 an estimated 9.6 million deaths are expected due to cancer, making it the second leading cause of death globally. ${ }^{1}$ The most common forms of cancer are lung (2.09 million cases), breast (2.09 million cases), colorectal (1.80 million cases) and prostate (1.28 million cases) cancer. ${ }^{2}$ Cancer arises from the transformation of normal cells into tumor cells. These changes are the result of the interaction between a person's genetic make-up and external factors. When identified early, cancer is more likely to respond to effective treatment and can result in a greater probability of surviving, less morbidity, and less expensive treatment. Early diagnosis is relevant in all settings and the majority of cancers. For adequate and effective treatment a correct cancer diagnosis is essential. Every cancer type requires a specific treatment plan, based on the tumor characteristics, that includes one or more options such as surgery, radiotherapy, and chemotherapy. Diagnosis is traditionally done by means of imaging (e.g. ultrasound, CT, MRI scan) and lab tests followed by confirmation through a biopsy of the tumor. Imaging and lab test are not sufficient to make a definitive diagnosis and surely are not capable to determine the genetic and protein make-up of the tumor for which cells of the actual tumor(s) are needed. Individual tumors can consist of diverse subpopulations, and frequently not all subpopulations present in the tumor(s) are detected. The heterogeneity of the tumor frequently increases with the advance of the disease and is heavily selected under therapy. Availability of tumor cells to identify the changes during the course of the disease is essential to assess their composition and determine the changes for certain therapies to be effective. As tumor biopsies cannot always be obtained, sampling of the blood to isolate tumor cells that have been released by the tumors throughout the body are being pursued to obtain a sufficient number of tumor cells and these circulating tumor cells can then serve as a liquid biopsy.

Circulating tumor cells (CTC) are cells that shed from a tumor site enter the blood, spread through the body and can form metastases at distant sites. These CTC may therefore represents the primary tumor in those cases where the tumor has not spread or the tumors spread throughout the body in case of metastasis. The presence of CTC in blood is a prognostic marker and predictor for patient outcome in major cancer types. CTC may have important prognostic and therapeutic implications but as their numbers are very small, detection is very difficult. CTC are found in frequencies in the order of 1 - 10 CTC per $\mathrm{mL}$ of whole blood in patients with metastatic disease. For comparison, $1 \mathrm{~mL}$ of blood contains around 5 million white blood cells and around 5 billion red blood cells. Techniques to isolate and characterize CTC can contribute to enhanced treatment efficiency and improve 
patient outcome. This does not only account at time of diagnosis but also during treatment, as tumor characteristics during treatment might change different treatment approaches are necessary. The isolation and characterization of CTC during treatment can serve as a real-time liquid biopsy. Currently the only FDA approved CTC enumeration technology is the CellSearch ${ }^{\circledR}$ system which makes use of the epithelial cell adhesion (EpCAM) molecule, present on cancer cells of epithelial origin, to magnetically separate CTC from the other blood components. Cellsearch, and also other technologies usually isolate CTC from $7.5 \mathrm{~mL}$ of blood. However, in many patients no CTC are detected in $7.5 \mathrm{~mL}$. Predictions suggest that virtually all patients including those who do not have detectable CTC have at least 1 CTC in $5 \mathrm{~L}$ of blood. ${ }^{3}$ Therefore techniques allowing for the isolation of CTC from large volumes of blood would be very beneficial for realizing a successful liquid biopsy.

This thesis describes the development of new technologies to isolate CTC both from small as well large blood volumes. Allowing for their enumeration and characterization. Sampling of large blood volumes and isolation of CTC thereof has been examined in patient studies.

\section{Thesis Outline}

In chapter 1 we discuss the CellSearch ${ }^{\circledR}$ system and the challenges that come along using this technique. We review challenges faced during the development of the CellSearch system and the difficulties in assigning objects as CTC. The large heterogeneity of CTC and the different approaches introduced in recent years to isolate, enumerate and characterize CTC results in a large variation of the number of CTC reported urging the need for a uniform and clear definition of CTC. In chapter $\mathbf{2}$ we developed antibody functionalized glass slides for the capture of CTC. We determined the binding affinity constants and epitope binding of the EpCAM antibodies VU1D-9, HO-3, EpAb3-5 and MJ-37. Binding of cells from the breast carcinoma cell line to the functionalized surfaces was compared. This chapter shows that the choice of antibody to capture CTC should be based on multiple assays. In chapter $\mathbf{3}$ we continue using antibody functionalized surfaces. Here we used combinations of antibodies targeting different antigens and/or epitopes. Also, we evaluated the conditions needed to isolate tumor cells from blood while passing antibody coated surfaces. In chapter $\mathbf{4}$ we developed and evaluated an EpCAM independent CTC isolation method combined with self-seeding microwells to obtain single viable CTC from blood and assess their potential to expand. In chapter $\mathbf{5}$ we proceed with the evaluation of EpCAM independent CTC isolation techniques both from small and large blood volumes. We also evaluate EpCAM dependent techniques of which most notably the therapeutic apheresis column developed within the 
European CTCTrap consortium to isolate CTC from the entire blood volume of a patient. In chapter $\mathbf{6}$ and chapter $\mathbf{7}$ we evaluate the methods developed for CTC isolation from large blood volumes, by means of diagnostic leukapheresis (DLA), in samples from metastatic breast and prostate in chapter 6 and non-small cell lung cancer patients in chapter 7 . We compared CTC counts in $7.5 \mathrm{~mL}$ of blood using CellSearch with CTC detected in DLA.

\section{References}

$1 \mathrm{WHO}$, Cancer, https://www.who.int/news-room/ fact-sheets/detail/cancer, (accessed 10 February 2019).

2 WHO, All cancers fact sheet, http://gco.iarc.fr/today/ fact-sheets-cancers, (accessed 10 February 2019).

3 F. A. W. Coumans, S. T. Ligthart, J. W. Uhr and L. W. M. M. Terstappen, Clin. Cancer Res., 2012, 18, 5711-5718. 


\section{Contents}

Chapter 1 Challenges in Circulating Tumor Cell Detection by the CellSearch System 13

Chapter 2 Capture of Tumor Cells on anti-EpCAM Functionalized Poly(Acrylic Acid) Coated Surfaces

Chapter 3 Tumor Cell Capture from Blood by Flowing Across Antibody-coated Surfaces

Chapter 4 Self-Seeding Microwells to Isolate and Assess the Viability of Single

Circulating Tumor Cells

Chapter 5 Techniques to Isolate Circulating Tumor Cells from Large Blood Volumes

Chapter 6 Towards a Real Liquid Biopsy in Metastatic Breast and Prostate Cancer: 129 Diagnostic LeukApheresis Increases CTC Yields in a European Prospective Multi-center Study (CTCTrap)

Chapter 7 Increasing Yield of Circulating Tumor Cells in NSCLC Patients Through 145 Diagnostic Leukapheresis

Chapter 8 Conclusions \& Outlook

Appendices Summary

Samenvatting

List of Publications 178

Acknowledgments 184 

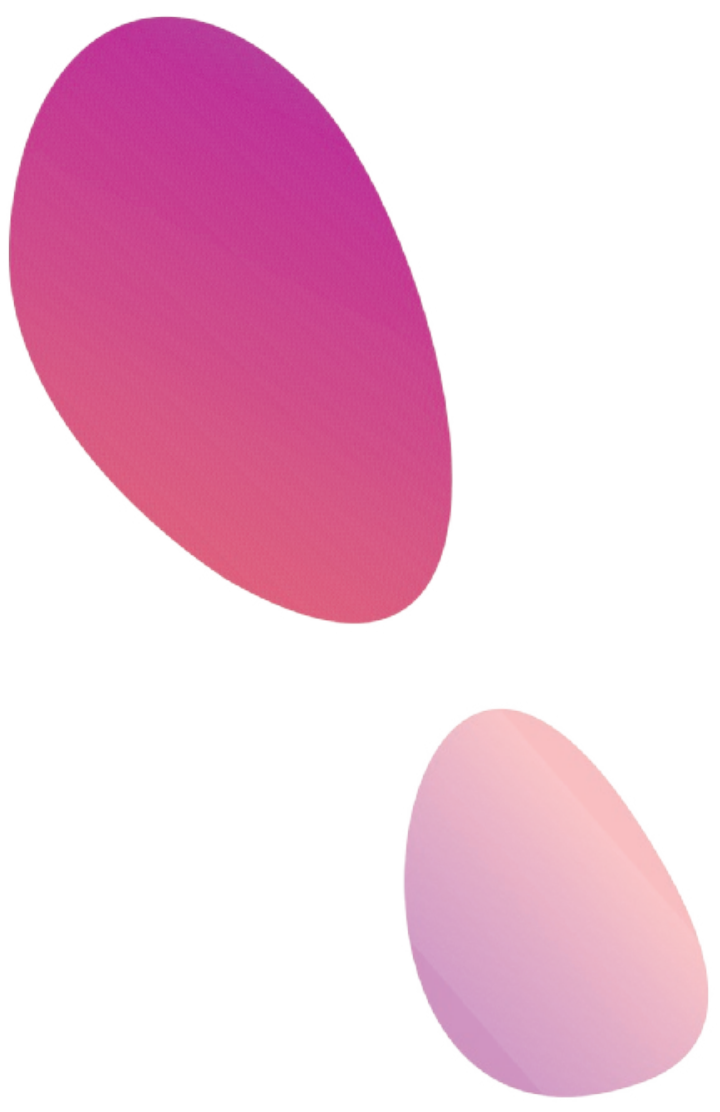


\section{CHAPTER 1}

\section{Challenges in Circulating Tumor Cell Detection by the CellSearch System}




\section{Abstract}

Enumeration and characterization of circulating tumor cells (CTC) hold the promise of a realtime liquid biopsy. They are however present in a large background of hematopoietic cells making their isolation technically challenging. In 2004, the CellSearch ${ }^{\circledR}$ system was introduced as the first and only FDA cleared method designed for the enumeration of circulating tumor cells in $7.5 \mathrm{~mL}$ of blood. Presence of CTC detected by CellSearch is associated with poor prognosis in metastatic carcinomas. CTC remaining in patients after the first cycles of therapy indicates a futile therapy. Here we review challenges faced during the development of the CellSearch system and the difficulties in assigning objects as CTC. The large heterogeneity of CTC and the different approaches introduced in recent years to isolate, enumerate and characterize CTC results in a large variation of the number of CTC reported urging the need for uniform definitions and at least a clear definition of what the criteria are for assigning an object as a CTC. 


\subsection{Introduction}

Circulating tumor cells (CTC) are cancer cells that detach from their primary site during the process of cancer metastasis. They enter the circulatory system, migrate through the body and can form secondary tumors at distant sites. If CTC are present, can be isolated and characterized they represent a minimally invasive source of spreading tumor cells and may serve as a liquid biopsy for management of cancer patients. CTC are however rare events compared to the number of hematopoietic cells, therefore, their detection and enumeration is technically challenging

At present the CellSearch ${ }^{\circledR}$ system is the only validated method for CTC detection that has been cleared by the U.S. Food and Drug Administration. The CellSearch system, designed for the enumeration of CTC in $7.5 \mathrm{~mL}$ of blood, was first introduced in 2004 where the analytical accuracy, reproducibility, and linearity of the system was shown.1,2 There are various challenges when isolating and enumerating CTC, in this review these challenges will be discussed using the CellSearch system as an example.

\subsection{Early evidence for circulating tumor cells}

Circulating tumor cells were first reported by Thomas Ashworth. ${ }^{3}$ He described the presence of tumor cells with similarities to the cells from the primary tumor, in the blood of a man with metastatic cancer. Engell ${ }^{4}$ described the occurrence of cancer cells in peripheral blood and in the venous blood that drained the tumor during operation and observed a larger frequency of tumor cells in the draining vein as compared to the peripheral blood. Evidence for CTC in the blood from patients with metastatic and primary carcinoma was found by immunohistochemistry staining several decades ago. Moss and Sanders ${ }^{5}$ found evidence for CTC in 7 out of 10 neuroblastoma patients with known disseminated disease by immunostaining. In 1993, CTC were identified with conventional cytology and cytokeratin staining in patients with colorectal cancer by Leather et al. ${ }^{6}$ They isolated tumor cells from 42 patients undergoing resection for colorectal cancer, using a density gradient followed by cytospin and showed immune histological evidence for CTC in 4 of these patients. In the 1990s, peripheral blood progenitor cells were increasingly used for autografting after highdose chemotherapy. Brugger et al. ${ }^{7}$ made the observation that tumor cells were detected in blood of a portion of breast cancer, small cell and non-small cell lung cancer patients before mobilization of peripheral blood hematopoietic progenitors and discovered an increase after the mobilization. Braun et al. ${ }^{8}$ reported that the presence of tumor cells in bone marrow was 
associated with poor prognosis. These studies provided important information that tumor cells could be detected by traditional immunochemistry techniques but also lacked the sensitivity to be used in larger multicenter studies.

\subsection{Challenge of rare events detection}

Tumor cells in blood are present in a high background of hematopoietic cells and are found in frequencies in the order of 1 - 10 CTC per $\mathrm{mL}$ of whole blood in patients with metastatic disease. ${ }^{9}$ One of the problems one faces in the development of assays to detect these rare cells is that one does not know whether tumor cells are present, and if so at what frequency. To test whether the developed methods are working, known numbers of cells from cancer lines are spiked in blood and the efficiency of the method is than evaluated by the determination of the number of cells observed after the procedure. A variety of cell lines should be tested in optimization of the methods. For example, cell lines with different densities of the target antigen, such as the epithelial cell adhesion molecule (EpCAM), for methods based on immune selection. Or a range of sizes, stiffness and densities when methods based on physical differences between hematopoietic cells and tumor cells are used. A frequent oversight is the challenge to accurately detect the "rare cell" among all the others. This is visualized in figure 1.1, which shows the probability distribution of two cell populations. A lognormal distribution for both staining intensities was assumed. Panel A shows two cell populations present in equal numbers and they can be easily discriminated from each other. In panel B the number of stained cells is reduced to 1 in 1000 and 48.9\% of the "rare" cells can no longer be discriminated. In panel $\mathrm{C}$ this ratio is changed to $1: 10.000$ and $70.3 \%$ of the cells can no longer be discriminated. In panel D this ratio is changed to 1:1.000.000 and in this case $96.2 \%$ of the cells can no longer be discriminated. To improve the separation one could improve the staining intensity. The use of for example Phycoerythrin (PE) instead of Fluorescein isothiocyanate (FITC) conjugated antibodies will improve the separation from autofluorescence due to higher quantum yield of the PE fluorochrome as compared to FITC. The limitation will however still be the number of antigens present on the cell. Amplification of the signal by for example increasing the antibody concentration or adding a secondary antibody to boost the signal will however also give rise to an increase in the background. Consideration of the frequency of the cell, that one needs to identify, is thus of utmost importance for the approach taken with the identification of the cells. ${ }^{10-12}$ 
The use of multiple markers is therefore a requirement for "rare" cell detection. One of the first techniques used for the detection of CTC in whole blood was flow cytometry. Gross et al. ${ }^{13}$ reported a flow cytometric assay, which allowed for the detection of cancer cells in blood by using multiple markers, each containing a different fluorophore. They showed that detection of cells, down to a frequency of 1 in $10^{7}$, is possible if $4 \times 10^{8}$ peripheral blood mononuclear cells (PBMCs) are analyzed. They used an approach to stain the unwanted subpopulation of the cells with one exclusion color and stain the rare cells of interest with one, two, or three different remaining colors. The drawback of this method is the large sample volume that needs to be analyzed, thereby limiting the number of samples that can be analyzed. In addition, the instrument has to be stable, the parameter settings have to be set in advance and cell settling and clumping must be avoided during the measurement.

The problems due to a large sample volume can be avoided by the enrichment of the tumor cells by either depletion of the leukocytes or selection of epithelial cells targeting for example the EpCAM antigen. The latter approach was reported by Racila et al. ${ }^{14}$ In this study, ferrofluids were labeled with antibodies targeting the EpCAM antigen, incubated with $20 \mathrm{~mL}$ of whole blood and mmune-magnetically enriched, followed by fluorescent labeling with a nucleic acid dye, PE-conjugated anti-cytokeratin (CAM5.2) and peridinin chlorophyll protein (PerCP) -labeled CD45 and analyzed by multiparameter flow cytometry. It was shown that cells of epithelial origin defined as nucleic acid+, CD45- and cytokeratin+ could be detected in patients with metastatic and organ confined breast and prostate cancer, whereas only few epithelial cells were detected in healthy controls. Using this assay a first indication was obtained that the presence and changes in these "epithelial cells" related to the clinical status of the patient and response to therapy. ${ }^{14-17}$

First evidence that these epithelial cells indeed were tumor cells was obtained by cytospin preparations after immunomagnetic enrichment targeting the EpCAM antigen. The cytospins were stained by immunocytochemistry to confirm that the circulating epithelial cells found in the cancer patients had the morphologic appearance typical for cancer cells, figure 1.2. The figure shows 20 thumbnails each containing a cell staining with cytokeratin (red) containing a relative large nucleus (blue) with some of them having clear nucleoli suggestive of the cells being active. Although these images did not provide sufficient evidence of these cells being cancer cells, it surely excluded that these cytokeratin expressing cells were, for example, derived from the venipuncture in which case cells with a large cytoplasm and small nucleus were to be expected. Further evidence was obtained by demonstration of cytogenetic aberrancies in the nucleic acid+, CD45- and cytokeratin+ cells. ${ }^{18}$ Exploration of further utility of circulating tumor cells was demonstrated by the ability to detect treatment targets on the circulating tumor cells. ${ }^{19-21}$ 
A

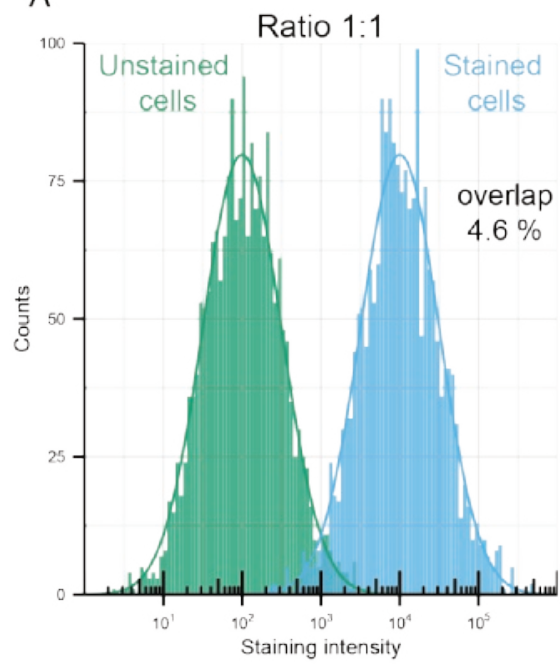

C

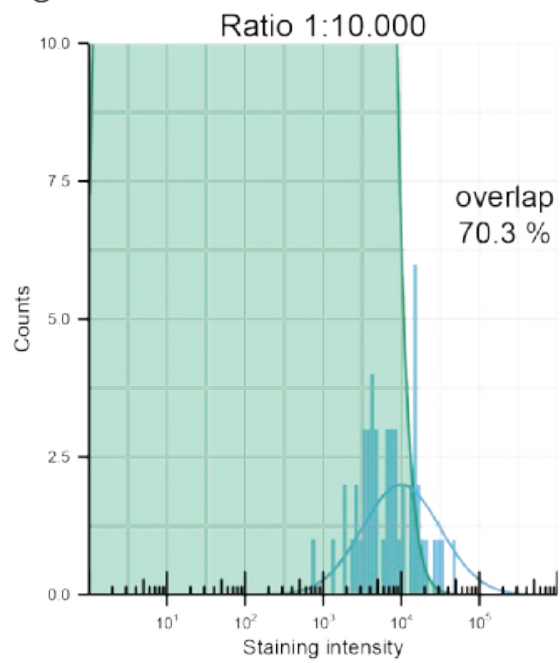

B

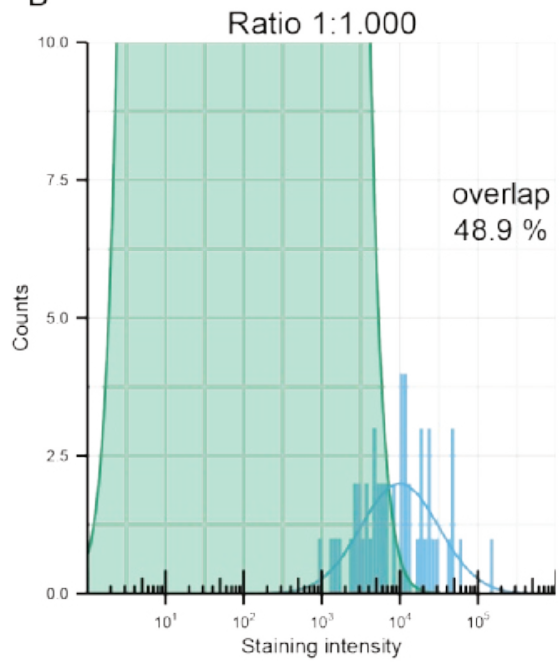

D

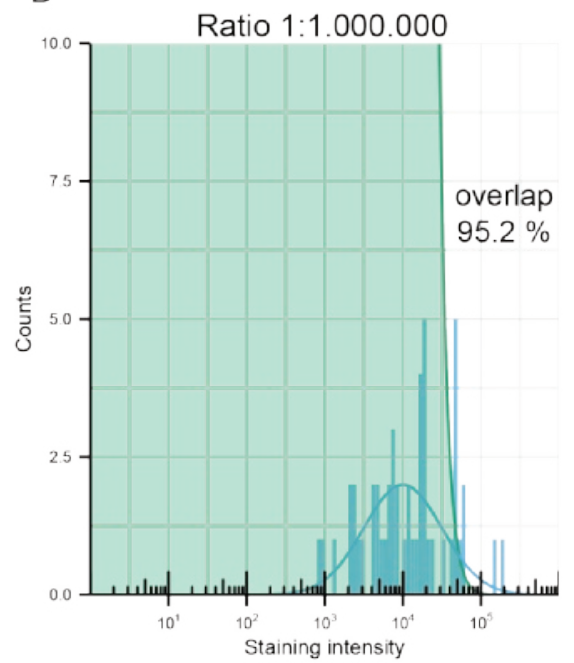

Figure 1.1: Rare cell detection. Probability distribution of two cell populations one unstained (green) and one stained (blue) appearing at a ratio of 1:1, panel A; 1:1.000 panel B, 1:10.000 panel C, and 1:1.000.000 panel D. The blue and green lines depict the probability distribution.

These studies formed the basis for the development of the CellSearch system. The manual sample separation was replaced by fully automated sample preparation to avoid errors made by manual sample processing (CellTracks Autoprep). ${ }^{22}$ Cell loss, accompanied by making cytospins was avoided by introduction of the CellTracks Magnest ${ }^{23}$ and the flowcytometer was replaced by a semi-automated fluorescent microscope to enable morphological confirmation that the nucleic acid+, cytokeratin+, CD45- objects were indeed cells (CellTracks Analyzer II).22 

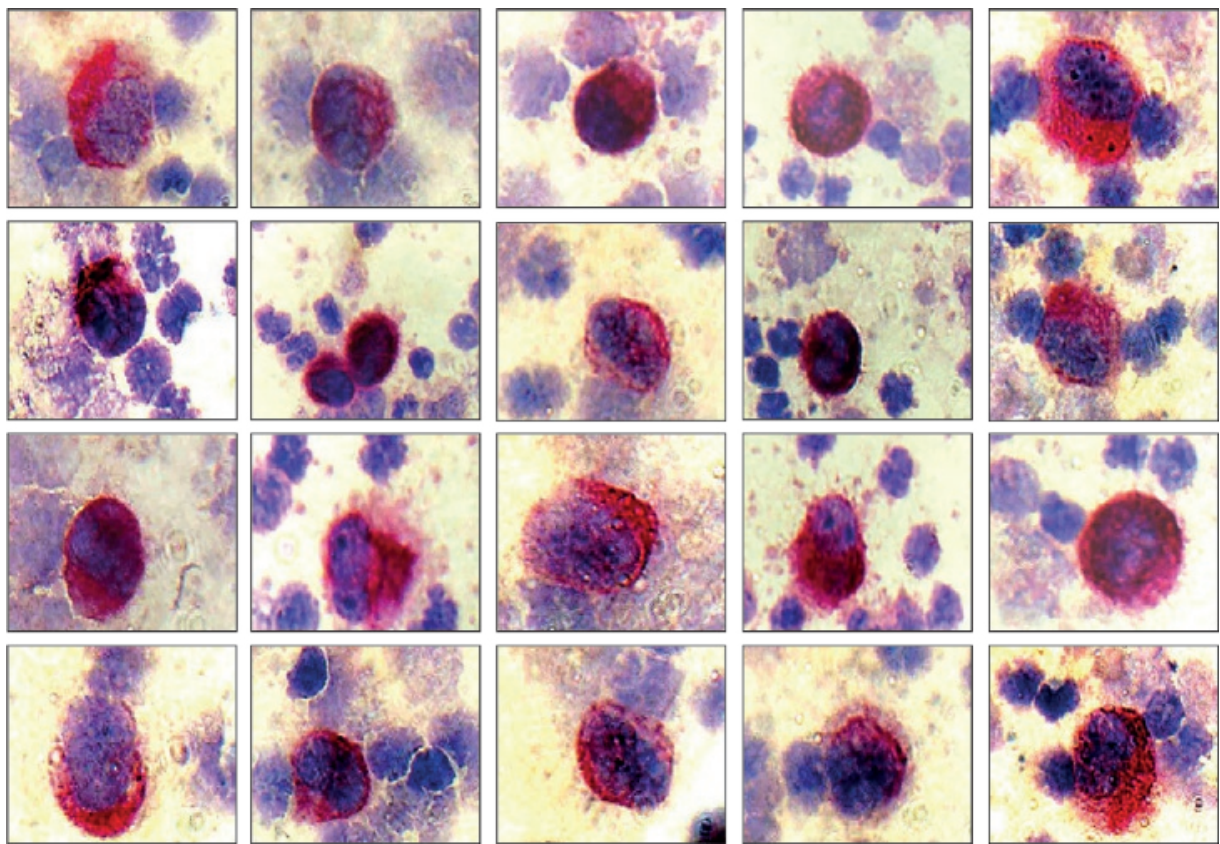

Figure 1.2: Immunocytochemistry. Typical images of CTC immunomagnetically enriched using EpCAM labeled ferrofluids and stained by immunocytochemistry with hematoxylin nuclear stain (blue purple) and cytokeratin (red). The brown yellow color can be contributed to the ferrofluids that are approximately $175 \mathrm{~nm}$ in size and is visual due to the accumulation.

\subsection{CellSearch system}

The system was designed for the immunomagnetic enrichment, fluorescent labeling and detection of rare cell populations. To enable the processing of blood samples up to 96 hours after blood draw, the CellSave blood draw tube was developed. In case viable cells are needed or extraction of RNA from the enriched cells, an EDTA blood draw tube should be used. The immunomagnetic enrichment was optimized such that cells expressing low as well as high antigens were selected. ${ }^{24}$ For enrichment of carcinoma cells (CTC kit, CXC kit, CTC profile kit) the VU1D9 antibody recognizing EpCAM is used, for melanoma cells (CMC kit) and endothelial cells (CEC and CEC profile kit) an antibody recognizing CD146 is used and for myeloma cells (CMMC kit) an antibody recognizing CD138. ${ }^{25}$

For enumeration of CTC the CTC kit is used in which reagents are provided to stain and fix the cells. The details of the protocol are described by Coumans and Terstappen. ${ }^{26}$ The performance of the system is extensively described in 2004 by Allard et al. ${ }^{1}$ Prevalence of 
CTC was determined in blood from healthy donors, patients with nonmalignant disease, and in samples from 964 patients with metastatic carcinomas. The control population contained practical no CTC, whereas $36 \%$ of the blood samples of cancer patients contained $>2$ CTC in $7.5 \mathrm{~mL}$, with a broad range of 0 to 23,618 CTC per $7.5 \mathrm{~mL}$.

The first clinical studies conducted with the CellSearch system showed that CTC are clearly associated with poor prognosis in metastatic breast ${ }^{27,28}$, colorectal ${ }^{29}$ and castration-resistant prostate cancer ${ }^{30}$. Later studies showed this for small cell lung cancer ${ }^{31,32}$ and non-small cell lung cancer (NSCLC) $)^{33}$, bladder cancer ${ }^{34}$, pancreas cancer ${ }^{35,36}$, head and neck cancer ${ }^{37}$, ovarian cancer $^{38}$, neuroendocrine cancer ${ }^{39,40}$, and hepatocellular cancer ${ }^{41,42}$. This association holds true in pre- and on- treatment patient blood samples. For these studies patients were assigned to a favorable group ( $<5$ CTC/7.5 mL of blood) or unfavorable group ( $\geq 5$ CTC/7.5 $\mathrm{mL}$ of blood). Transition from the unfavorable group to the favorable group improves survival and can therefore be used as a predictive factor for treatment response. 27,29,30,43 In actuality, the larger the CTC count the worse the prognosis as is illustrated by Kaplan Meier plots in figure 1.3. In the plots, patients are divided into categories with O CTC, 1 - 4 CTC, 5 - 24 CTC, and $>24$ CTC and CTC counts in $7.5 \mathrm{~mL}$ blood samples taken before a new line of therapy was initiated. The difference in survival curves increases after the first cycles of therapy, as the CTC in those patients are eliminated by successful therapy. Interpretation of changes in CTC counts is described elsewhere (Coumans et al., 2012). In short for a treatment to be effective and prolong survival of the patient it is clear that all CTC will need to be eliminated.

Using CellSearch CTC are not only found in metastatic patients, several studies have reported on the presence of CTC before and after surgery for non-metastatic breast ${ }^{45-52}$, colorectal cancer $^{53-57}$, oesophagus cancer ${ }^{58}$ and bladder cancer ${ }^{59}$.

The number of CTC per $\mathrm{mL}$ found in these studies is much lower than in metastatic patients. To increase the sensitivity of EpCAM+, CK+, CD45-, DAPI+ CTC as detected by CellSearch larger blood volumes will need to be tested. Extrapolation of the frequency of CTC detected in $7.5 \mathrm{~mL}$ of blood of prostate, breast and colorectal cancer patients to large blood volumes showed that in all patients CTC could have been detected in when 1 liter of blood would have been examined. ${ }^{60} \mathrm{~A}$ model predicting the CTC frequency in patients with early breast disease suggested the presence of CTC at a frequency of 0.9 CTC/ liter at the time of first metastasis in breast cancer. ${ }^{61}$ One of the approaches taken to overcome this low frequency problem and test larger blood volumes is the use of leukapheresis. Fischer et al. ${ }^{62}$ introduced diagnostic leukapheresis (DLA), a shortened leukapheresis protocol which uses the conditions 

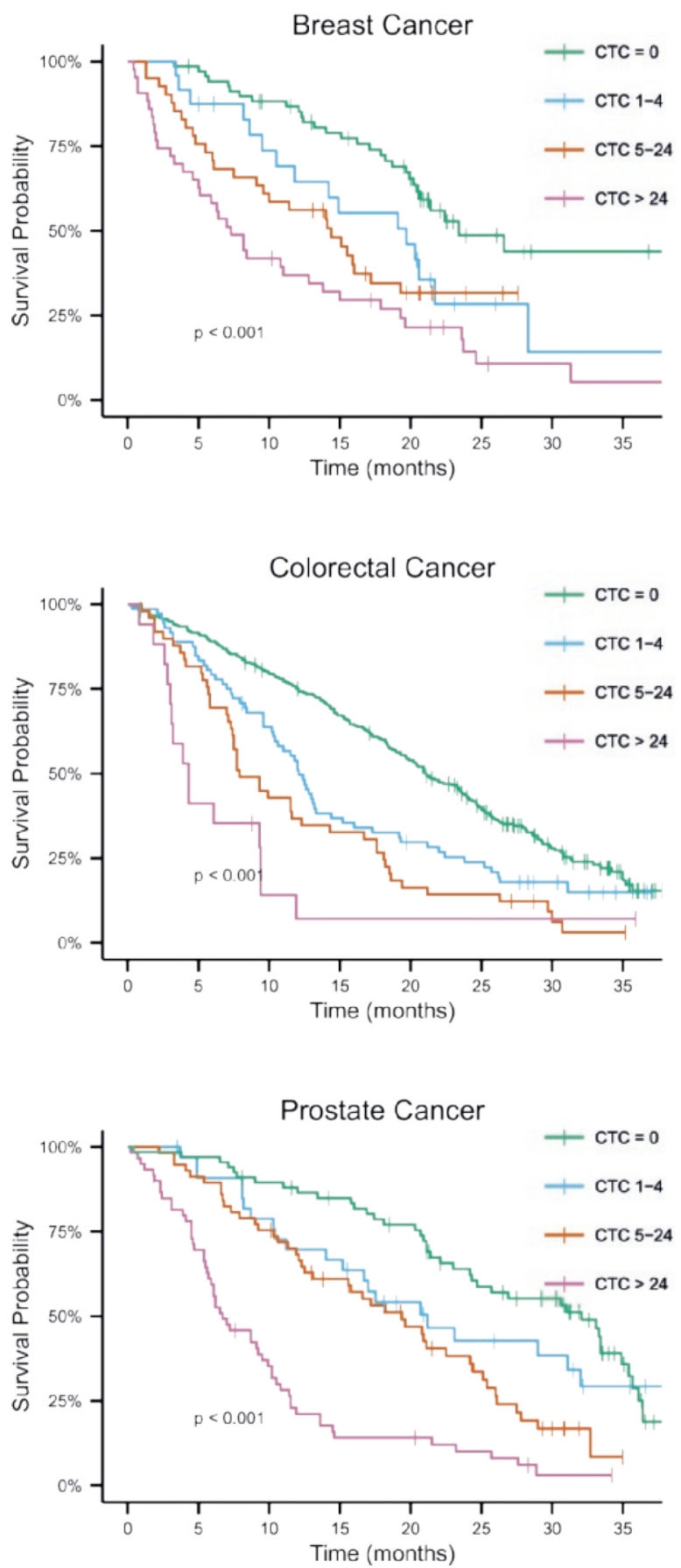

Figure 1.3: CTC versus survival in breast, colon and prostate cancer. Kaplan-Meier plots of metastatic breast (top), colon (middle) and prostate (bottom) cancer patients with 0, 1-4, 5-24 and >24 CTC before initiation of a new line of therapy. Plots were generated using the data from the studies presented by ${ }^{28-30}$. 
to harvest peripheral blood stem cells, but without stem cell mobilization. The CellSearch assay was adapted and up to $2 \times 10^{8}$ leukocytes ( $60 \mathrm{~mL}$ of peripheral blood) could be processed while maintaining the ability to recover spiked tumor cells and increasing the number of CTC detected in cancer patients. For cancer cells not of epithelial cell origin, EpCAM will be not be expressed and other target antigens are needed to enrich the cancer cells. For example, for melanoma the CD146 antigen was chosen. After immunomagnetic enrichment of CD146 expressing cells the cells were stained with the nucleic acid dye 4',6-diamidino-2-phenylindole (DAPI), antibodies recognizing CD45 \& CD34 labeled with Allophycocyan (APC) and antibodies recognizing the high molecular weight melanoma-associated antigen (HMW-MAA) labeled with PE. The CD146 antigen is not only expressed on melanoma cells but also on endothelial cells, therefore there is a need for CD34 (expressed on hematopoietic progenitor cells and endothelial cells) in addition to CD45. The presence of circulating melanoma cells defined as CD146+, HMWMAA+, CD45-, CD34- cells was also associated with poor prognoses.63,64

By not using the staining reagents, the immunomagnetic enrichment of CD146 cells can be used for gene profiling of endothelial cells. ${ }^{65}$ Labeling CD146 enriched cells with CD45 and CD105 identifies endothelial cells that are present in blood of healthy donors but appear in higher frequencies in cancer patients. ${ }^{66-68}$

To determine which antigens are expressed on CTC additional fluorescently labeled antibodies can be added, such as for example Her $2{ }^{69}$ For antigens expressed at a low antigen density such as IGF-1R or bcl-2, FITC does not provide a sufficiently strong signal and the PE fluorochrome is preferred. In these cases the PE labeled antibodies recognizing cytokeratin are replaced by FITC antibodies. ${ }^{70,71}$

In case viable tumor cells are needed, for example for the use in animal models or for molecular characterization, the CTC Profile kit can be used. The EpCAM enriched CTC along with 5000 leukocytes can be used for gene expression profiling ${ }^{72}$ and these viable cells but also non-viable cells from the CTC kit can be immunofluorescently labeled and isolated as single tumor cells with various technologies for molecular analysis. ${ }^{73-77}$

\subsection{CTC appearance and relation with survival}

The current CellSearch system defines a CTC as an object that has a nucleus (stains positive for DAPI); stains positively for cytokeratin's, recognized by the antibodies C11 and A53-B/A2; does not stain for CD 45 ; is more than $4 \times 4 \mu \mathrm{m}^{2}$ in size and has cell like morphology and immunological features. ${ }^{1}$ When looking at the morphological features of CTC, a large heterogeneity within and 
between carcinoma patients is found. ${ }^{1,78}$ In a study by Coumans et al. ${ }^{79}$ these cytokeratin staining objects were divided in various categories, their frequency was determined as well as their relation to clinical outcome. Figure 1.4 shows images of these objects and their relative frequencies in patients with metastatic disease. The most abundant cytokeratin positive objects are small round vesicles. The frequency of such vesicles may well be underestimated as the fluorescent microscope used has a limit of $\sim 1 \mu \mathrm{m}$, in addition the blood is spun down at $800 \mathrm{~g}$ and the plasma is aspirated before the blood is processed on the CellTracks Autoprep which will remove all extracellular vesicles with a lower density/size. The relevance of these extracellular vesicles, that also contain tumor derived exosomes, is explored by a large number of groups. ${ }^{80}$ Next in line, are small apoptotic cells or fragments of cells, proof that these indeed were undergoing apoptosis was obtained by staining with antibodies recognizing cleaved cytokeratin $18 .{ }^{78}$ Larger cytokeratin and CD 45 - cells are also observed, in these cells one clearly can discern the fragmentation of the cytokeratins strings that are clustered in small round vesicles within the cell. Intact CTC such as depicted in the figure only are a minority among the objects classified as CTC using the CellSearch criteria. Even less frequent are clusters of CTC observed with CellSearch. ${ }^{1}$ Before initiation of the clinical studies a definition of a CTC needed to be set and we decided to count a cluster of CTC as one CTC. One of the reasons being that it is often very difficult to assess how many cells are within a tumor cell cluster. The earlier versions of the image analysis software had the tools incorporated to enumerate tumor cell clusters, but to simplify matters it was omitted from the commercial versions of the software. These tumor cell clusters are also observed using other platforms ${ }^{81-86}$ but also for these platforms no clear guidance is provided what is and what is not a cluster. A minority of these clusters are composed of tumor cells and lymphocytes of which an example is shown in the figure. In this example, 4 lymphocytes are attached to the CTC suggesting that these lymphocytes recognize and "attack" the tumor cell. This phenomenon suggests an active role of the immune system and a boost of this response may represent alternative strategies for therapies. In case enrichment strategies are used based on depletion of leukocytes this phenomenon cannot be observed.

Demonstration that the presence of EpCAM+, Cytokeratin+, CD45- objects subdivided into different groups based on morphological appearance also related to clinical outcome was shown by Coumans et al. ${ }^{79}$ Figure 1.5 shows the relation with survival of metastatic prostate cancer patients and cells classified according to the CellSearch criteria, cells classified as intact CTC, cells classified as apoptotic and the EpCAM+, CK+ extracellular vehicles (Evs) which were called tumor micro particles in the original publication. Although the relation between EpCAM+, CK+,CD45- Evs and clinical outcome strongly suggests that they are derived from the tumor, proof can only be obtained by subsequent molecular analysis which is feasible on cells

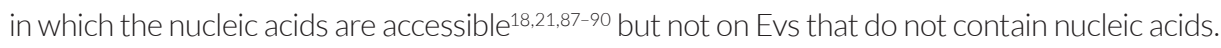




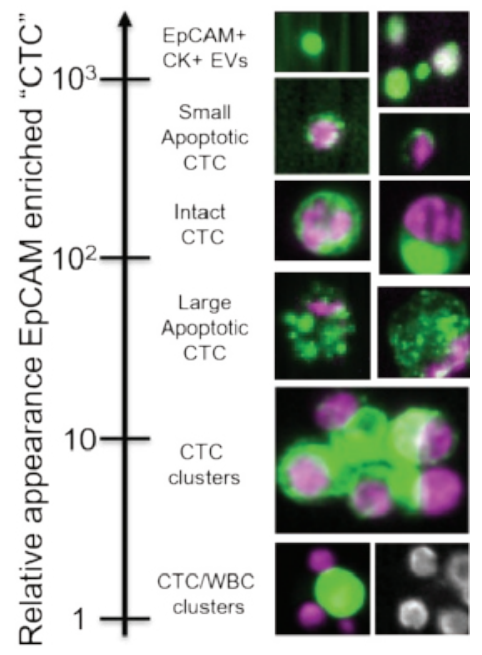

Figure 1.4: Different appearances of CTC. From top to bottom: EpCAM+, CK+ extracellular vesicles; small apoptotic CTC; CellSearch CTC; large apoptotic CTC; clusters of CTC and lymphocytes attached to CTC. The relative frequencies are indicated on the $y$-axis.
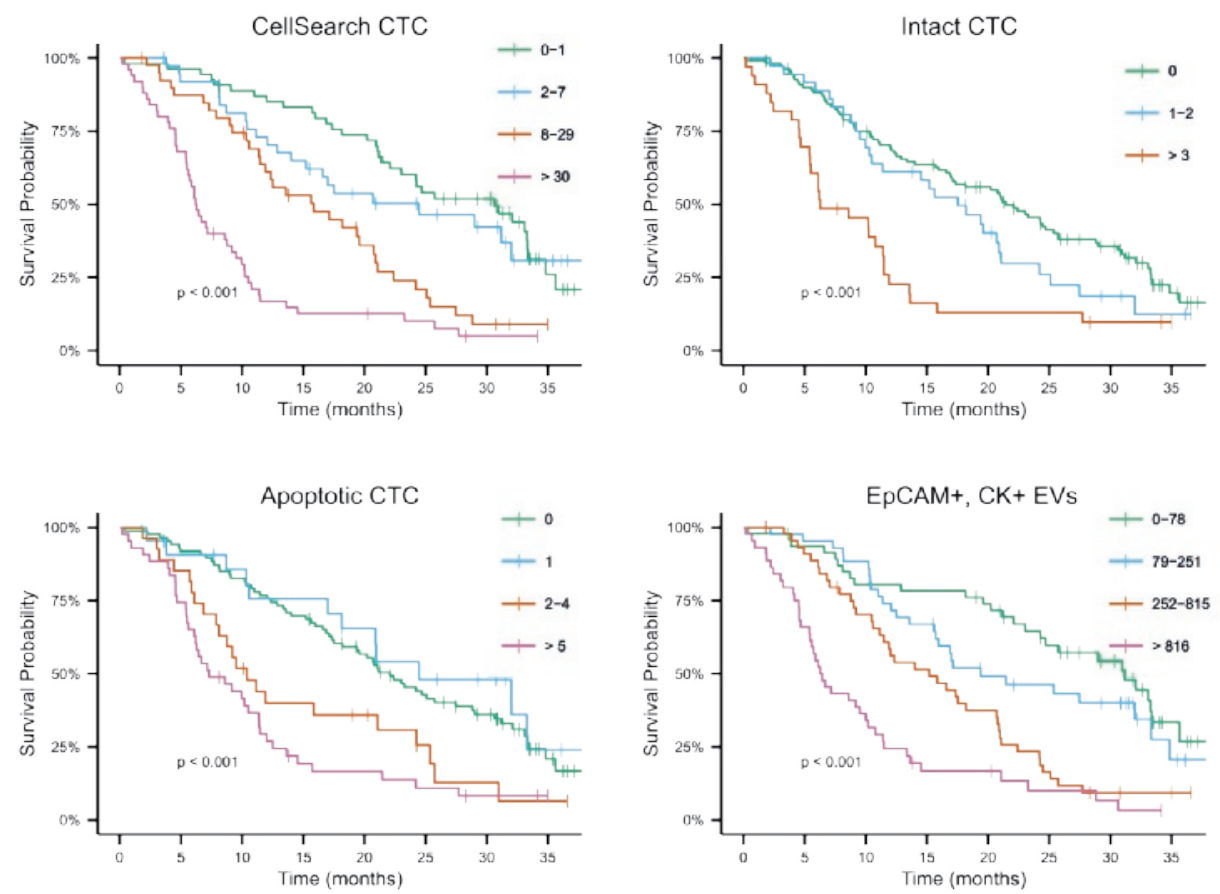

Figure 1.5: Survival versus CTC definition. Kaplan-Meier plots showing the relation with survival of objects, from metastatic prostate cancer patients, subdivided into different groups. A) cells classified according to the CellSearch criteria; B) cells classified as intact CTC; C) cells classified as apoptotic and D) the EpCAM+, CK+ extracellular vehicles (EVs). Plots were generated using the data from the studies presented by ${ }^{79}$. 


\subsection{Need for uniform definition and ultimately automated classification of CTC}

The number of CTC reported vary widely between different platforms urging the need for uniform definitions and at least a clear definition of what the criteria are for assigning an object as a CTC. Various validation studies have been performed using the CellSearch system ${ }^{91-93}$ and show a reasonable concordance. Still the large variety in the appearance of the cells will always result in different assignments of objects with manual review of the images by different operators. Figure 1.6 illustrated seven areas in which the CellTracks software identified objects stained with Cytokeratin as well as DAPI. These areas are presented to the reviewer as thumbnails to identify CTC. To the right the decision three is provided that the reviewer follows to sore the objects. The thumbnail images shown by the CellSearch system have been adapted to increase contrast and reduce storage space. The image processing in CellSearch is described in more detail by Coumans and Terstappen. ${ }^{26}$ To visualize the effect of scaling of the images thumbnails of the CK staining as presented by CellTracks software (Normalized CK) and a thumbnail that is not scaled (Unscaled CK) is shown beside the DNA, CD45 and CK/DNA overlay. The unscaled image in figure 1.6 is a reconstruction of the original image where 0 and 255 are mapped to the full camera range. The top left corner of the Unscaled CK thumbnail shows a $4 \times 4 \mu \mathrm{m}$ box used as a minimum size criteria of a CTC. All seven objects fit the size criteria. All reviewers likely will score the object in row 1 as a CTC. In row 2 four nuclei can be observed one clearly staining for CK, but is it staining with CD45? Actual measurement of the signal and comparison with that of leukocytes could provide a quantitative assessment. In row 3 two objects can be discerned the lower one can be assigned as a leukocyte, the other object stains with $\mathrm{CK}$, but is its morphology consistent with that of a cell and is the nucleus for at least 50\% within the cytoplasm? In row 4 also two objects are present one can be assigned as a leukocyte and the other stains with CK, has a clear nucleus, but at least two speckles of CK are present so do we assign it as a CTC? In row 5, 6 \& 7 nuclei can be observed of which only one faintly stains with CD45, in the unscaled CK images no signal is observed and none of the objects would be assigned as a CTC. In the normalized CK images a CK signal is observed and one might assign one of them as a CTC. This illustrates that it is not that simple to identify CTC even within one platform and not only highlights the need for uniforms criteria such as outlined in the decision three of figure 1.6, but also the need for a more quantitative approach or preferably introduce automation in the classification of CTC. ${ }^{94}$ 


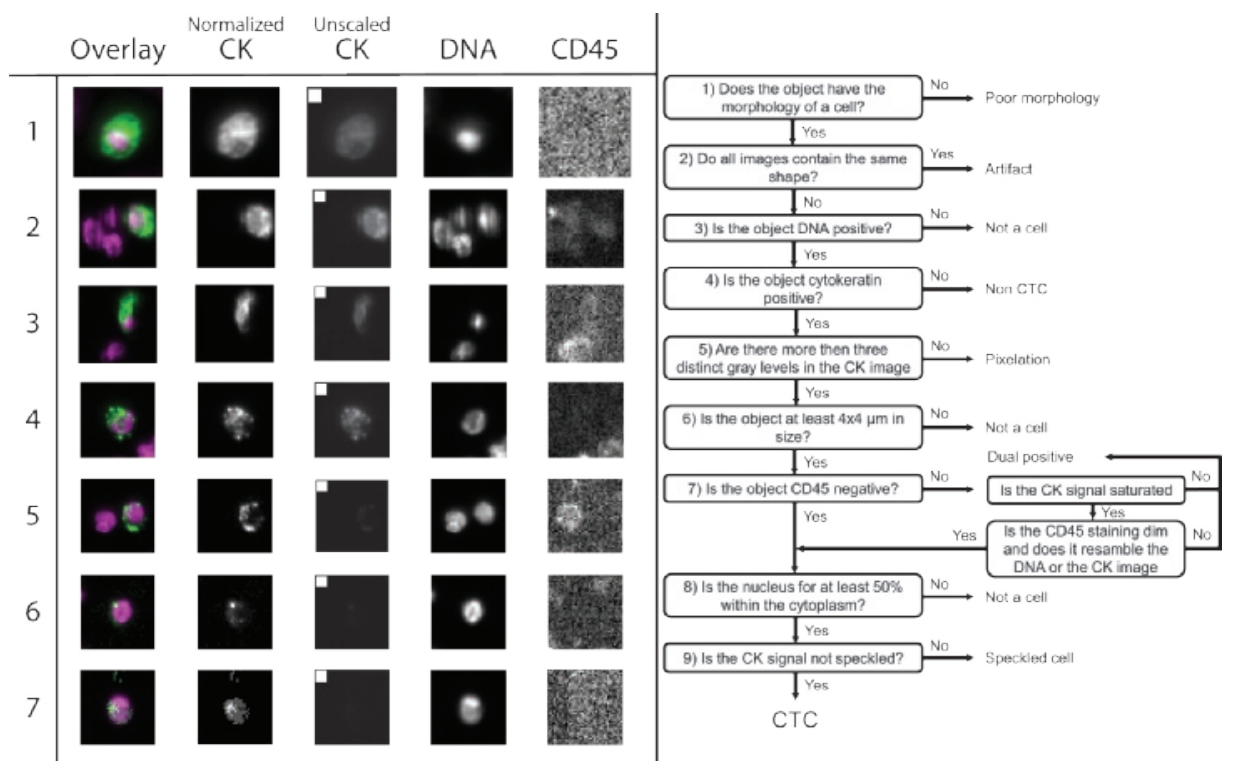

Figure 1.6: What is and what isn't a CTC. Left part of the figure shows seven areas with objects in which the CellTracks software identified Cytokeratin (CK) as well as DNA staining. Shown are, thumbnails of the CK staining as presented by CellTracks software (Normalized CK); CK staining that is not scaled (Unscaled CK); DNA; CD45 and a CK/DNA overlay. To the right the decision three is provided that the reviewer follows to sore the objects. All seven objects fit the size criteria.

Effort to arrive at a CTC definition consensus across platforms have been started in the EU funded CANCER-ID program and ACCEPT an Open Source Computer program has been made available to identify CTC in images obtained from various platforms. The program can be downloaded free of charge from www.CANCER-ID.eu. The program is continuously being improved using input of the experts in the field that participate in this program.

\subsection{Concluding remarks}

Here we discussed the challenges faced during the development of the CellSearch system and the difficulties in assigning objects as CTC. In order to use CTC as a liquid biopsy, it would be ideal to detect as many CTC as possible in as many cancer patients as possible. However, the low frequency of CTC together with the heterogeneity observed in CTC makes the detection very difficult. This demands for a technique both very sensitive as well targeting a broad range and variety of CTC. Criticism is often expressed on the fact that CellSearch only detects EpCAM+ cells, thereby missing CTC lacking EpCAM expression. Still the CellSearch system remains the gold standard for CTC enumeration and has set the bar quite high. ${ }^{95,96}$ Over the years several alternative technologies have been developed reviewed extensively 
elsewhere ${ }^{97-100}$ and demonstrated to detect CTC both by targeting EpCAM and not targeting EpCAM but using other characteristics such as physical properties or biological features. However, up until now it remains difficult to compare these technologies due to the lack of a uniform CTC definition. Also, new technologies need to be tested in multi-center clinical trials in order to compare their performance. For a new technology to become useful in clinical practice it is of utmost importance that a system went through a through validation and can be used and accessed easily. 


\section{References}

1 W. J. Allard, J. Matera, M. C. Miller, M. Repollet, M. C. Connelly, C. Rao, A. G. J. Tibbe, J. W. Uhr and L. W. M. M. Terstappen, Clin. Cancer Res., 2004, 10, 6897-6904.

2 W. J. Allard and L. W. M. M. Terstappen, Clin. Cancer Res., 2015, 21, 2883-2885.

3 T. R. Ashworth, Aust. Med. J., 1869, 14, 146-149.

4 H. C. Engell, Acta Chir. Scand. Suppl., 1955, 201, 1-70.

5 T. J. Moss and D. G. Sanders, J. Clin. Oncol., 1990, 8, $736-40$.

6 A. J. Leather, N. C. Gallegos, G. Kocjan, F. Savage, C. S. Smales, W. Hu, P. B. Boulos, J. M. Northover and R. K. Phillips, Br. J. Surg., 1993, 80, 777-80.

7 W. Brugger, K. J. Bross, M. Glatt, F. Weber, R. Mertelsmann and L. Kanz, Blood, 1994, 83, 636-640.

8 S. Braun, K. Pantel, P. Müller, W. Janni, F. Hepp, C. R. Kentenich, S. Gastroph, A. Wischnik, T. Dimpfl, G. Kindermann, G. Riethmüller and G. Schlimok, N. Engl. J. Med., 2000, 342, 525-33.

9 M. C. Miller, G. V Doyle and L. W. M. M. Terstappen, J. Oncol., 2010, 2010, 617421.

10 L. W. M. M. Terstappen, in Hematopoietic Stem Cell Transplantation, eds. A. D. Ho, R. Haas and R. E. Champlin, CRC Press, 2000, pp. 137-152.

11 H. M. Shapiro, in Practical Flow Cytometry, John Wiley \& Sons, Inc, Hoboken, New Jersey, $4^{\text {th }}$ edn., 2003, pp. 468-470.

12 A. G. J.Tibbe, M. C. Miller and L.W. M. M. Terstappen, Cytometry. A, 2007, 71, 154-62.

13 H. J. Gross, B. Verwer, D. Houck, R. a Hoffman and D. Recktenwald, Proc. Natl. Acad. Sci. U. S. A., 1995, 92 , 537-541.

14 E. Racila, E. Racila, D. Euhus, D. Euhus, a J. Weiss, a J. Weiss, C. Rao, C. Rao, J. McConnell, J. McConnell, L. W. Terstappen, L. W. Terstappen, J. W. Uhr and J. W. Uhr, Proc. Natl. Acad. Sci. U. S. A., 1998, 95, 4589-94.

15 L.W. Terstappen, C. Rao, S. Gross and A. J. Weiss, Int. J. Oncol., 2000, 17, 573-8.
16 L. W. Terstappen, C. Rao, S. Gross, V. Kotelnikov, E. Racilla, J. Uhr and A. Weiss, Vox Sang., 1998, 74 Suppl 2, 269-74.

17 J. G. Moreno, S. M. O'Hara, S. Gross, G. Doyle, H. Fritsche, L. G. Gomella and L. W. Terstappen, Urology, 2001, 58, 386-92.

18 T. Fehm, A. Sagalowsky, E. Clifford, P. Beitsch, H. Saboorian, D. Euhus, S. Meng, L. Morrison, T. Tucker, N. Lane, B. M. Ghadimi, K. Heselmeyer-Haddad, T. Ried, C. Rao and J. Uhr, Clin. Cancer Res., 2002, 8, 2073-84.

19 D. F. Hayes, T. M. Walker, B. Singh, E. S. Vitetta, J. W. Uhr, S. Gross, C. Rao, G. V Doyle and L. W. M. M. Terstappen, Int. J. Oncol., 2002, 21, 1111-7.

20 S. Meng, D. Tripathy, S. Shete, R. Ashfaq, B. Haley, S. Perkins, P. Beitsch, A. Khan, D. Euhus, C. Osborne, E. Frenkel, S. Hoover, M. Leitch, E. Clifford, E. Vitetta, L. Morrison, D. Herlyn, L. W. M. M. Terstappen, T. Fleming, T. Fehm, T. Tucker, N. Lane, J. Wang and J. Uhr, Proc. Natl. Acad. Sci. U. S. A., 2004, 101, 9393-8.

21 S. Meng, D. Tripathy, S. Shete, R. Ashfaq, H. Saboorian, B. Haley, E. Frenkel, D. Euhus, M. Leitch, C. Osborne, E. Clifford, S. Perkins, P. Beitsch, A. Khan, L. Morrison, D. Herlyn, L. W. M. M. Terstappen, N. Lane, J. Wang and J. Uhr, Proc. Natl. Acad. Sci. U. S. A., 2006, 103, 17361-5.

22 M. Kagan, D. Howard, T. Bendele, J. Mayes, J. Silvia, M. Repollet, J. Doyle, J. Allard, N. Tu, T. Bui, T. Russell, C. Rao, M. Hermann, H. Rutner and L. W. M. M. Terstappen, J. Clin. Ligand Assay, 2002, 25, 104-110.

23 A. G. J. Tibbe, B. G. de Grooth, J. Greve, G. J. Dolan, C. Rao and L.W. M. M. Terstappen, Cytometry, 2002, 47, 163-72.

24 P. A. Liberti, C. G. Rao and L. W. M. M. Terstappen, J. Magn. Magn. Mater., 2001, 225, 301-307.

25 B. M. Weiss, K. Sasser, C. Rao, B. Foulk, S. Gross, G. Mallon, C. Erb, A. Berkowitz, P. Mangan, B. K. Shelly, A. D. Cohen, D. T. Vogl, A. L. Garfall and E. A. Stadtmauer, in American Society of Hematology ,Annual meeting and Exposition, 2014.

26 F. Coumans and L. Terstappen, in Methods in Molecular Biology, 2015, pp. 263-278. 
27 M. Cristofanilli, G. T. Budd, M. J. Ellis, A. Stopeck, J. Matera, M. C. Miller, J. M. Reuben, G. V Doyle, W. J. Allard, L. W. M. M. Terstappen and D. F. Hayes, N. Engl. J. Med., 2004, 351, 781-791.

28 M. Cristofanilli, D. F. Hayes, G. T. Budd, M. J. Ellis, A. Stopeck, J. M. Reuben, G. V. Doyle, J. Matera, W. J. Allard, M. C. Miller, H. a. Fritsche, G. N. Hortobagyi and L. W. M. M. Terstappen, J. Clin. Oncol., 2005, 23, 1420-1430.

29 S. J. Cohen, C. J. A. Punt, N. Iannotti, B. H. Saidman, K. D. Sabbath, N. Y. Gabrail, J. Picus, M. Morse, E. Mitchell, M. C. Miller, G. V Doyle, H. Tissing, L. W. M. M. Terstappen and N. J. Meropol, J. Clin. Oncol., 2008, 26, 3213-3221.

30 J. S. de Bono, H. I. Scher, R. B. Montgomery, C. Parker, M. C. Miller, H. Tissing, G. V Doyle, L. W. W. M. Terstappen, K. J. Pienta and D. Raghavan, Clin. Cancer Res., 2008, 14, 6302-6309.

31 T. J. N. Hiltermann, M. M. Pore, A. van den Berg, W. Timens, H. M. Boezen, J. J. W. Liesker, J. H. Schouwink, W. J. A. Wijnands, G. S. M. A. Kerner, F. A. E. Kruyt, H. Tissing, A. G. J. Tibbe, L. W. M. M. Terstappen and H. J. M. Groen, Ann. Oncol., 2012, 23, 2937-42.

32 J.-M. Hou, M. G. Krebs, L. Lancashire, R. Sloane, A. Backen, R. K. Swain, L. J. C. Priest, A. Greystoke, C. Zhou, K. Morris, T. Ward, F. H. Blackhall and C. Dive, J. Clin. Oncol., 2012, 30, 525-532.

33 M. G. Krebs, R. Sloane, L. Priest, L. Lancashire, J.-M. Hou, A. Greystoke, T. H. Ward, R. Ferraldeschi, A. Hughes, G. Clack, M. Ranson, C. Dive and F. H. Blackhall, J. Clin. Oncol., 2011, 29, 1556-63.

34 P. Gazzaniga, A. Gradilone, E. de Berardinis, G. M. Busetto, C. Raimondi, O. Gandini, C. Nicolazzo, A. Petracca, B. Vincenzi, A. Farcomeni, V. Gentile, E. Cortesi and L. Frati, Ann. Oncol., 2012, 23, 2352-6.

35 B. P. Negin, N. J. Meropol, R. K. Alpaugh, K. Ruth, C. McAleer, T. Halbherr, C. Bingham, P. Fittipaldi and S. J. Cohen, ASCO Meet. Abstr., 2010, 28, 4127.

36 T. Kurihara, T. Itoi, A. Sofuni, F. Itokawa, T. Tsuchiya, S. Tsuji, K. Ishii, N. Ikeuchi, A. Tsuchida, K. Kasuya, T. Kawai, Y. Sakai and F. Moriyasu, J. Hepatobiliary. Pancreat. Surg., 2008, 15, 189-95.
37 A. C. Nichols, L. E. Lowes, C. C. T. Szeto, J. Basmaji, S. Dhaliwal, C. Chapeskie, B. Todorovic, N. Read, V. Venkatesan, A. Hammond, D. A. Palma, E. Winquist, S. Ernst, K. Fung, J. H. Franklin, J. Yoo, J. Koropatnick, J. S. Mymryk, J. W. Barrett and A. L. Allan, Head Neck, 2012, 34, 1440-4

38 A. Poveda, S. B. Kaye, R. McCormack, S. Wang, T. Parekh, D. Ricci, C. A. Lebedinsky, J. C. Tercero, P. Zintl and B. J. Monk, Gynecol. Oncol., 2011, 122, 567-72.

39 M. S. Khan, T. Tsigani, M. Rashid, J. S. Rabouhans, D. Yu, T. V. Luong, M. Caplin and T. Meyer, Clin. Cancer Res., 2011, 17, 337-45.

40 P. E. Oberstein and M.W. Saif, JOP, 2012, 13, 368-71.

41 B. C. Zee, C. Wong, T. Kuhn, R. Howard, W. Yeo, J. Koh, E. Hui and A. T. Chan, ASCO Meet. Abstr., 2007, 25, 15037.

42 K. Schulze, C. Gasch, K. Staufer, B. Nashan, A. W. Lohse, K. Pantel, S. Riethdorf and H. Wege, Int. J. Cancer, 2013, 133, 2165-71.

43 D. F. Hayes, M. Cristofanilli, G. T. Budd, M. J. Ellis, A. Stopeck, M. C. Miller, J. Matera, W. J. Allard, G. V Doyle and L. W. W. M. Terstappen, Clin. Cancer Res., 2006, 12, 4218-24.

44 F. A. Coumans, S. T. Ligthart and L. W. Terstappen, Transl. Oncol., 2012, 5, 486-91.

45 B. Franken, M. R. de Groot, W. J. B. Mastboom, I. Vermes, J. van der Palen, A. G. J. Tibbe and L. W. M. M. Terstappen, Breast Cancer Res., 2012, 14, R133.

46 A. Lucci, C. S. Hall, A. K. Lodhi, A. Bhattacharyya, A. E. Anderson, L. Xiao, I. Bedrosian, H. M. Kuerer and S. Krishnamurthy, Lancet Oncol., 2012, 13, 688-95.

47 G. van Dalum, G. J. van der Stam, A. G. J. Tibbe, B. Franken, W. J. B. Mastboom, I. Vermes, M. R. de Groot and L. W. M. M. Terstappen, Int. J. Oncol., 2014, 46, 407-413.

48 W. J. Janni, B. K. Rack, L. W. M. M. Terstappen, J.-Y. Pierga, T. Fehm, C. Hall, M. Groot, F.- C. Bidard, F. Meier-Stiegen, T.W. P. Friedl, P. Fasching and A. Lucci, in SABC, 2014, pp. PD6-7.

49 J.-Y. Pierga, D. Hajage, T. Bachelot, S. Delaloge, E. Brain, M. Campone, V. Diéras, E. Rolland, L. Mignot, C. Mathiot and F.-C. Bidard, Ann. Oncol., 2012, 23, 618-24. 
50 J.-Y. Pierga, F.-C. Bidard, C. Mathiot, E. Brain, S. Delaloge, S. Giachetti, P. de Cremoux, R. Salmon, A. Vincent-Salomon and M. Marty, Clin. Cancer Res., 2008, 14, 7004-10.

51 B. Rack, C. Schindlbeck, J. Jückstock, U. Andergassen, P. Hepp, T. Zwingers, T. W. P. Friedl, R. Lorenz, H. Tesch, P. A. Fasching, T. Fehm, A. Schneeweiss, W. Lichtenegger, M. W. Beckmann, K. Friese, K. Pantel and W. Janni, J. Natl. Cancer Inst.

52 M. J. Serrano, P. S. Rovira, I. Martínez-Zubiaurre, M. D. Rodriguez, M. Fernández and J. A. Lorente, Exp. Ther. Med., 2012, 4, 43-48.

53 G. van Dalum, G.-J. Stam, L. F. A. Scholten, W. J. B. Mastboom, I. Vermes, A. G. J. Tibbe, M. R. De Groot and L. W. M. M. Terstappen, Int. J. Oncol., 2015, 46, 1361-8.

54 M. Thorsteinsson, G. Soletormos and P. Jess, Anticancer Res, 2011, 31, 613-617.

55 J. Sastre, M. L. Maestro, J. Puente, S. Veganzones, R. Alfonso, S. Rafael, J. A. García-Saenz, M. Vidaurreta, M. Martín, M. Arroyo, M. T. Sanz-Casla and E. DíazRubio, Ann. Oncol., 2008, 19, 935-8.

56 K. Hiraiwa, H. Takeuchi, H. Hasegawa, Y. Saikawa, K. Suda, T. Ando, K. Kumagai, T. Irino, T. Yoshikawa, S. M atsuda, M. Kitajima and Y. Kitagawa, Ann. Surg. Oncol., 2008, 15, 3092-100.

57 P. Gazzaniga, W. Gianni, C. Raimondi, A. Gradilone, G. Lo Russo, F. Longo, O. Gandini, S. Tomao and L. Frati, 6 Tumour Biol., 2013, 34, 2507-9.

58 M. Reeh, K. E. Effenberger, A. M. Koenig, S. Riethdorf, D. Eichstädt, E. Vettorazzi, F. G. Uzunoglu, Y. K. Vashist, J. R. Izbicki, K. Pantel and M. Bockhorn, Ann. Surg., 2015, 261, 1124-30.

59 A. Karl, S. Tritschler, S. Hofmann, C. G. Stief and C. Schindlbeck, Eur. J. Med. Res., 2009, 14, 487-90.

60 F. A. W. Coumans, S. T. Ligthart, J. W. Uhr and L. W. M. M. Terstappen, Clin. Cancer Res., 2012, 18, 57115718.

61 F.A. Coumans, S. Siesling and L. W. Terstappen, BMC Cancer, 2013, 13, 283.
62 J. C. Fischer, D. Niederacher, S. A. Topp, E. Honisch, S. Schumacher, N. Schmitz, L. Zacarias Föhrding, C. Vay, I. Hoffmann, N. S. Kasprowicz, P. G. Hepp, S. Mohrmann, U. Nitz, A. Stresemann, T. Krahn, T. Henze, E. Griebsch, K. Raba, J. M. Rox, F. Wenzel, C. Sproll, W. Janni, T. Fehm, C. A. Klein, W. T. Knoefel and N. H. Stoecklein, Proc. Natl. Acad. Sci. U. S. A., 2013 110, 16580-5.

63 C. Rao, T. Bui, M. Connelly, G. Doyle, I. Karydis, M. R. Middleton, G. Clack, M. Malone, F. A. W. Coumans and L. W. M. M. Terstappen, Int. J. Oncol., 2011, 38 755-60.

64 L. Khoja, P. Lorigan, C. Zhou, M. Lancashire, J. Booth, J. Cummings, R. Califano, G. Clack, A. Hughes and C. Dive, J. Invest. Dermatol., 2013, 133, 1582-90.

65 D. A. Smirnov, B. W. Foulk, G. V Doyle, M. C. Connelly, L.W. M. M. Terstappen and S. M. O'Hara, Cancer Res. 2006, 66, 2918-22

66 J. L. Rowand, G. Martin, G. V. Doyle, M. C. Miller, M. S. Pierce, M. C. Connelly, C. Rao and L. W. M. M. Terstappen, Cytom. Part A, 2007, 71A, 105-113.

67 L. H. J. Simkens, J. Tol, L. W. M. M. Terstappen, S. Teerenstra, C. J. A. Punt and I. D. Nagtegaal, Ann. Oncol., 2010, 21, 2447-2448.

68 M. H. Strijbos, C. Rao, P. I. M. Schmitz, J. Kraan, C. H. Lamers, S. Sleijfer, L. W. M. M. Terstappen and J. W. Gratama, Thromb. Haemost., 2008, 100, 642-7.

69 S. T. Ligthart, F.-C. Bidard, C. Decraene, T. Bachelot, S. Delaloge, E. Brain, M. Campone, P. Viens, J.-Y. Pierga and L. W. M. M. Terstappen, Ann. Oncol., 2013, 24 1231-8.

70 J. S. de Bono, G. Attard, A. Adjei, M. N. Pollak, P. C. Fong, P. Haluska, L. Roberts, C. Melvin, M. Repollet, D. Chianese, M. Connely, L. W. M. M. Terstappen and A. Gualberto, Clin. Cancer Res., 2007, 13, 3611-6.

71 J. B. Smerage, G. T. Budd, G. V Doyle, M. Brown, C. Paoletti, M. Muniz, M. C. Miller, M. I. Repollet, D. A. Chianese, M. C. Connelly, L.W.W. M. Terstappen and D. F. Hayes, Mol. Oncol., 2013, 7, 680-92.

72 D. A. Smirnov, D. R. Zweitzig, B. W. Foulk, M. C. Miller, G. V Doyle, K. J. Pienta, N. J. Meropol, L. M. Weiner, S. J. Cohen, J. G. Moreno, M. C. Connelly, L. W. M. M. Terstappen and S. M. O'Hara, Cancer Res., 2005, 65, 4993-7. 
73 J. F. Swennenhuis, J. Reumers, K. Thys, J. Aerssens and L.W.W.M. M. Terstappen, Genome Med., 2013, 5, 1-11.

74 J. F. Swennenhuis, A. G. J. Tibbe, M. Stevens, M. R. Katika, J.van Dalum, H. D. Tong, C. J. M. van Rijn, L. W. M. M. Terstappen, H. Duy Tong, C. J. M. van Rijn and L. W. M. M. Terstappen, Lab Chip, 2015, 15, 3039-46.

75 R. P. L. Neves, K. Raba, O. Schmidt, E. Honisch, F. Meier-Stiegen, B. Behrens, B. Möhlendick, T. Fehm, H. Neubauer, C. A. Klein, B. Polzer, C. Sproll, J. C. Fischer, D. Niederacher and N. H. Stoecklein, Clin. Chem., 2014, 60, 1290-7.

76 D. J. E. Peeters, B. De Laere, G. G. Van den Eynden, S. J. Van Laere, F. Rothé, M. Ignatiadis, A. M. Sieuwerts, D. Lambrechts, A. Rutten, P. A. van Dam, P. Pauwels, M. Peeters, P. B. Vermeulen and L. Y. Dirix, Br. J. Cancer, 2013, 108, 1358-67.

77 C. L. Hodgkinson, C. J. Morrow, Y. Li, R. L. Metcalf, D. G. Rothwell, F. Trapani, R. Polanski, D. J. Burt, K. L. Simpson, K. Morris, S. D. Pepper, D. Nonaka, A. Greystoke, P. Kelly, B. Bola, M. G. Krebs, J. Antonello, M. Ayub, S. Faulkner, L. Priest, L. Carter, C. Tate, C. J. Miller, F. Blackhall, G. Brady and C. Dive, Nat. Med., 2014, 20, 897-903.

78 C. J. Larson, J. G. Moreno, K. J. Pienta, S. Gross, M. Repollet, S. M. O'Hara, T. Russell and L. W. M. M. Terstappen, Cytometry, 2004, 62A, 46-53.

79 F. A. W. Coumans, C. J. M. Doggen, G. Attard, J. S. de Bono and L.W. M. M. Terstappen, Ann. Oncol., 2010, 21, 1851-1857.

80 M. R. Speicher and K. Pantel, Nat. Biotechnol., 2014, 32, 441-3.

81 J. Adebayo Awe, M. C. Xu, J. Wechsler, N. BenaliFuret, Y. E. Cayre, J. Saranchuk, D. Drachenberg and S. Mai, TransI. Oncol., 2013, 6, 51-IN4.

82 M. Hosokawa, H. Kenmotsu, Y. Koh, T. Yoshino, T. Yoshikawa, T. Naito, T. Takahashi, H. Murakami, Y. Nakamura, A. Tsuya, T. Shukuya, A. Ono, H. Akamatsu, R. Watanabe, S. Ono, K. Mori, H. Kanbara, K. Yamaguchi, T. Tanaka, T. Matsunaga and N. Yamamoto, Plos One, 2013, 8, e67466.

83 S. L. Werner, R. P. Graf, M. Landers, D. T. Valenta, M. Schroeder, S. B. Greene, N. Bales, R. Dittamore and D. Marrinucci, J. Circ. Biomarkers, 2015, 1.
84 N. Aceto, A. Bardia, D. T. Miyamoto, M. C. Donaldson, B. S. Wittner, J. A. Spencer, M. Yu, A. Pely, A. Engstrom, H. Zhu, B. W. Brannigan, R. Kapur, S. L. Stott, T. Shioda, S. Ramaswamy, D. T. Ting, C. P. Lin, M. Toner, D. A. Haber and S. Maheswaran, Cell, 2014, $158,1110-22$.

85 A. F. Sarioglu, N. Aceto, N. Kojic, M. C. Donaldson, M. Zeinali, B. Hamza, A. Engstrom, H. Zhu, T. K. Sundaresan, D. T. Miyamoto, X. Luo, A. Bardia, B. S. Wittner, S. Ramaswamy, T. Shioda, D. T. Ting, S. L. Stott, R. Kapur, S. Maheswaran, D. A. Haber and M. Toner, Nat. Methods, 2015, 12, 685-691.

86 B. Molnar, A. Ladanyi, L. Tanko, L. Sreter and Z. Tulassay, Clin. Cancer Res., 2001, 7, 4080-4085.

87 J. F. Swennenhuis, A. G. J. Tibbe, R. Levink, R. C. J. Sipkema and L. W. M. M. Terstappen, Cytometry. A, 2009, 75, 520-7.

88 G. Attard, J. F. Swennenhuis, D. Olmos, A. H. M. Reid, E. Vickers, R. A'Hern, R. Levink, F. Coumans, J. Moreira, R. Riisnaes, N. B. Oommen, G. Hawche, C. Jameson, E. Thompson, R. Sipkema, C. P. Carden, C. Parker, D. Dearnaley, S. B. Kaye, C. S. Cooper, A. Molina, M. E. Cox, L. W. M. M. Terstappen and J. S. de Bono, Cancer Res., 2009, 69, 2912-8.

89 C. Gasch, T. Bauernhofer, M. Pichler, S. LangerFreitag, M. Reeh, A. M. Seifert, O. Mauermann, J. R. Izbicki, K. Pantel and S. Riethdorf, Clin. Chem., 2013, $59,252-60$

90 S. Meng, D. Tripathy, E. P. Frenkel, S. Shete, E. Z. Naftalis, J. F. Huth, P. D. Beitsch, M. Leitch, S. Hoover, D. Euhus, B. Haley, L. Morrison, T. P. Fleming, D. Herlyn, L. W. M. M. Terstappen, T. Fehm, T. F. Tucker, N. Lane, J. Wang and J. W. Uhr, Clin. Cancer Res., 2004, 10, 8152-62.

91 S. Riethdorf, H. Fritsche, V. Müller, T. Rau, C. Schindlbeck, B. Rack, W. Janni, C. Coith, K. Beck, F. Jänicke, S. Jackson, T. Gornet, M. Cristofanilli and K. Pantel, Clin. Cancer Res., 2007, 13, 920-8.

92 J. Cummings, K. Morris, C. Zhou, R. Sloane, M. Lancashire, D. Morris, S. Bramley, M. Krebs, L. Khoja and C. Dive, BMC Cancer, 2013, 13, 415. 


\section{Chapter 1}

93 J. Kraan, S. Sleijfer, M. H. Strijbos, M. Ignatiadis, D. Peeters, J.-Y. Pierga, F. Farace, S. Riethdorf, T. Fehm, L. Zorzino, A. G. J. Tibbe, M. Maestro, R. Gisbert-Criado, G. Denton, J. S. de Bono, C. Dive, J. A. Foekens and J. W. Gratama, Cytometry B. Clin. Cytom., 2011, 80, 112-8.

94 S. T. Ligthart, F. A. W. Coumans, G. Attard, A. Mulick Cassidy, J. S. de Bono and L. W. M. M. Terstappen, Plos One, 2011, 6, e27419.

95 N. Mehra, Z. Zafeiriou, D. Lorente, L. W. M. M. Terstappen and J. S. de Bono, Clin. Cancer Res., 2015, 21, 4992-4995.

96 F.-C.Bidard, D. J. Peeters, T. Fehm, F. Nolé, R. GisbertCriado, D. Mavroudis, S. Grisanti, D. Generali, J. A. Garcia-Saenz, J. Stebbing, C. Caldas, P. Gazzaniga, L. Manso, R. Zamarchi, A. F. de Lascoiti, L. De MattosArruda, M. Ignatiadis, R. Lebofsky, S. J. van Laere, F. Meier-Stiegen, M.-T. Sandri, J. Vidal-Martinez, E. Politaki, F. Consoli, A. Bottini, E. Diaz-Rubio, J. Krell, S.-J. Dawson, C. Raimondi, A. Rutten, W. Janni, E. Munzone, V. Carañana, S. Agelaki, C. Almici, L. Dirix, E.-F. Solomayer, L. Zorzino, H. Johannes, J. S. ReisFilho, K. Pantel, J.-Y. Pierga and S. Michiels, Lancet Oncol., 2014, 15, 406-414.

97 C. Alix-Panabières and K. Pantel, Nat. Rev. Cancer, 2014, 14, 623-31.

98 A. M. C. Barradas and L. W. M. M. Terstappen, Cancers (Basel)., 2013, 5, 1619-42.

99 J.H. Myung and S. Hong, Lab Chip. 2015, 15, 45004511

100 M. G. Krebs, R. L. Metcalf, L. Carter, G. Brady, F. H. Blackhall and C. Dive, Nat. Rev. Clin. Oncol., 2014, 11, 129-144. 
Challenges in CTC Detection by the CellSearch System 

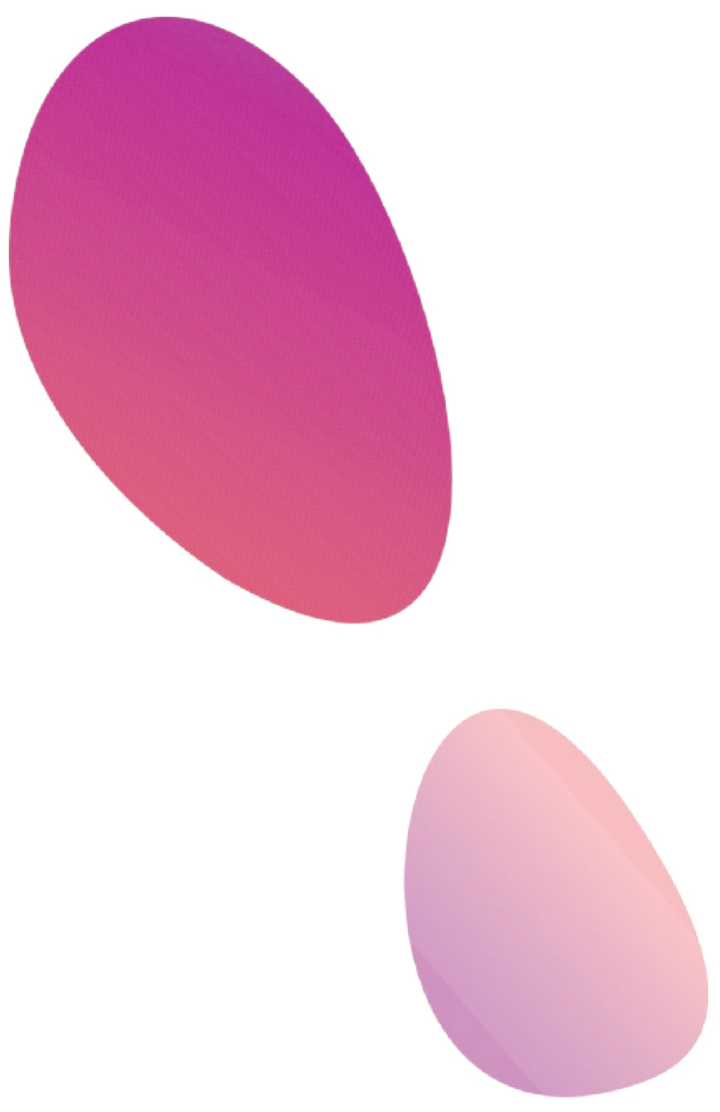


\section{CHAPTER 2}

\section{Capture of Tumor Cells on anti-EpCAM Functionalized Poly(Acrylic Acid) Coated Surfaces}




\section{Abstract}

The presence of tumor cells in blood is predictive of short survival in several cancers and their isolation and characterization can guide towards the use of more effective treatments. These circulating tumor cells (CTC) are however extremely rare and require a technology that is sufficiently sensitive and specific to identify CTC against a background of billions of blood cells. Immuno-capture of cells expressing the epithelial cell adhesion molecule (EpCAM) are frequently used to enrich CTC from blood. The choice of bio conjugation strategy and antibody clone is crucial for adequate cell capture but is poorly understood. In this study, we determined the binding affinity constants and epitope binding of the EpCAM antibodies VU1D-9, HO-3, EpAb3-5 and MJ-37 by Surface Plasmon Resonance imaging (SPRi). Glass surfaces were coated using a poly(acrylic acid) based coating and functionalized with anti-EpCAM antibodies. Binding of cells from the breast carcinoma cell line (SKBR-3) to the functionalized surfaces were compared. Although EpAb3-5 displayed the highest binding affinity $\mathrm{HO}-3$ captured the highest amount of cells. Hence we report differences in the performance of the different antibodies and more importantly that the choice of antibody to capture CTC should be based on multiple assays. 


\subsection{Introduction}

Tumor cells present in blood are referred to as Circulating Tumor Cells (CTC) and their load is associated with poor outcome in breast, prostate, lung and colorectal cancer. ${ }^{1}$ The availability of tumor material through a blood sample is generally referred to as a liquid biopsy. ${ }^{2}$

Enumeration and isolation of CTC is challenging as it implies capturing and detecting cells that occur in a frequency of 1 to 10 amongst billions of blood cells. ${ }^{3}$ Capturing strategies can be essentially categorized in those based on differences in physical-or immunological-properties between CTC and blood cells. Most techniques that explore the immunological properties of CTC target the epithelial cell adhesion molecule CD326 (EpCAM). ${ }^{4}$ EpCAM is a type I transmembrane protein and functions as a cell adhesion molecule which is expressed in the majority of normal epithelial tissues but not on blood cells. ${ }^{5}$ EpCAM was initially described as a tumor-associated antigen ${ }^{6}$ and is of particular interest since it is overexpressed in the majority of human epithelial cancers ${ }^{7}$ including colorectal ${ }^{8}$, breast $^{9}$, gastric ${ }^{10}$, prostate ${ }^{11}$ and hepatic cancer ${ }^{12}$. Also, it was the first human tumor-associated antigen to be identified with the use of monoclonal antibodies and the first target of monoclonal antibody therapy in humans. ${ }^{13}$ The CellSearch system (Veridex, LLC, Raritan, NJ, USA) is the only FDA cleared system for CTC enumeration and based on CTC enrichment using ferrofluids coated with anti-EpCAM antibodies. ${ }^{14}$ Similarly, the CTC-iChip employs magnetic beads coated with anti-EpCAM. ${ }^{15}$ Other technologies, such as the Gedi ${ }^{16}$, CTC-Chip ${ }^{17}$ and HB-Chip ${ }^{18}$ use anti-EpCAM antibodies functionalized on micropatterned surface of microfluidic devices. Most of the referred technologies use avidin-biotin chemistry as surface functionalization strategy. The choice of anti-EpCAM clone is however rarely justified and in some cases not even mentioned. However this choice can have a dramatic influence in the capture performance of the devices, since the binding affinity to CTC of these antibodies can vary.

Here we report a poly(acrylic acid) coating and functionalization with four different antiEpCAM antibodies of surfaces to capture CTC and compare the ability to capture cells from the breast cancer cell line SKBR-3. 


\subsection{Materials and Methods}

\subsubsection{Materials}

Poly(acrylic acid) (PAA) solution, average Mw 250,000, 35\% in water; N-(3Dimethylaminopropyl)-N'-ethylcarbodiimide hydrochloride (98\%, EDC); N-hydroxysuccinimide (98\%, NHS), MES solution for molecular biology, (0.5 M in water); sodium hydroxide; and absolute ethanol were purchased from Sigma-Aldrich (St.Louis, MO, USA). (3-Aminopropyl)triethoxysilane was purchased from Gelest (Morrisville, PA, USA).

\section{Methods}

\subsubsection{Amine-coated glass slides}

Microscope glass slides were cleaned with acetone and wiped with tissues (VWR, Spec-Wipe ${ }^{\circledR}$ 3) and subsequently cleaned with piranha solution $\left(1: 3, \mathrm{H}_{2} \mathrm{O}_{2} 3: \mathrm{H}_{2} \mathrm{SO}_{4}\right)$ for 30 min to create silanol groups on the surface. The samples were rinsed 3 times with an excess of water. The piranha treated samples were incubated in a solution of (3-aminopropyl)triethoxysilane (0.1M) in absolute ethanol with water (5\%) and acetic acid $(0.25 \%)$ for $4 \mathrm{~h}$ at $40^{\circ} \mathrm{C}$. After incubation the samples were rinsed 3 times with ethanol and dried under vacuum.

\subsubsection{Poly(acrylic acid) coating (PAA coating)}

PAA stock solution was diluted to a concentration of $1 \mathrm{~g} \cdot \mathrm{L}^{-1}$. $1 \mathrm{M} \mathrm{NaOH}$ solution was added to the PAA solution to reach a final concentration of 0.005M. EDC (0.006M) and NHS (0.005M) were added into the mixture. After 15 min. of stirring, amine-coated glass slides were immersed into the mixture for $1 \mathrm{~h}$ under stirring conditions. Subsequently the samples were rinsed 3 times with excess of water during $1 \mathrm{~h}$. The PAA-coated glass slides were kept at $4^{\circ} \mathrm{C}$ until further usage up to 3 weeks after preparation.

\subsubsection{Antibody surface functionalization}

Prior to PAA functionalization, glass slides were dried under a stream of nitrogen. Immediately afterwards, slides were placed in a slide holder (Grace Bio-Labs ProPlate ${ }^{\circledR}$ microarray system) with square $6 \times 6 \mathrm{~mm}$ microwells. PAA coatings were reacted with a solution of $0.3 \mathrm{M} \mathrm{NHS}$ and EDC (NHS/EDC) in MES buffer (100 mM, pH 5.5) at room temperature for 30 minutes, to obtain a NHS-activated PAA layer. Residual NHS/EDC was washed away with sodium acetate buffer (2 mM, pH 5). All washing steps were carried out in this manner and always repeated 3 times. Anti-EpCAM antibodies or Bovine Serum Albumin (BSA) were pipetted in sodium acetate buffer at a concentration of $20 \mu \mathrm{g} / \mathrm{mL}$. The following anti-EpCAM clones were used: EpAb3-519 (BioMab, Inc., Taipei, Taiwan), HO-320 (Trion Research GmbH, Germany) 
MJ-3721 (a kind gift of Noel Warner, BD Biosystems, San Jose, CA, USA) and VU1D-94 (kind gift from Immunicon, Huntingdon Valley, PA, USA). To capture T-Iymphocytes, the anti-CD-3 (clone: UCH-T1, Cat\#:ab22, Abcam, Cambridge, UK) was used. Antibodies were permitted to bind for 2 hours, after which unbound antibody was washed away. To block any unreacted binding sites, a solution of $0.5 \mathrm{M}$ ethanolamine hydrochloride (E6133, Sigma-Aldrich) in demineralized water was added and incubated for 30 minutes. After another washing step, the functionalized microscope glass slides were further used for either immunostaining or cell capture experiments.

\subsubsection{X-ray Photoelectron Spectroscopy (XPS)}

The XPS analysis of surfaces was performed using a JPS-9200 Photoelectron Spectrometer (JEOL, Japan). The high-resolution spectra were obtained under UHV conditions using monochromatic Al KaX-ray radiation at $12 \mathrm{kV}$ and $25 \mathrm{~mA}$, using an analyzer pass energy of $10 \mathrm{eV}$. High-resolution spectra were corrected with a linear background before fitting

\subsubsection{SKBR-3 cells}

Breast carcinoma cell line SKBR-3 was obtained from ATCC (Manassa, VA, USA) and cultured in DMEM (Gibco, Life Technologies, Waltham, MA, USA) containing 2 mM L-glutamine (G7513, Sigma-Aldrich), $100 \mathrm{U} / \mathrm{mL}$ penicillin and $100 \mu \mathrm{g} / \mathrm{mL}$ streptomycin (P4333, Sigma-Aldrich) and 10\% FBS (F4135, Sigma-Aldrich). Cells were trypsinized when nearing confluency with $0.05 \%$ Trypsin-EDTA (1X) with Phenol Red (Gibco, Life Technologies) and re-plated at a seeding density never below 20,000 cells $/ \mathrm{cm}^{2}$. Culture medium was refreshed twice a week. Cells were counted using the Luna automated cell counting system (Logos Biosystems, Annandale, VA, USA) by loading $12 \mu \mathrm{l}$ of cell suspension into the respective counting slides. For dynamic cell capture experiments cells were stained overnight before harvesting using $10 \mu \mathrm{M}$ Cell Tracker Orange (Invitrogen, Carlsbad, CA, USA). For static cell capture experiments SKBR-3 cells were stained in PBS with $4 \mu \mathrm{g} / \mathrm{mL}$ of Hoechst 33342 (Life Technologies) and used immediately after.

\subsubsection{Mononuclear cells}

Blood was collected from healthy (no prior history of cancer or blood transmittable disease) volunteers aged 20 - 55 who provided informed consent prior to the donation, in accordance to the study protocol approved by the METC Twente ethics committee. Blood was drawn into CellSave vacutainers (Veridex, Raritan, NJ, USA) and processed within 2 hours after being drawn using Ficoll-Paque PLUS (GE Healthcare Europe GmbH, Eindhoven, The Netherlands) for mononuclear cell isolation, following the manufacturer's protocol. Mononuclear cells were resuspended in PBS and counted following a similar protocol as described for SKBR-3. 
Lymphocytes were stained in PBS with 1 mg/mL of Hoechst 33342 (Life Technologies) and used immediately for the cell capture experiments.

\subsubsection{Antibody immunostaining}

For secondary antibody immunostaining, sheep anti-mouse F(ab')2 Anti-Mouse IgG Phycoerythrin (PE) (12-4010-82, eBioscience, San Diego, CA, USA), from here on named anti-IgG-PE, was diluted 40x in PBS, to an approximate concentration between 22.5 and $27.5 \mu \mathrm{g} / \mathrm{mL}$.

\subsubsection{Anti-EpCAM antibodies cross-blocking using flow cytometer}

Antibody cross-blocking was determined with flow cytometry using a FACSAria II (BD Biosciences, San Jose, CA, USA). Approximately 200,000 SKBR-3 cells were resuspended

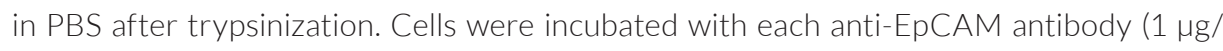
$\mathrm{mL}$ ) followed by incubation with anti-IgG-PE (40× dilution) or VU1D-9-PE (kind gift from Immunicon) (1 $\mathrm{\mu g} / \mathrm{mL}$ ) for 30 minutes at Room Temperature (RT) and with Hoechst 33342 (4 $\mathrm{\mu g} / \mathrm{mL}$ ) for 15 minutes at $370 \mathrm{C}$ just before analysis. In between incubation steps, cells were washed with $1 \%$ BSA in PBS.

\subsubsection{Anti-EpCAM binding affinity using Surface Plasmon Resonance imaging}

Antibody binding affinity was measured with SPRi (IBIS MX96, IBIS technologies B.V., Enschede, the Netherlands) using Easy2Spot ${ }^{\circledR}$ pre-activated G-type Senseye ${ }^{\circledR}$ sensors (Ssens BV, Enschede, The Netherlands) as gold SPR sensor surfaces. Recombinant human EpCAM protein (rhEpCAM, Abcam, Cambridge, UK) and the 4 different anti-EpCAM antibodies, previously diluted in $10 \mathrm{mM}$ immobilization buffer (IB) in concentrations ranging from $64 \mathrm{nM}$ to $0.3 \mathrm{nM}$ (obtained in serial dilution factor steps of 3), were immobilized on the sensor surface using the Continuous Flow Microfluidic (CFM) spotter (Wasatch microfluidics LLC, Salt Lake City, Utah, USA).22 Immobilization buffer (IB) ( $\mathrm{pH} 4$.5) was composed of $0.2 \mathrm{M}$ anhydrous sodium acetate solution (Sigma-Aldrich chemie GmbH, Steinheim, Germany), 0.2 M acetic acid solution (Merck Schuchardt OHG, Hohenbrunn, Germany) and ultrapure demineralized water, in the following proportions respectively: 1.93:3.07:95. Sensor areas outside ligand regions (regions of interest) were deactivated with 1\% BSA (Sigma-Aldrich chemie GmbH) in IB solution followed by 100 mM ethanolamine solution (MP Biomedicals LLC, IIlkrich, France), pH 8. After immobilization and deactivation steps, anti-EpCAM antibodies and rhEpCAM, previously diluted in system buffer (PBS $+0.075 \%$ tween), were injected consecutively in concentrations of 32, 16, 8, 4, 2, 1 and $0.5 \mathrm{nM}$. To obtain kinetic data of the antibody samples, a script was programmed consisting of an initial baseline time of 1 minute, followed by 5 
minutes of association between the antibodies and the immobilized ligands and 8 minutes of dissociation using fresh system buffer, at a flow speed of $4 \mu \mathrm{l} / \mathrm{sec}$. Finally, a regeneration with $10 \mathrm{mM}$ glycine- $\mathrm{HCl}, \mathrm{pH}$ 2.5, was performed for 1 minute, after which the analytes detached from the ligands. Antibody affinity was calculated by the interpolation method for accurate affinity ranking of arrayed ligand analyte interactions as described in more detail elsewhere. ${ }^{23}$

\subsubsection{Cell capture experiments (static and dynamic)}

For experiments without flow (static conditions), SKBR-3 cells (approximately 30,000 or otherwise if indicated) were pipetted onto the respective microwell. Cells were incubated for 30 minutes to maximize binding opportunity with surface functionalized proteins (anti-EpCAM or control BSA). Unbound cells were washed with PBS using a micropipette. The procedure was repeated $3 \times$ before microscopy pictures were taken. For experiments under flow (dynamic conditions), the glass slide was released from the holder and immediately after attached to a channel slide 400 um in height (sticky-Slide I 0.4 Luer, sterile, ibidi GmbH, Munich, Germany). The inlet and outlet ports were connected, with latex rubber tubing, to a syringe filled with the cell suspension and to a waste container. Flow speed was controlled using a syringe pump (NE-1000, ProSense, Oosterhout, the Netherlands). Before applying the cell suspension, the system was primed with clean PBS to remove air bubbles from the tubing and slide channel.

\subsubsection{Image acquisition and analysis}

Images were acquired while maintaining the glass slide in the glass holder (static) or through the channel transparent slide ceiling (dynamic). The microwells area or the slide channel's area were imaged using a fluorescence microscope equipped with a Mercury Arc lamp as light source, a 4X (0.45NA) objective, a computer-controlled CCD camera (Hamamatsu C4742-95-12NRG CCD), a X,Y,Z stage and a 4-filter cube exchanger. The PE filter was used to identify Cell Tracker Orange stained cells. The microscope was controlled with a Labview (National Instruments, Austin, TX, USA) in house-developed script. Before image acquisition, the focal planes were determined using immunofluorescence ( $X, Y$ plane) and iterative determination of the focus at 16 locations (Z plane). All images from one sample were placed in a directory for image analysis. Scanned images from each well were stitched into a whole using the script developed by Preibisch et al. ${ }^{24}$ Stitching was required instead of a montage to avoid overlap between adjacent images. For each stitched well, a ROI of 2500 px in diameter was manually selected around the well center, to exclude cells observed at the border of all wells, irrespectively of glass functionalization status. Hoechst stained cells in ROIs were counted with the in house developed CellCounter script executed in Matlab using a non-commercial license of the DIPlib function base. For each experiment, cell counts are the result of 3 averaged wells. In the case of 
static experiments or secondary immunostaining, images were acquired using a fluorescence microscope (Nikon, Tokyo, Japan) equipped with a $2 \times$ and $4 \times$ objective (0.45NA), a Hoechst filter and a CCD camera (Hamamatsu C4742-95-12NRG CCD).

Statistical analysis was performed using IBM SPSS statistics, version 23 (IBM, Armonk, NY, USA). Significant difference between cells captured on BSA and EpCAM functionalized surfaces was calculated using an independent T-test. A One-Way ANOVA using Tukey posthoc multiple comparison was used to determine significant difference between the 4 antibody cell capturing results.

\subsection{Results}

\subsubsection{Coating and antibody functionalization}

Poly(acrylic acid) (PAA) was coated on glass slides to enable covalent binding of antibodies to the surfaces (scheme 1). This was done by first creating an amine terminated self-assembled monolayer of 3-aminopropyl(triethoxy) silane (APTES) on the surface. To this amine layer PAA was grafted using EDC/NHS chemistry. ${ }^{25}$ PAA-coated glass surfaces were characterized by XPS. The wide-scan XPS spectrum showed presence of all expected elements (Supporting information): carbon from the poly(acrylic acid), carbon and nitrogen from the precursor APTES layer, silicon from glass substrate and oxygen derived from both organic layer and substrate (figure S2.1). The narrow-scan XPS spectrum of C1s region of the PAA-coated surface is similar to the published reference XPS data for pure PAA (figure S2.2). ${ }^{26}$ The results confirmed the presence of PAA on the glass substrate.

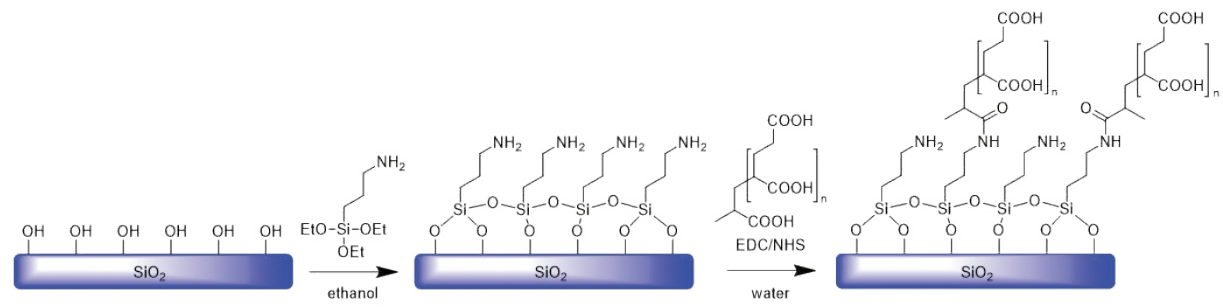

Scheme 2.1: Poly(acrylic acid) grafting to the glass surfaces.

After characterization of the PAA coating, an antibody functionalization protocol was developed, based on NHS/EDC chemistry. To prove that the functionalization protocol could immobilize antibodies on the surface exposing active binding sites, we tested the capture of mononuclear cells with anti-CD3 functionalized microscope glass slides. Therefore, glass surfaces were coated as previously described and microwells were created with a microscope 
glass slide holder and each microwell surface was functionalized with either BSA or anti-CD3. The presence of anti-CD3 was detected using an anti-IgG1-PE. No fluorescence signal from the BSA surface was detected whereas clear fluorescence signals were detected using the CD3 functionalized surface (figure 2.1 A and B). Next, approximately 50,000 mononuclear cells isolated from blood were stained with Hoechst and added to the functionalized microwells with a micropipette. Cells were incubated for 30 minutes. After washing with PBS, few lymphocytes remained at the BSA surface $(C)$ whereas many cells were bound to the anti-CD3 surface (D) indicating that the developed protocol functionalizes the surface with antibodies having exposed active binding sites.

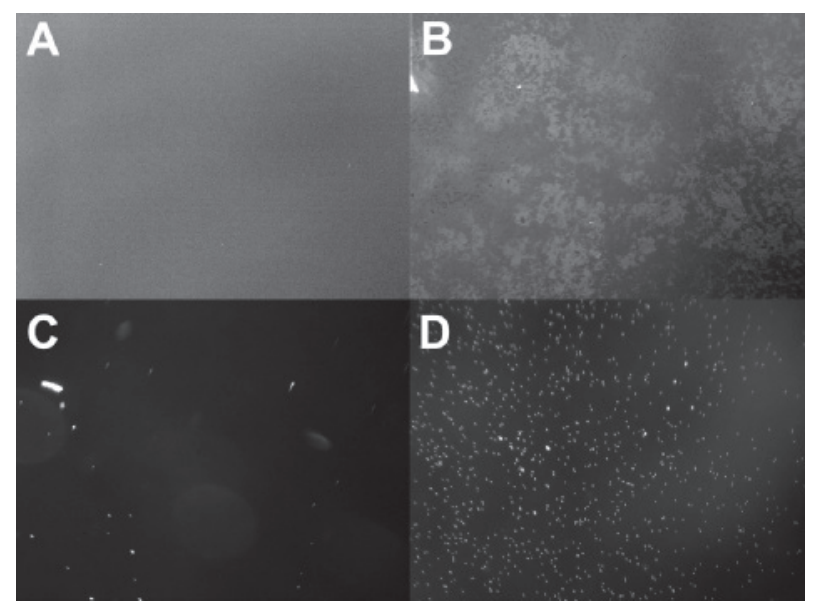

Figure 2.1: Anti-IgG1-PE staining of a BSA- (A) and CD3- (B) coated microwell regions. Mononuclear cells freshly isolated from blood were incubated for 30 minutes on a BSA-coated (C) and CD3-functionalized surface (D). After washing, only T-lymphocytes remained bound to the CD3 antibodies compared to the BSA surface.

\subsubsection{Static and dynamic capture of SKBR-3 cells}

Next, we applied the functionalization protocol to VU1D-9, a widely used anti-EpCAM antibody. ${ }^{27}$ Capture properties of VU1D-9 functionalized surfaces were tested under static conditions (no flow) using SKBR-3 cells, a well characterized breast carcinoma cell line, known to express high levels of EpCAM4 . For both static and dynamic experiments, fresh cells were used. Immediately after trypsinization, SKBR-3 cells suspended in PBS were stained with Hoechst. Approximately 30,000 cells were pipetted into microwells coated with VU1D-9 and microwells coated with BSA (3 replicates of each condition) and incubated for 30 minutes, Nonbound cells were removed by washing 3 times with PBS, using a micropipette. Immediately after washing, cells were visualized with a fluorescent microscope and imaged. Figure 2.2 is a representative image of one of those experiments showing that SKBR-3 cells bound more to the anti-EpCAM functionalized surface than to the control surface. Table 2.1 summarizes 
the cells bound by quantification of 2 static independent experiments, showing that SKBR-3 cells bound, on average, 2 times more to the VU1D-9 surface than to the BSA one. These data shows that SKBR-3 cells are specifically captured by an anti-EpCAM functionalized surface.

Following the static experiments, we developed a model to test SKBR-3 cell capture followed by dynamic washing conditions using flow. For this, we coupled a syringe to a channel slide with a height of $400 \mu \mathrm{m}$, and attached onto the pre-functionalized microscope glass slides. Scheme 2.2 represents the flow model.

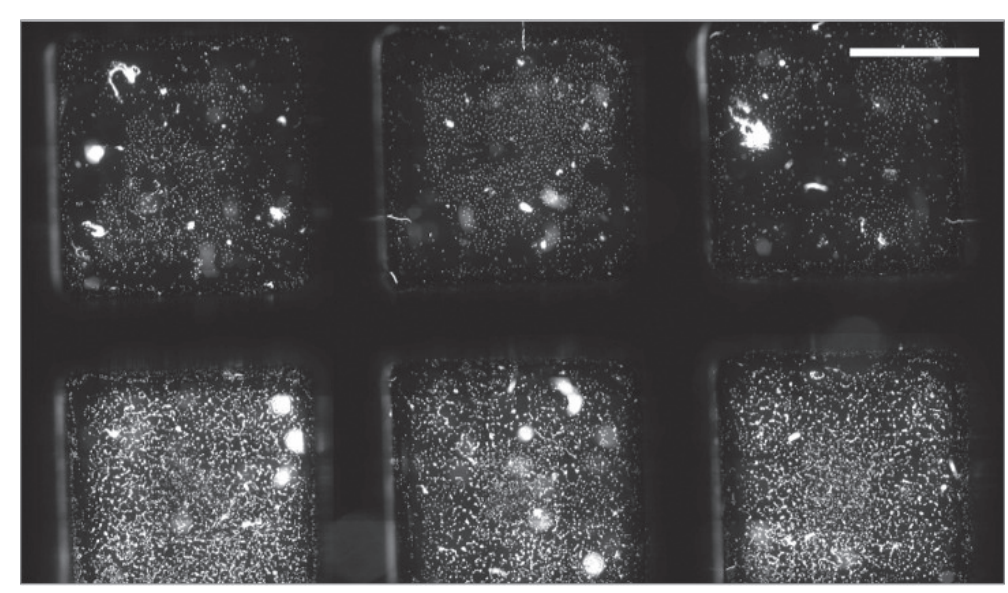

Figure 2.2: Hoechst stained SKBR-3 cells were allowed to bind for 30 minutes to a BSA (top) or VU1D-9 (bottom) functionalized surfaces. Image is representative of 1 independent experiment, showing 3 wells per condition. After rinsing the cells 3 times with PBS, SKBR-3 bound 2 times more to the VU1D-9 functionalized microwells than to the BSA wells. Scale bar represents $3 \mathrm{~mm}$.

Table 2.1: Quantification of SKBR3 cells bound to BSA and VU1D-9 functionalized surfaces under static and dynamic conditions.

\begin{tabular}{|c|c|c|c|c|c|c|}
\hline \multirow{2}{*}{\multicolumn{2}{|c|}{ Experiment }} & \multirow[t]{2}{*}{ BSA-bound cells * } & \multirow{2}{*}{$\begin{array}{r}\text { VU1D-9 } \\
\text { bound cells* }\end{array}$} & \multirow{2}{*}{$\begin{array}{l}\text { Percentage } \\
\text { BSA bound }\end{array}$} & \multirow{2}{*}{$\begin{array}{r}\text { Percentage } \\
\text { VU1D-9 bound }\end{array}$} & \multirow[t]{2}{*}{ p value ${ }^{\#}$} \\
\hline & & & & & & \\
\hline \multirow{2}{*}{ 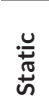 } & 1 & 626 & 1264 & $33 \%$ & $67 \%$ & 0.08 \\
\hline & 2 & 1164 & 2379 & $33 \%$ & $67 \%$ & 0.005 \\
\hline \multirow{3}{*}{ 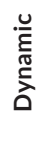 } & 1 & 1107 & 3877 & $22 \%$ & $78 \%$ & 0.03 \\
\hline & 2 & 1923 & 11318 & $15 \%$ & $85 \%$ & 0.03 \\
\hline & & & verage of 3 & & & \\
\hline
\end{tabular}

\#p value calculated with a Student's t-test 
Initially 600,000 SKBR-3 cells suspended in PBS were added via the syringe reservoir and left to sediment in the channel for 30 minutes. Following the sedimentation phase, the syringe reservoir was exchanged for PBS and the flow switched on at $100 \mu \mathrm{l} / \mathrm{min}$ and maintained for 30 minutes. After that period, the flow was set to 500 $\mu \mathrm{l} / \mathrm{min}$ for another 30 minutes. Figure 2.3 shows that more cells bound to the VU1D-9 functionalized surface than to the BSA surface, indicating that also under dynamic conditions the epitope-antibody binding is sustained. Quantification of cell numbers described in table 2.1 for 2 independent dynamic experiments shows that of all bound cells, $78 \%$ and $85 \%$ of the cells bound to the VU1D-9 surface.

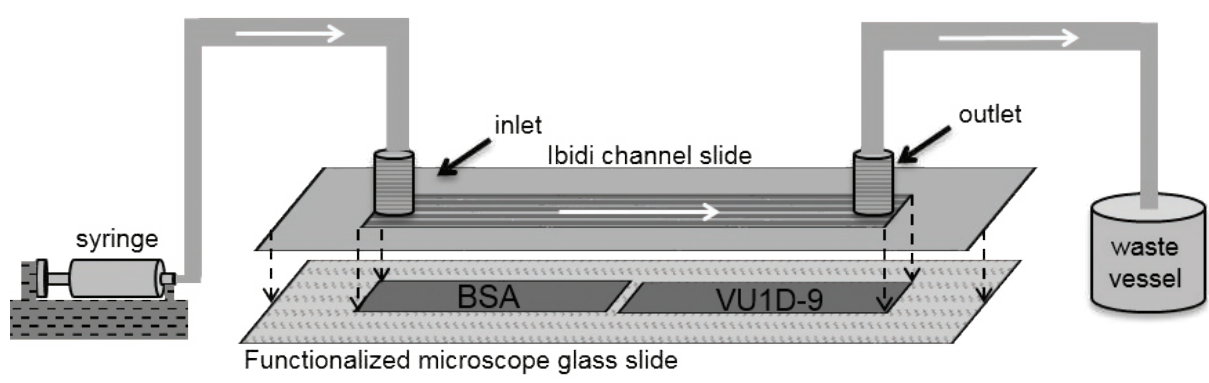

Scheme 2.2: Representation of the flow model used to test SKBR-3 cells capture on BSA and VU1D-9 antibody functionalized surfaces.

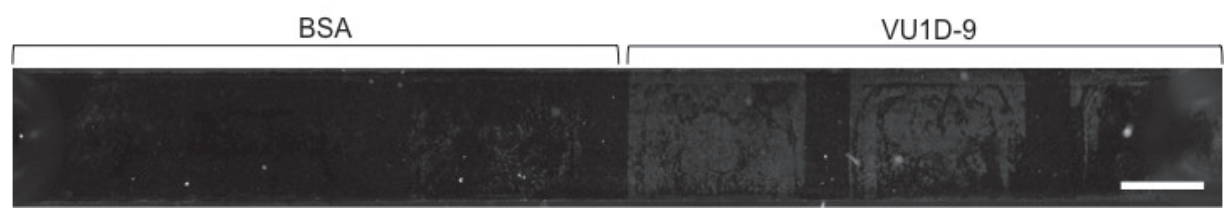

Figure 2.3: Hoechst stained SKBR3 cells were allowed to flow for 30 minutes through a BSA (control) and VU1D-9 functionalized surfaces. Image is representative of one independent experiment. SKBR-3 bound approximately 3 to 4 times more to the VU1D-9 functionalized glass surface than to the BSA one. Scale bar represents $3 \mathrm{~mm}$.

\subsubsection{Antibodies affinity and cross-blocking}

To test whether the PAA coating could be functionalized with various anti-EpCAM antibodies, we applied the same functionalization protocol to four different antibodies and performed a secondary immunostaining to detect their presence. Microwells were defined in a microscope glass slide following functionalizing. In each microwell, the glass slide surface was functionalized with one of the following antibodies: EpAb3-5, HO-3, MJ-37 and VU1D-9, the most widely used anti-EpCAM antibodies for CTC applications. In addition, a BSA-functionalized surface and an empty one (same functionalization protocol except that protein incubation step was performed only with the buffer) were used as controls. After functionalization, the surfaces were incubated with an Anti-IgG-PE antibody and visualized with a fluorescence microscope. 
There was no fluorescent signal coming from the BSA and empty surfaces (figure 2.4 A and B) whereas signal could be detected in all surfaces functionalized with the anti-EpCAM antibodies (figure 2.4, C-F), indicating that the functionalization protocol can be applied to several antibodies.
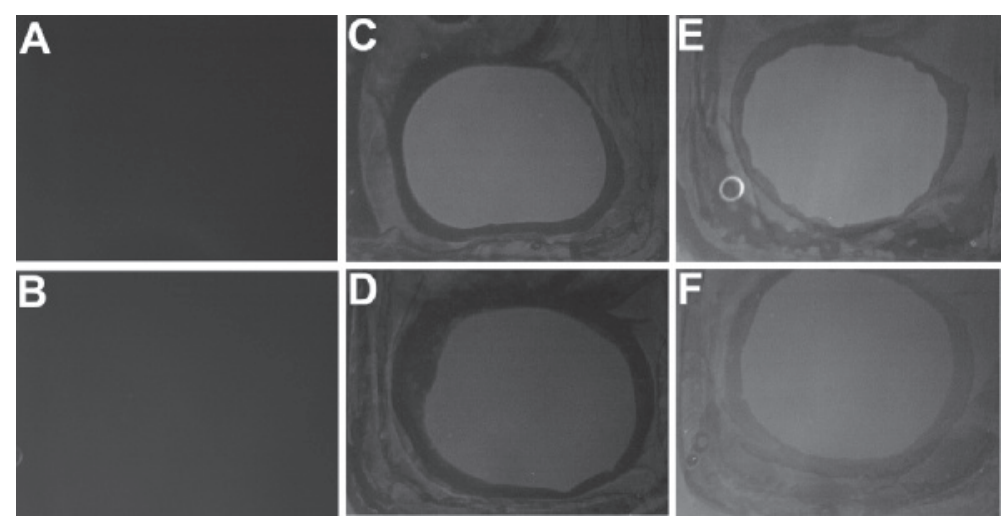

Figure 2.4: Anti-IgG-PE staining of a blank glass microscope slide surface (A), treated as described in the functionalization protocol except that protein incubation was performed with sodium acetate buffer only, and of functionalized surfaces with BSA (B), VU1D-9 (C), HO-3 (D), EpAb3-5 (E) and MJ-37 (F). Only anti-EpCAM functionalized surfaces stained positive.

Flowcytometry was used to determine cross blocking of EpAb3-5, MJ-37 and HO-3 with VU1D-9. Fresh SKBR-3 cells were first incubated with one of the anti-EpCAM antibodies and subsequently with VU1D-9-PE. EpAb3-5 abrogated the VU1D-9-PE signal whereas HO-3 and MJ-37 did not. These results indicate that EpAb3-5 cross blocks with VU1D-9 (figure 2.5, right column) whereas HO-3 and MJ-37 bind to different epitopes than VU1D-9 does. Control samples, where SKBR-3 cells were incubated with one of the anti-EpCAM antibodies and subsequently with IgG-PE, presented in figure 2.5 (left columns) show normal binding of EpAb3-5, HO-3, MJ-37 and VU1D-9 to SKBR-3 cells. The bottom row shows SKBR-3 without Ab unstained (right) and the isotype control with only lgG-PE (left).

SPRi was performed to compare the binding affinity of the 4 different antibodies. Recombinant human EpCAM as well the 4 different anti-EpCAM antibodies were immobilized on the surface of a gold SPR sensor and the 4 different anti-EpCAM antibodies were injected in the system in concentrations of 32, 16, 8, 4, 2, 1 and $0.5 \mathrm{nM}$, to obtain kinetic data. The sensorgrams obtained from the measurements were used to determine the affinities and kinetics of the antibodies tested. The on-rate $\left(k_{d}\right)$ and off-rate $\left(k_{a}\right)$ and dissociation equilibrium $\left(K_{D}\right)$ constants for various ligand densities and analyte concentrations were exponentially interpolated to the $K_{D}$ at $R \max =100 . K_{D}$ represents the analyte concentration under equilibrium conditions at 
which $50 \%$ of the ligand molecules are bound. ${ }^{28}$ Results are shown in table 2.2. Judging by the determined $K_{D}$ values, EpAb3-5 showed the highest binding affinity $\left(K_{D}=2.6 E-11 \mathrm{M}\right)$ comparable to the affinity of HO-3 $\left(K_{D}=4.0 E-11 \mathrm{M}\right)$ followed by VU1D-9 $\left(K_{D}=2.7 E-10 \mathrm{M}\right)$ and $\mathrm{MJ}-37$ respectively $\left(\mathrm{K}_{\mathrm{D}}=2.8 \mathrm{E}-9 \mathrm{M}\right)$.

$A b+$ anti-lgG-PE

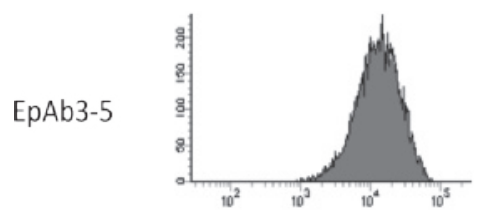

HO-3

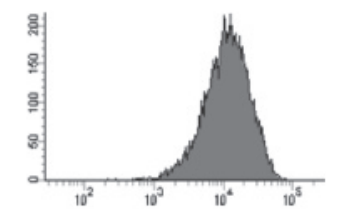

MJ-37

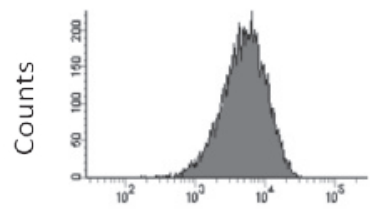

VU1D-9

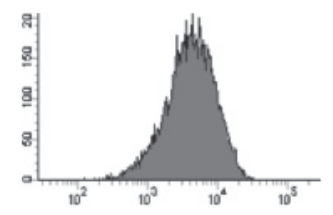

No Ab

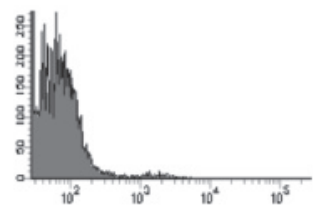

$A b+V U 1 D-9-P E$
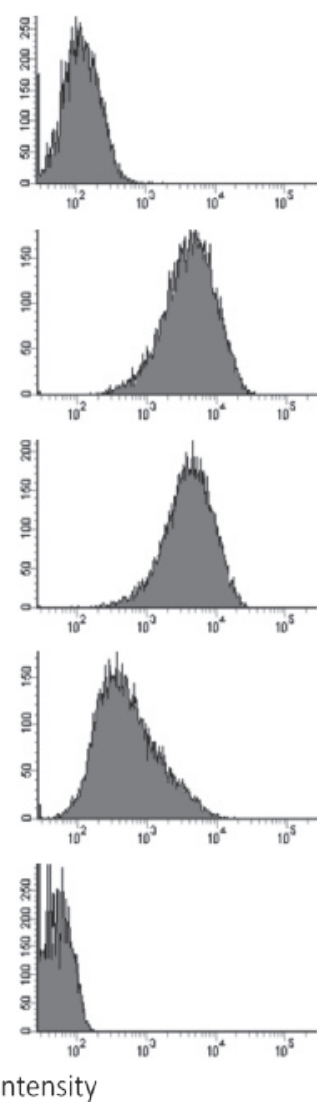

Figure 2.5: Determination of EpAb3-5, HO-3 and MJ-37 epitope cross blocking with VU1D-9. VU1D-9 signal is abrogated by binding of EpAb3-5 but not in the cases of $\mathrm{HO}-3$ and $\mathrm{MJ}-37$, indicating that the latter bound to different epitopes than VU1D-9 does.

Table 2.2: Surface Plasmon Resonance measurements of anti-EpCAM/rhEpCAM binding.

\begin{tabular}{l|lll} 
Antibody & $\mathbf{k}_{\mathbf{a}}(\mathbf{S}-\mathbf{- 1 M}-\mathbf{1})$ & $\mathbf{k}_{\mathbf{d}}(\mathbf{S}-\mathbf{1})$ & $\mathbf{K}_{\mathrm{D}}(\mathrm{M}) \mathbf{R} \max =100$ \\
\hline EpAb3-5 & $3.1 \mathrm{E}+05$ & $1.1 \mathrm{E}-05$ & $2.6 \mathrm{E}-11$ \\
HO-3 & $1.5 \mathrm{E}+05$ & $5.9 \mathrm{E}-05$ & $4.0 \mathrm{E}-11$ \\
MJ-37 & $1.6 \mathrm{E}+05$ & $4.3 \mathrm{E}-04$ & $2.8 \mathrm{E}-09$ \\
VU1D-9 & $3.1 \mathrm{E}+05$ & $8.2 \mathrm{E}-05$ & $2.7 \mathrm{E}-10$
\end{tabular}




\subsubsection{SKBR-3 capture using different Abs}

After analyzing binding affinity and crossblocking, the antibodies were tested for the capture of EpCAM expressing cells. Moreover, the amount of captured SKBR-3 cells was expected to correlate with the obtained $K_{D}$ values, i.e. more cells captured by antibodies with higher $K_{D}$ values. Therefore, SKBR-3 capture was tested under flow in microscope glass slides functionalized with either EpAb3-5, HO-3, MJ-37 or VU1D-9. After functionalization, the slides were placed onto the slide channels with a height of $400 \mu \mathrm{m}$ and 200,000 Cell Tracker Orange stained SKBR-3 cells were pipetted into the slide channel and left to incubate for 30 minutes. Afterwards, PBS was pumped using the setup described in scheme 2.2 through the channel for 30 minutes at $500 \mu \mathrm{l} / \mathrm{min}$.

In figure 2.6, each row represents the entire scanned channel, before (A) and after (B) pumping the PBS. The left surface of all slides was treated with BSA and the right side with an antiEpCAM antibody. It is notorious, for all tested antibodies, that the amount of cells on the left side of the channel is dramatically reduced after pumping PBS, whereas the antibodies on the right side retain most of the SKBR-3 initially scanned. The BSA coated surface was used to correct for variation in coating efficiency and cell seeding between experimental days. Figure 2.7 shows the quantified results for these capture experiments. The total number of bound cells present in the slide after rinsing (B rows in figure 2.6) was set to $100 \%$ and the diagram shows the percentage of cells present on the EpCAM functionalized surface and the percentage of cells on the BSA functionalized control surface. Comparison with the control BSA functionalized surface showed that the $\mathrm{HO}-3$ antibody functionalized surface bound most SKBR-3 cells ( $88.9 \%$ versus $11.1 \%$ with a SD of \pm 7.0 ), followed by VU1D-9 ( $88 \%$ versus $12 \% \pm 4.6$ ), EpAb3 -5 (86,4\% versus $13.6 \% \pm 9.8 \%$ ), and MJ-37 (70\% versus $30 \% \pm 6.1$ ). There is a significant difference between the 4 antibodies ( $p=0.037$ ). When performing post-hoc multiple comparison it shows that there is no significant difference between $\mathrm{HO}-3$, EpAb3-5 and VU1D9, but there is significant difference at the 0.05 level between $\mathrm{HO}-3$ and MJ-37. 

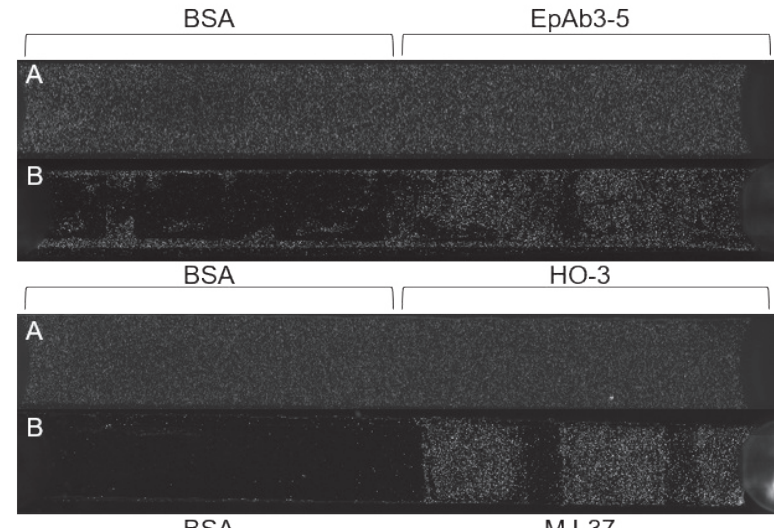

BSA

MJ-37

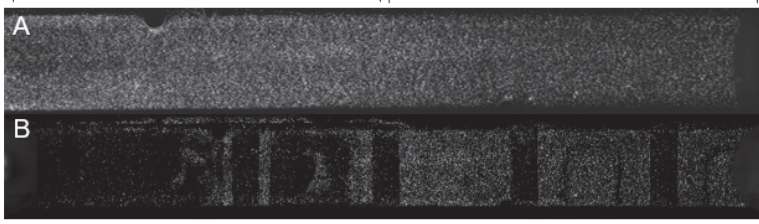

BSA

VU1D-9

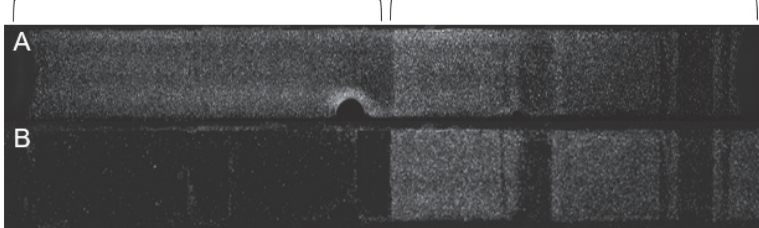

Figure 2.6: Determination of EpAb3-5, HO-3, MJ-37 and VU1D-9 binding of SKBR-3 under dynamic conditions. A) slide after cell sedimentation, B) slide after washing by flowing the PBS.

Percentage of cells bound to surface

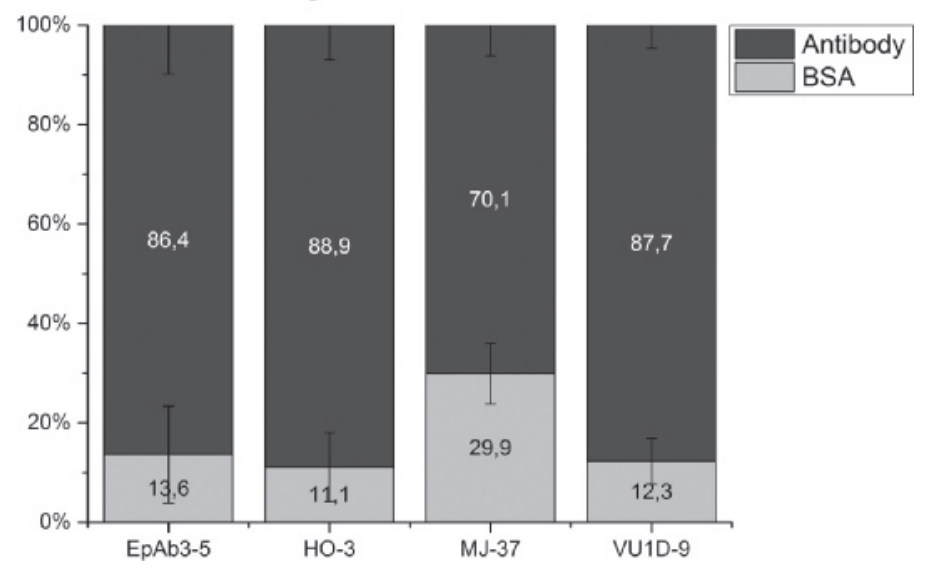

Figure 2.7: Quantification of bound SKBR3 cells to BSA and various anti-EpCAM antibodies functionalized surfaces under dynamic conditions. Total number of cells present on both BSA and EpCAM functionalized surface is set as $100 \%$. (n=3*total of 3 wells) 


\subsection{Discussion}

Presence of CTC is associated with poor outcome and changes in the CTC count can be used to monitor treatment in cancer patients. Moreover assessment of treatment targets on CTC can guide the choice of the most effective therapy. Current techniques to isolate CTC are frequently based on immuno-based cell capture, mostly using avidin-biotin chemistry. Although the epitope target is in most cases justified, the rational for the choice of the antibody clone is often missing, which can have implications in the performance of the developed systems.

Here we present a coating that enables covalent binding of antibodies that can be used for CTC capturing. In addition we compare four different antibodies recognizing the EpCAM antigen. The choice for a PAA coating was made because a direct covalent binding of antibody on PAA is a more simple chemistry compared to the mostly used avidin-biotin chemistry. Only one activating step with well-known EDC/NHS mixture is needed while avidin-biotin chemistry consists of 3 steps (attachment of avidin onto surfaces, biotinylation of the antibody and coupling of biotinylated-antibody onto the avidin-coated surface). Especially, by using a polycarboxylate coating, which binds antibodies electrostatically by choosing the right $\mathrm{pH}$ above the pl of the antibody. A subsequent rapid reaction of NHS moieties to lysine groups available around the antibody makes the binding efficient. Due to hydrophilicity and the negative charge of the PAA layer, it also can act as a kind of hydrogel layer and plays a role as a repellent to other components. In contrast to the avidin-biotin chemistry, which is also known to have a high non-specific binding because of its tendency to bind to other components than biotin and the strong positive charge on the avidin may cause ionic interaction, especially with cell surfaces. ${ }^{29}$ In case of direct binding of antibody to a PAA layer, non-specific binding is reduced and the unreacted NHS moieties can be converted back to carboxylic acid 30.

Functionalization of this coating with a CD3 monoclonal antibody recognizing T-lymphocytes provided the proof of concept of its binding ability by retaining lymphocytes on a CD3 coated surface while the BSA coated surface remained empty (figure 2.1). BSA is inert and binds to 'sticky' surface spots, thus preventing undesired binding of functional proteins. ${ }^{31}$ Further on we functionalized this coating with anti-EpCAM antibodies derived from the VU1D-9 clone and performed similar experiments to that of CD3. High EpCAM expressing SKBR-3 cells were retained two times more on a VU1D-9 functionalized surface as compared to a BSA-functionalized surface (figure 2.2 and table 2.1), further demonstrating the binding properties of the functionalized coating. Unlike in the CD3 experiment, SKBR-3 did stick to the BSA-treated surface likely due to its adhesion properties, in contrast to lymphocytes 
that are non-adherent cells. It is likely that in the specific case of SKBR-3 cells the incubation time was long enough to permit the assembly of focal adhesions with the surface anchoring points. This hypothesis is further strengthened by the fact that in the dynamic experiments the percentage of bound SKBR-3 cells to the VU1D-9 surface is higher (between 75 and 85\%) than in the static experiment (table 2.1). This indicates that the PBS flow detaches some of the already adhering SKBR-3 cells, at least those with the weakest adhesion points, thereby increasing the difference between the two conditions. More importantly it also indicates that the binding affinity of the VU1D-9 antibody is sufficiently high to sustain the cell capture under flow conditions.

After showing the cell capture ability of VU1D-9 functionalized PAA coating under static conditions and dynamic washing conditions using flow, we compared the performance of other anti-EpCAM clones in our system. First it was proven that all antibodies tested could be functionalized and detected on the coated surface (figure 2.4) and second the epitope binding and binding affinity was compared by flow cytometry. The EpAb3-5 shares the same target epitope as VU1D-9, whereas HO-3 and MJ-37 have a different epitope (figure 2.5). The availability of antibodies targeting two different epitopes of the EpCAM antigens can be exploited either by increasing the binding efficiency of EpCAM bearing cells by the use of two antibodies or by using one antibody to capture the cells and another one to discriminate between the specifically and non-specifically bound cells. In the latter case the antibody can for example be conjugated to a fluorescent molecule and the cells examined by fluorescent microscopy.

Assessment of the affinity of the antibodies to recombinant EPCAM was done by SPRi and showed the highest binding affinity for EpAb3-5 followed by HO-3, VU1D-9 and MJ37 respectively (table 2.2). Following the setup presented in scheme 2.2, all antibodies were tested for their ability to capture SKBR-3 cells. The three antibodies with the highest affinity did not show a capture efficiency significantly different from each other. However the MJ-37 antibody with the lowest affinity captured significantly less SKBR-3 cells (70\%) as compared to the HO-3 antibody.

These results emphasize the need that when choosing an antibody for such applications thorough tests should be performed to make the best choice for the desired application. Evaluating binding affinity constants might anticipate the antibody performance results (as in the case of HO-3) but might not be enough and therefore other tests should be performed and taken into account before a decision is made. 


\subsection{Conclusion}

We showed a simple poly(acrylic acid) coating on glass slides. Using this coating we were able to functionally bind anti-CD3 and four different types of anti-EpCAM antibodies, confirmed by lymphocyte and SKBR-3 cell binding respectively, in contrast to their BSA control surfaces where no or less cells were found. Among the four different anti-EpCAM antibodies EpAb3-5 and VU1D-9 shared the same epitope target. EpAb3-5 displayed the highest binding affinity constant when analyzed by SPRi using rhEpCAM, followed by HO-3, VU1D-9, and MJ-37 respectively. In line with the expectations, EpAb3-5, HO-3 and VU1D-9 bound most SKBR-3 cells in a flow model chamber and MJ-37 bound the least cells. These results point towards careful selection of antibody clones when targeting specific cell surface markers and emphasize the need to perform multiple assays before choosing one.

\section{Acknowledgments}

The authors would like to thank Niels van der Velde and Dr. Richard Schasfoort from IBIS Technologies B.V. for their excellent support in obtaining and analyzing the SPRi data. 


\section{References}

1 A. M. C. Barradas and L. W. M. M. Terstappen, Cancers (Basel)., 2013, 5, 1619-1642.

2 C. Alix-Panabières and K. Pantel, Clin. Chem., 2013, 59, 110-8.

3 K. C. Andree, G. van Dalum and L. W. M. M. Terstappen, Mol. Oncol., 2016, 10, 395-407.

4 C. G. Rao, D. Chianese, G. V Doyle, M. C. Miller, T. Russell, R. A. Sanders and L. W. M. M. Terstappen, Int. J. Oncol., 2005, 27, 49-57.

5 U. Schnell, V. Cirulli and B. N. G. Giepmans, Biochim. Biophys. Acta, 2013, 1828, 1989-2001.

6 H. Koprowski, Z. Steplewski, K. Mitchell, M. Herlyn, D. Herlyn and P. Fuhrer, Somatic Cell Genet., 1979, 5, 957-71.

7 C. Patriarca, R. M. Macchi, A. K. Marschner and H. Mellstedt, Cancer Treat. Rev., 2012, 38, 68-75.

8 K. Flatmark, E. Borgen, J. M. Nesland, H. Rasmussen, H.-O. Johannessen, I. Bukholm, R. Rosales, L. Hårklau, H. J. Jacobsen, B. Sandstad, K. Boye and Ø. Fodstad, Br. J. Cancer, 2011, 104, 1434-9.

9 W. A. Osta, Y. Chen, K. Mikhitarian, M. Mitas, M. Salem, Y. A. Hannun, D. J. Cole and W. E. Gillanders, Cancer Res., 2004, 64, 5818-24.

10 M. Imano, T. Itoh, T. Satou, A. Yasuda, K. Nishiki, H. Kato, O. Shiraishi, Y.-F. Peng, M. Shinkai, M. Tsubaki, T. Yasuda, H. Imamoto, S. Nishida, Y. Takeyama, H. Furkawa, K. Okuno and H. Shiozaki, Target. Oncol., 2013, 8, 231-5

11 J. Ni, P. J. Cozzi, W. Duan, S. Shigdar, P. H. Graham, K. H. John and Y. Li, Cancer Metastasis Rev., 2012, 31, 779-91.

12 J. Ji, T. Yamashita, A. Budhu, M. Forgues, H.-L. Jia, C. Li, C. Deng, E. Wauthier, L. M. Reid, Q.-H. Ye, L.-X. Qin, W. Yang, H.-Y. Wang, Z.-Y. Tang, C. M. Croce and X. W. Wang, Hepatology, 2009, 50, 472-80.

13 M. Simon, N. Stefan, A. Plückthun and U. Zangemeister-Wittke, Expert Opin. Drug Deliv., 2013, 10, 451-68.
14 M. Cristofanilli, G. T. Budd, M. J. Ellis, A. Stopeck, J. Matera, M. C. Miller, J. M. Reuben, G. V Doyle, W. J. Allard, L. W. M. M. Terstappen and D. F. Hayes, N. Engl. J. Med., 2004, 351, 781-791.

15 E. Ozkumur, A. M. Shah, J. C. Ciciliano, B. L. Emmink, D. T. Miyamoto, E. Brachtel, M. Yu, P. Chen, B. Morgan, J. Trautwein, A. Kimura, S. Sengupta, S. L. Stott, N. M. Karabacak, T. A. Barber, J. R. Walsh, K. Smith, P. S. Spuhler, J. P. Sullivan, R. J. Lee, D. T. Ting, X. Luo, A. T. Shaw, A. Bardia, L. V Sequist, D. N. Louis, S. Maheswaran, R. Kapur, D. A. Haber and M. Toner, Sci. Transl. Med., 2013, 5, 179ra47.

16 B. J. Kirby, M. Jodari, M. S. Loftus, G. Gakhar, E. D. Pratt, C. Chanel-Vos, J. P. Gleghorn, S. M. Santana, H. Liu, J. P. Smith, V. N. Navarro, S. T. Tagawa, N. H. Bander, D. M. Nanus and P. Giannakakou, PLoS One, 2012, 7, e35976.

17 S. Nagrath, L. V Sequist, S. Maheswaran, D. W. Bell, D. Irimia, L. Ulkus, M. R. Smith, E. L. Kwak, S. Digumarthy, A. Muzikansky, P. Ryan, U. J. Balis, R. G. Tompkins, D. A. Haber and M. Toner, Nature, 2007, 450, 1235-9.

18 S. L. Stott, C.-H. Hsu, D. I. Tsukrov, M. Yu, D. T. Miyamoto, B. A. Waltman, S. M. Rothenberg, A. M. Shah, M. E. Smas, G. K. Korir, F. P. Floyd, A. J. Gilman, J. B. Lord, D. Winokur, S. Springer, D. Irimia, S. Nagrath, L. V Sequist, R. J. Lee, K. J. Isselbacher, S. Maheswaran, D. A. Haber and M. Toner, Proc. Natl. Acad. Sci. U. S. A., 2010, 107, 18392-7.

19 M.-Y. Liao, J.-K. Lai, M. Y.-P. Kuo, R.-M. Lu, C.-W. Lin, P.-C. Cheng, K.-H. Liang and H.-C. Wu, Oncotarget, 2015, 6, 24947-68.

20 P. Ruf, O. Gires, M. Jäger, K. Fellinger, J. Atz and H. Lindhofer, Br. J. Cancer, 2007, 97, 315-21.

21 L. De Leij, W. Helrich, R. Stein and M. J. Mattes, Int. J. Cancer. Suppl., 1994, 8, 60-3.

22 S. Natarajan, P. S. Katsamba, A. Miles, J. Eckman, G. A. Papalia, R. L. Rich, B. K. Gale and D. G. Myszka, Anal. Biochem., 2008, 373, 141-6.

23 R. B. M. Schasfoort, K. C. Andree, N. van der Velde, A. van der Kooi, I. Stojanović and L. W. M. M. Terstappen, Anal. Biochem., 2016, 500, 21-23.

24 S. Preibisch, S. Saalfeld and P. Tomancak, Bioinformatics, 2009, 25, 1463-5. 
25 P. Vermette and L. Meagher, Langmuir, 2002, 18, 10137-10145.

26 P. Louette, F. Bodino and J.-J. Pireaux, Surf. Sci. Spectra, 2005, 12, 22.

27 A. Tsubura, H. Senzaki, M. Sasaki, J. Hilgers and S. Morii, J. Cutan. Pathol., 1992, 19, 73-9.

28 R. B. M. Schasfoort, W. de Lau, A. van der Kooi, H. Clevers and G. H. M. Engbers, Anal. Biochem., 2012, 421, 794-6.
29 G.T.Hermanson, Bioconjugate Techniques, Academic press, Boston, third edit., 2013.

30 P. Vermette, T. Gengenbach, U. Divisekera, P. A. Kambouris, H. J. Griesser and L. Meagher, J. Colloid Interface Sci., 2003, 259, 13-26.

31 R. A. Sperling and W. J. Parak, Philos. Trans. A. Math. Phys. Eng. Sci., 2010, 368, 1333-83. 


\section{Supplementary data}

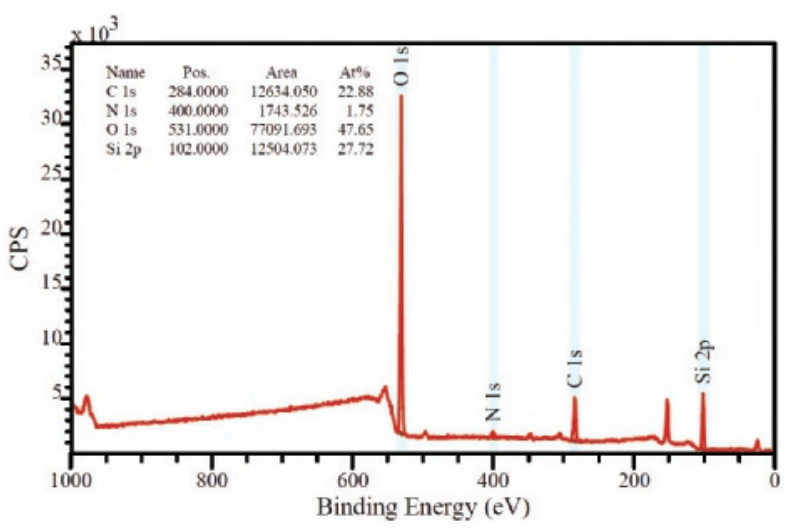

Figure S 2.1: Wide-scan XPS spectra of PAA-coated glass slide

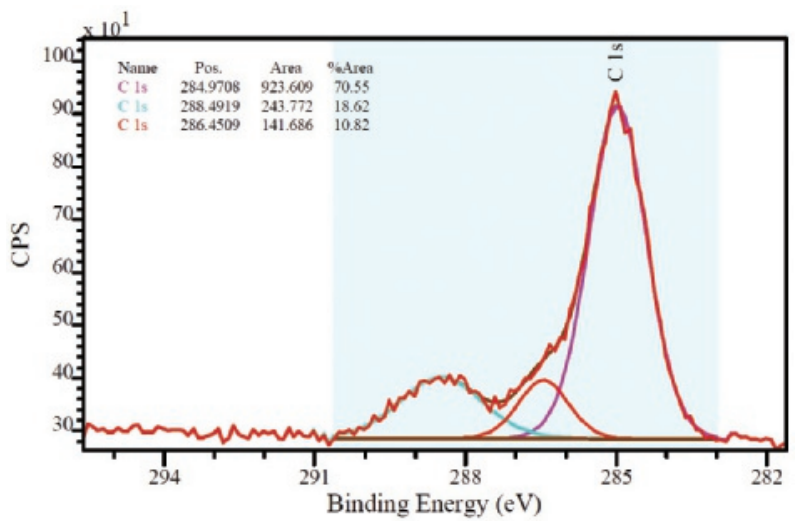

Figure S 2.2: Narrow-scan XPS spectra of Carbon region of PAA-coated glass slide 

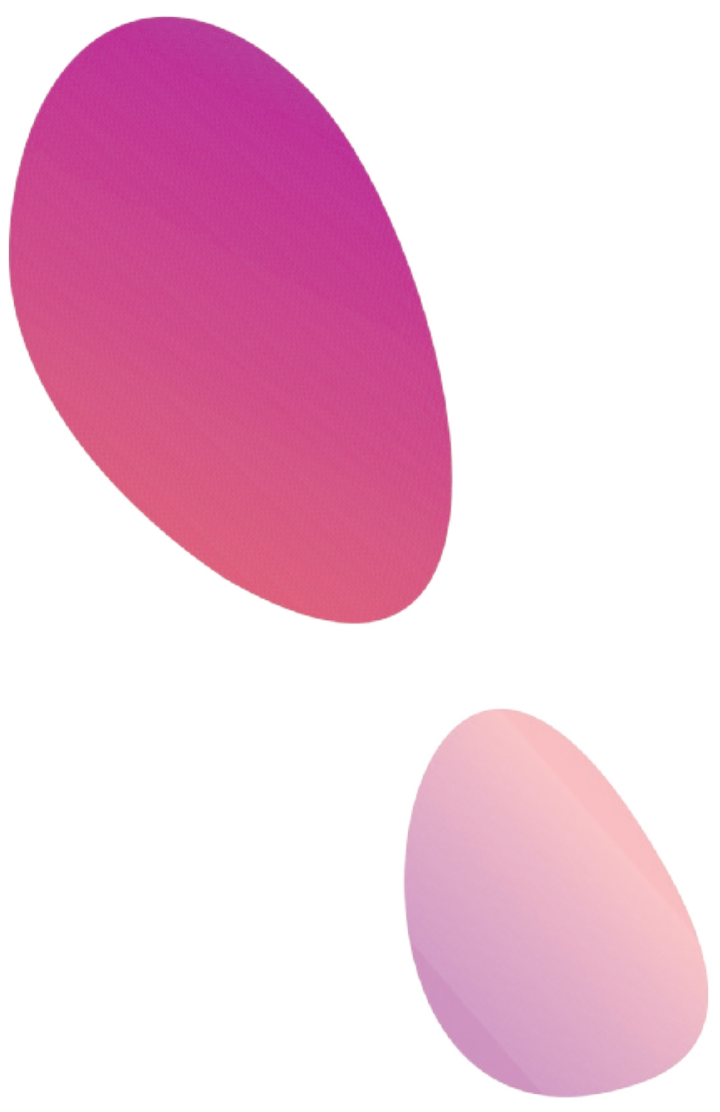


\section{CHAPTER 3}

\section{Tumor Cell Capture from Blood by Flowing Across Antibody-coated Surfaces}




\section{Abstract}

The load of circulating tumor cells (CTC) is related to poor outcome in cancer patients. A sufficient number of these cells would enable a full characterization of the cancer. An approach to probe larger blood volumes, allowing for the detection of more of these very rare CTC is the use of leukapheresis. Currently available techniques allow only the analysis of a small portion of leukapheresis product. Here, we present a method that uses flow rather than static conditions which allows processing larger volumes. We evaluated conditions needed to isolate tumor cells from blood while passing antibody coated surfaces. Results show that our set-up efficiently captures cancer cells from whole blood. Results show that the optimal velocity at which cells are captured from blood is $0.6 \mathrm{~mm} / \mathrm{sec}$. Also, it can be concluded that the VU1D9 antibody targeting the EpCAM antigen has a very high capture efficiency. When using an antibody that does not capture $100 \%$ of all cells, combining multiple antibodies on the capture surface is very beneficial leading to an increase in cell capture and is therefore worthwhile considering in any cancer cell capture methodology. 


\subsection{Introduction}

Tumor cells present in blood are referred to as circulating tumor cells (CTC) and their load is associated with poor outcome in cancer patients. ${ }^{1-3}$ The genetic make-up of CTC may be used to guide therapy, provided they indeed are representative of the cancer and can be retrieved in sufficient quantities. CTC are however extremely rare and the blood volume that is needed to obtain sufficient quantities in all patients with disseminated disease is liters rather than milliliters of blood. ${ }^{4}$ An approach to probe larger blood volumes for the presence of CTC is leukapheresis, a procedure that for example is used to obtain sufficient numbers of hematopoietic progenitor cells for stem cell transplantation. ${ }^{5}$ This technology has been applied to harvest CTC and baptized Diagnostic Leukapheresis (DLA). ${ }^{6-8}$ With currently available techniques to isolate CTC only a small portion ( 5\%) of the DLA product can be analyzed for the presence of CTC. This is mainly due to the high number of cells present in DLA products reaching the limit of cells that techniques can process. One of the potential solutions is to isolate tumor cells from DLA or blood under flow rather than static conditions, e.g. CellSearch ${ }^{\circledR}$, RosetteSep ${ }^{\mathrm{TM}}$, allowing for isolation from bigger volumes. Here we present a microfluidic chip and evaluate conditions needed to isolate tumor cells from blood while passing the antibody coated surfaces of this chip. Also, we investigate multiple antibodies targeting EpCAM and Her 2 antigens to show the effect on the capture efficiency of tumor cells.

\subsection{Materials and methods}

\subsubsection{Experimental set-up}

The experimental set-up is depicted in figure 3.1.a. A syringe pump (Harvard Apparatus, Holliston, MA, USA) with a $5 \mathrm{~mL}$ Luer lock syringe (BD, Franklin Lakes, NJ, USA) containing the sample was used to flow the sample through the microfluidic chip. A stirring bar was placed in the syringe to ensure constant mixing of the sample by the use of a rotating magnet next to the syringe. The chip was placed on a fluorescence microscope (Nikon Eclipse E400, Nikon Instruments, Amsterdam, The Netherlands), equipped with a 4x objective (NA 0.13 WD 17.1), a camera (Hamamatsu flash 4, 6.5 pixel per um, Hamamatsu, Almere, the Netherlands) and fluorescent filter cubes to capture the staining of the nucleic acid dye Hoechst 33342 and the membrane dyes Cell Tracker Orange and Cell Tracker Green (Invitrogen, Thermo Fisher, Waltham, MA, USA). The syringe was attached to the inlet of the chip using tubing (Tygon ${ }^{\circledR}$ ND 100-80, ID = 0,51 mm, OD = 1,52 mm, Saint-Gobain, Courbevoie, France) and the outlet of the chip was connected with the same tubing to a waste container. 
a

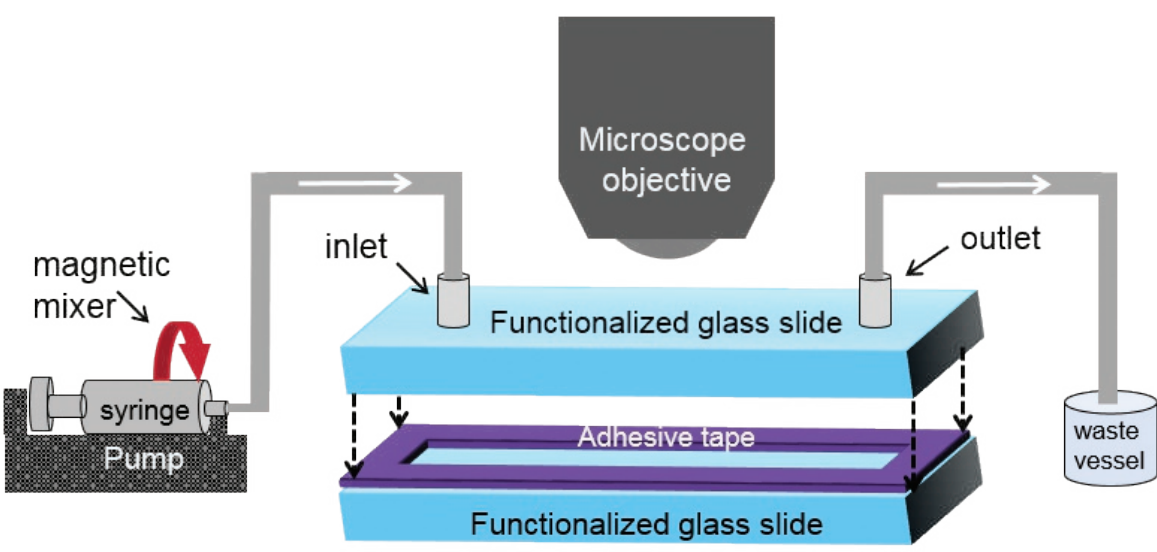

b

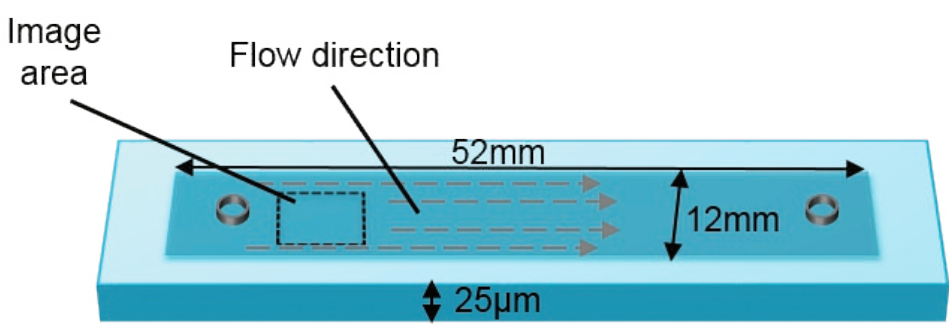

Figure 3.1: a) Experimental set-up, cells were imaged using a microscope, while the sample was flown through the flow chip using a syringe and syringe pump to control the flow rate. b) chip dimensions and area used for imaging using microscope is depicted.

\subsubsection{Microfluidic chips}

Chips were fabricated by adhering two microscopic glass slides (Menzel Gläzer, ThermoFischer, Braunschweig, Germany) together with double sided sticky tape with a thickness of $25 \mu \mathrm{m}$ (3M, Maplewood, MN, USA). An in house developed interferometer was used to confirm the $25 \mu \mathrm{m}$ spacing. The flow channels were created by cutting a rectangle in the tape using the Craft ROBO and ROBO master software (Graphtec \& Silhouette Portrait, Wrexham, UK). Dimensions of the rectangle were a width of $12 \mathrm{~mm}$ and a length of $52 \mathrm{~mm}$. In one of the glass slides two holes were drilled ( $\varnothing 1.6 \mathrm{~mm}, 52 \mathrm{~mm}$ distance) to create an inlet and an outlet for connection to the flow channel. Tubing with a typical length of $25 \mathrm{~cm}$ was glued to the inlet and outlet using a 1/16" ferrule (IDEX, Oak Harbor, WA, USA), superglue (Loctite, Dusseldorf, Germany) and 5 minute epoxy glue (Bison, Goes, The Netherlands). To the other end of the tubing a Luer lock precision tip (Techcon Systems, Hampshire, UK) was connected enabling attachment of a $5 \mathrm{~mL}$ Luer lock syringe (BD, Vianen, The Netherlands). 


\subsubsection{Modification of the glass surfaces}

The Microblaster (Comco MB1002, Burbank, CA, USA) in combination with $29 \mu \mathrm{m} \mathrm{Al}_{2} \mathrm{O}_{3}$ crystals were used to modify the surface roughness of the glass surface. After powder blasting, the microscopic glass slides were cleaned with acetone and 70\% ethanol to remove the mask and $\mathrm{Al} 2 \mathrm{O} 3$ crystal residues. For antibody coating, glass slides were cleaned with acetone and wiped with tissues (Spec-Wipe ${ }^{\circledR}$, VWR, Amsterdam, The Netherlands) and subsequently cleaned with piranha solution $\left(1: 3, \mathrm{H}_{2} \mathrm{O}_{2} 3: \mathrm{H}_{2} \mathrm{SO}_{4}\right)$ for 30 min to create silanol groups on the surface. The samples were rinsed 3 times with an excess of water. The piranha treated samples were incubated in a solution of (3-aminopropyl)triethoxysilane (0.1 M) in absolute ethanol with water (5\%) and acetic acid $(0.25 \%)$ for $4 \mathrm{~h}$ at $40^{\circ} \mathrm{C}$. After incubation the samples were rinsed 3 times with ethanol and dried under vacuum. A poly(acrylic acid) (PAA) coating was applied to the surface as previously described. ${ }^{9}$ The PAA-coated glass slides were kept at $4^{\circ} \mathrm{C}$ until further usage up to 3 weeks after preparation. To obtain a NHS-activated PAA layer the slides were reacted with a solution of $0.3 \mathrm{M} \mathrm{NHS}$ and EDC (NHS/EDC) in MES buffer (50 mM, pH 4.5 - 5) at room temperature for 15 minutes. Residual NHS/EDC was washed away with an acetic acid solution ( 5 mM, pH 5.5 - 6). All washing steps were repeated 3 times. Antibodies or bovine serum albumin (BSA) were pipetted in sodium acetate buffer ( $5 \mathrm{mM}, \mathrm{pH}$ 5) at a final concentration of $20 \mathrm{\mu g} / \mathrm{mL}$. The anti-EpCAM antibodies HO-3 (Trion Research GmbH, Planegg, Germany) and VU1D-9 (kind gift from Immunicon, Huntingdon Valley, PA, USA) recognizing different epitopes of the EpCAM antigen and the anti-HER2 antibody, Her81 (kind gift from Immunicon, Huntingdon Valley, PA, USA), were used alone or in combination. Antibodies were permitted to bind for 60 minutes at room temperature, after which unbound antibody was washed away. To block any unreacted binding sites, a solution of 0.1 M ethanolamine hydrochloride ( $\mathrm{pH}$ 8.5) (E6133, Sigma-Aldrich) in demineralized water was added and incubated for 30 minutes. After another washing step, the functionalized microscope glass slides were used to create the microfluidic chip.

\subsubsection{Cell lines and antigen density}

Breast carcinoma cell lines SKBR-3 and MCF-7 were obtained from ATCC (Manassa, VA, USA) and cultured in DMEM (Lonza, Basel, Switzerland) with 10\% FBS (Sigma) and 1\% pen/ strep (Lonza), cells were trypsinized when nearing confluence using 0.05\% Trypsin-EDTA (1x) (Gibco, Life Technologies, Waltham, MA, USA) and re-plated at a seeding density never below 20,000 cells $/ \mathrm{cm}^{2}$. The Luna automated cell counting system (Logos Biosystems, Westburg, Leusden, The Netherlands) was used to count the cells by loading $12 \mu \mathrm{L}$ of cell suspension into the respective counting slides. Cells were stained overnight before harvesting using $1 \mu \mathrm{M}$ Cell Tracker Orange or 10 $\mathrm{\mu M}$ Cell Tracker Green. Absolute numbers of EpCAM and Her2 antigens 
on the cell lines were determined using Quantibrite-phycoerythrin (PE) beads (BD Biosciences) according to manufacturer's instructions. Beads have known numbers of PE molecules per bead which were compared to the staining intensity of either a-EpCAM or a-Her2 PE labeled cell lines. SKBR-3 cells expressed 376,606 EpCAM and 957,731 Her2 antigens, MCF7 cells $\sim 880,189$ EpCAM and $~ 57,916$ Her2 antigens.

\subsubsection{Sample preparation}

Blood collected in EDTA vacutainer tubes (BD) from healthy donors was obtained from the TNW-ECTM-donor services (University of Twente, Enschede, The Netherlands). Blood was stained using the nucleic acid dye Hoechst 33342 (Life Technologies, USA) at a final concentration of $4 \mu \mathrm{g} / \mathrm{mL}$ for 30 min at $37^{\circ} \mathrm{C}$. The nuclear staining enables to track cells, and/ or to discriminate white blood cells from the spiked cells from, cell tracker pre-stained, tumor cell lines. Cells from the tumor cell lines were diluted in PBS/BSA $1 \%$ and spiked into blood to obtain a final concentration between 125,000 - 250,000 cells/ml.

\subsubsection{Image acquisition and analysis}

Time lapses of the cells flowing through the chip were made with an integration time of 0.2 s and image time of $1 \mathrm{frame} / \mathrm{s}$ using Hokawo imaging software (Hamamatsu, Herrsching am Ammersee, Germany). The movies and images were taken $1 \mathrm{~cm}$ from the inlet in the middle of the channel and using a 4 x objective, this resulted in imaging $\sim 1 / 50$ of the surface area of the microfluidic channel. Images and movies of cells and cell flow were analyzed using Icy (open source imaging software ${ }^{10}$, Hokawo. An example of a movie is provided in the supplemental data. To determine the entire number of cells on chip the open access program ACCEPT ${ }^{11}$ was used. To enumerate the number of Cell Tracker Green pre-stained MCF-7 and Cell Tracker Orange pre-stained SKBR-3 cells the following gates were used: for SKBR-3 mean intensity Hoechst $<5$, mean intensity PE $>500$, eccentricity of PE signal $\leq 0.95$; for MCF-7 mean intensity Hoechst $>4$, mean intensity FITC $>400$, eccentricity FITC $\leq 0.95$.

\subsubsection{Statistical analysis}

Statistical analysis was done using Origin Pro 9.1 (OriginLab Corp. Northampton, MA, USA) using a two samples t-test. 


\subsection{Results and discussion}

\subsubsection{Measurement of cell capture and cell release efficiency}

Figure 3.2 shows a typical image frame of a time lapse in which Cell Tracker Orange stained cells pass the microfluidic chip. The white vertical stripes represent the cells passing by, whereas the white dots represent the cells captured on the chip surface. The insert shows a larger magnification of an area. To measure the capture efficiency, time lapses were made starting at a velocity of $0.8 \mathrm{~mm} / \mathrm{sec}$ and decreasing the velocity to 0 over a time period of 17 minutes. To calculate the actual velocity of the samples in the chip at various flow rates of the samples we used $v z(t)=\left(6^{*} i\right) /\left(\left(a^{*} d^{\wedge} 3\right)^{*} z^{*}(d-z)\right)$ where $v z$ is the velocity in $x$ direction, $i$ is the cumulative flow rate, $a$ and $d$ are the channel width and height respectively and $z$ is the distance from the wall. In supplementary table S3.1 the flow speeds and their corresponding velocities are provided. To measure cell release the velocity was increased to $30 \mathrm{~mm} / \mathrm{sec}$ over a time period of 10 minutes. Frames of the time lapse were analyzed for the number of attached cells at different velocities. Leukocytes were counted as DAPI+, Cell Tracker Orange stained cells.

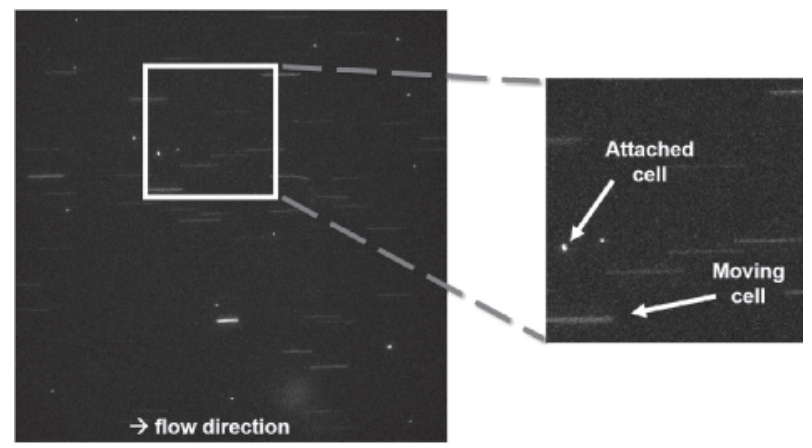

Figure 3.2: Frame of a time lapse on the left, part of the imaged enlarged on the right depicting attached cell and a moving cell.

\subsubsection{Velocity at which cells were captured and released}

Figure 3.3 shows the capture of cells from the breast cancer cell line MCF-7 (panel A) from whole blood on various surfaces, and release of MCF-7 cells (panel B) as a function of velocity. Cells were counted in the image area of the chip covering $2 \%$ of the surface area of the microchannel (figure 3.1b). For optimal capture, not only should the velocity be such that the tumor cell EpCAM antigens have sufficient time to interact with the anti-EpCAM antibody binding sites. This interaction should also be strong enough to withstand the viscous drag force of the tumor cell after it has been captured. Functionalization of the top and bottom slide were analyzed as well as the addition of surface roughness on attachment and detachment 
behavior. The lines in figure 3.3 represent the mean over three separate experiments. The individual data of each experiment is provided in supplementary figure S3.2. Experiments were performed with uncoated microfluidic chips and chips of which the bottom was treated with PAA or a-EpCAM antibodies. No MCF-7 cells were captured using uncoated and PAA coated surface. Whereas an increase in MCF-7 capture was observed with decreasing velocity when using VU1D9 coated surfaces. At a velocity of $0.4 \mathrm{~mm} / \mathrm{sec}$ the number of MCF-7 cells no longer increased. Very few leukocytes were captured on the a-EpCAM coated surfaces whereas a larger number were bound non-specifically to the PAA coated surface. The velocity at which the MCF-7 cells started to release was $20 \mathrm{~mm} / \mathrm{sec}$ in contrast the non-specifically bound leukocytes released from the surface at much lower velocity. These observations are in line with previous reports in which CTC were captured in microfluidic chip using anti-EPCAM affinity binding. ${ }^{12,13,22,23,14-21}$

\section{a}
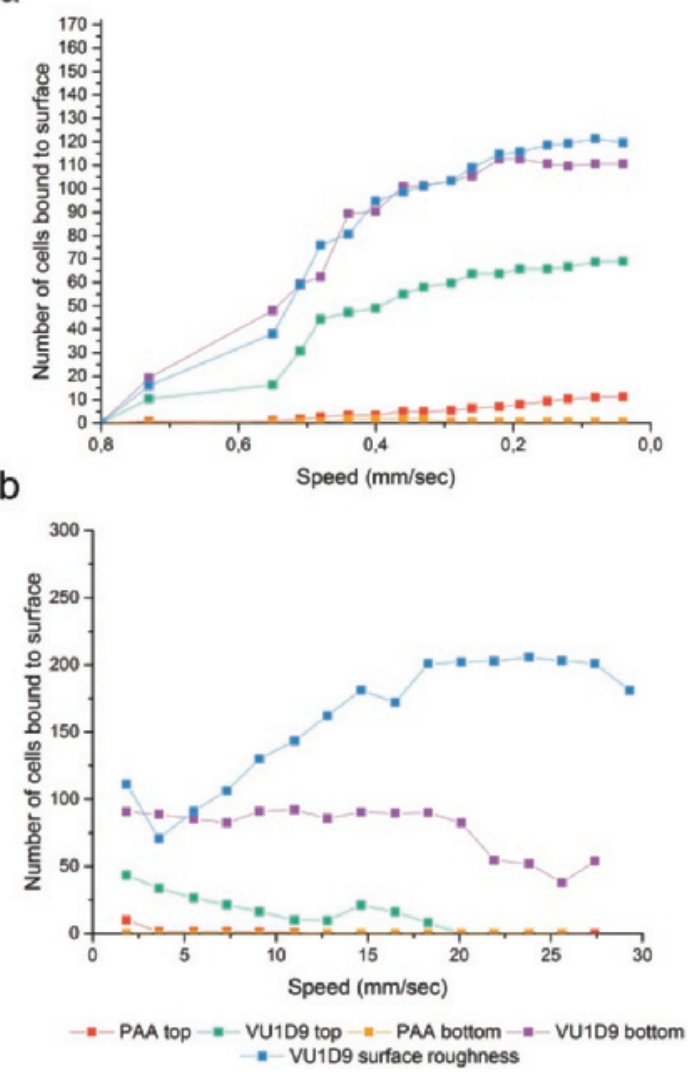

Figure 3.3: a) Attachment of MCF-7 cells onto the slide, counted in the image area as indicated in figure $1 \mathrm{~b}$. Lines represent the average of three individual experiments. b) Detachment of MCF-7 cells, lines represent the average of three individual measurements. 


\subsubsection{Increasing the surface roughness}

Next, it was investigated whether an increase of the roughness of the surface opposite of the capture surface could alter the flow pattern and increase the collisions of the cells to increase the number of captured cells. It was hypothesized that roughness works as a microvortex, forcing MCF-7 cells against the a-EpCAM functionalized wall. This was investigated by a-EpCAM coating of the upper surface and either a rough or a smooth surface at the bottom part of the chip. The use of surface roughness did not results in a significant increase in the amount of captured MCF-7 cells as compared to no surface roughness (figure 3.3a). It did however show that a larger flow rate was needed to detach the cells from the surface (figure 3.3b). This will be a problem when the cells need to be released for further analysis. Also surface roughness resulted in an increase of non-specific binding of leukocytes. Therefore, it was decided to continue without surface roughness. To obtain optimal capture efficiency it was decided to continue with functionalization of both the upper and bottom slide.

\subsubsection{Influence of cell surface antigen densities and antibody coating on cell capture and release}

Next, SKBR-3 and MCF-7 cells were used to determine whether antigen density on those cell lines influences capture and to determine the optimal velocity for cell capture experiments. The optimal velocity for cell capture was defined as the highest flow speed at which a significant increase in cell capture is observed. The attachment and detachment velocities were determined for each cell line and antibody combination. Results are shown in figure 3.4. The individual measurement data is available in figure S3.3. Results show that SKBR-3 cells, with a high Her2 expression ( 957,731 Her2 antigens), are being captured on an a-Her2 functionalized surface whereas significantly less MCF-7 cells ( 57,916 Her2 antigens) are captured on this surface. The binding affinity of the antibody is clearly not as important for cell capture, as the $\mathrm{HO}-3$ antibody recognizing EpCAM has a higher affinity $\left(\mathrm{K}_{d} 4.0 \times 10^{-11}\right){ }^{24}$ for EpCAM than the VU1D9 antibody recognizing a different epitope on the EpCAM antigen ${ }^{9}\left(K_{d}\right.$ $\left.2.7 \times 10^{-10}\right)^{24}$, but captures slightly less cells. The affinity of the Her 81 antibody recognizing the Her2 antigen $\left(K_{d} 4.4 \times 10^{-10}\right){ }^{25}$ has an affinity comparable to the VU1D9 antibody and suggests that the number of available antigens on the target cells is the most important factor for cell capture. Another explanation could be that, as all three antibodies used have affinities in the nanomolar range, the differences in capture efficiency is negligible. Also, results show that using a-Her2 antibodies, cells are being captured at a higher speed. The release of the cells starts at a speed of $\sim 1 \mathrm{~mm} / \mathrm{sec}$. To release the Her 2 captured SKBR-3 cells larger velocities are needed. As the antigen density on the surface of cancer cells is the most important factor for cell capture, either multiple targets or an amplification of the targets present on the cell 
surface will need to be explored to increase the efficiency of tumor cell capture. From these experiments we conclude that $0.6 \mathrm{~mm} / \mathrm{sec}$ is the optimal velocity as it is the highest flow speed at which there is a highly acceptable capture rate. Also, this velocity is in accordance with what we found in literature where we searched for velocities presented in other papers, describing CTC capture using microfluidic chips. 14, 19, 22-25

\subsubsection{Efficiency of tumor cell capture from blood}

To evaluate the recovery of SKBR3 and MCF7 cells from blood, $100 \mu \mathrm{L}$ of EDTA blood was spiked with pre-stained cells and flown at the optimal conditions established with the cell lines as shown in figure 3.4. A constant flow rate of $0.6 \mathrm{~mm} / \mathrm{sec}$ for $16 \mathrm{~min}$ was used to flow the $100 \mu \mathrm{L}$ of sample, immediately after, $100 \mu \mathrm{L}$ PBS/BSA $1 \%$ was flown through the chamber at the same speed to remove any unbound cells. The capture surfaces were coated with VU1D9, HO-3, Her81, VU1D9 + HO-3, VU1D9 + Her81, HO-3 + Her81 and a combination of the three antibodies (VU1D9 + HO-3 + Her81). After flowing the samples, the complete surface of the chip was scanned on the microscope. Cell numbers were automatically counted using the ACCEPT program.

Figure 3.5 shows the capture of cells from the breast cancer cell line MCF-7 and SKBR-3 on antibody functionalized surfaces. Figure 3.5 shows the relative amount of cells bound to the surface of the entire chip. The amount of cancer cells found on glass were set as 1 , for each of the other surfaces the fold of cells captured compared to cells on glass were plotted. The total number of cells was determined automatically to exclude any operator bias and to allow processing these large numbers of images in a reasonable amount of time.

Capture of MCF-7 cells using VU1D9 targeting EpCAM ( 880,189 antigens) was $~ 8.8$ fold higher when compared to Her2 ( 57,916 antigens). Capture of SKBR-3 cells expressed using EpCAM ( 376,606 antigens) was lower when compared to Her2 ( 957,731 antigens). Capture of SKBR-3 using Her 2 was 3 fold higher compared to MCF-7 capture ( 57,916 antigens). The distribution of the target antigens over the surface of both cell lines is not a likely explanation of the capture efficiency as the average size of the SKBR-3 (17.1 $\mu \mathrm{m} \pm 18.5)$ and MCF-7 (16.3 $\mu \mathrm{m}$ $\pm 23.8)$ are similar. Also these effects could be eliminated by the fact that a larger cell diameter, results in moving closer to the coating surface, which should be beneficial for cell capture. Results show that the highest amount of cells both for MCF-7 as well as SKBR-3 are captured when using VU1D9. Indicating that this antibody is the most efficient for capturing cells from flow using our set-up. To get an idea on the percentages of total cells that were captured within our set-up we measured the spiked blood samples before and after flowing through the chip. 

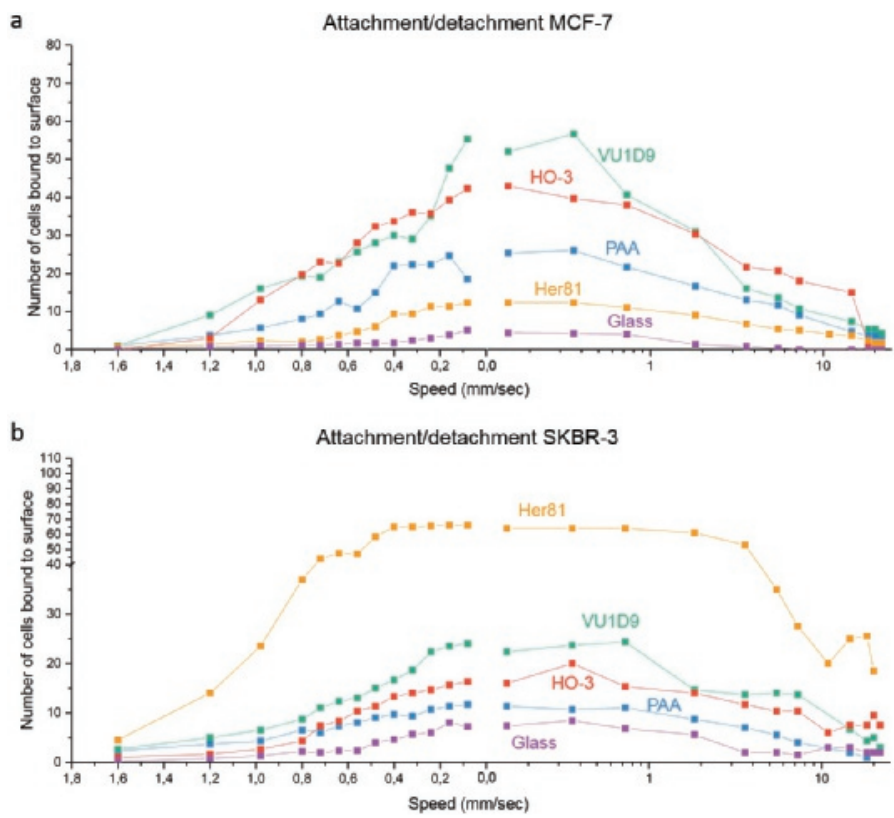

Figure 3.4: Attachment and detachment of MCF-7 and SKBR-3 cells to various antibodies functionalized. At a velocity of $0.6 \mathrm{~mm} / \mathrm{sec}$ a clear capture of cells starts at which almost all cells passing the surface get captured. Cells were counted in the image area as indicated in figure 3.1b.

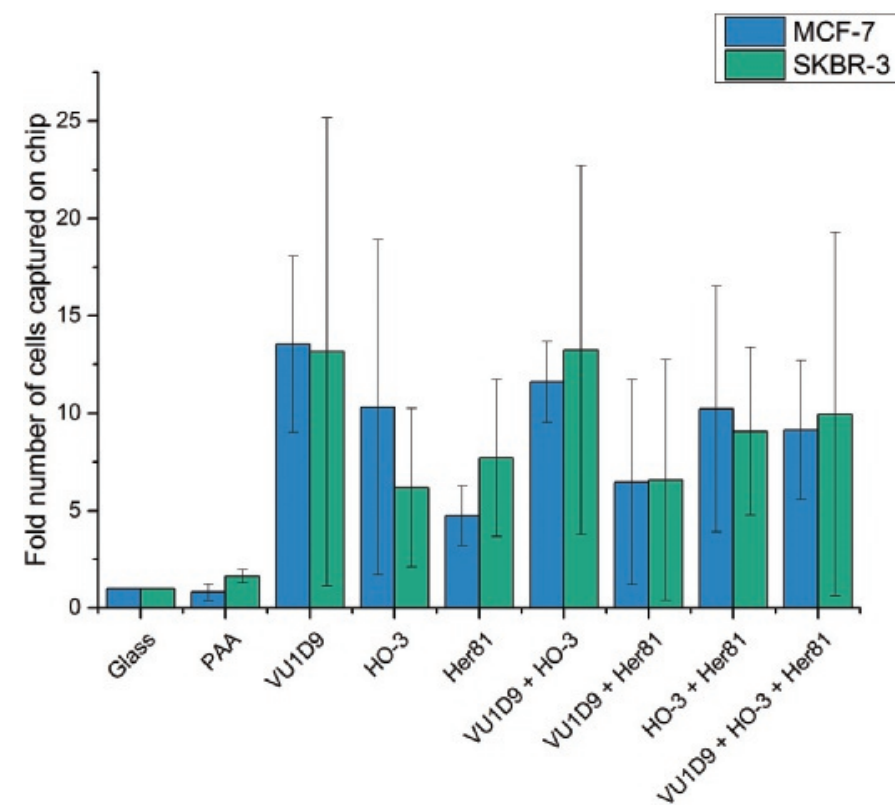

Figure 3.5: The amount of MCF-7 and SKBR-3 cells captured compared to the amount of cells on glass. Absolute cell counts normalized to absolute count on glass, where glass is 1 . $(n=3)$ 
Results obtained indicated that when using VU1D9 already up to 90\% of the spiked cancer cells is removed from the blood sample that leaves the chip.

As shown in figure 3.5, when adding other antibodies, either Her81 or $\mathrm{HO}$-3, the amount of captured cells does not increase and in some cases even decreases. This in contrast of what was expected, we hypothesized that combining antibodies targeting different antigens or epitopes would result in an increase in the amount of cells captured. This could be explained by the fact that the surfaces of the chips are functionalized using a concentration of $20 \mu \mathrm{g} / \mathrm{mL}$ at which the surface is saturated with antibodies. Apparently, $\mathrm{HO}-3$ and Her81 are less efficient for cell capture compared to VU1D9. A likely explanation is that when adding another antibody in addition to VU1D9 at the same concentration, the VU1D9 surface is reduced resulting in a lesser cell capture efficiency. When however, antibodies with a lesser binding efficiency such as $\mathrm{HO}-3$ and Her81, the combination of both antibodies results in a higher cell capture as compared to the use of both antibodies individually. Therefore, combining several antibodies targeting different epitopes or antigens could be very beneficial but will have to be determined experimentally as it cannot be predicted by the affinity of the antibodies.

Blood is passed in our chip at a rate of $7.5 \mu \mathrm{L} / \mathrm{min}$ implying that a blood volume of $7.5 \mathrm{~mL}$ as used in the CellSearch system would take 1000 minutes. In comparison, the CellSearch system needs 100 minutes to isolate CTC from $7.5 \mathrm{~mL}$ (without the staining steps). This limitation can simply be overcome by parallel processing using for example a stack of 10 chips. The cell binding capacity is determined by the surface area and one chip can accommodate $~ 3.000 .000$ cells of $15 \mu \mathrm{m}$. Although this is plenty for CTC as such numbers are not observed in blood of metastatic cancer patients ${ }^{4}$ the non-specific binding of leukocytes could be the limiting factor. We observed an average binding of 12 leukocytes per image frame which translated to approximately 1000 leukocytes per $100 \mu \mathrm{L}$ of blood (containing in total $5 \times 10^{5}$ leukocytes). The binding of the leukocytes to the surface is however less tight and the majority of the leukocytes can be removed by altering the flow speed. In the time lapse videos made during the experiments one can observe that leukocytes can form clusters on the surface but these are very loosely bound as they appear and disappear. A very small fraction of the cells stick to the surface even at high velocity. At these high velocities $>30 \mathrm{~mm} / \mathrm{sec}$ cells start to be sheared apart. Example of cells being sheared apart is shown in figure S3.4. It is important to notice that at high velocities cells lose their viability and probably also at lower velocities, shear stress caused by flow, influence the viability of cells. 
No differences could be observed in the binding of leukocytes with the different antibody coated surfaces, in supplemental figure S3.5 the binding of SKBR-3 cells and leukocytes on Her2, HO-3 and VU1D9 coated surface is plotted with increasing flow speed and one can observe the sudden decrease of leukocytes at some of the time points. Even when the surface would completely be occupied by cells the chips would not clog as the blood passes across the layer of cells.

To capture CTC in all patients with metastatic disease, CTC will need to be isolated from larger blood volumes. This can be achieved through the use of DLA during which the mononuclear cell fraction of a patient's blood is obtained. This results in a mononuclear cell suspension of 45 $\mathrm{mL}$ with a leukocyte concentration of $\sim 66 \times 10^{6} / \mathrm{mL}$ representing liters of blood. ${ }^{12}$ The question remains whether or not the chip as we present it here can handle such high concentrations of leukocytes. If not, dilution of the samples to decrease the cell concentration could be a solution. The use of larger volumes will increase processing time as the flow speed of $0.6 \mathrm{~mm} /$ sec is the limiting factor. However, this can be overcome by running several chips in parallel. The relatively simple production of our chips makes it easy to scale up to decrease processing time while processing larger volumes.

\subsection{Conclusions}

Here we presented a set-up which can be used to capture cancer cells in continues flow from whole blood using a functionalized surface. Results show that there is an optimal flow speed at which cells are captured, which was determined to be $0.6 \mathrm{~mm} / \mathrm{sec}$ in our setup. This allowed for the processing of $100 \mu \mathrm{L}$ of whole blood in 16 minutes in the presented setup. The anti-EpCAM antibody VU1D9 performed the best. Replacing part of the capturing surface with another antibody did not increase capture. Combining multiple antibodies on the capture surface may be beneficial for capturing cancer cells with a more heterogenic antigen expression. 


\section{References}

1 M. Cristofanilli, G. T. Budd, M. J. Ellis, A. Stopeck, J. Matera, M. C. Miller, J. M. Reuben, G. V Doyle, W. J. Allard, L. W. M. M. Terstappen and D. F. Hayes, N. Engl. J. Med., 2004, 351, 781-791.

2 D. F. Hayes, M. Cristofanilli, G. T. Budd, M. J. Ellis, A. Stopeck, M. C. Miller, J. Matera, W. J. Allard, G. V Doyle and L.W.W. M. Terstappen, Clin. Cancer Res., 2006, 12, 4218-24.

3 J. S. de Bono, H. I. Scher, R. B. Montgomery, C. Parker, M. C. Miller, H. Tissing, G. V Doyle, L. W. W. M. Terstappen, K. J. Pienta and D. Raghavan, Clin. Cancer Res., 2008, 14, 6302-6309.

4 F. A. W. Coumans, S. T. Ligthart, J. W. Uhr and L. W. M. M. Terstappen, Clin. Cancer Res., 2012, 18, 57115718.

5 R. L. Eifler, J. Lind, D. Falkenhagen, V. Weber, M. B. Fischer and R. Zeillinger, Cytom. Part B Clin. Cytom., 2011, 80B, 100-111.

6 J. C. Fischer, D. Niederacher, S. A. Topp, E. Honisch, S. Schumacher, N. Schmitz, L. Zacarias Föhrding, C. Vay, I. Hoffmann, N. S. Kasprowicz, P. G. Hepp, S. Mohrmann, U. Nitz, A. Stresemann, T. Krahn, T. Henze, E. Griebsch, K. Raba, J. M. Rox, F. Wenzel, C. Sproll, W. Janni, T. Fehm, C. A. Klein, W. T. Knoefel and N. H. Stoecklein, Proc. Natl. Acad. Sci. U. S. A., 2013, 110, 16580-5.

7 K. C. Andree, A. Mentink, L. L. Zeune, L. W. M. M. Terstappen, N. H. Stoecklein, R. P. Neves, C. Driemel, R. Lampignano, L. Yang, H. Neubauer, T. Fehm, J. C. Fischer, E. Rossi, M. Manicone, U. Basso, P. Marson, R. Zamarchi, Y. Loriot, V. Lapierre, V. Faugeroux, M. Oulhen, F. Farace, G. Fowler, M. Sousa Fontes, B. Ebbs, M. Lambros, M. Crespo, P. Flohr and J. S. de Bono, Int. J. Cancer, 2018, 143, 2584-2591.

8 M. B. Lambros, G. Seed, S. Sumanasuriya, V. Gil, M. Crespo, M. S. Fontes, R. Chandler, N. Mehra, G. Fowler, B. Ebbs, P. R. Flohr, S. Miranda, W. Yuan, A. Mackay, A. Ferreira, R. Pereira, C. Bertan, I. Figueiredo, R. Riisnaes, D. Nava Rodrigues, A. Sharp, J. Goodall, G. Boysen, S. Carreira, D. Bianchini, P. Rescigno, Z. Zafeiriou, J. Hunt, D. Moloney, L. Hamilton, R. P. L. Neves, J. F. Swennenhuis, K. C. Andree, N. H. Stoecklein, L. W. Terstappen and J. S. de Bono, Clin. Cancer Res., 2018, clincanres.0862.2018.
K. C. Andree, A. M. C. Barradas, A. T. Nguyen, A. Mentink, I. Stojanovic, J. Baggerman, J. van Dalum, C. J. M. van Rijn and L. W. M. M. Terstappen, ACS Appl. Mater. Interfaces, 2016, 8, 14349-14356.

10 F. de Chaumont, S. Dallongeville, N. Chenouard, N. Hervé, S. Pop, T. Provoost, V. Meas-Yedid, P. Pankajakshan, T. Lecomte, Y. Le Montagner, T. Lagache, A. Dufour and J.-C. Olivo-Marin, Nat. Methods, 2012, 9, 690-696.

11 L. Zeune, Leonie, https://github.com/LeonieZ/ ACCEPT, https://github.com/LeonieZ/ACCEPT, (accessed 18 January 2018).

12 T. Fehm, F. Meier-Stiegen, C. Driemel, B. Jager, F. Reinharddt, J. Naskou, A. Franken, H. Neubauer, R. P. Neves, G. van Dalum, E. Ruckhaberle, D. Niederacher, J. M. Rox, J. C. Fischer and N. H. Stoecklein, Cytom. Part A.

13 J. H. Myung, C. A. Launiere, D. T. Eddington and S. Hong, Langmuir, 2010, 26, 8589-8596.

14 H. J. Yoon, T. H. Kim, Z. Zhang, E. Azizi, T. M. Pham, C. Paoletti, J. Lin, N. Ramnath, M. S. Wicha, D. F. Hayes, D. M. Simeone and S. Nagrath, Nat. Nanotechnol., 2013, 8, 735-741.

15 S. L. Stott, C.-H. Hsu, D. I. Tsukrov, M. Yu, D. T. Miyamoto, B. A. Waltman, S. M. Rothenberg, A. M. Shah, M. E. Smas, G. K. Korir, F. P. Floyd, A. J. Gilman, J. B. Lord, D. Winokur, S. Springer, D. Irimia, S. Nagrath, L. V. Sequist, R. J. Lee, K. J. Isselbacher, S. Maheswaran, D. A. Haber and M. Toner, Proc. Natl. Acad. Sci., 2010, 107, 18392-18397.

16 Y. Deng, Y. Zhang, S. Sun, Z. Wang, M. Wang, B. Yu, D. M. Czajkowsky, B. Liu, Y. Li, W. Wei and Q. Shi, Sci. Rep., 2015, 4, 7499.

17 J.-Y. Chen, W.-S. Tsai, H.-J. Shao, J.-C. Wu, J.-M. Lai, S.-H. Lu, T.-F. Hung, C.-T. Yang, L.-C. Wu, J.-S. Chen, W.-H. Lee and Y.-C. Chang, PLoS One, 2016, 11 e0149633.

18 S. Maheswaran, L. V. Sequist, S. Nagrath, L. Ulkus, B. Brannigan, C. V. Collura, E. Inserra, S. Diederichs, A. J. lafrate, D. W. Bell, S. Digumarthy, A. Muzikansky, D. Irimia, J. Settleman, R. G. Tompkins, T. J. Lynch, M. Toner and D. A. Haber, N. Engl. J. Med., 2008, 359 , 366-377. 
19 S. L. Stott, R. J. Lee, S. Nagrath, M. Yu, D. T. Miyamoto, L. Ulkus, E. J. Inserra, M. Ulman, S. Springer, Z. Nakamura, A. L. Moore, D. I. Tsukrov, M. E. Kempner, D. M. Dahl, C. L. Wu, A. J. lafrate, M. R. Smith, R. G. Tompkins, L. V. Sequist, M. Toner, D. A. Haber and S. Maheswaran, Sci. Transl. Med., 2010, 2, 25ra2325 ra23.

20 R. B. M. Schasfoort, K. C. Andree, N. van der Velde, A. van der Kooi, I. Stojanović and L. W. M. M. Terstappen, Anal. Biochem., 2016, 500, 21-23.

21 I. Stojanovic, E. Coenen, R. B. M. Schasfoort and L. W. W. M. Terstappen, in SPRi Cytometry Sensitivily sensing the sensitive inside of cells, Enschede, 2016, pp. 108-121.
22 S. Nagrath, L. V. Sequist, S. Maheswaran, D. W. Bell, D. Irimia, L. Ulkus, M. R. Smith, E. L. Kwak, S. Digumarthy, A. Muzikansky, P. Ryan, U. J. Balis, R. G. Tompkins, D. A. Haber and M. Toner, Nature, 2007, 450, 12351239.

23 J.-Y. Chen, W.-S. Tsai, H.-J. Shao, J.-C. Wu, J.-M. Lai, S.-H. Lu, T.-F. Hung, C.-T. Yang, L.-C. Wu, J.-S. Chen, W.-H. Lee and Y.-C. Chang, PLoS One, 2016, 11, e0149633.

24 C.-H. Hsu, D. Di Carlo, C. Chen, D. Irimia and M. Toner, Lab Chip, 2008, 8, 2128.

25 A.-E. Saliba, L. Saias, E. Psychari, N. Minc, D. Simon, F.-C. Bidard, C. Mathiot, J.-Y. Pierga, V. Fraisier, J. Salamero, V. Saada, F. Farace, P. Vielh, L. Malaquin and J.-L. Viovy, Proc. Natl. Acad. Sci. U. S. A., 2010, 107, 14524-9. 


\section{Supplementary data}

S3.1: List of flow rates and corresponding velocities used in the flow experiments.

\begin{tabular}{r|l|l} 
Flow $(\mu \mathrm{L} / \mathrm{min})$ & Velocity $(\mathrm{mm} / \mathrm{sec})$ \\
\hline 1 & 0.08 \\
2 & 0.16 \\
3 & 0.24 \\
4 & 0.32 \\
5 & 0.4 \\
6 & 0.48 \\
7 & 0.56 \\
8 & 0.64 \\
9 & 0.72 \\
10 & 0.8 \\
11 & 1 \\
50 & 4 \\
100 & 8 \\
200 & 16 \\
250 & 20 \\
300 & 24
\end{tabular}

a
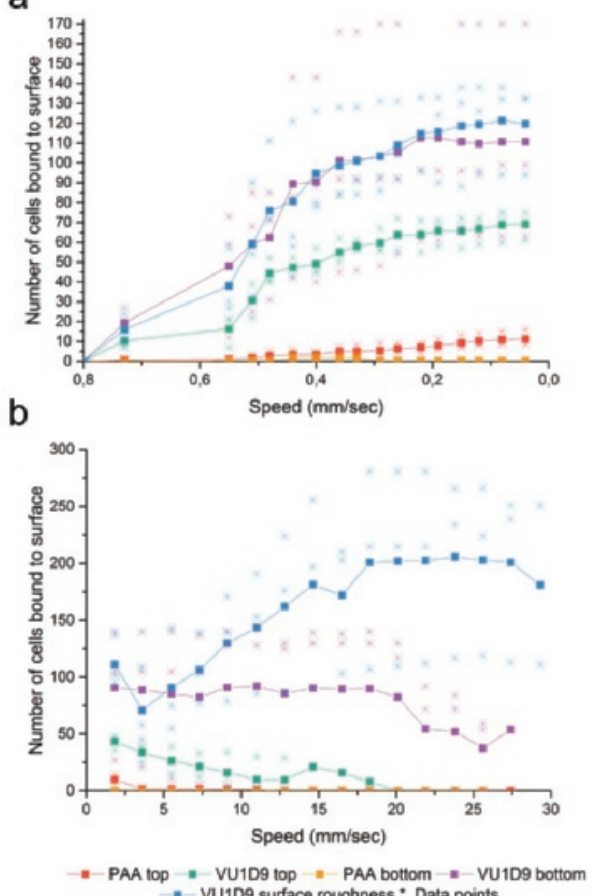

Figure S 3.2: Data of individual attachment and detachment experiments using various functionalized surfaces shown as party transparent data point. Dots connected by continues line represents the mean. 
a

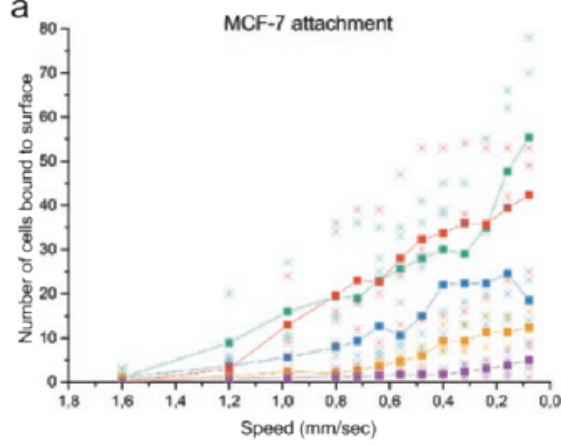

C

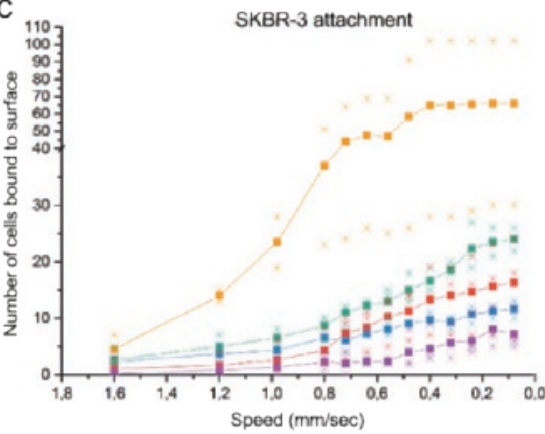

b

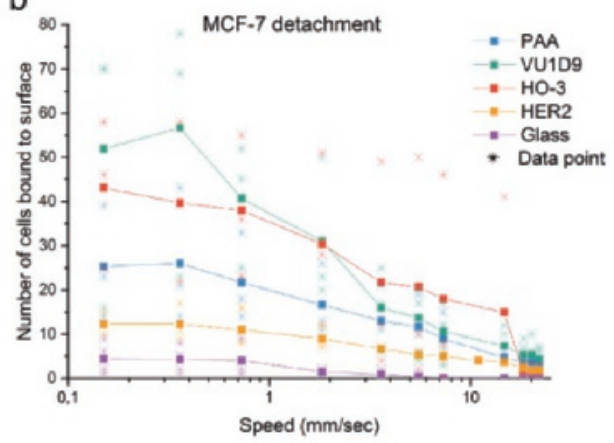

d

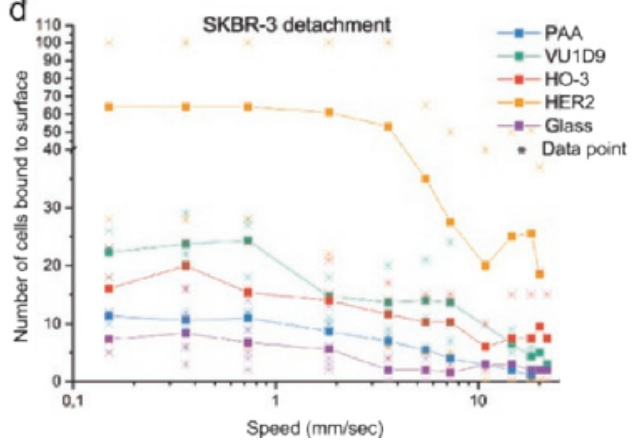

Figure S 3.3: Data points of individual measurements and the mean of each of the different antibodies used for functionalization.

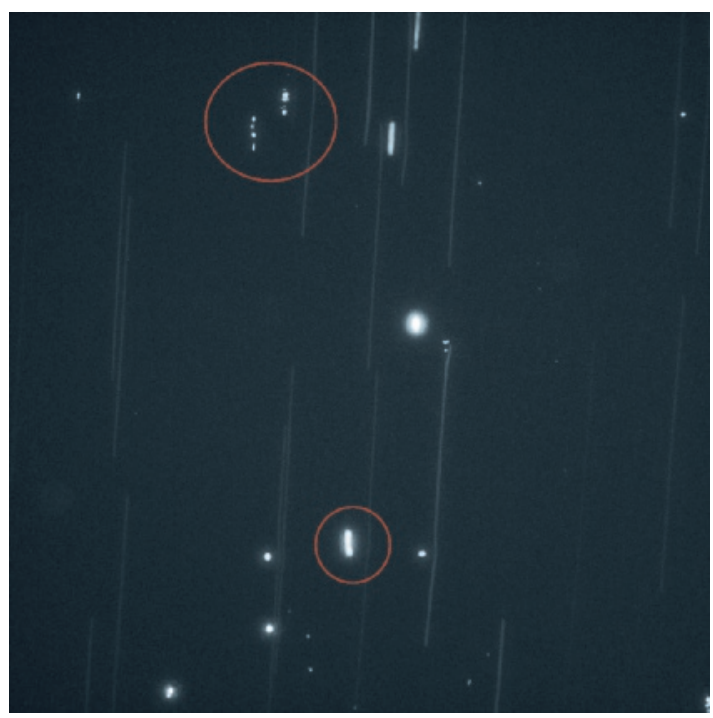

Figure S 3.4: example of cells being sheared apart because of high velocity, red circles indicate cells attached to chip surface being dragged apart because of shear stress of high flow speed. 
Chapter 3

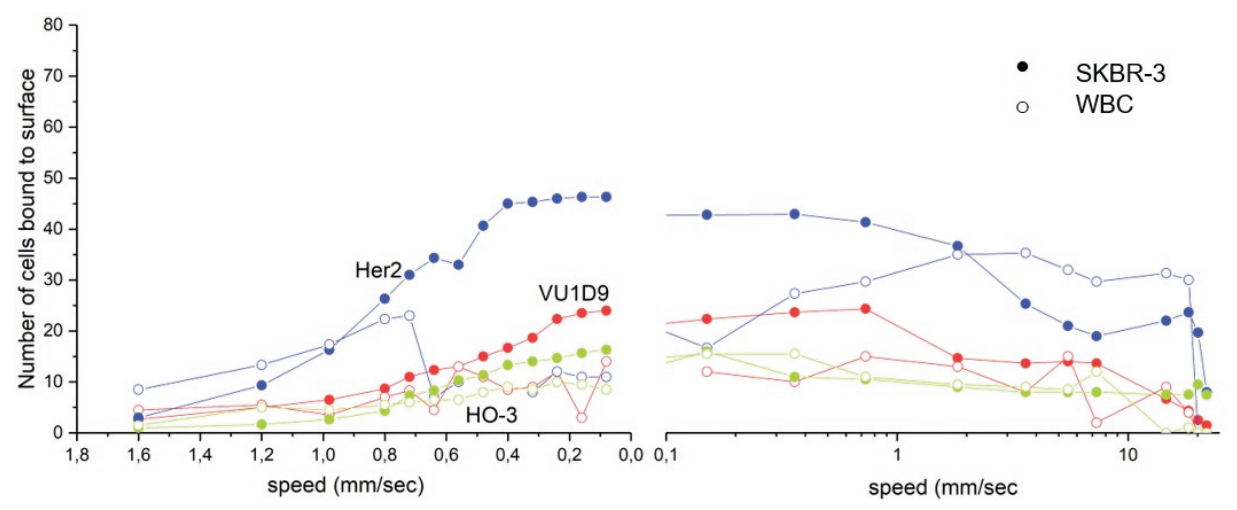

Figure S 3.5: Number of SKBR-3 cells and white blood cells bound to Her-2, HO-3 and VU1D9 coated surfaces 
Tumor Cell Capture from Blood by Flowing Across Ab-coated Surfaces 

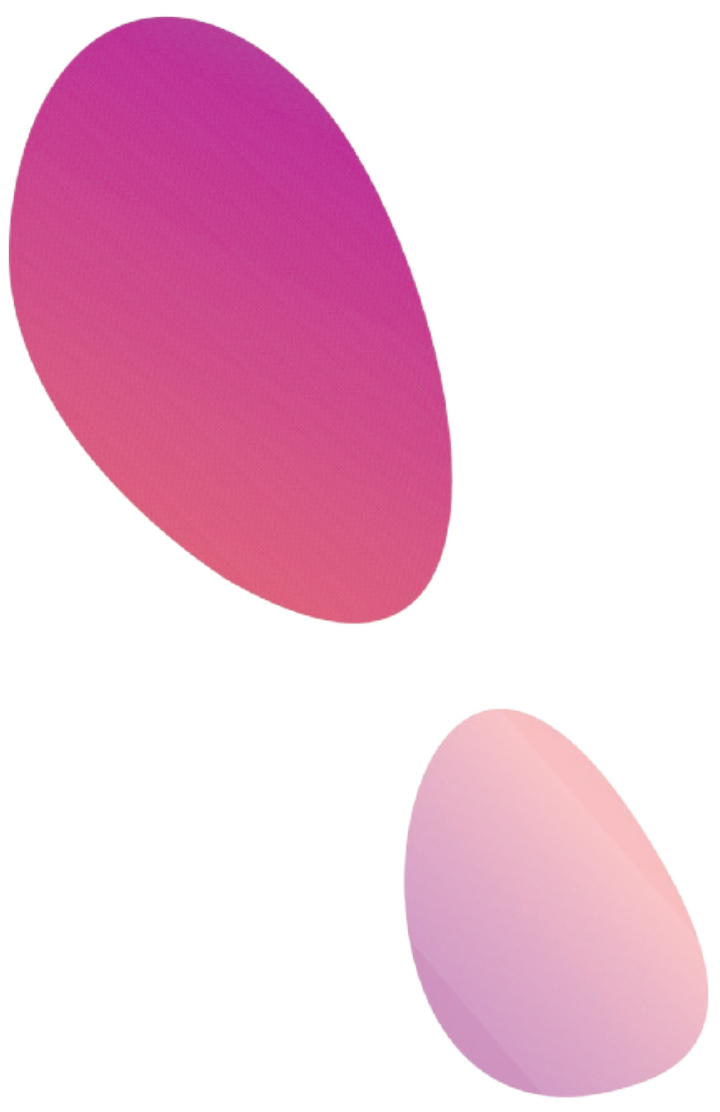


\section{CHAPTER 4}

\section{Self-Seeding Microwells to Isolate and Assess the Viability of Single Circulating Tumor Cells}




\section{Abstract}

The availability of viable tumor cells could significantly improve the disease management of cancer patients. Here we developed and evaluated a method using self-seeding microwells to obtain single circulating tumor cells (CTC) and assess their potential to expand. Conditions were optimized using cells from the breast cancer cell line MCF-7 and blood from healthy volunteers collected in EDTA blood collection tubes. 43\% of the MCF-7 cells (nucleus+, Ethidium homodimer-1-, Calcein AM+, a-EpCAM+, a-CD45-) spiked into $7.5 \mathrm{~mL}$ of blood could be recovered with $67 \%$ viability and these could be further expanded. The same procedure tested in metastatic breast and prostate cancer patients resulted in a CTC recovery of only 0 - 5\% as compared with CTC counts obtained with the CellSearch ${ }^{\circledR}$ system. Viability of the detected CTC ranged from 0 - 36\%. Cell losses could be mainly contributed to the smaller size and greater flexibility of CTC as compared to cultured cells from cell lines and loss during leukocyte depletion prior to cell seeding. Although CTC losses can be reduced by fixation, to obtain viable CTC no fixatives can be used and pore size in the bottom of microwells will need to be reduced, filtration conditions adapted and pre-enrichment improved to reduce CTC losses. 


\subsection{Introduction}

Assessment of the molecular characteristics of tumor cells from patients is essential for treatment decision making and for research. Currently, tissue from solid tumors for such characterization is obtained through invasive surgical procedures such as taking a biopsy. ${ }^{1,2}$ These procedures cannot be performed on a regular basis and for patients with metastatic disease one tumor site may not be representative for all the metastatic sites. Tumor cells continuously change at the molecular level and frequently is associated with the occurrence of resistance to the administrated drugs. ${ }^{3}$ Availability of non-invasive methods for the detection and monitoring of cancer is sought after but remains a technical challenge. The presence of tumor cells and tumor nucleic acids in blood of cancer patients are being investigated for their potential as non-invasive real-time biopsies. These non-invasive methods can yield information about the genetic profile of cancers and track genomic transformations. ${ }^{1,4,5}$

Circulating tumor cells (CTC) are a rare heterogeneous cell population shed by tumors into the blood. CTC can be used to monitor efficacy of therapy and their molecular characterization can improve treatment strategies. For probing the reaction of drugs to CTC one however needs viable CTC. Although the frequency of CTC is known in various cancers ${ }^{6}$ little knowledge is available on the proportion of viable CTC.7.-9 To date protocols ${ }^{10}$ are available for the culture of organoids from tumor biopsies to be used as a model for disease. ${ }^{11,12}$ However, culturing CTC has only been demonstrated by a few groups. Kolostova et al. used a size based separation method to isolate and culture urothelial CTC directly on the separation membrane. ${ }^{13}$ Second, Cayrefourcq et al. negatively enriched blood samples from 71 patients with metastatic colon cancer patients and successfully established one permanent cell line from a patient having a CTC count of $\geq 300 .{ }^{14}$ In prostate cancer, Gao et al. succeeded in establishing a 3D organoid system for the long-term culture of CTC derived from peripheral blood of castration resistant metastatic patients. ${ }^{12}$ The group of Nagrath focused on lung cancer and developed a novel in situ capture and culture methodology for ex vivo expansion of CTC using a 3D co-culture model. CTC were successfully expended from 14 of 19 early stage lung cancer patients, using a three dimensional co-culture model, including fibroblasts, to support tumor development. ${ }^{15}$

In addition, very recently several groups looked into the use of leukapheresis products, as a source for CTC, where the likelihood of finding of CTC is greater and were able to establish CTC cultures in mouse models. ${ }^{16,17}$ These discussed examples indicate that the establishment of functional CTC cell line models is feasible. The isolation and in vitro culture of CTC may provide an opportunity to noninvasively monitor the changing patterns of drug resistance in 
individual patients while their tumors acquire new mutations and might improve treatment. As methods to expand CTC are still in its infancy. Several key factors have to be considered, no universal recipe for culturing patient derived CTC exists and in fact, each patient's cell might require slightly different growth conditions. Hence development and optimization of isolation techniques require to be gentle on the cells to incorporate efficient culturing strategies. Also, when interested in CTC heterogeneity what is lacking in the studies discussed above is the possibility to assess molecular heterogeneity between CTC within an individual patient. Cultures are established from the bulk of CTC isolated from patients making it harder to assess their heterogeneity. Single cell isolation techniques might contribute to this demand. Here we use the previously introduced self-sorting microwells. ${ }^{18,19}$ to establish methods to discriminate between individual viable and non-viable cancer cells and establish conditions to maintain the viability of the cancer cells. We demonstrate a relatively fast $(<2 \mathrm{~h}$ from whole blood to viable individual CTC) and easy workflow to isolate pure CTC without any background of hematopoietic cells and their subsequent culture. The methods and conditions are optimized using cells from cancer cell lines and tested on blood samples from metastatic breast and prostate cancer patients.

\subsection{Materials and Methods}

\subsubsection{Cell culture}

The human breast cancer cell lines MCF-7 (ATCC ${ }^{\circledR}$ HTB-22 $^{\text {TM }}$ ) and MDA-MB-231 (ATCC ${ }^{\circledR}$ HTB-26 ${ }^{\mathrm{TM}}$ ) were cultured in polystyrene flasks using Dulbecco's modified Eagle medium (DMEM, Sigma) with 10\% fetal bovine serum (FBS, Greiner Bio-One), $1000 \mathrm{IU} / \mathrm{L}$ penicillin and 1mg/L streptomycin and 4mM L-Glutamine (Gibco). When flasks showed 80-90\% confluence cells were trypsinized (0.05\% trypsin-EDTA, Gibco) and replated in fresh culture flasks and incubated at $37^{\circ} \mathrm{C}$ at $5 \%$ CO2. For experiments flasks with $70 \%$ confluence were used.

\subsubsection{Viability assay}

MCF-7 cells were labeled with Calcein AM (Calc AM, live cells) and Ethidium homodimer 1 (EthD1, dead cells) (Live/Dead assay life Technologies, Invitrogen) prior to seeding in microwells. Cells were harvested, washed once with $1 \times$ phosphate buffered saline (PBS) and finally diluted in $1 \mathrm{~mL}$ PBS. Subsequently cells were fluorescently labeled with Calc AM and EthD1 (1:10 v/v). Cells were incubated with live/dead staining solution in $100 \mu \mathrm{L}$ for $20 \mathrm{~min}$ at $37^{\circ} \mathrm{C}$. Finally, a number of 6000 cells was seeded in microwells and imaged using an automated fluorescence microscope (VyCAP) and cells were incubated in petri-dishes at $37^{\circ} \mathrm{C}$ and $5 \%$ $\mathrm{CO}_{2}$. To determine cell viability in microwells overtime (4h, 1 day, 2 days and 4 days), the cells 
were stained in the microwells. Here a sponge (VyCAP) was used which enabled the removal of the cell culture medium from the bottom of the microwells. Once all medium was removed, $50 \mu \mathrm{L}$ of Live/Dead mixture was added on top of the microwells and cells were incubated for 30 min at $37^{\circ} \mathrm{C}$. Microwells were scanned directly to determine the number of live and dead cells. Cells seeded by fluorescent activated cell sorting (FACS) and a manual pipette using dilution series were used as control.

\subsubsection{Microwell degassing and sterilization}

Prior to cell seeding, microwells (VyCAP) were degassed in 1xPBS with $0.1 \%$ Tween at a pressure of -0.5 bars for 15 minutes. Subsequently, the microwells were sterilized in $70 \%$ ethanol for 30 minutes and washed with $1 \times$ PBS to remove ethanol and finally incubated with cell culture medium for $30 \mathrm{~min}$ at $37^{\circ} \mathrm{C}$ in the incubator.

\subsubsection{Cell punching}

For live cell punching of viable cells for further growth in 96 well tissue culture plates, microwells were scanned. From the acquired fluorescence images the wells which contain viable cells were selected by using the punching software program (VyCAP). Cells were retrieved from the microwells by punching the well bottoms from the microwells. Single cells or colonies were stained for viability and scanned. From the obtained fluorescent images viable cells were selected. Before punching the cells, fluid contact between the 96 well plate and the bottom of the microwells chip was made using cell culture medium. After establishing liquid contact and selection of the cells needed to be punched, the punch-software directs the needle to the selected microwells and punches the membrane containing the cell into the indicated well of the 96 well plate. The cell diffuses by gravity and hydrodynamic forces towards the bottom of the well and settle down. In some experiments, cells were left to grow for 2 day in microwells and only those that underwent cell division were punched. In other experiments cells were punched after seeding into culture wells plates. After punching the number of cells was counted and followed in time to determine the number of cells undergoing cell division.

\subsubsection{FACS sorting}

For fluorescent activated cell sorting (FACS) of cells a FACS ARIA II (BD Biosciences) was used. Cells were stained using the Live/Dead assay as described above. Cells were sorted into 96 well culture plates (Greiner Cellstar). The instrument was calibrated using CS\&T beads (BD Biosciences) before use. Before sorting, the sort gates and the number of cells to be sorted into the wells were set. 


\subsubsection{Manual pipetting}

Cells were harvested and counted using a Luna cell counter (Logos Biosystems). Cells were diluted to a concentration of 1 cell/uL. A volume of $1 \mathrm{uL}$ of this cell suspension was pipetted into a 96 wells culture plate. Using a fluorescence microscope the presence of the cell in a well was confirmed.

\subsubsection{Spiking and enrichment}

MCF-7 and MDA-MB-231 cells were pre-stained with CellTrace Violet (1:5000) (Invitrogen) and a number of 300 cells was spiked in $7.5 \mathrm{~mL}$ of EDTA anticoagulated whole blood from anonymized healthy volunteers obtained through the TNW-ECTM-donor services at the University of Twente. The research does not fall within the scope of the Dutch Medical Research Involving Human Subjects Act. Informed consent is obtained from all volunteers and blood collection procedure has been approved by the local Medical Research Ethics Committee. Leukocytes were depleted from the blood by the RosetteSep ${ }^{\text {TM }}$ Human CD45 Depletion kit (Stemcell Technologies) that was used according to manufacturer's instructions. The enriched fraction of tumor cells was gently collected and washed in PBS. Subsequently, this fraction was incubated with Alexa647 conjugated a-EpCAM (1:50 v/v, and PerCP conjugated a-CD45+ and with mixture of viability dye (Calc AM and EthD1,) for 30 minutes at room temperature, the volume was increased by adding $1 \mathrm{~mL}$ of culture medium. Finally, the sample was seeded in microwells and imaged. Tumor cells were considered positive for respectively EpCAM, CellTrace Violet, and negative for CD45. Viable tumor cells were Calc AM positive, EthD1 negative and dead tumor cells Calc AM negative, EthD1 positive. Recoveries were determined as number of counted tumor cells/number of spiked tumor cells $\times 100 \%$. Optimally tumor cells were selected and punched out from microwells into a 96 wells plate. Microwell chip and the 96 wells plate were then incubated at $37^{\circ} \mathrm{C}$ and $5 \% \mathrm{CO}_{2}$.

\subsubsection{Patient samples}

Blood was drawn in CellSave vacutainers (Menarini Silicon Biosystems) for CellSearch ${ }^{\circledR}$ analysis and screened for the presence of 10 or more CTC in $7.5 \mathrm{~mL}$ of blood at the Erasmus Medical Centre in Rotterdam, The Netherlands. From two metastatic breast and four castration resistant prostate cancer patients with 10 or more CTC by CellSearch analysis blood an additional blood tube was collected in EDTA vacutainers for self-sorting microwell analysis. Patients provided written informed consent and protocols approved by the Erasmus Ethics Committee (ethics reference number: MEC-17-238). $7.5 \mathrm{~mL}$ of blood samples for selfsorting microwell analysis were processed the next day. $7.5 \mathrm{~mL}$ of the sample was processed using the RosetteSep ${ }^{\text {TM }}$ Human CD45 depletion kit according to manufacturer's instructions. The collected fraction was washed with 1 xPBS and subsequently stained using a-EpCAM- 
Alexa647, a-CD45-PerCP, Calc AM and EthD1 and Hoechst 33342 for 30 min at 370C. Next $1 \mathrm{~mL}$ of cell culture medium was added and the sample was filtered onto a sterilized and degassed microwell chip by adding the sample into the chip and applying a pressure ranging from -10 to -70mbar pressure. The microwells were scanned using a fluorescence microscope as soon as possible. After scanning the microwell chip was kept in culture for 3 days, by placing the chip in culture medium and incubation at $37^{\circ} \mathrm{C}$ at $5 \% \mathrm{CO}_{2}$. The chip was checked on daily basis for any contamination and scanned to monitor cell viability.

\subsection{Results}

\subsubsection{Cell viability in microwells}

A cell suspension of MCF-7 cells was stained with Calcein AM (Calc AM) to identify live cells and Ethidium homodimer-1 (EthD1) to identify dead cells and seeded into the microwells. The viability of the cells in the microwells was assessed by fluorescence microscopy. Panel A of figure 4.1 shows 30 of the 6400 microwells, 11 wells contained a single viable cell (green dots), 1 well with two viable cells, 1 well with one dead cell (red dot) and one well with a viable and dead cell (green and red dot). We observed that the majority of the cells ( 95\%) was viable directly after seeding into the microwells. Subsequent examination after 4h, 1 day, 2 days and 4 days, while keeping the microwells in culture conditions, showed a decrease in viability to respectively 88, 65, 57 and $34 \%$ (Panel B). As control for the microwell seeding, MCF-7 cells were FACS sorted and manually pipetted into a 96 wells plate and viability overtime is illustrated in figure 4.1B. Between 0 and 4 hours no difference was observed between the three methods, but after 1,2 and 4 days the pipetted cells showed the least decrease in viability followed by the microwell seeding and FACS sorted cells.

a

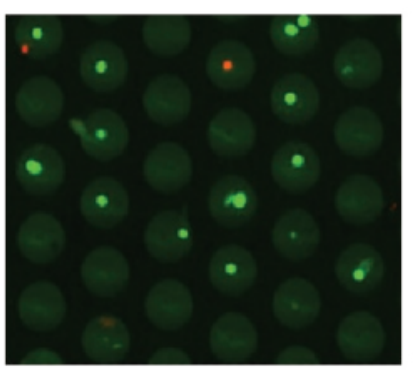

b

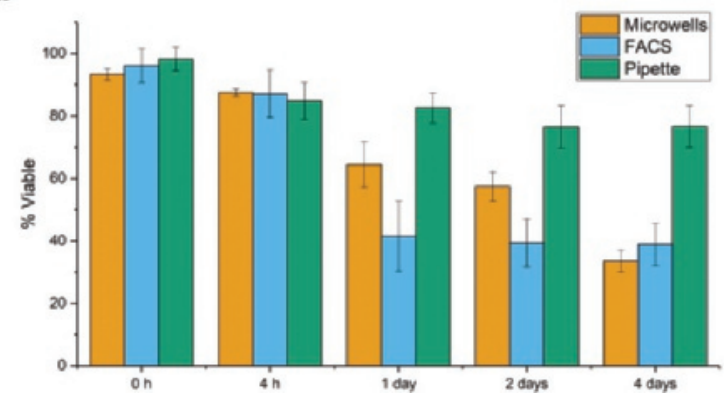

Figure 4.1: a) Microscopic image of MCF-7 cells seeded into microwells. Live cells, Calc AM positive (green) EthD1 negative or dead cells EthD1 positive (red), Calc AM negative. b) Viability of single cells obtained by self-sorting microwells, FACS and pipette. 


\subsubsection{Cell viability after punching}

The punching efficiency and viability after punching was established by seeding MCF-7 cells into microwells and punching them directly or 2 days after seeding, into a 96 well culture plate for further expansion. Figure 4.2 shows typical growth patterns of punched single cells immediately after seeding and cells that were punched 2 days after seeding. The figure shows the punched cells after 1,2 and 8 days.

The number of cells recovered, the viability and the number of cells that divided were counted. In total more than 80 microwell bottoms containing single viable cells and 78 well bottoms with cells that formed colonies after 2 days of culture were punched. Microwell bottoms that were detectable in the culture plate after punching were counted as a successful punch.

The punch efficiency for MCF-7 cells after seeding and immediate punching ranged from 74 90\% (mean 82\%, SD = 7) and the punch efficiency of MCF-7 cells that divided within the two days after seeding and punched after two days ranged from 68 - 87\% (mean 79\%, SD = 7). We observed that the cells that formed colonies were able to migrate inside the wells. This could be an explanation for the lower punching efficiency two days after seeding into the microwells as cells might have migrated to the wall of the microwell and therefore could not be successfully punched.

The effect of punching on the cell viability was assessed by allowing the cells to adhere to the culture plate for 4 hours. The number of viable cells, dead cells and cells that divided were counted. For comparison to punching cells, cells were also sorted by FACS and by manually pipetting into a cell culture plate. The highest percentage of living cells were found for FACS (range 89 - 100\%, mean 96\%, SD = 4\%) followed by punching (range 78 - 82\%, mean 79\%, SD $=2 \%$ ) and pipetting (range $54-94 \%$, mean 78\%, SD = 13\%). Viable cells were cultured and cell growth was monitored. To assess the growth efficiency after punching, the total number of single cells which formed colonies after 14 days of culture was determined for the three different cell seeding methods. Direct punching of cells resulted in the colony formation ranging from 73 - 93\% (mean 81\%, SD = 10\%). A decrease in colony formation is found for FACS, range 38 - 51\%, mean 43, SD 4.3 and pipetting, range 52 - 84\% (mean 70\%, SD = 11\%), figure 4.3. 

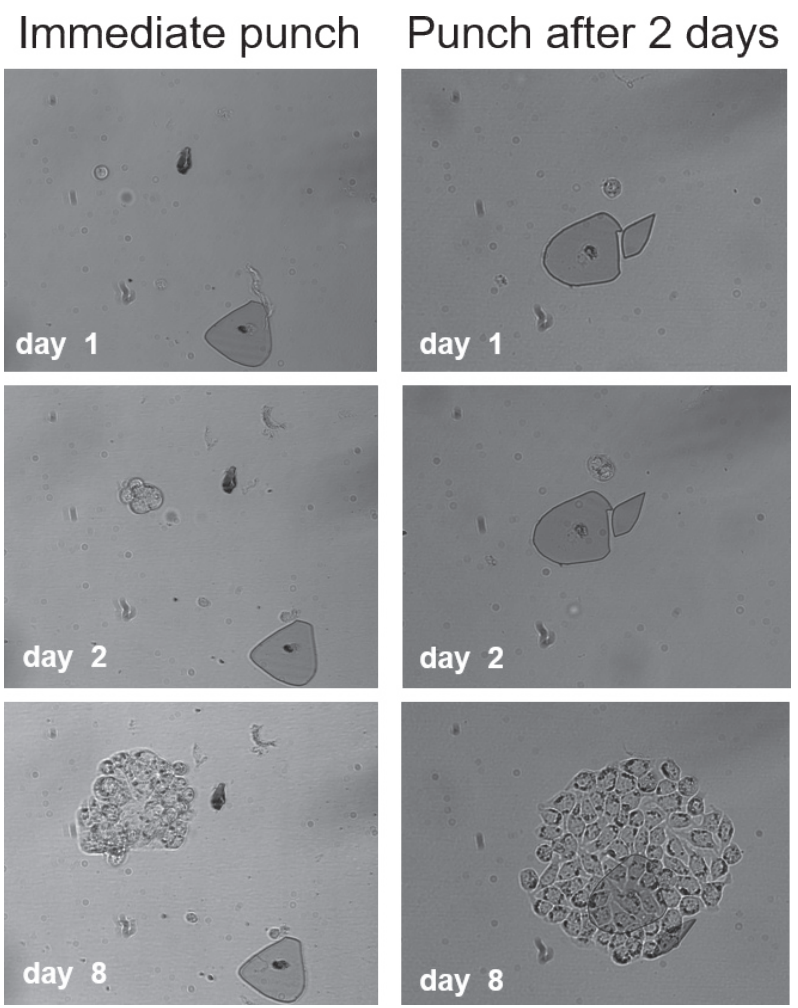

Figure 4.2: Growth pattern of single cells expanding after being punched from microwells into wells of a 96 well culture plate immediately after seeding (left) or 2 days after seeding (right).

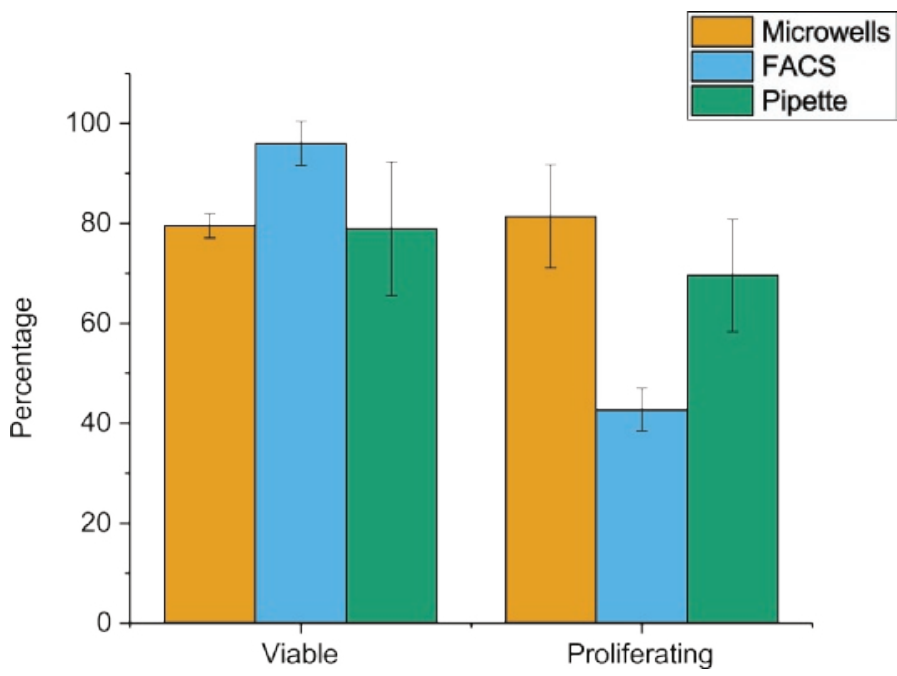

Figure 4.3: Cell viability and colony formation after punching compared to FACS sorting and pipetting. Percentage of viable cells and the percentage of cells that formed colonies is shown. 


\subsubsection{Isolation of tumor cells in whole blood}

The complete workflow of single CTC isolation and identification followed by culture is illustrated in figure 4.4. To simulate CTC in cancer patients 300 pre-stained MCF-7 and $\sim 300$ MDA-MB-231 were spiked in two $7.5 \mathrm{~mL}$ whole blood aliquots from 10 healthy volunteers. The spiked blood was depleted of CD45+ cells and the suspension was placed on the selfsorting microwells. The MCF-7 and MDA-231 cells present in the microwells were identified by fluorescence microscopy and 53\% \pm 11 of the MCF-7 cells and 50\% \pm 11 of the MDA-231 could be recovered. The origin of the cell losses was investigated. Seven experiments were conducted in which pre-stained MCF-7 and MDA-MB- 231 were directly seeded onto the microwells and resulted in a loss of 26\% \pm 15 for MCF-7 and 18\% \pm 9 for MDA-MB-231 cells. The loss of MCF-7 and MDA-MB-231 cells by depletion of CD45+ cells through RosetteSep ${ }^{\text {TM }}$ was investigated in four experiments in which the pre-stained MCF-7 and MDA-MB-231 cells were measured by flowcytometry in the leukocyte depleted cell suspension and showed a loss of $26 \% \pm 7$ for MCF-7 and $29 \% \pm 6$ for MDA-MB-231 cells. These results indicated that the $\sim 50 \%$ cell loss could be accounted for by both the filtration through the $5 \mu \mathrm{m}$ pores of the microwells and the leukocyte depletion.

Next, a staining protocol for the identification of the enriched tumor cells was developed and tested. The protocol contained Hoechst to identify the cell nucleus, Calc AM to identify viable cells, EthD1 to identify death cells, CD45-PerCP to identify leukocytes and EpCAM-Alexa647 to identify cells of epithelial origin. To enable the evaluation of the procedure the MCF-7 and MDA-231 cells were prelabelled with CellTrace ${ }^{\mathrm{TM}}$ Violet. A typical example of a stained MCF-7 cell in a microwell is shown in figure 4.5 .

The entire workflow was performed on $7.5 \mathrm{~mL}$ blood aliquots from six donors spiked with either 100 MCF-7 cells or 100 MDA-MB-231 cells. The efficiency of the method was determined by analyzing the recovery of spiked tumor cells inside the microwells. In addition, the percentage of viable tumor cells and the percentage of cells that showed cell growth after 2 days of culture was determined. The results are shown in table 4.1. In these experiments 85 - 95\% of the 6400 wells are occupied with a cell. 

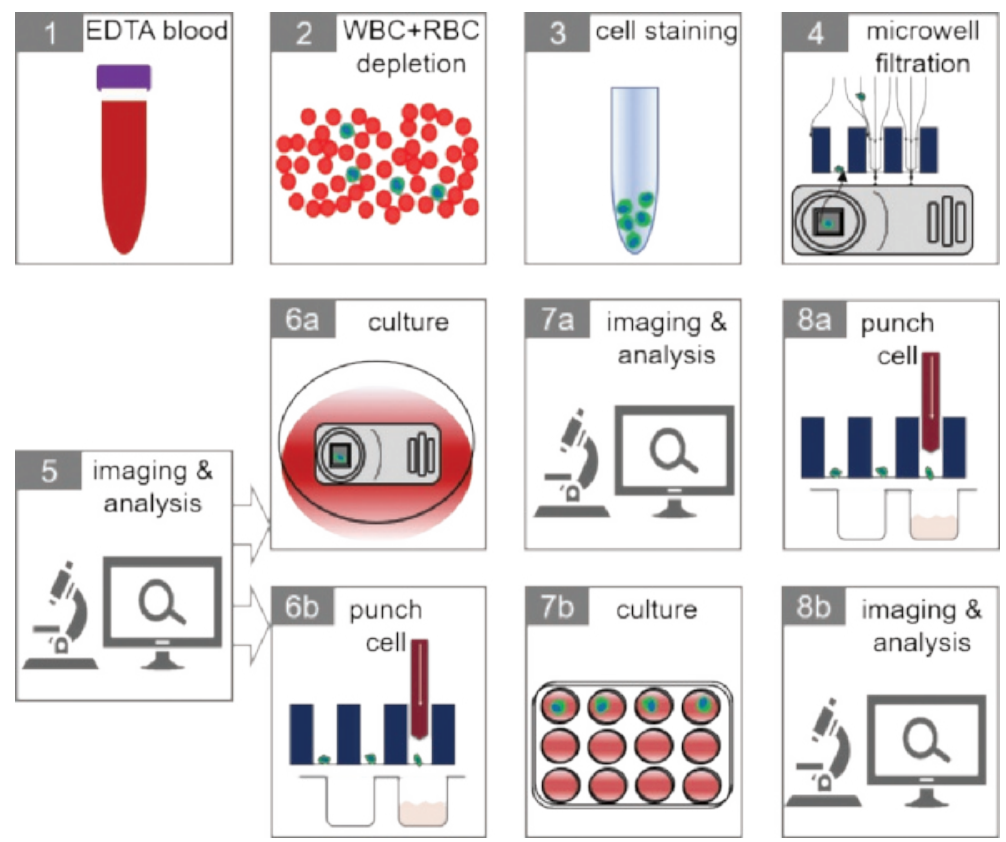

Figure 4.4: Schematic figure describing every step of our workflow to isolate and identify CTC from whole blood and subsequent cell culture. $7.5 \mathrm{~mL}$ of EDTA blood (1) is depleted of WBC and erythrocytes (2). The enriched cells are then stained (3) using a live/dead assay, nuclear stain, WBC marker (CD45) and a CTC marker (EpCAM). Cells are filtered into the microwells (4) and imaged using a microscope and analyzed to identify viable CTC and dead CTC (5). Next, the microwell is either placed in culture (6a) or cells of interest are isolated (6b). After culture of the microwell plate (6a), they can be reexamined (7a) and the cells of interest isolated (8a). Following direct isolation (6b) the cells can be placed in the desired place for cell culture (7b) and imaged and analyzed at any time (8b).
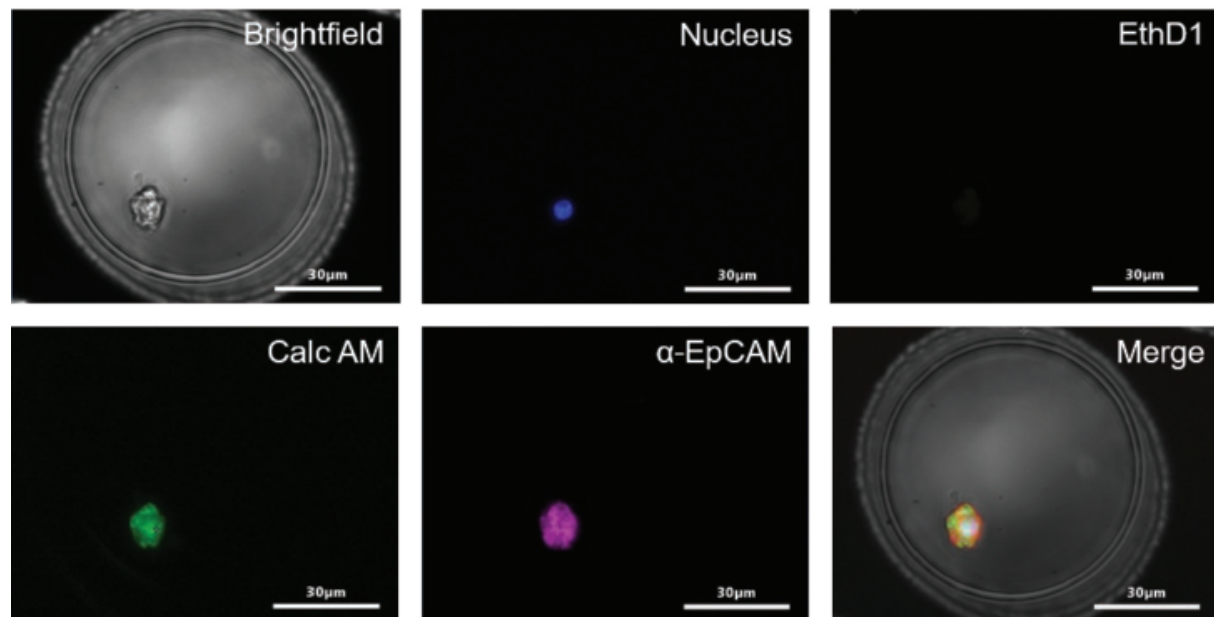

Figure 4.5: Identification of MCF-7 cell in a microwell. Bright field, Hoechst 33342 (nucleus), Ethidium homodimer-1 (EthD1) to identify death cells, Calcein AM (Calc AM) to identify viable cells, EpCAM-Alexa647 to identify cells of epithelial origin. Not shown is the CD45-PerCP image to identify leukocytes. 
Table 4.1: Recovery and viability after processing $7.5 \mathrm{~mL}$ EDTA blood spiked with 100 MCF-7 and 100 MDA-MB231 cells. After 2 days of cell culture the percentage of cells that showed cell growth was determined. In two of the experiments an infection was observed (inf).

\begin{tabular}{|c|c|c|c|c|c|c|}
\hline & \multicolumn{2}{|c|}{$\%$ recovery } & \multicolumn{2}{|c|}{$\%$ viable } & \multicolumn{2}{|c|}{ \% grow } \\
\hline & MCF-7 & MDA-MB-231 & MCF-7 & MDA-MB-231 & MCF-7 & MDA-MB-231 \\
\hline 1 & 61 & 67 & 63 & 78 & 55 & 49 \\
\hline 2 & 47 & 51 & 61 & 67 & 55 & 48 \\
\hline 3 & 43 & 39 & 74 & 65 & 64 & inf \\
\hline 4 & 45 & 49 & 75 & 65 & 61 & 44 \\
\hline 5 & 33 & 38 & 72 & 77 & 59 & inf \\
\hline 6 & 30 & 41 & 58 & 65 & 69 & 54 \\
\hline mean & 43 & 48 & 67 & 70 & 59 & 49 \\
\hline SD & 11 & 11 & 7 & 6 & 4 & 4 \\
\hline
\end{tabular}

\subsubsection{Tumor cells in blood of metastatic breast and prostate cancer patients}

To evaluate whether also CTC from cancer patients could be isolated with this procedure, es established on spiked tumor cells from cell lines, $7.5 \mathrm{~mL}$ blood samples collected in EDTA blood draw tubes from five metastatic breast and two prostate cancer patients were processed. Only samples with >10 CTC enumerated using the CellSearch system were used and the results are shown in table 4.2. Whereas with MCF-7 cells and MDA-MB-231 cell recoveries of respectively 43 and $48 \%$ were obtained in cancer patients a recovery of CTC of only 0 - 5\% as compared with the number detected by CellSearch was obtained. Possible explanations of this cell loss are a smaller size and greater flexibility of the CTC in cancer patients as compared to the cell lines and a lower expression of the EpCAM antigen on the CTC in cancer patients as compared to the cell lines. To probe whether the recovery of CTC could be improved two blood samples of a prostate cancer patient were processed with the procedure one with the standard approach and one in which the CD45 depleted sample was permeabilized and fixed to allow for Cytokeratin staining. The CTC recovery improved from 2 to $27 \%$. Whether this improvement is because the cells become more rigid after the fixation and or the higher density of Cytokeratin as compared to EpCAM cannot be concluded from this experiment.

Enumeration in the microwells and viability was assessed using a microscope. Figure 4.6 shows an example of 3 CTC found in a patient blood sample. 
Table 4.2: Number of CTC in 5 metastatic breast and 2 prostate cancer patients detected in $7.5 \mathrm{~mL}$ of blood by CellSearch ${ }^{\circledR}$ and in the microwells after CD 45 depletion of $7.5 \mathrm{~mL}$ of blood and passage into the self-sorting microwells. Shown is the recovery in the microwells compared to CellSearch, also the percentage of cells that are viable inside the microwells. In addition the percentage of viable cells still showing viability after two days. NA is not applicable.

\begin{tabular}{|c|c|c|c|c|c|c|}
\hline & Cancer & $\begin{array}{r}\text { CellSearch }^{\circledR} \\
\text { CTC }\end{array}$ & $\begin{array}{r}\text { Microwell } \\
\text { СTC }\end{array}$ & \% Recovery & $\%$ Viable & $\begin{array}{r}\% \text { Viable } \\
\text { after } 2 \text { days }\end{array}$ \\
\hline 1 & Breast & 102 & 1 & 1 & 0 & 0 \\
\hline 2 & Breast & $>100$ & 0 & 0 & 0 & 0 \\
\hline 3 & Prostate & 498 & 22 & 4 & 36 & 25 \\
\hline 4 & Breast & 94 & 3 & 3 & 33 & 0 \\
\hline 5 & Breast & 22 & 0 & 0 & 0 & 0 \\
\hline 6 & Breast & 111 & 5 & 5 & 20 & 100 \\
\hline $7 a$ & Prostate & 55 & 1 & 2 & 0 & 0 \\
\hline mean & & 140 & 5 & 2 & 13 & 18 \\
\hline SD & & 161 & 8 & 2 & 17 & 37 \\
\hline $7 b^{*}$ & Prostate & 55 & 15 & 27 & NA & NA \\
\hline
\end{tabular}

*An additional blood sample obtained from patient 7 was processed identical except for the staining which now included Cytokeratin for which cell permeabilization and fixation was needed before passage onto the self-sorting microwells.

a
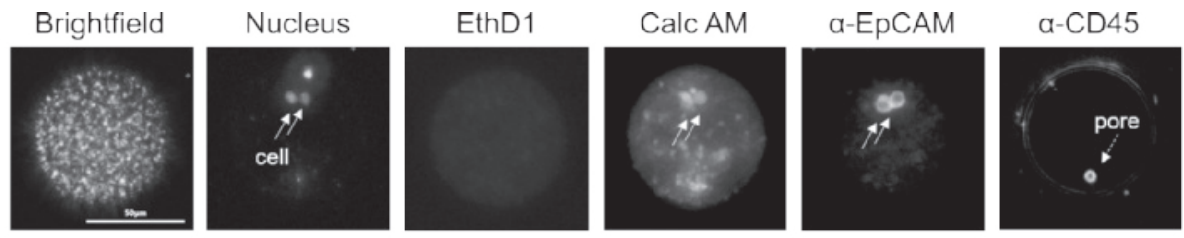

b
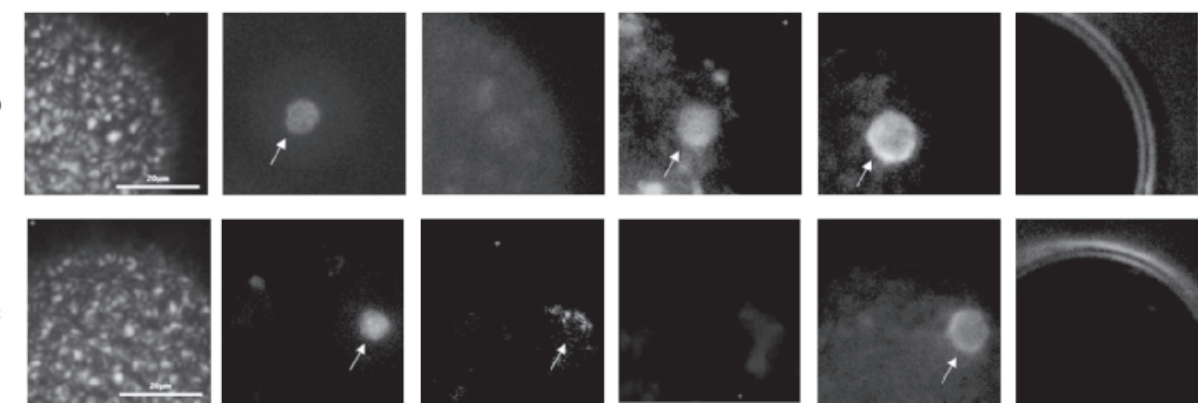

Figure 4.6: Images of CTCs in three microwells (panels a, b \& c) after isolation from $7.5 \mathrm{~mL}$ blood of a metastatic prostate cancer patient. The first image in the panels shows a bright field image showing the contours of the microwell, the objects in the image are residual red blood cells that end up in the well after blockage of the pore. Panel A shows the images of a CTC cluster consisting of two viable CTC (Nucleus+, EthD1-, Cals AM+, a-EpCAM+, a-CD45-). Panel B shows an example of a single viable CTC (Nucleus+, EthD1-, Cals AM+, $\mathbf{a}-\mathrm{EpCAM+,} \mathbf{a - C D 4 5 - )}$ and panel $\mathrm{C}$ shows a dead CTC (Nucleus+, EthD1+, Cals AM-, a-EpCAM+, a-CD45-). The solid arrows point to the position of the cells and the dashed arrow in the right image of panel A shows the position of the pore in the microwell visible through the PerCP filter cube. 


\subsection{Discussion}

In this study we aimed to develop a workflow where self-sorting microwells are used as a tool to isolate and grow single CTC from blood. To investigate whether cell viability could be maintained within the microwells after seeding and punching we first placed cells from the breast cancer cell line MCF-7 present in cell culture medium on the microwells and showed a single cell sorting efficiency of $~ 90 \%$ with a cell viability immediately after seeding of $90 \%$. Similar viabilities were obtained after sorting single MCF-7 cells by FACS or by manual pipetting (figure 4.1). After 1, 2 and 4 days of culture inside the microwells viability decreased more rapidly in the microwells as compared to manually pipetted cells but less when compared to FACS. Hydrodynamic forces and physical stress endured during the filtration or FACS may account for this difference. ${ }^{18,20,21}$ For filtration contact of the cells with the well bottom surface of the microwells, made of silicon nitride, may also account for the larger decrease in viability as compared to manual pipetting and maybe overcome by applying a cell friendly coating on the well bottom surface before cell seeding.

Next, we investigated whether the 'punching' of the cells into wells of microtiter plates effected the viability. A rather good punch efficiency for MCF-7 cells of $\sim 82 \%$ was obtained with a viability of $\sim 79 \%$. Viability was comparable with that obtained by FACS ( 96\%) and pipetting ( $78 \%)$. The ability of these single cells to form colonies after 14 days of culture was remarkable good in the microwells with $21 \%$ of the MCF-7 cells forming colonies compared to $43 \%$ when using FACS and $\sim 70 \%$ when using pipetting. The punching method therefore did not affect cell viability and cells were able to expand even when they adhered to the well bottom that came along with the punching (figure 4.2).

To be able to isolate CTC from blood and determine their viability and potential for cell division the number of leukocytes in $7.5 \mathrm{~mL}$ of blood is too large to pass through self-sorting microwells containing 6400 individual wells without clogging the pores in the wells. To reduce the number of leukocytes in blood we used the RosetteSep ${ }^{\text {TM }}$ leukocyte depletion protocol.7,19 To fluorescently label CTC. Hoechst was used as a nuclear stain, a-EpCAM-Alexa647 to identify CTC, a-CD45-PerCP to exclude leukocytes and Calc AM and EthD1 to identify the viable and dead CTC. CellTrace Violet labelled cells from the breast cancer cell line MCF-7 and MDAMB-231 spiked into blood were used to determine the feasibility of the approach. Recovery of $\sim 43 \%$ of MCF-7 and $\sim 48 \%$ of MDA-MB-231 cells was obtained with a viability of 67 and $70 \%$ and cell growth of 59 and $49 \%$ of the single cells. Loss of the cells could be contributed equally to the leukocyte depletion and filtration. The slightly larger loss by filtration of the 
MDA-MB-231 cells as compared to the MCF-7 cells can be contributed to the larger size of the MCF-7 cells $(16.3 \mu \mathrm{m}$ versus $15.6 \mu \mathrm{m}) .^{22}$

To evaluate whether this workflow could also be used to identify CTC from patients and determine their viability and capability to grow we processed blood samples from metastatic cancer patients with at least 10 CTC in $7.5 \mathrm{~mL}$ of blood by CellSearch. Only $2 \%$ of CTC could be retrieved using this workflow raising the question where the CTC are lost. Possible explanations are the smaller size of CTC as compared to the cells from the cell lines. CTC are generally larger in size then WBC, and this difference is used in the microwell filtration step to remove remaining WBC and RBC after depletion and obtain individual CTC in the microwells. However, where the size of cells from tumor cell lines is known, the actual size of CTC in individual patient is unknown and might cover a wide range..$^{23}$ In addition to size, also cell stiffness or rigidity has an important role in passage through a pore ${ }^{24}$, cell stiffness of patient CTC may vary and be less than in cell lines, this might explain part of the cell loss. In addition to these physical properties, variation in biological cell properties might also contribute to cell loss. For example because of lesser staining with EpCAM as compared to Cytokeratin as used in the CellSearch system. In order not to affect viability, EDTA was used as anticoagulant in contrast to the draw tubes that contain preservative / fixatives such as in the CellSave ${ }^{25}$ and Transfix ${ }^{26}$ blood collection tubes frequently used for size-based enrichment procedures. These preservatives / fixatives make the cells more rigid facilitating the capture in the micropores. A potential solution would be to decrease the pore size of $5 \mu \mathrm{m}$ to enable the capture of the smaller CTC. The reduction of leukocytes will however need to be sufficient to not block the pores. The observed loss of spiked cultured tumor cells through the leukocyte depletion protocol of 26 and $29 \%$ suggest that a similar portion of CTC might be loss. Alternatively, positive enrichment procedure such as used in the CellSearch Profile kit ${ }^{27}$, MagSweeper ${ }^{28}$, EasySep $^{\text {TM }} 29$, Dynal beads ${ }^{29}$ and EpCAM independent methods ${ }^{30}$ can be used to enrich CTC and pass them through the microwells. In one patient we obtained a second blood sample collected in a EDTA vacutainer and processed it similarly except we changed the staining and added fixation of the cells before placing the enriched sample on the microwells. The CTC recovery increase from 2 to $27 \%$ showing that the increased rigidity and higher fluorescent signals obtained from the Cytokeratin versus the EpCAM staining.

Viability of the CTC ranged from 0 - 33\% (mean 13\%) which is not surprising as many CTC detected with the CellSearch system show apoptotic features. ${ }^{31-33}$ Some of the viable CTC remained viable for a couple of days but none divided. One of our aims is to measure the secretome of CTC and one the most important precondition for this to work is the availability 
of CTC that remain viable for a couple of days. Previously we have already shown that we can measure products secreted by individual cells present in the self-sorting microwells. ${ }^{34}$

Other systems are available to assess single cells, for example a self-sufficient micro-droplet generation system which facilitates encapsulation, chemical stimulation and microscopic analysis of viable cells inside droplets. ${ }^{35}$ However many cells are used and it has not been shown that such systems work for rare cell populations like CTC, Single cell isolation technologies suitable for CTC analysis, including viable cells do exist like DEPArray ${ }^{\text {TM }}{ }^{36}$, ALS cellselector ${ }^{\text {TM }}$ ${ }^{37}$ or FACS sorting ${ }^{38}$ but no successful CTC cultures have been published yet. A workflow to successfully obtain viable CTC using self-sorting microwells is presented here. The present configuration of the microwells, the pre-enrichment of CTC before placing the suspension on the sieves and the fluorescent labeling will have to be improved for a more efficient use of this workflow. 


\section{References}

1 S. J. Diaz-Cano, Diaz-Cano and S. J., Int. J. Mol. Sci., 2012, 13, 1951-2011.

2 E. Crowley, F. Di Nicolantonio, F. Loupakis and A. Bardelli, Nat. Rev. Clin. Oncol., 2013, 10, 472-484.

3 D. Hanahan and R. A. Weinberg, Cell, 2011, 144, $646-674$

4 K. C. Andree, G. van Dalum and L. W. M. M. Terstappen, Mol. Oncol., 2016, 10, 395-407.

5 K. Pantel and C. Alix-Panabières, Mol. Oncol., 2016, 10, 371-3.

6 W. J. Allard, J. Matera, M. C. Miller, M. Repollet, M. C. Connelly, C. Rao, A. G. J. Tibbe, J. W. Uhr and L. W. M. M. Terstappen, Clin. Cancer Res., 2004, 10, 6897-6904.

7 A. Soler, L. Cayrefourcq, M. Mazel and C. AlixPanabières, in Methods in molecular biology (Clifton, N.J.), Humana Press, New York, NY, 2017, vol. 1634, pp. 263-276.

8 D. A. Haber, N. S. Gray and J. Baselga, Cell, 2011, 145, 19-24.

9 M. Yu, A. Bardia, N. Aceto, F. Bersani, M. W. Madden, M. C. Donaldson, R. Desai, H. Zhu, V. Comaills, Z. Zheng, B. S. Wittner, P. Stojanov, E. Brachtel, D. Sgroi, R. Kapur, T. Shioda, D. T. Ting, S. Ramaswamy, G. Getz, A. J. lafrate, C. Benes, M. Toner, S. Maheswaran and D. A. Haber, Science, 2014, 345, 216-20.

10 J. Drost, W. R. Karthaus, D. Gao, E. Driehuis, C. L. Sawyers, Y. Chen and H. Clevers, Nat. Protoc., 2016, 11, 347-358

11 A. Fatehullah, S. H. Tan and N. Barker, Nat. Cell Biol., 2016, 18, 246-254.

12 D. Gao, I. Vela, A. Sboner, P. J. laquinta, W. R. Karthaus, A. Gopalan, C. Dowling, J. N. Wanjala, E. A. Undvall, V. K. Arora, J. Wongvipat, M. Kossai, S. Ramazanoglu, L. P. Barboza, W. Di, Z. Cao, Q. F. Zhang, I. Sirota, L. Ran, T. Y. MacDonald, H. Beltran, J.-M. Mosquera, K. A. Touijer, P. T. Scardino, V. P. Laudone, K. R. Curtis, D. E. Rathkopf, M. J. Morris, D. C. Danila, S. F. Slovin, S. B. Solomon, J. A. Eastham, P. Chi, B. Carver, M. A. Rubin, H. I. Scher, H. Clevers, C. L. Sawyers and Y. Chen, Cell, 2014, 159, 176-187.
13 K. Kolostova, M. Cegan and V. Bobek, Can. Urol. Assoc. J., 2014, 8, E715-20.

14 L. Cayrefourcq, T. Mazard, S. Joosse, J. Solassol, J. Ramos, E. Assenat, U. Schumacher, V. Costes, T. Maudelonde, K. Pantel and C. Alix-Panabières, Cancer Res., 2015, 75, 892-901.

15 Z. Zhang, H. Shiratsuchi, J. Lin, G. Chen, R. M. Reddy, E. Azizi, S. Fouladdel, A. C. Chang, L. Lin, H. Jiang, M. Waghray, G. Luker, D. M. Simeone, M. S. Wicha, D. G. Beer, N. Ramnath, S. Nagrath, Z. Zhang, H. Shiratsuchi, J. Lin, G. Chen, R. M. Reddy, E. Azizi, S. Fouladdel, A. C. Chang, L. Lin, H. Jiang, M. Waghray, G. Luker, D. M. Simeone, M. S. Wicha, D. G. Beer, N. Ramnath and S. Nagrath, Oncotarget, 2014, 5, 12383-12397.

16 M. B. Lambros, G. Seed, S. Sumanasuriya, V. Gil, M. Crespo, M. S. Fontes, R. Chandler, N. Mehra, G. Fowler, B. Ebbs, P. R. Flohr, S. Miranda, W. Yuan, A. Mackay, A. Ferreira, R. Pereira, C. Bertan, I. Figueiredo, R. Riisnaes, D. Nava Rodrigues, A. Sharp, J. Goodall, G. Boysen, S. Carreira, D. Bianchini, P. Rescigno, Z. Zafeiriou, J. Hunt, D. Moloney, L. Hamilton, R. P. L. Neves, J. F. Swennenhuis, K. C. Andree, N. H. Stoecklein, L. W. Terstappen and J. S. de Bono, Clin. Cancer Res., 2018, clincanres.0862.2018.

17 V. Faugeroux, O. Deas, C. Catelain, E. Pailler, K. Andree, F. Lucibello, E. Alexandrova, J. Judde, N. Stoecklein, J. Scoazec, N. Manaresi, V. Marty, N. Tramalloni, M NgoCamus, C. Nicotra, L. Terstappen, V. Lapierre, K. Fizazi, Y. Loriot and F. Farace, in ACTC, Rhodes, 2017, p. 106.

18 J. F. Swennenhuis, A. G. J. Tibbe, M. Stevens, M. R. Katika, J. van Dalum, H. Duy Tong, C. J. M. van Rijn and L. W. M. M. Terstappen, Lab Chip, 2015, 15, 3039-3046.

19 M. Stevens, L. Oomens, J. Broekmaat, J. Weersink, F. Abali, J. Swennenhuis and A. Tibbe, Cytom. Part A, 2018, 93, 1255-1259.

20 H. M. Shapiro, in Practical Flow Cytometry, WileyLiss, New York, 3th edn., 1994, pp. 217-228.

21 H. M. Shapiro, in Practical Flow Cytometry, WileyLiss, New York, 3th edn., 1994, pp. 133-134. 
22 F.A.W. Coumans, G. van Dalum, M. Beck and L.W. M. M. Terstappen, PLoS One, 2013, 8, e61770.

23 F. Coumans, G. Dalum and L. W. M. M. Terstappen, Cytom. Part A, 2018, 93, 1197-1201.

24 F.A.W. Coumans, G. van Dalum, M. Beck and L. W. M. M. Terstappen, PLoS One, 2013, 8, e61774.

25 C. Mulherin, C. Larson, ... A. H.-C. and undefined 2004, WILEY-LISS DIV JOHN WILEY \& ....

26 Z. Mu, N. Benali-Furet, G. Uzan, A. Znaty, Z. Ye, C. Paolillo, C. Wang, L. Austin, G. Rossi, P. Fortina, H. Yang, M. Cristofanilli, Z. Mu, N. Benali-Furet, G. Uzan, A. Znaty, Z. Ye, C. Paolillo, C. Wang, L. Austin, G. Rossi, P. Fortina, H. Yang and M. Cristofanilli, Int. J. Mol. Sci., 2016, 17, 1665.

27 D. A. Smirnov, D. R. Zweitzig, B. W. Foulk, M. C. Miller, G. V Doyle, K. J. Pienta, N. J. Meropol, L. M. Weiner, S. J. Cohen, J. G. Moreno, M. C. Connelly, L. W. M. M. Terstappen and S. M. O'Hara, Cancer Res., 2005, 65, 4993-7.

28 A. H. Talasaz, A. A. Powell, D. E. Huber, J. G. Berbee, K.-H. Roh, W. Yu, W. Xiao, M. M. Davis, R. F. Pease, M. N. Mindrinos, S. S. Jeffrey and R. W. Davis, Proc. Natl. Acad. Sci. U. S. A., 2009, 106, 3970-5.

29 K. G. Leong, K. Niessen, I. Kulic, A. Raouf, C. Eaves, I. Pollet and A. Karsan, J. Exp. Med., 2007, 204, 29352948.

30 M. Ø.Agerbæk, S. R. Bang-Christensen, M.-H. Yang, T. M. Clausen, M. A. Pereira, S. Sharma, S. B. Ditlev, M. A. Nielsen, S. Choudhary, T. Gustavsson, P. H. Sorensen, T. Meyer, D. Propper, J. Shamash, T. G. Theander, A. Aicher, M. Daugaard, C. Heeschen and A. Salanti, Nat. Commun., 2018, 9, 3279.

31 E. Rossi, U. Basso, R. Celadin, F. Zilio, S. Pucciarelli, M. Aieta, C. Barile, T. Sava, G. Bonciarelli, S. Tumolo, C. Ghiotto, C. Magro, A. Jirillo, S. Indraccolo, A. Amadori and R. Zamarchi, Clin. Cancer Res., 2010, 16, 523343.

32 J. B. Smerage, G. T. Budd, G. V. Doyle, M. Brown, C. Paoletti, M. Muniz, M. C. Miller, M. I. Repollet, D. A. Chianese, M. C. Connelly, L.W.W. M. Terstappen and D. F. Hayes, Mol. Oncol., 2013, 7, 680-692.

33 C. J. Larson, J. G. Moreno, K. J. Pienta, S. Gross, M. Repollet, S. M. O'Hara, T. Russell and L. W. M. M. Terstappen, Cytometry, 2004, 62A, 46-53.
34 F. Abali, M. Stevens, A. G. J. Tibbe, L. W. M. M. Terstappen, P. N. van der Velde and R. B. M. Schasfoort, Anal. Biochem., 2017, 531, 45-47.

35 P. Thurgood, S. Baratchi, C. Szydzik, J. Y. Zhu, S. Nahavandi, A. Mitchell and K. Khoshmanesh, Sensors Actuators B Chem., 2018, 274, 645-653.

36 M. Di Trapani, N. Manaresi and G. Medoro, Cytom. Part A, DOI:10.1002/cyto.a.23687.

37 C. Nelep and J. Eberhardt, Cytom. Part A, DOI:10.1002/cyto.a.23568.

38 L. Yu, S. Sa, L. Wang, K. Dulmage, N. Bhagwat, S. S. Yee, M.Sen, C. H. Pletcher, J. S. Moore, S. Saksena, E. P. Dixon and E. L. Carpenter, Cytom. Part A, 2018, 93 , 1226-1233. 
Self-Seeding Microwells to Isolate and Assess the Viability of Single Cells 

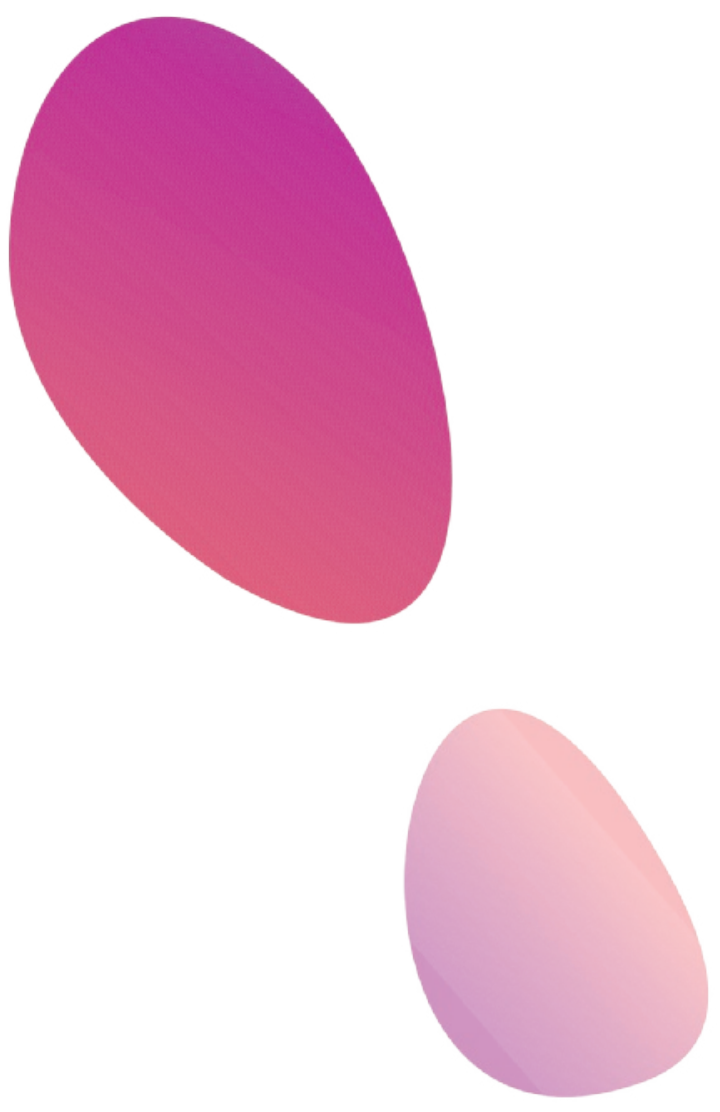


\section{CHAPTER 5 \\ Techniques to Isolate Circulating Tumor Cells from Large Blood Volumes}




\section{Abstract}

Circulating tumor cells (CTC) represent a "liquid biopsy" that can be used to guide treatment for individual patients. In the CTCTrap consortium it was aimed to use therapeutic apheresis (TA), for the collection of CTC from peripheral blood in cancer patients. In addition, alternative approaches were pursued to process large blood volumes from leukapheresis products. The developed CTCTrap device showed very low recovery of tumor cells and a high carryover of leukocytes in the processed sample resulting in no enrichment of tumor cells. As these results indicate that the use of the developed CTCTrap device was not suitable for processing the large volume of leukapheresis product it was decided to continue using alternative techniques. As alternative to the CTCTrap device several other techniques were evaluated for their ability of processing large leukapheresis volumes and large cell numbers followed by detection and enumeration of CTC. This resulted in the development of a leukocyte depletion protocol based on the commercially available RosetteSep CTC enrichment kit for processing leukapheresis products. Leukapheresis product successfully can be processed using the developed methods. Although a higher number of CTC could be obtained when processing larger DLA volumes all attempted approached still were accompanied by CTC losses. 


\subsection{Introduction}

Tumor cells can detach from a primary tumor or metastatic site, they can then enter the peripheral blood, circulate through the vasculature and may extravasate at distant sites to form metastasis. Reports indicate that these circulating tumor cells (CTC) provide important information on therapeutic targets and drug resistance mechanisms in patients with carcinoma. ${ }^{1,2}$ Therefore these CTC represent a "liquid biopsy" that can be used to guide treatment for individual patients. CTC are however rare and can only be obtained in sufficient amounts for further characterization in a small fraction of patients. This is visualized in figure 5.1 in which the number of CTC per blood volume is plotted against the probability to detect 10 CTC. The number of CTC in $7.5 \mathrm{~mL}$ blood was determined using the CellSearch system (DAPI+, CK+, CD45- nucleated cells >4 $\mu \mathrm{m}$ in size) in $411 \mathrm{NSCL}, 428$ colorectal, 177 breast an 231 metastatic prostate cancer patients. ${ }^{3}$ Using these numbers the frequency distribution could be determined for the smaller blood volumes and a fit was made through this distribution to estimate the frequency in volumes larger than $7.5 \mathrm{~mL}$. From the figure it is clear that processing larger blood volumes will be needed to obtain a sufficient number of tumor cells for further characterization and determine the best treatment options. In the CTCTrap consortium universities, research institutions and SMEs were linked in a common effort to use Therapeutic Apheresis (TA), for the collection of CTC from peripheral blood in cancer patients. The goal within this consortium was to develop a new TA column to capture CTC and then reintroduce the blood depleted of tumor cells back into the body with the promise to obtain CTC in all metastatic cancer patients. In short, the TA module should consist of an advanced biocompatible three dimensional matrix containing columns for the immobilization of biological substances implemented into a new CTC apheresis device. The columns will contain a matrix that is chemically functionalized and permits coupling of antibodies. To capture CTC not exhibiting the antibodies the columns may contain an outer surface membrane that contains a sufficient number of pores with a diameter that allows passage of the erythrocytes, platelets and the majority of leukocytes, while retaining the larger CTC. The goal is to process 2.5 liters of blood in one hour. After CTC apheresis, the CTC will be harvested by incubation with a modified cell protecting solution from the columns. After depletion of remaining leukocytes, sufficient amounts of tumor cells are available for detailed characterization. The molecular characterization of these CTC is expected to gather new knowledge on metastasis' mechanism, provide a risk assessment and the optimal therapy choice during the course of the disease of cancer patients. In the CANCER-ID program the plan was to validate the developed technologies in NSCLC. 


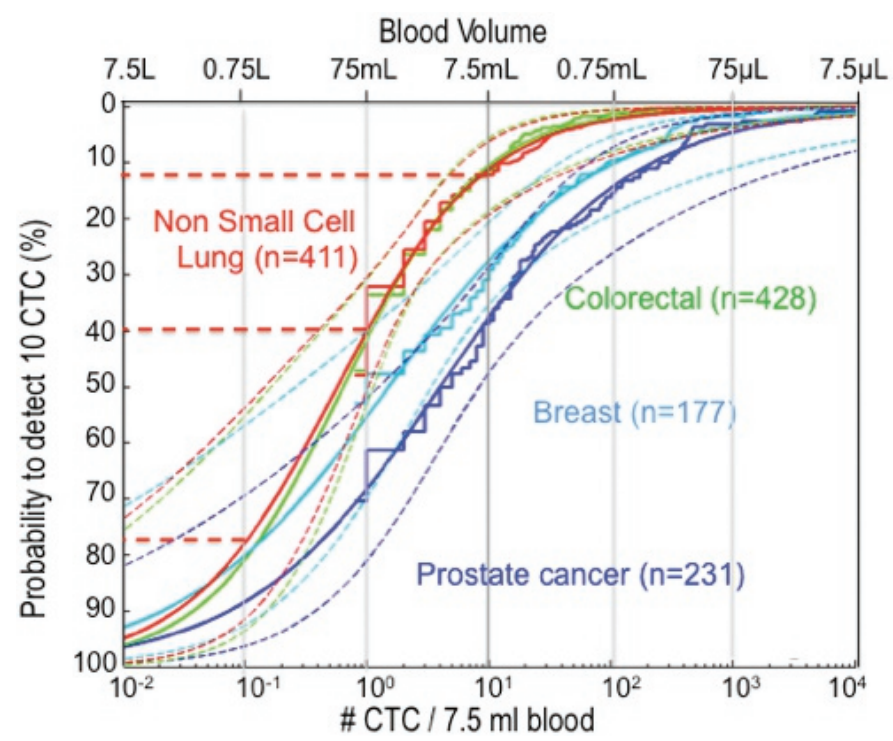

Figure 5.1: Frequency distribution of CTC in patients with metastatic cancer. Adapted from ${ }^{1}$

In this chapter we summarize the approaches that have been evaluated for the isolation of CTC from larger blood volumes. Parallel to the development of a TA column by Leukocare alternative approaches were pursued to process larger blood volumes from leukapheresis products. First, we will summarize the development and evaluation of the TA column followed by evaluation of protocols to deplete leukocytes from blood and leukapheresis product and then the development and evaluation of filtration techniques, we finish the chapter with the optimization of techniques to isolate CTC from large volumes.

\subsection{TA column}

In the CTCTrap program the company Leukocare (https://www.leukocare.com) was assigned the task to develop a CTC apheresis device, baptized CTC Trap, for CTC removal and retrieval from peripheral blood. The concept is depicted in the figure 5.2. Blood is drawn into a CTC capture module and the blood depleted of CTC is returned to the patient (A). After passage of a complete blood volume of a patient the CTC capture module is disconnected and the CTC, trapped in the module, are released and placed in a collection tube for further characterization (B). Several tasks needed to be accomplished: 1. Development of CTC capture and release chemistry, 2. Production of a bench scale circulation module, 3. Scale up of the set-up 4. Testing of the final CTC apheresis device. 

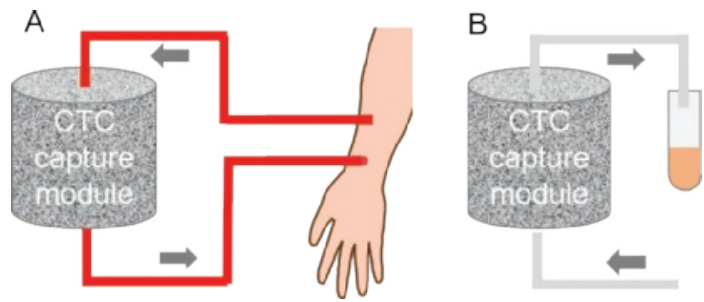

Figure 5.2: Concept of the TA column for CTC capturing. A) Blood from a patient is taken and passed through a CTC capture module after which the blood depleted of CTC is returned to the patient. B) After CTC collection the column is detached from the patient and CTC are retrieved and characterized.

\subsection{1 СTC capture and release chemistry}

The EpCAM antigen was chosen as the target antigen for CTC capture as clinical and biological significance of tumor cells expressing this antigen has been proven. As capture molecules, antibodies targeting EpCAM and proteins designed to bind recombinant EpCAM binding (DARPin) were tested. From the initial testing the EpCAM specific antibody (VU1D9) and the EpCAM specific DARPin Ec1 were selected for further optimization. The molecules needed to be attached to a matrix contained within a capture module as illustrated in figure 5.3. The coupling chemistry needed to be such that it allowed for the specific binding of cells expressing the EpCAM antigen but also to be able to release the bond and with that the release of cells.
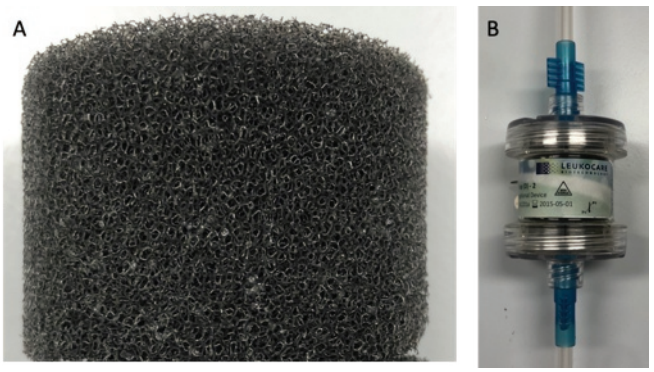

Figure 5.3: A) Advanced biocompatible three dimensional matrix B) matrix inside the housing of the capture module.

\subsubsection{Bench scale circulation module}

Next, a circulation model system was developed to confirm the binding of EpCAM expressing cells in a flow system having similar properties as the final CTCTrap in the blood circulation of a patient during apheresis. A functional 1:5 downscaled bench scale model based on infusion set materials and a peristaltic pump system was developed. Initial testing of the module showed that it was compatible with blood and cells expressing EpCAM bound to the matrix under clinical relevant flow conditions. Next, a protocol for the elution of the cells bound to the EpCAM binding molecules on the matrix in laboratory vessels was established based on elution by competitive elution with multivalent DARPin. 
Next, the goal was to upscale to the final CTC Trap for clinical use. With the selected materials and protocols in terms of CTC capturing from full blood a functional CTC Trap prototype was produced. During the progress of the up-scaling work it turned out that the previously selected DARPin molecules could not be used in direct contact to the patient for legal issues. Therefore, alternative strategies were developed for selecting different EpCAM binding molecules. Additionally, it turned out that the upscaling to the circulation systems was not compatible with the elution protocol as developed for the DARPins. Therefore, a new coating strategy was developed allowing more efficient elution. An elution protocol was established that allows the elution of 10 - 25\% of captured SKBR-3 cells from the CTC Trap. The configuration is shown in figure 5.4. Besides the EpCAM binding protein there is an 3C protease cleavage site, and two linker sequences. One linker located between the binding protein and the cleavage site, and another one between the cleavage site and the CTC Trap matrix. Both of these linkers are important for the accessibility of the $3 \mathrm{C}$ protease cleavage site by the protease for the elution of the cells. A general setup of the desired coating construct is depicted in figure 5.4. Elution was achieved using a mixture of TrypLE and 3 C protease. In order to avoid direct patient contact it was decided to continue using leukapheresis products instead of applying the column during leukapheresis. Two design layouts for using the CTC Trap with the DARPin capture molecules after leukapheresis without patient contact with infusion pump or with syringe pump were presented.

At this moment a lab bench scale model of the CTC Trap column which consisted of a CTC Trap column and a syringe pump to control flow was available and tested for feasibility for processing leukapheresis products. A picture of the bench scale model is depicted in figure 5.5.

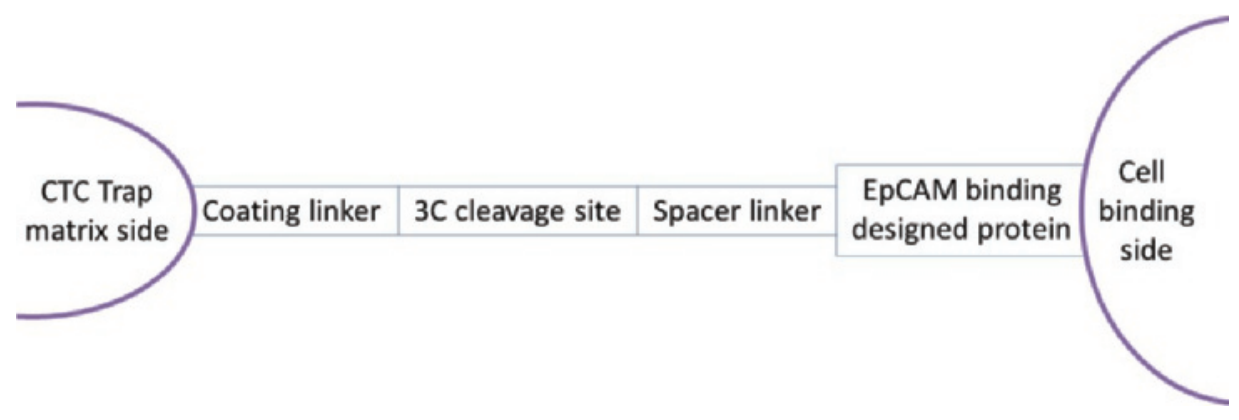

Figure 5.4: Principle arrangement of the designed EpCAM binding protein on the CTC Trap matrix, for binding EpCAM expressing cells. Two linkers and the $3 \mathrm{C}$ protease cleavage site separate the protein from the matrix in order to modulate the accessibility of the capture molecule during the cell binding within the apheresis and additionally the accessibility of the $3 \mathrm{C}$ cleavage site by the protease within the elution reaction. 


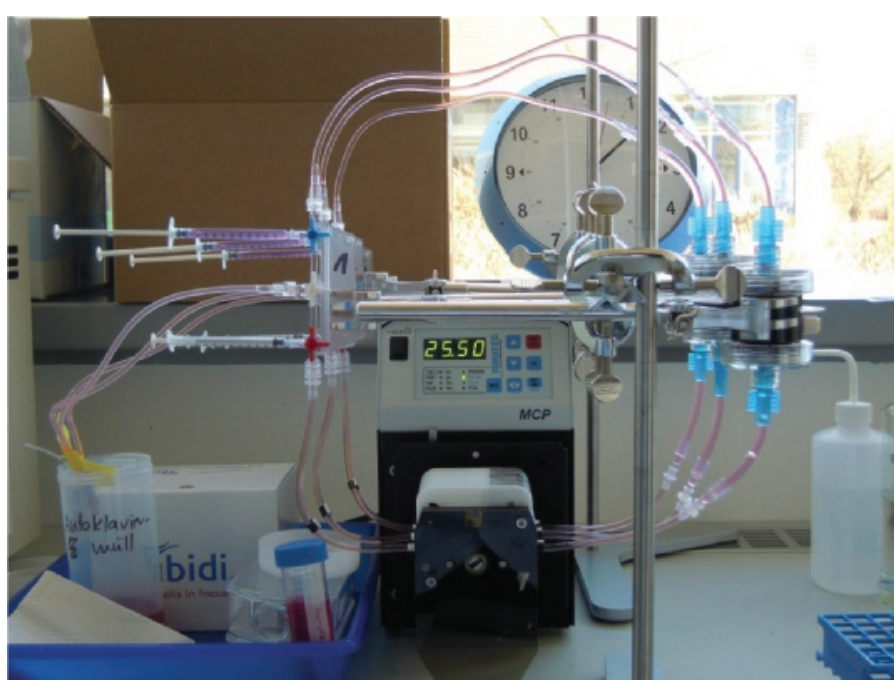

Figure 5.5: Laboratory setup for in vitro CTC Trap circulation with SKBR-3 cells. In this picture 3 CTC Trap devices (on the right side) are processed at the same time.

Five $\mathrm{mL}$ of $200.000 / \mathrm{mL}$ pre-stained SKBR-3 cells were pipetted into a CellSave tube (Janssen, Huntingdon Valley, PA, USA). The cell suspension was prepared by mixing 20 mL PBS/BSA 5\%, 0.5 mL SKBR-3 and 80 mL PBS. The CTC Trap lab scale procedure was performed and the following samples were collected: 1) start sample: is the cell-suspension added to the system 2) waste when adding cell suspension: after priming $100 \mathrm{~mL}$ cell suspension was added to the system, the waste coming from the system was collected. 3) waste washing step: $250 \mathrm{~mL}$ PBS pumped through the system for washing, $250 \mathrm{~mL}$ waste coming from the system was collected. 4) eluate: elution liquid removed from the CTCTrap. One $\mathrm{mL}$ of each 'sample' was filtered onto a $2 \mathrm{uM}$ VyCAP microsieve, $40 \mathrm{~mL}$ of 4 ) eluate was filtered onto a $5 \mathrm{uM} \vee \mathrm{V} C \mathrm{AP}$ microsieve. After filtration the filter was scanned and the number of cells was counted.

Figure 5.6 shows a pie chart with the percentage of cells in each fraction, were the cell suspension is set at $100 \%$. The fraction indicated with '?' is the percentage of cells that was not detected and is probably still trapped inside the device. First results show that a major part (62\%) of the cell suspension applied onto the CTC Trap device already left the system before circulation across the CTCTrap could start. This problem is due to the volume $(100 \mathrm{~mL})$ of the cell suspension applied. The volume of the cell suspension should be decreased and be adapted to the volume of the bench scale model. Decreasing the volume of cell suspension is possible by not diluting the sample. Whether this can cause clogging of the CTCTrap due to higher cell concentrations remains to be tested. In some preliminary 
experiments in the preparation of these setups it turned out that within the CTC Trap a flow rate higher than $10 \mathrm{ml} / \mathrm{min}$ is required in order to avoid sedimentation of the cells with the diluted leukaphereses product. Additionally, it proved to be advantageous if incubation time within the CTC Trap is higher than 60 minutes. Considering these boundary conditions, it becomes clear that single-pass setups are not feasible, since the intended volume is too low for pumping it through the system with the high flow rate and at the same time one needs such long incubation time. Thus a circulation system for the liquid became necessary. To accomplish this an Otsuka apheresis system was planned for use in combination with the CTCTrap module for its use in in vivo apheresis on patients. Picture of the set-up is shown in figure 5.7

\section{$\%$ of cells in different fractions}
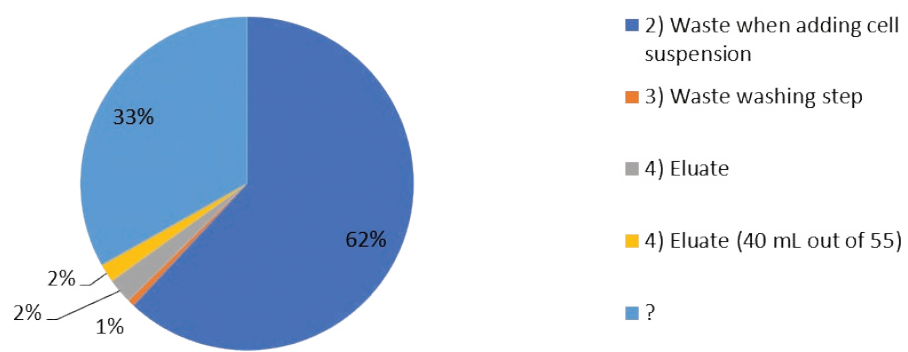

Figure 5.6: Pie chart showing the percentages of measured cells of each collected fraction from the CTC Trap device.

\subsubsection{Scale up and testing}

Production of the CTC Trap modules was scaled up and functionality testing with the CTCTrap apheresis system was performed. The CTCTrap device was tested in 3 experiments using DLA products. From each experiment $18 \mathrm{~mL}$ of unfixed DLA product was used for testing the CTCTrap device, $18 \mathrm{~mL}$ of Cellsave fixed DLA product was split into one $17 \mathrm{~mL}$ aliquot for leukocyte depletion using RosetteSep and a $1 \mathrm{~mL}$ aliquot for direct filtration. RosetteSep was performed according to the SOP RosetteSep and staining (supplementary data). CTCTrap device and filtration were performed as described in the methods section. RosetteSep and direct filtration were analyzed by staining on sieve and microscopic analysis. For CTCTrap the number of cells was measured (hematology analyzer) at start, in the discarded liquid of the washing steps and in the final eluate. The final eluate of the CTCTrap was split in two aliquots, 1/2 was used for FACS analysis and 1/2 part was used for filtration (for 2nd and 3th DLA sample, filtration part was again split, 1/2 part filtered immediately, $1 / 2$ part fixed in CellSave overnight and filtered the next day). 


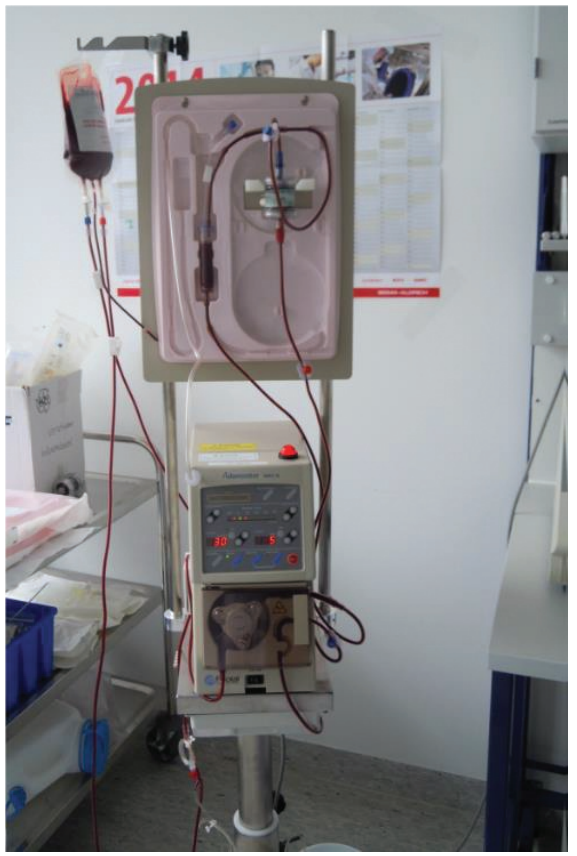

Figure 5.7: In vitro CTC Trap apheresis with full blood from blood donation center with spiked-in SK-BR-3 cells at a concentration of 20 cells $/ \mathrm{ml}$.

For FACS analysis of the CTCTrap eluate (1/2 part of entire eluate) was centrifuged 8 min at 300xg, supernatant was removed and cells were resuspended in $1 \%$ formaldehyde ( $1 \mathrm{~mL}$ ) kept at room temperature (RT) for 15 min to fix the sample. 5mL PBS/BSA 1\% was added, centrifuged 300xg for $8 \mathrm{~min}$. Supernatant was removed and cells were resuspended in 50 $\mu \mathrm{L}$ staining mix containing $4 \mu \mathrm{L}$ anti-CD45-PerCP (Life Technologies, MHCD4531, clone HI30) and $1 \mu \mathrm{L}$ anti-CKpan-NanoParticles 575 (AcZon, clone C11 and AE1/AE3) in PBS/ BSA 1\%/saponin 0.05\%). Staining was performed for $15 \mathrm{~min}$ at 37oC. $5 \mathrm{~mL}$ PBS/BSA was added, centrifuged 300xg for 8 min. Supernatant was removed and cells were resuspended in $2 \mathrm{~mL}$ PBS/BSA, Hoechst 33342 at final concentration of $4 \mathrm{ug} / \mathrm{mL}$ was added and incubated for $15 \mathrm{~min}$ at $37^{\circ} \mathrm{C}$. Sample was kept on ice and measured by FACS immediately, for actual cell counting BD TruCount tubes were used according to manufacturers' instructions.

In one of the 3 DLA samples around 300 Cell Tracker green pre-stained SKBR-3 were spiked in both $18 \mathrm{~mL}$ DLA tubes. Results are summarized in table 5.1. Tables in the figure show the results for CTCTrap, RosetteSep, and direct filtration.

Also depletion of WBC when using CTC Trap device with EpCAM positive selection and depletion when using RosettSep depletion is shown in figure 5.8. 
Table 5.1: Table shows results of 3 experiments where direct filtration, RosetteSep depletion and the CTCTrap device with EpCAM+ selection were compared for the isolation of CTC from DLA of which one sample was spiked with SKBR-3 cells. ${ }^{*}$ counts on sieve after adding CellSave fixative to the unfixed eluate of the CTCTrap device.

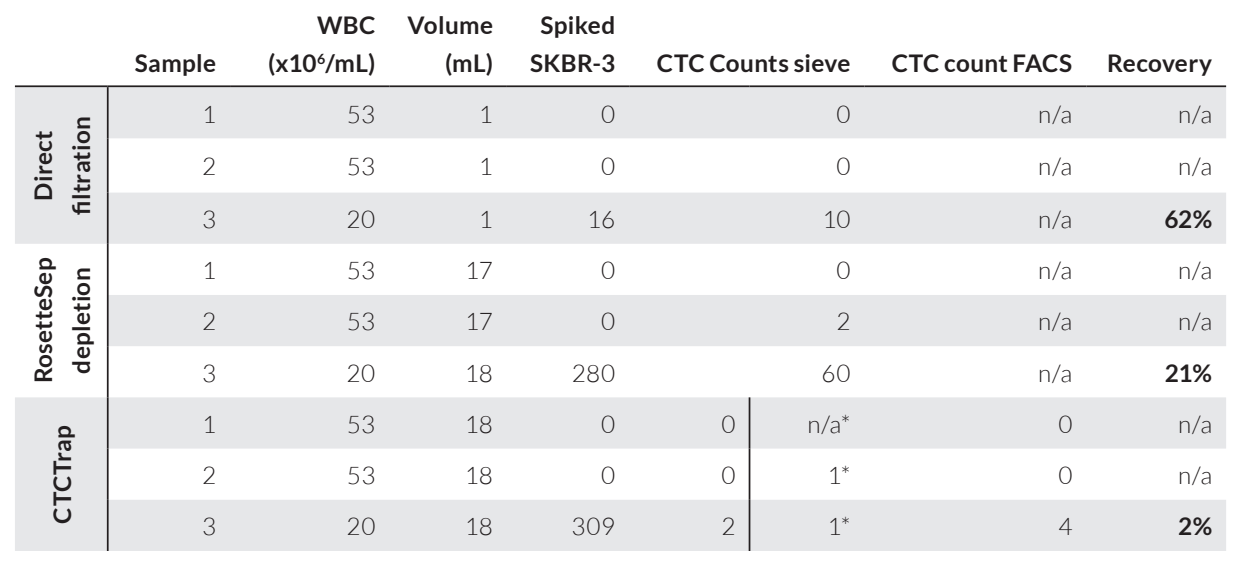

Figure 5.9 shows what the VyCAP filters looked like, with respect to the number of cells on the filter and the staining, after filtration and staining of each sample. All after processing the 3th DLA samples which contains spiked cells. For CTC trap device it means there is about 1.7 log depletion of WBC. 1 CTC was found on sieve in DLA 2. Spiking experiment DLA 3 started

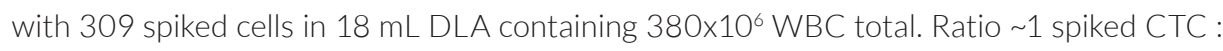
$1 \times 10^{6} \mathrm{WBC}$. The final eluate contained $9 \times 10^{6} \mathrm{WBC}$. A total of 7 spiked CTC (sieve and FACS) was identified. Ratio 1 CTC : 1×106 WBC. The composition or CTC : WBC ratio of start DLA sample and final CTCTrap eluate remained the same, which means there is no enrichment.

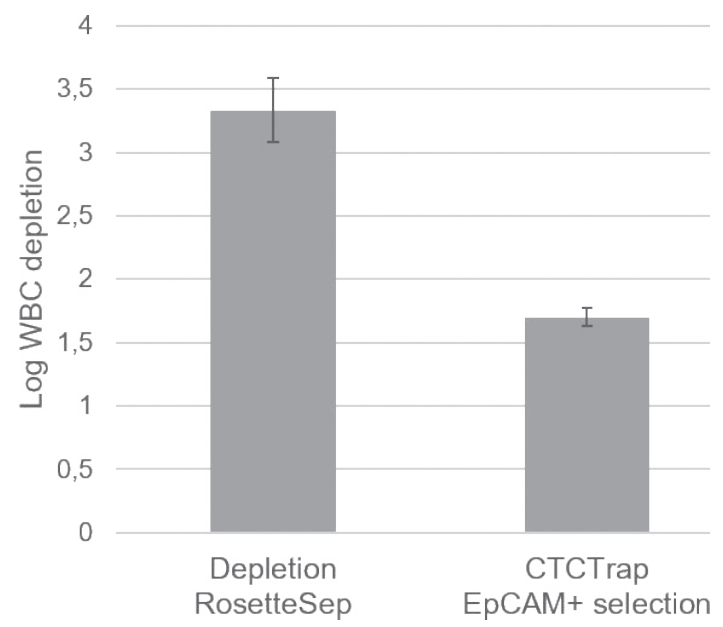

Figure 5.8: Column chart shows depletion rate after depletion by RosetteSep ( $n=3,3.3 \mathrm{log}$ ) and EpCAM selection $(n=3,1.7 \mathrm{log})$. Depletion for RosetteSep was tested in a separate experiment using DLA spiked with LNCaP cells: a recovery of $40-60 \%$ was measured. 

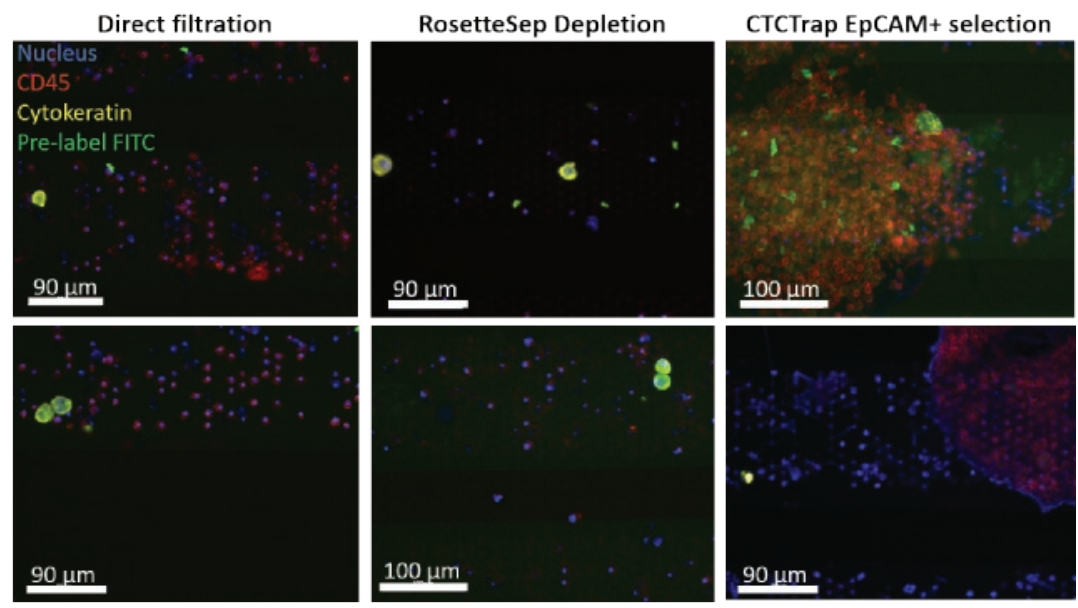

Figure 5.9: Fluorescence Microscope images after each of the enrichment techniques. Indicating cell numbers and sample quality.

\subsection{Leukocyte depletion from blood and leukapheresis products}

In order to explore alternative technologies for the isolation of CTC from blood and leukapheresis product, various methods were tested and evaluated. Here we evaluated the commercially available depletion technologies EasySep, Miltenyi, Dynabeads and RosetteSep and an inhouse developed Ferrofluid depletion protocol.

\section{EasySep}

EasySep is a cell separation technology that makes use of monoclonal antibodies and magnetic particles that can bind to these antibodies after which cells can be magnetically separated. Blood from healthy donors was drawn into EDTA vacutainer tubes. Whole blood samples were spiked with cultured MCF-7 cells, and samples were transferred to $5 \mathrm{~mL}$ FACS tubes. The EasySep human CD45 depletion kit (StemCell Technologies, Cologne, Germany) was performed according to manufacturer's instructions. The purified cells were then quantified with FACS (FACS ARIA II, BD Biosciences) using CountBright ${ }^{\text {TM }}$ absolute counting beads (Invitrogen, Thermo Fisher Scientific, Waltham, MA, USA) according to the manufacturer's instructions.

The EasySep human CD45 depletion kit showed a WBC depletion of 3.8 log. The WBC depletion was calculated by dividing the amount of WBC left after EasySep depletion by the amount of WBC in the start sample before depletion. Each sample that was used consisted of $1 \mathrm{~mL}$ whole blood containing approximately $5 \times 10^{6} \mathrm{WBC} / \mathrm{mL}$ and 10.000 spiked MCF-7 cells. Despite the high amount of WBC depletion the recovery of spiked cells is relatively low ranging 
between 20 - 54\%. The depletion of 3.8 log is very promising and sufficient for processing DLA product with large cell numbers.

\section{Miltenyi}

Column based MACS technology from Miltenyi makes use of a combination of superparamagnetic nano-sized beads and a very high magnetic gradient in their MACS Columns. This allows for the depletion of unwanted cells by labeling and magnetically separating them. For depletion of CD45 positive cells the standard protocol from the manufacturer was used (Miltenyi Biotec, Bergisch Gladbach, Germany) using CD45 microbeads, human (Miltenyi) and a MACS separator (Miltenyi). In short, blood or apheresis product was resuspended in $80 \mu \mathrm{L}$ Cell Buffer (Miltenyi) and incubated with $20 \mu \mathrm{L} \mathrm{CD} 45$ MicroBeads for 15 minutes at $40^{\circ} \mathrm{C}$. Cells were washed with 2 $\mathrm{mL}$ Cell Buffer and resuspended in $500 \mu \mathrm{L}$ Cell Buffer before application on the column. Column was prepared by rinsing with $500 \mathrm{\mu L}$ Cell Buffer. Cells were applied on the column and unbound cells were collected in a tube. Three washing steps with $500 \mu \mathrm{L}$ Cell Buffer followed and total effluent was collected in the same tube. Then, the column was removed from the magnetic Seperator and bound cells were eluted with $1 \mathrm{~mL}$ Cell Buffer using a plunger. All cells were stained with Hoechst and measured with FACS using CountBright absolute counting beads (Invitrogen) according to the manufacturer's instructions.

The efficiency of CD45 depletion using Miltenyi's MACS cell separation beads was determined using blood and apheresis product. First, blood was separated using Ficoll to get rid of the RBC and then processed using the CD45 microbeads. Next to this, apheresis product was used directly without any preprocessing steps. Using blood, a depletion of 2.6 log was reached and for apheresis product 1.8 log depletion of WBC. However, many tumor cells were detected in the bound fraction which means they are lost from the sample (figure 5.10). It seems that the tumor cells are captured by the MicroBeads in some way or they get stuck between the bound WBC. For this reason, we decided not to continue using Miltenyi beads for processing large DLA volumes.

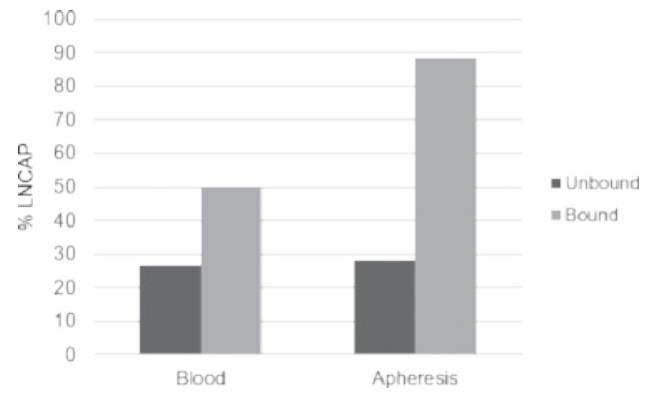

Figure 5.10: The percentage of tumor cells retained in the different fractions after the depletion procedure 


\section{Dynabeads}

Dynabeads ${ }^{\circledR}$ CD45 (Invitrogen) were used according to manufacturer's instructions in combination with the BD Biosciences Imagnet Cell Separation Magnet (BD Biosciences). Depletion was measured using FACS using BD Trucount tubes (BD Biosciences) according to manufacturer's instructions.

Dynabeads were tested in three separate experiments using leukapheresis product. Dynabead depletion resulted in $80 \%(\min =78.8 \%, \max =82.2 \%$ ) of the $\mathrm{WBC}$ being depleted which is 0.7 log of depletion. This is by far not enough for depletion of leukapheresis product were you potentially start with a billion WBC. Therefore it was decided to not continue using this method.

\section{RosetteSep}

EDTA blood or DLA sample was measured with a hematology analyzer. 25.000 LNCAP cells were pre-stained with cell tracker orange (life technologies) and spiked into $1 \mathrm{~mL}$ of EDTA blood or DLA mixed with erythrocytes from EDTA blood to adjust the right erythrocyte to leukocyte ratio. RosetteSep was performed according to protocol using either the RosetteSep CD45 depletion cocktail (StemCell Technologies) or the RosetteSep CTC enrichment cocktail containing anti-CD36 (StemCell Technologies). After the RosetteSep protocol, cells were stained Hoechst 33342 as nuclear dye. Cells were counted with a flowcytometer using countbright absolute counting beads.

Depletion results of whole blood using either the CD45 depletion cocktail or the CTC enrichment cocktail are shown in figure 5.11.a. The CD45 depletion cocktail resulted in a 2.3 log depletion. The CTC enrichment cocktail containing CD36 resulted in a 3.2 log depletion. Next, these two RosetteSep kits were compared on $1 \mathrm{~mL}$ of leukapheresis products. Results show a 3.2 log depletion of WBC from DLA product with the CD45 depletion kit and a 4.2 log depletion with the CTC enrichment kit as shown in figure 5.11.b. Recovery of spiked LNCAP cells was on average $60 \%$.

a

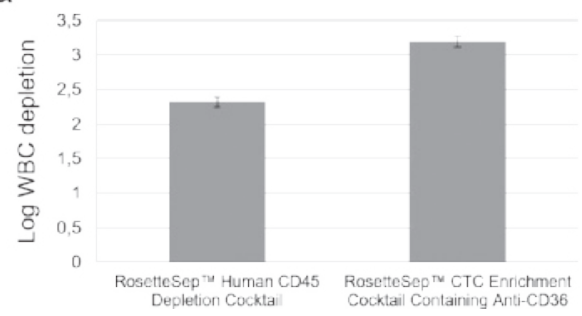

$\mathrm{b}$

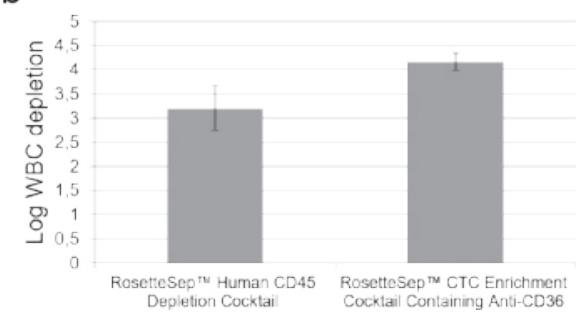

Figure 5.11: Columns showing the depletion of WBC reached with two different RosetteSep kits on blood (a) and on leukapheresis product (b) 


\section{Ferrofluid depletion}

An inhouse ferrofluid depletion protocol was developed. Where ferrofluids bind to antibodies targeting WBC, these WBC can then magnetically be depleted. Biotinylated antibodies against CD45 (eBioscience, or inhouse conjugated), CD56 (eBioscience), CD16, CD2, CD19, CD3 (BD Pharmingen ${ }^{\mathrm{TM}}$ ) and CD14 (CALTAG) were used for depletion by targeting specific WBC populations. These antibodies were used at concentrations as suggested by the manufacturer. Antibodies were added to a whole blood sample and were allowed to react for 15 minutes at RT. Washing using PBS/BSA 1\%, PBS/2\% FBS or CellSearch dilution buffer was used to remove unreacted antibodies. Streptavidin labelled ferrofluids (SAVFF) (BioMagnetic Solutions) were added to a final concentration of $10 \mu \mathrm{g} / \mathrm{mL}$, followed by a 15 min incubation at RT and a 10 min magnetic incubation at RT. Afterwards the sample was carefully transferred to a clean tube using a glass Pasteur pipette. The sample was transferred to a new tube and all fractions were prepared and stored for analysis with the FACSAria ${ }^{\mathrm{TM}}$ II Cell Sorter (BD Biosciences). A schematic overview of the workflow is illustrated in figure 5.12 .

It was hypothesized that ferrofluids, as they are being used within the CellSearch system for the enrichment of EpCAM positive cells, can be used for depletion of unwanted WBC as well. An inhouse ferrofluid depletion protocol was developed and optimized where biotinylated antibodies targeting WBC were used in combination with streptavidin-ferrofluids (FF) to allow for the magnetic depletion of WBC. Several antibodies were tested to determine the optimal antibody cocktail for depletion. Anti-CD45 was used as this targets all WBC, additional Abs targeting subpopulations were added and the percentage of WBC depleted from the sample was determined, results are shown in figure 5.13. In addition to the optimal antibody cocktail optimization also involved defining optimal concentration of streptavidinFF, optimal blocking solution, optimal magnetic incubation time resulting in the protocol as described below in paragraph 5.5 in optimized ferrofluid depletion for leukapheresis samples.

\subsection{Filtration from blood and leukapheresis samples}

In addition to depletion methods for the isolation of CTC also filtration based enrichment methods were evaluated. Filtration methods using a functionalized sieve to enhance capture efficiency and a filtration method where multiple cells are sorted into wells allowing for characterization of the cells in the individual wells after filtration. 


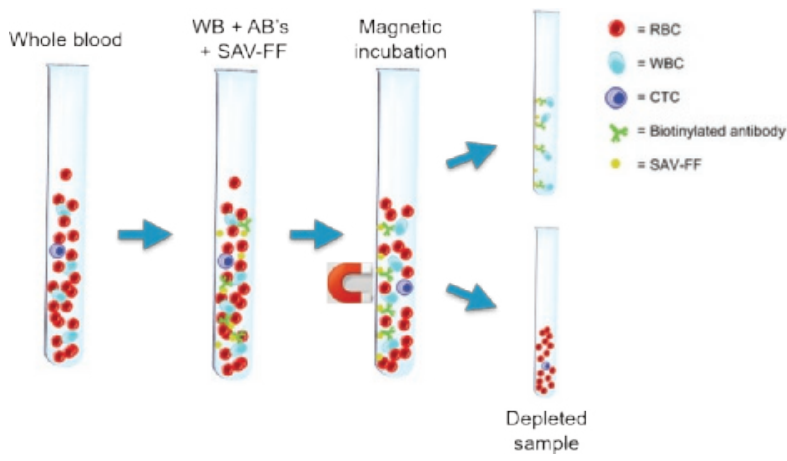

Figure 5.12: Illustration of ferrofluid deletion protocol. In short. biotinylated antibodies and streptavidinferrofluids are added to whole blood. After incubation the cells with bound ferrofluids are removed from the blood, resulting in a depleted sample.

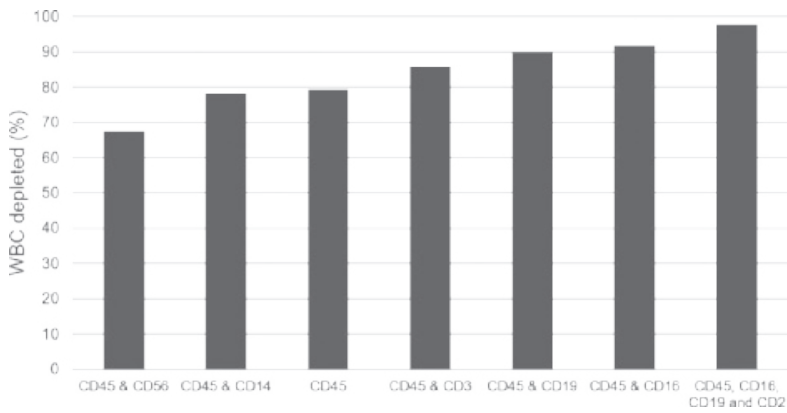

Figure 5.13: WBC depletion when using various antibodies targeting different WBC populations. $(n=2)$

\section{Functionalized microsieves}

\section{Microsieve functionalization}

Silicon nitride microsieves of $1 \mu \mathrm{m}$ thickness containing a poly(acrylic acid) (PAA)-coating (Aquamarijn, Zutphen, The Netherlands) with 5, 7, 10, 15 or $20 \mu \mathrm{m}$ pore sizes were used. The PAA-coated microsieves were incubated in freshly-filtered Milli-Q before activation with EDC/ NHS. 4.6 mg NHS with 800 LL of MES buffer and 25 mg EDC (Sigma Aldrich, Zwijndrecht, The Netherlands) were prepared. Shortly before use, EDC was dissolved in NHS and MES. Twice, $50 \mu \mathrm{L}$ of NHS/EDC was added on the sieves consecutively. The first layer was provided to coat the inside of the pores of the sieves and the second layer to cover the sieve up. The sieves were incubated in EDC/NHS for 30 minutes. The samples were rinsed in acetic acid solution and $50 \mu \mathrm{L}$ of the required $A b$ concentration in sodium acetate was added onto the microsieves. Anti-CD $45 \mathrm{Ab}$ (Janssen diagnostics, Clone HI30) and anti-EpCAM Ab (Janssen diagnostics, Clone VU1D9) were used. The microsieves were incubated in the solution for 1 hour. Next, the microsieves were rinsed with freshly-filtered Milli-Q before $50 \mu \mathrm{L}$ of $0.5 \mathrm{M}$ ethanolamine blocking solution was added. The samples were incubated in ethanolamine for 30 minutes. Afterwards, the microsieves were rinsed with $1 \times$ PBS and $50 \mu \mathrm{L}$ of $1 \times$ PBS was added and the samples were preserved in PBS until use. 


\section{Filtration using functionalized microsieves}

Antibody coated microsieves were rinsed with 50 $\mu \mathrm{lPBS} / 1 \% \mathrm{BSA}$ and then incubated with $50 \mu \mathrm{l}$ $\mathrm{PBS} / 1 \% \mathrm{BSA}$ for 10 minutes. $2 \mu \mathrm{L}$ of whole blood sample was added to $1 \mathrm{~mL}$ of PBS/1\%BSA and pre-stained MCF-7 cells were spiked to mimic epithelial circulating tumor cells. A peristaltic pump was used to filter the sample through the sieve at a constant flow rate of $100 \mu \mathrm{L} / \mathrm{min} .100$ $\mu \mathrm{L}$ of PBS/1\%BSA was filtered through the sieve, followed by $1 \mathrm{~mL}$ of sample and then followed by a washing step with $100 \mu \mathrm{L}$ of PBS/1\%BSA. The PBS/1\%BSA and sample that was filtered through the sieve was collected and filtered through a $2 \mu \mathrm{m}$ sieve at a negative pressure of -10 bar and used for enumerating the cells in the waste. Images were made using a fluorescence microscope and cells were counted using ICY Biolmage analysis software.

CTC can be enriched based on their size by means of filtration. It was hypothesized that the addition of antibodies targeted against antigens expressed on CTC can contribute to a higher capture efficiency. Therefore, microsieves functionalized with Abs were tested. Microsieves were coated with PAA and functionalized with $100 \mu \mathrm{g} / \mathrm{mL}$ Ab. Microsieves were functionalized with anti-EpCAM, anti-CD45 as a negative control or were not functionalized to determine the influence of antibodies on capturing cells. Spiked whole blood samples were diluted in PBS and were filtered through the microsieves. An Acridine Orange staining was used on the microsieve after filtration to stain all entrapped WBCs and MCF-7 cells. Using fluorescence microscopy cells were imaged. The pictures were merged together to obtain a clear image of the position of MCF-7 cells. The Icy image analysis software was used to obtain the number of captured cells. An example image of a microsieve after filtration of blood with spiked cells is shown in figure 5.14 .
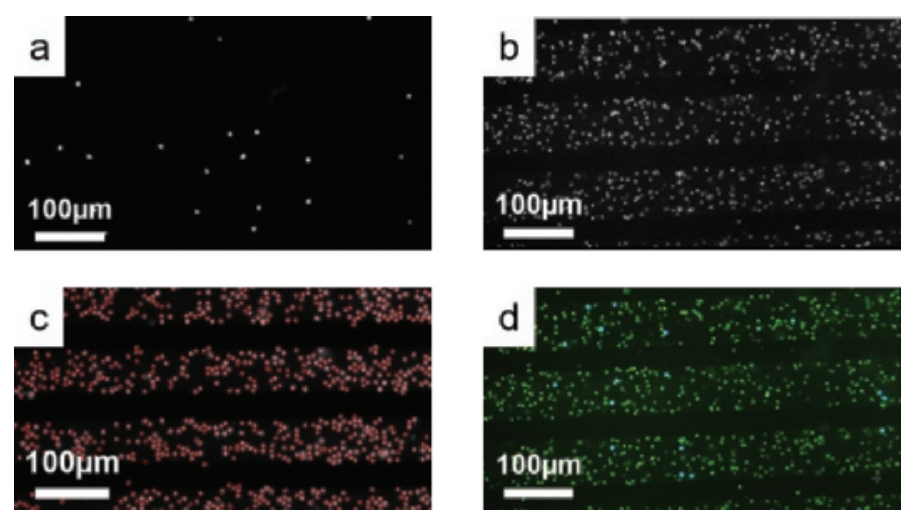

Figure 5.14: Detection of cells on functionalized sieves. a) DAPI pre-stained MCF-7 cells, b) acridine orange positive cells, c) ICY image analysis software, red circles mark cells identified by software and counted as event, d) merged false colored image of DAPI and acridine orange stained cells. 
Microsieves with a pore size of $7 \mu \mathrm{m}, 10 \mu \mathrm{m}, 15 \mu \mathrm{m}$ and $20 \mu \mathrm{m}$ were used to determine the effect of pore size on CTC capture. Cells in the filtrate (here called waste) were determined by counting using FACS. The results of the effect of pore size and antibody coating on capturing MCF-7 cells is shown in figure 5.15 .

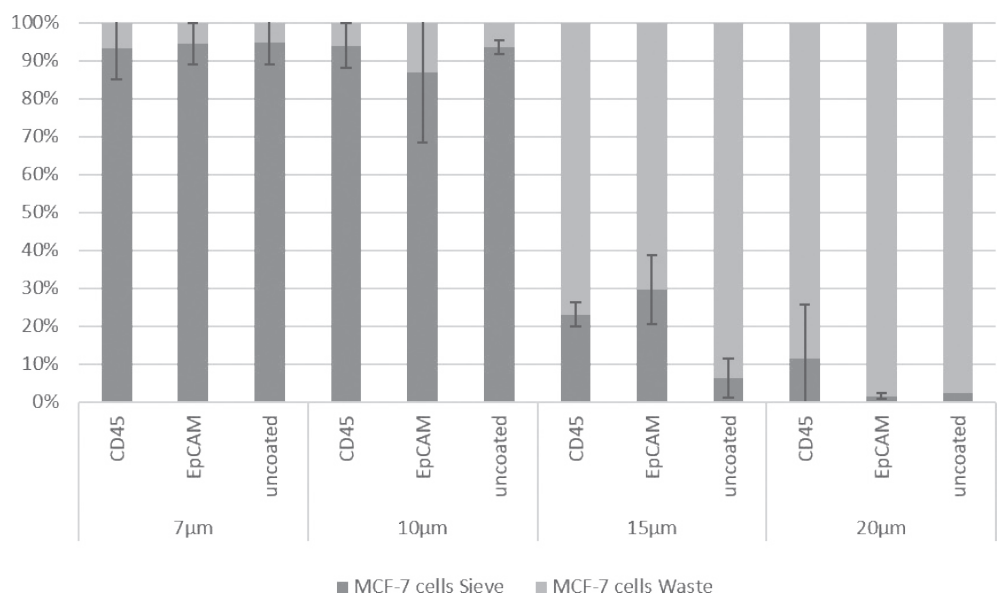

Figure 5.15: The effect of pore size and antibody coating on CTC capture.

Results show that when using smaller pore sizes more cells are being captured, as was expected. When using 7 or $10 \mu \mathrm{m}$ microsieves more than $90 \%$ of the MCF-7 cells are captured and therefore the effect of the antibody coating is negligible. When using $15 \mu \mathrm{m}$ sieves it seems that more cells are captured when an anti-EpCAM coating is present as compared to a microsieve without any antibody coating. Antibody coating on $20 \mu \mathrm{m}$ sieves does not show any additional capture of cells.

\section{Multipores microsieves}

Blood was drawn into Transfix tubes (Cytomark, Buckingham, UK, Cat\#CTC-TVT-09-50). Fresh harvested SKBR-3 or MCF-7 cells were spiked into $9 \mathrm{~mL}$ of Transfix whole blood. The sample was filtered into 8 pore microwells (VyCAP B.V., Deventer, The Netherlands) while applying a -100mbar pressure. Pressure was increased up to -200mbar while flow through microwells decreased. After the entire samples was filtered, $5 \mathrm{~mL}$ PBS was added to the microwell chip to wash. Cells were stained according to manufacturer's instructions (VyCAP, staining on sieve protocol v2.1) using Fix and Perm (Nordic Mubio, Susteren, The Netherlands) and using the following antibodies: anti-Pan Cytokeratin CK-11 PE (Cell Signaling Technology, \#5075S, clone C-11) anti-Pan Cytokeratin AE1/AE3 eFluor 570 (eBioscience, 41-9003-82, clone AE1/AE3) anti-CD45 APC (eBioscience, 17-0459-41 / 42, clone HI30) anti-CD16 
APC (BioLegend, \#302011, clone 3G8). The incubation times were doubled compared to the original protocol to ensure diffusion inside the wells. After staining of the cells inside the wells the microwells were washed using $5 \mathrm{~mL}$ PBS to wash away unbound antibodies. Microwells were imaged using the Puncher System (VyCAP) using the following integration times: DAPI $100 \mathrm{~ms}$, PE $150 \mathrm{~ms}$ and APC $600 \mathrm{~ms}$.

Four experiments were performed using spiked SKBR-3 cells. An average recovery of 52\% inside the 8 pore wells was measured. Three experiments using spiked MCF-7 cells showed an average recovery of 51\%. The results of individual experiments are shown in table 5.2.

Table 5.2: Recovery results of individual experiments of filtration of spiked whole blood samples into 8pore micro

\begin{tabular}{l|lll}
\multicolumn{1}{l|}{ Cell line } & Recovery rate on-chip & Filtration time & mbar \\
\hline SKBR-3 & $69 \%$ & $04: 38$ & 200 \\
\hline MCF-7 & $51 \%$ & $01: 37$ & 150 \\
& $44 \%$ & $01: 12$ & 100 \\
\hline
\end{tabular}

Results show that filtration of whole blood into 8 pore microwell chips is possible. Also the staining protocol used is feasible and results in a clear staining of both CD45 positive cells and spiked tumor cells. Typical images are shown in figure 5.16. However, cell staining is not equal across the entire chip. At the edges of the microwell chip more non-specific staining is detected making identification of tumor cells more difficult. Optimization of the staining protocol and washing steps are needed to improve this.

a

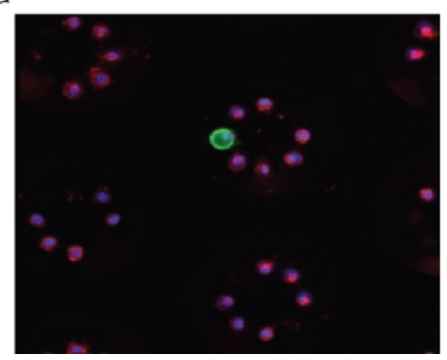

\section{b}

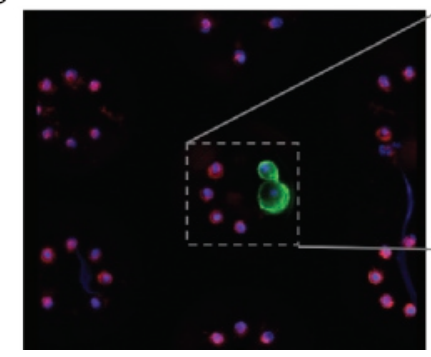

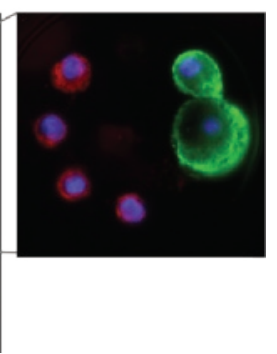

Figure 5.16: Typical image of microwells containing upto 8 cells. A) shows 4 microwells of which 1 contains 1 tumor cell and 6 WBC and one pore is still free. B) shows several microwells with one microwell containing a double tumor cell and 4 WBC. Blue $=$ Nucleus, Green $=$ Cytokeratin, Red $=$ CD45 + CD16 


\subsection{Leukocyte depletion from large volumes}

\section{RosetteSep WBC depletion large volumes}

The RosetteSep protocol was adjusted and optimized for the depletion of large volumes of leukapheresis product containing very high amounts of cells. This was first done testing various WBC concentrations in starting sample, to determine the maximum amount of cells at which the procedure still shows sufficient depletion. Log depletions for low, medium and high WBC concentrations are shown in table 5.3

Table 5.3: Depletion efficiency using low, medium and high WBC concentrations

\begin{tabular}{llll} 
Sample & WBC at start & Total WBC after depletion & Log depletion \\
\hline Ficoll only & $2,3 \times 10^{7}$ & 681048 & $\sim 1$ \\
\hline RosetteSep low WBC & $2,3 \times 10^{7}$ & 19544 & 3,1 \\
RosetteSep medium WBC & $4,6 \times 10^{7}$ & 11728 & 3,6 \\
RosetteSep high WBC & $6,6 \times 10^{7}$ & 30624 & 3,3
\end{tabular}

Next, the RBC to WBC ratio was optimized. According to manufacturer's instructions a minimal ratio of at least 30 - 50 RBC per nucleated cell should be present. ${ }^{4}$ Experiments were performed using RBC:WBC ratios ranging from 20:1 - 100:1. Results showed that a lower depletion was reached when using a RBC:WBC ratio lower than 30:1. Therefore it was decided to continue using a minimal ratio of 40:1, also to compensate any interpatient variability regarding depletion efficiency.

Several approaches to stain the depleted product after RosetteSep depletion have been tested. The two main approaches tested were 1) filtration onto a $5 \mu \mathrm{m}$ VyCAP sieve followed by staining on sieve 2) staining of cells in solution followed by filtration onto a $5 \mu \mathrm{m}$ VyCAP sieve. Within the staining protocol several parameters were tested e.g. fixation, concentration of permeabilization reagent, incubation times etc. The two approaches were tested on depleted product from whole blood and DLA products.

Results showed a lot of variation in the samples which were stained using approach 2, where cells were first stained followed by filtration. Overall very few cells were found on sieve after filtration of stained cells compared to samples processed according to approach 1 were cells were filtered followed by staining on sieve. Figure 5.17 shows an example image of a sieve after filtration of cells stained in solution (left) and an image of a sieve with a depleted sample which was filtered followed by staining on sieve (right). 
Images show that very few cells are presents in the sample stained in solution and the cells which are present are very big and look like they are 'blown up'. This was seen in many samples stained and filtered this way. Several variations in fixation have been tested to avoid this but no solution was found. The few cells might be due to the fact that the cells are already permeabilized during the staining procedure and by filtering these permeabilized cells the cells get destroyed and pulled through the pores of the filter. Decided was to continue with the approach were the sample was filtered followed by staining on sieve. Optimization of RosetteSep depletion resulted in an standard operating procedure (SOP) for leukocyte depletion of DLA within the CTCTrap consortium. The SOP is shown as supplementary data. The protocol as developed here was further evaluated on clinical samples of which results are shown in chapter 6 and chapter 7 of this thesis.
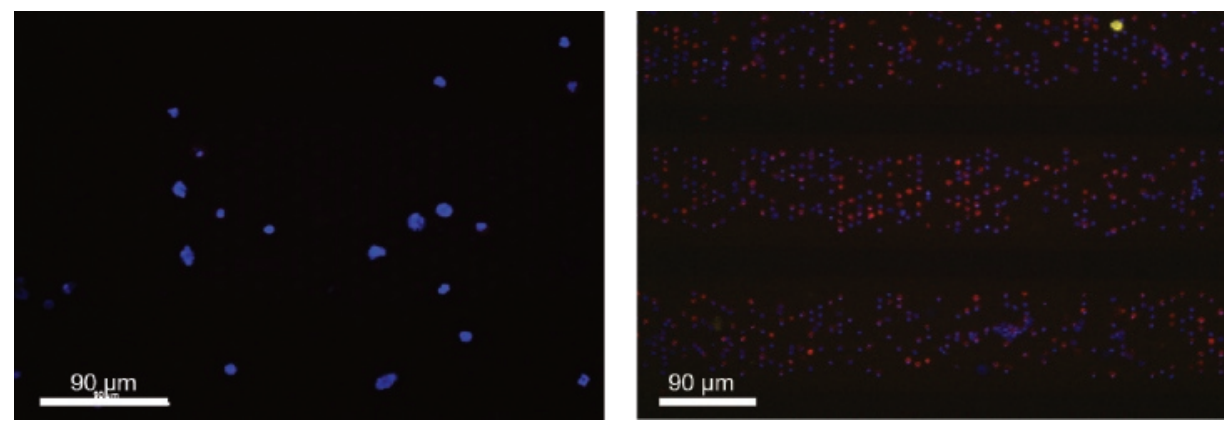

Figure 5.17: Typical images of microsieve with stained cells. On the left cells stained in solution followed by filtration onto a microsieve. On the right cells filtered onto a microsieve followed by staining on sieve.

\section{Optimized ferrofluid depletion for leukapheresis samples}

The ferrofluid depletion protocol was scaled up, minor changes had to be made resulting in the following procedure for the depletion and analysis of CTC in DLA depleted by ferrofluids.

Biotinylated anti-CD45 (inhouse conjugated), CD2, CD16 and CD19 (BD Pharmingen ${ }^{\mathrm{TM}}$ ), was added to the leukapheresis sample at a final concentration of $4 \mu \mathrm{g} / \mathrm{mL}$ and was incubated for 15 min. at RT. CellSearch dilution buffer was added and the sample was centrifuged at 800xg for 10 min. Streptavidin labelled ferrofluids (SAV-FF) (BioMagnetic Solutions, State College, PA, USA) were added to a final concentration of $18 \mu \mathrm{g} / \mathrm{mL}$, followed by a $15 \mathrm{~min}$ incubation at RT and a 10 min magnetic incubation at RT after which the unbound fraction was carefully removed with a Pasteur pipette using a syringe pump (speed: $2 \mathrm{~mL} / \mathrm{min}$ ). For enumeration the samples were processed using filtration or using CellSearch. 
For CellSeach analysis the depleted sample was transferred to a conical tube and the sample was processed using a CTC kit according to manufacturer's instructions. For analysis by filtration the depleted sample was filtered onto a VyCAP filter according to manufacturer's instructions using CD45-PerCP (Life Technologies, MHCD4531, clone HI30) and CK-11 PE (Cell Signaling Technology, \#5075S, clone C-11) anti-Pan Cytokeratin AE1/AE3 eFluor 570 (eBioscience, 41-9003-82, clone AE1/AE3). In addition to this the WBC concentration was measured using a hematology analyzer before and after ferrofluid depletion to calculate the log depletion.

In total 20 leukapheresis samples were processed from patients with non-small cell lung cancer or breast cancer. On average $7.8 \mathrm{~mL}$ ( $\mathrm{min}=4.0 \mathrm{max}=13.5$ ) of DLA with an average WBC concentration of $114 \times 10^{6} / \mathrm{mL}$ ( $\min =65$, $\max =198$ ) was depleted of WBC. This resulted in an average depletion of $83 \%$ ( $\min =35, \max =99)$, which is similar to 0.7 log depletion. The individual depletion of each sample process is plotted in figure 5.18, showing the wide range of depletion efficiency.

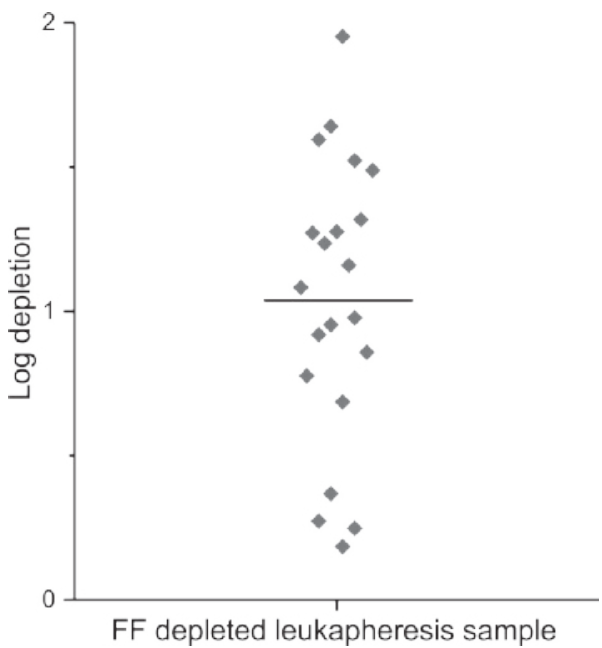

Figure 5.18: Log depletion of WBC plotted for each of the 20 patients samples processed using the ferrofluid depletion protocol.

An average CTC recovery of only $8 \%$ ( $\min =0 \%, \max =34 \%$ ) compared to the amount of CTC detected using CellSearch was achieved. Results show that the majority of CTC (average >90\%) is lost, resulting in very low recovery rates. Therefore it was decided not to continue with this approach. 


\subsection{Discussion}

The CTCTrap consortium we aimed to use therapeutic apheresis, as a way to collect CTC from the blood of cancer patients. The SME Leukocare was assigned to develop this CTCTrap device. Development started with CTC capture and release chemistry followed by the production of a bench scale circulation module, this model was then scaled up and testing of the final CTC apheresis device was performed. Key challenges during the development were minimizing non-specific binding of cells to tubing, housings etc. Minimizing binding of non-specific cells to the antibody matrix and minimizing sedimentation of cells in dead space. Also, damage to cells by pumps, sheer stress and other mechanical forces had to be avoided. Results obtained by testing the bench scale CTCTrap device showed that most of these challenges were not conquered. Data as shown in figure 5.6 shows that $33 \%$ of the cells get lost somewhere while processing samples using the CTCTrap device. This loss can very well be assigned to cell sedimentation in dead space or cells being damaged or destroyed due to mechanical stress. The data in this figure also shows that $62 \%$ of the cells already leave the system before the sample has the change to properly incubate with the matrix as the sample volume of $100 \mathrm{~mL}$ does not match the volume of the bench scale model. In the final scaled up version of the CTCTrap device this volume issue was overcome. However, still the problem of cell loss remained. Another major challenge was the non-specific binding of many WBC to the matrix. Therefore after emptying the CTCTrap device a large background of WBC remained. The fluorescence microscopy images in figure 5.9 show the large amounts of WBC that needed to be dealt with after EpCAM+ selection with the CTCTrap device. The direct filtration images give an idea of the pure DLA sample after filtration, the depleted sample shows the number of cells after filtration of $18 \mathrm{~mL}$ of DLA product after depletion of WBC using RosetteSep. The images after EpCAM+ selection show the cells after filtration of $18 \mathrm{~mL}$ of DLA product that was processed using the CTCTrap device. These images also show that clumps of cells are presents after processing with the CTCTrap device making the analysis and enumeration of CTC very difficult. Recovery results show that the recovery of spiked tumor cells is very low (2\%). As recovery is very low and high WBC numbers are present still in the processed sample no real enrichment of tumor cells take place. These results indicate that this CTCTrap device was not suitable for processing large volume of DLA product and it was decided to continue using alternative techniques.

During the development of the CTCTrap device it was decided to continue using apheresis products rather than using the device directly attached to the patients. Leukapheresis product is frequently used to isolate mononuclear cells (MNC) from blood for various applications 
including stem cell harvest. Leukapheresis enables the extracorporeal continuous densitybased cell separation of MNC with a density of 1.055-1.08 g/mL from several liters of blood. ${ }^{5}$ It was hypothesized that an average leukapheresis product consists of $25 \times 10^{8} \mathrm{MNC}$ in a volume of roughly $40 \mathrm{~mL}$ and therefore represents liters of blood. This serves as a source of CTC but enrichment or depletion of unwanted cells is necessary for one to be able to detect the cells of interest.

As alternative to the CTCTrap device several other techniques were evaluated for their ability of processing large leukapheresis volumes and large cell numbers followed by detection and enumeration of CTC. Accurate detection of rare events such as CTC requires the ability to detect single cells with specific characteristics against a background of other cells. Detection of CTC in a blood sample is limited by the sensitivity and specificity of the biomarkers used to identify the CTC in a background of other blood cells. In order to maximize sensitivity in rare event detection, most assays that aim at accurately detecting events below a frequency of 1: 100,000 generally apply a sample enrichment step to increase the likelihood of finding the events of interest. Enrichment approaches include either positive selection or negative selection using immunomagnetic methods, density gradient centrifugation, and/or filtration based on cell size and stiffness. ${ }^{6}$ Positive selection involves the use of an antibody specifically targeting the CTC (e.g. anti-EpCAM) attached to magnetic beads which can be used for

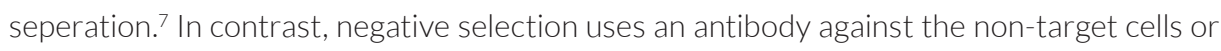
background leukocytes. Positive selection approaches usually result in fairly high purity of the sample recovered, since only CTC will be selected. However, the recovery of CTC may be lower than in negative selection approaches, since CTC that have low or absent expression of EpCAM (or other positive selection markers) may be lost. ${ }^{8}$ In addition, enrichment methods that employ a minimum number of processing steps are best in order to minimize CTC loss. Results of the techniques evaluated next to the CTCTrap device are summarized in table 5.4. Aimed was for at least a 3-log depletion of WBC. As the goal is to process half of the product $\left(18 \mathrm{~mL}\right.$ ) obtained through leukapheresis, a starting sample contains $\sim 10 \times 10^{8} \mathrm{MNC}$. After 3 log depletion of unwanted WBC this means $10 \times 10^{5}$ cells are left which is the amount of background cells where reasonable detection of rare CTC is possible. ${ }^{3,9,10}$ This requirement results is the fact that only the EasySep CD45 depletion kit and the RosettSep kits achieve in a sufficient amount of depletion. As the recovery of spiked tumor cells using the Easysep kit was lower compared to RosetteSep it was decided to continue using the RosettSep CTC enrichment kit incl. CD36 as this has the highest depletion rate overall. 
Table 5.4: Depletion and tumor cells recovery for each of the evaluated technologies to process leukapheresis produ

\begin{tabular}{l|ll} 
Method & Log WBC Depletion & Tumor Cell Recovery \\
\hline CTCTrap & 1.7 & $<5 \%$ \\
\hline Easysep CD45 Depletion Kit & 3.8 & $20-54 \%$ \\
\hline Miltenyi CD45 Beads & $1.8-2.6$ & $50-88 \%$ \\
\hline Dynabeads CD45 & 0.7 & $\mathrm{~N} / \mathrm{A}$ \\
\hline RosetteSep CD45 Depletion Kit & $2.3-3.2$ & $60 \%$ \\
\hline RosetteSep CTC Enrichment Kit Incl. CD36 & $3.2-4.2$ & $60 \%$ \\
\hline Ferrofluid Depletion & 1.7 & $\mathrm{~N} / \mathrm{A}$ \\
\hline
\end{tabular}

The RosetteSep protocol was optimized for processing leukapheresis products. Main challenges were the high number of total cells and the low concentration of RBC which are necessary for forming the rosettes and therefore successful depletion. Paragraph 5.5 describes this optimization, resulting in assigning the maximum cell concentration at $70 \times 10^{6} / \mathrm{mL}$ and a WBC : RBC ratio of 1: 40. This ratio is achieved by adding RBC, isolated from EDTA blood tubes from the same patient, to the leukapheresis product. The depleted product is filtered onto a $5 \mu \mathrm{m}$ filter and stained using DAPI, Cytokeratin as inclusion marker and CD45 as an exclusion marker, followed by fluorescence microscopy for CTC enumeration. The established protocol, was executed and evaluated using patient samples in chapter 6 and chapter 7.

Next to this protocol, based on the commercially available RosettSep kit, an inhouse ferrofluid protocol was established. Ferrofluids as they are being used in the CellSearch system, where CTC are enriched using ferrofluids bound to anti-EpCAM targeting the EpCAM antigen present on CTC, were used to target WBC and allowing for the magnetic separation of these cells. The protocol was optimized by finding the optimal antibody cocktail targeting different WBC populations, also optimal concentrations and incubation circumstances were determined. This protocol resulted in a depletion of $1.7 \mathrm{log}$. The optimal protocol as described in 5.5 was tested on 20 leukapheresis from metastatic breast and non-small cell lung cancer patients. Results show that the depletion of WBC in these patients showed a large of variation ranging from 0.2 to $2.0 \mathrm{log}$. The relatively low depletion rate and large variation is most likely due to inter and intra operator differences. As pipetting while using a magnetic field for separating the cells is very critical for example disturbance of the liquid can resuspend cells in the fluid again after magnetic separation. Automation of the workflow pipetting steps will most likely reduce these variations. Also recovery of tumor cells was very low. CellSearch results of processing a small aliquot of leukapheresis product was used to calculate CTC recovery. These low recovery's might also be due to pipetting variation. In addition, gravitational forces result in cells settling down at the bottom of the reaction tube during incubation. Depending on 
pipetting performance these cells are not recovered, thereby contributing to CTC loss. Overall at the moment the ferrofluid depletion protocol does not show sufficient performance to successfully process a leukapheresis sample. However, automatization of the pipetting steps probably can improve a lot regarding depletion and recovery numbers.

In addition to the techniques described above, filtration based approaches were tested, The goal here was to use functionalized sieves to increase capture efficiency while increasing pore size, which would allow for processing larger cell numbers. However, results show that the additional capture of tumor cells does not compensate for the percentage of cells lost due to larger pore size. Overall less than a 10\% additional capture of tumor cells is achieved when functionalizing sieves using anti-EpCAM. As large pores are needed to be able to process large numbers of cells as present in leukapheresis product this approach is not feasible. Wat was tested in addition were 8 pore microwells. Microwells are used for the isolation of single cells from enriched samples. ${ }^{11,12}$ As these microwells are optimized for processing the enriched product of a single tube of blood the enriched, or depleted, leukapheresis sample contains too many cells for successful use. An enriched blood sample contains on average between 5.000 and 50.000 cells, as mentioned before, an enriched leukapheresis sample after 3 log depletion still holds $10 \times 10^{5}$ cells. Therefore 8 pore microwells could be the solution as 8 times the amount the cells can be processed compared to traditional single pore microwells.

Overall, processing large volumes with large cell numbers remains very challenging. Here methods were developed to successfully process leukapheresis products. This allows for access to higher CTC counts as compared to traditional isolation from a single tube of blood or small volumes of DLA. Additional depletion steps can indeed lower the leukocyte background but also will lead to additional CTC losses. At present we are evaluating a novel approach which is based on the concept "reuse of ferrofluids". ${ }^{13}$ The basis of the concept is that only a very small number of antibody labelled ferrofluids are binding to the CTC thus permitting the use of the ferrofluids not binding to a target to capture CTC. This may enable the processing of large sample volumes with no loss of CTC and strongly reducing the number of captured leukocytes. 


\section{References}

1 E. Heitzer, M. Auer, C. Gasch, M. Pichler, P. Ulz, 7 M. Cristofanilli, G. T. Budd, M. J. Ellis, A. Stopeck, J. E. M. Hoffmann, S. Lax, J. Waldispuehl-Geigl, O. Mauermann, C. Lackner, G. Hofler, F. Eisner, H. Sill, H. Samonigg, K. Pantel, S. Riethdorf, T. Bauernhofer, J. B. Geigl and M. R. Speicher, Cancer Res., 2013, 73, 2965-2975.

Matera, M. C. Miller, J. M. Reuben, G. V Doyle, W. J. Allard, L. W. M. M. Terstappen and D. F. Hayes, N. Engl. J. Med., 2004, 351, 781-791.

8 A. M. Sieuwerts, J. Kraan, J. Bolt, P. van der Spoel, F. Elstrodt, M. Schutte, J.W. M. Martens, J.-W. Gratama,

2 K. Pantel and C. Alix-Panabieres, Cancer Res., 2013, S. Sleijfer and J. A. Foekens, JNCI J. Natl. Cancer Inst., 73,6384-6388. 2009, 101, 61-66.

3 N. H. Stoecklein, J. C. Fischer, D. Niederacher and L. W. M. M. Terstappen, Expert Rev. Mol. Diagn., 2016, 16, 147-164.

K. C. Andree, G. van Dalum and L. W. M. M. Terstappen, Mol. Oncol., 2016, 10, 395-407.

10 D. Recktenwald, R. A. Hoffman, H. J. Gross, B. Verwer and D. Houck, Proc. Natl. Acad. Sci., 2006, 92, $537-$ 541.

5 J. C. Fischer, D. Niederacher, S. A. Topp, E. Honisch, S. Schumacher, N. Schmitz, L. Zacarias Föhrding, C. Vay, I. Hoffmann, N. S. Kasprowicz, P. G. Hepp, S. Mohrmann, U. Nitz, A. Stresemann, T. Krahn, T. Henze, E. Griebsch, K. Raba, J. M. Rox, F. Wenzel, C. Sproll, W. Janni, T. Fehm, C. A. Klein, W. T. Knoefel and N. H. Stoecklein, Proc. Natl. Acad. Sci. U. S. A., 2013, 110, 16580-5.

6 A. L. Allan and M. Keeney, J. Oncol., 2010, 2010, 426218.

11 K. Andree, F. Abali, L. Oomens, F. Passanha, J. Broekmaat, J. Kraan, P. Mendelaar, S. Sleijfer and L. Terstappen, Int. J. Mol. Sci., 2019, 20, 477.

12 J. F. Swennenhuis, A. G. J. Tibbe, M. Stevens, M. R. Katika, J. van Dalum, H. D. Tong, C. J. M. van Rijn, L. W. M. M. Terstappen, H. Duy Tong, C. J. M. van Rijn and L. W. M. M. Terstappen, Lab Chip, 2015, 15, 3039-46.

13 M. Stevens, F. T. Nijsink, G.van Dalum, J. J. Broekmaat, A. G. J. Tibbe and L. W. M. M. Terstappen, 2018 PCT/ EP2018/059607, US 62/485,414. 


\section{Supplementary data}

\section{SOP RosetteSep DLA}

Leukocyte depletion followed by CTC detection

\section{Sample}

- $18 \mathrm{~mL}$ diagnostic leukapheresis product (DLA) (Cellsave fixated)

- $\quad 2 \times 10 m L$ EDTA blood

\section{Materials}

\section{RosetteSep}

- RosetteSep ${ }^{\mathrm{TM}}$ CTC Enrichment Cocktail Containing Anti-CD36 (Stemcell Technologies Catalog\# 15167)

- Ficoll-Paque PLUS (GE Healthcare, Product code:17-1440-02)

- Phosphate buffered saline with 2\% fetal bovine serum (PBS/ 2\% FBS)

- $50 \mathrm{~mL}$ tubes

- Centrifuge

- Hematology analyzer (e.g. Coulter Counter)

\section{Filtration and staining}

- Filtration station (VyCAP)

- Flltertube with sieve (VyCAP)

- Sieve standard including sponge (VyCAP)

- PBS/BSA 1\%/saponin 0.05\%

- PBS/BSA 1\%

- 1 XPBS

- $1 \%$ Formaldehyde in $1 \times$ PBS

- Staining solution:

> Anti-CD45-PerCP (Life technologies,MHCD4531, clone:HI30): final concentration 4ug/mL. (2uL from 100ug/mL stock)

> Anti-CKpan-NanoParticles 575 (Aczon, clone C11 and AE1/AE3): final concentration 3,5ug/mL. (1uL from stock)

Adjust to a total volume of 50uL with PBS/BSA 1\%/saponin 0,05\% (47uL).

- Mounting medium: ProLong Diamond antifade Mountant with DAPI (Life Technologies, cat.no.:P36971)

- Coverslips: $2 \times 0.85 \mathrm{~cm}^{2}$ custom cut at Menzel-Gläser, Saarbrückener, Germany 


\section{Method}

\section{RosetteSep}

- Concentrate the red blood cells (RBC) in the EDTA tubes by centrifuging the two EDTA tubes 8 minutes at $800 \times$ G. After centrifugation remove the plasma and buffycoat. Mix the tube with only RBC by tilting the tube several times.

- Measure the white blood cell concentration (WBC) in the DLA product using a hematology analyzer.

* If WBC concentration of DLA is $>70 \times 10^{6} / \mathrm{mL}$ dilute DLA to $70 \times 10^{6} \mathrm{WBC} / \mathrm{mL}$ using $\mathrm{PBS} / 2 \%$ FBS and continue the protocol with $18 \mathrm{~mL}$ of this diluted DLA product.

- Measure the RBC concentration of the concentrated RBCs using hematology analyzer. (if concentration is too high for accurate measurement dilute 1:1 using 1xPBS.

- The WBC to RBC ratio should be 1:40. Calculate the amount of RBC that need to be added to the DLA using the following calculation:

$>18 \mathrm{~mL} \times($ WBC Concentration $)=\mathrm{X}$

$>40 \times X=Y$

$>\quad \frac{\mathrm{Y}}{\text { (RBC Concentration) }}=\mathrm{mL} \mathrm{RBC}$ to be added

- Add the calculated amount of RBC to $18 \mathrm{~mL}$ DLA and measure the WBC and RBC concentration of this mixture.

- RBC to WBC ration should be at least 40:1, to confirm: $\frac{\text { RBC concentration }}{\text { WBC Concentration }}=>40$

- Add 50uL of RosetteSep ${ }^{\text {TM }}$ CTC Enrichment Cocktail Containing Anti-CD36 reagent for each $1 \mathrm{~mL}$ of sample. (e.g. $18 \mathrm{~mL} \mathrm{DLA}+3 \mathrm{~mL}$ $\mathrm{RBC}=21 \mathrm{~mL}$ in total à $1050 \mathrm{uL}$ of reagent to be added) Mix well by vortexing. (Figure 1. Step 1)

- Incubate 20 minutes at room temperature. (Figure 1. Step 2)

- After incubation, dilute the sample with an equal volume of PBS $+2 \% \mathrm{FBS}$ and mix gently.

- Prepare two 50mL tubes with each containing $15 \mathrm{~mL}$ of Ficoll-Paque PLUS as a density gradient. Divide the sample over the two tubes by layering $1 / 2$ part of the sample over the density gradient in each $50 \mathrm{~mL}$ tube. (Figure 1. Step 3) Note: Be careful to minimize mixing of the density gradient medium and sample.

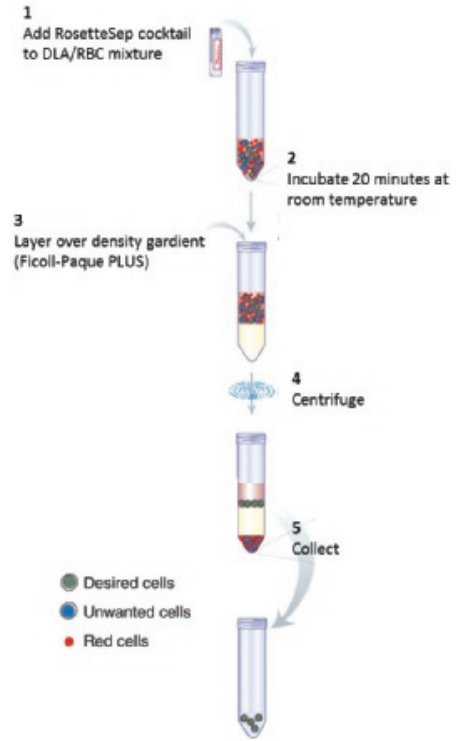

Figure 1: Schematic worksflow RosetteSep 
- Centrifuge for 20 minutes at $1200 \times$ G at room temperature with the brake off. (Figure 1. Step 4)

- Collect the enriched cells from the density gradient medium - plasma interface. Pipet the collect cells into a 50mL tube. (Figure 1. Step 5) To make collection more easy, first remove half of the fluid on top of the desired cells by pipetting and discard, then continue with collection of desired cells.

Note: Sometimes it is difficult to see the cells at the interface. It is advisable to remove some of the density gradient medium along with the enriched cells in order to ensure their complete recovery.

- Wash the cells by adding 3 volumes of PBS/2\% FBS to the volume of the collected cells.

- Centrifuge for 8 minutes at $300 \times G$ at room temperature.

- Remove supernatant, do not disturb the cells and leave about 100uL on top of the cells.

- Resuspend the cells in $18 \mathrm{~mL} 1 \times$ PBS

- For analysis continue with Filtration and staining.

\section{Filtration and staining}

- Connect filtration tube containing the sieve onto the filtration station. (Figure 2)

- Pressure is OFF: apply the cells in PBS onto the filter.

- Put the pressure ON, and keep on to filter the sample, but do not let the sieve run dry.

- Shut the pressure OFF when the entire sample is filtered, but do not let it run dry completely.

- Remove the sieve from the filtration station.

- Place the sieve in a sieve standard (Figure 3) and remove any remaining solution on the sieve by gently pressing down the sieve down on the sponge.

- Wash the sieve once with $50 \mu \mathrm{L}$ PBS/ BSA 1\%

- Apply $50 \mu \mathrm{L}$ of staining solution and incubate $15 \mathrm{~min}$ at $37^{\circ} \mathrm{C}$ in a humidified environment.

Note: During incubation, make sure the sieve does not touch the sponge or any other surface.

- Remove the solution by gently pushing the sieve down.

- Wash the sieve once with $50 \mu \mathrm{L}$ PBS/BSA $1 \%$.

- Apply 50uL PBS/BSA 1\% and incubate 5 minutes at RT to remove unbound antobodies.

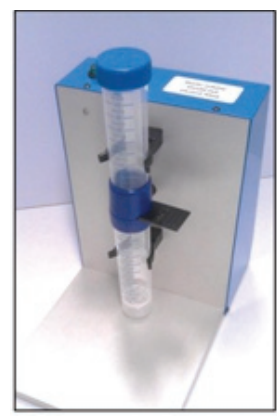

Figure 2: $V y C A P$ filtration station and filtration tube containing sieve

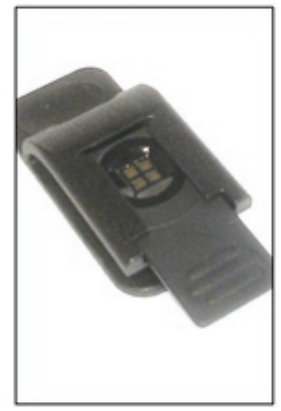

Figure 3: Sleve in sieve standard

- Fix the cells with $50 \mu \mathrm{L} 1 \%$ formaldehyde for 10 min at RT. 
- Remove the solution by gently pushing the sieve down.

- Wash the sieve two times with $50 \mu \mathrm{L}$ PBS/BSA $1 \%$.

- Turn the sieve upside down in the staining holder. Pipet $20 \mu \mathrm{L}$ ProLong ${ }^{\circledR}$ mounting medium. By moving your pipet on the edge of every lane, the lanes will fill with mounting medium (this requires in total $\sim 10 \mu \mathrm{L}$ medium). This filling of the lanes is visible by eye, but takes a little patience and some practice. Apply the coverslip on the backside of the microsieve.

- Turn the sieve back in the right position. Apply the remaining $(>10 \mu \mathrm{L})$ mounting medium gently on the microsieve. Apply the coverslip and prevent any air bubbles.

- Analyse the samples with the fluorescence microscope. The mounting medium is hardened after several hours. Store the samples at $-20^{\circ} \mathrm{C}$.

\section{Scanning}

- Use the following filter cubes for scanning of the microsieves on a mercury arc fluorescence microscope (see Optical Filters document for more information):

\begin{tabular}{llll} 
Filter cube & Excitation $(\mathbf{n m})$ & Dichroic $(\mathbf{n m})$ & Emission $(\mathbf{n m})$ \\
\hline DAPI & $377 / 50$ & 409 LP & 409 LP \\
\hline PE & $543 / 22$ & 562 LP & $593 / 40$ \\
\hline PerCP & $435 / 40$ & 510 LP & $676 / 29$
\end{tabular}

- Use a 20X objective, with minimal 0.45NA.

- Define the optimal exposure time for the scanning of the microsieves. Use this exposure time for every sample. Make sure the lamp is not too old and beware of bleaching the sample. 
Techniques to Isolate CTC from Large Blood Volumes 

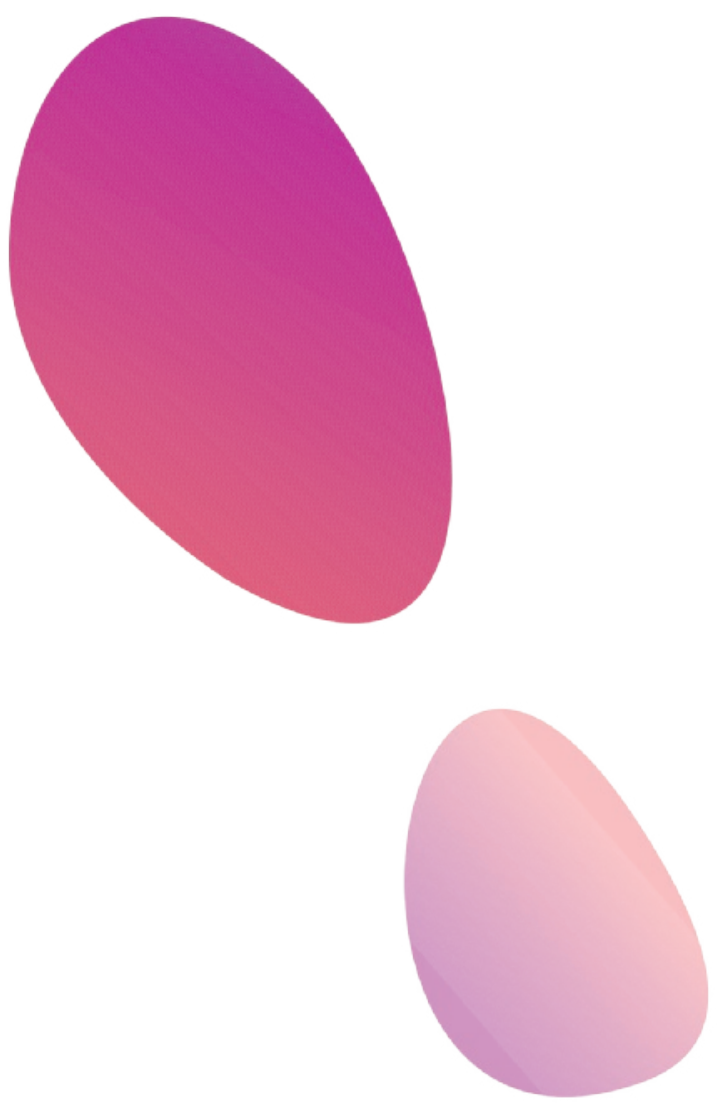


\section{CHAPTER 6}

Towards a Real Liquid Biopsy in Metastatic Breast and Prostate

Cancer: Diagnostic LeukApheresis Increases CTC Yields in a European Prospective Multi-center Study (CTCTrap)

Kiki C Andree, Anouk Mentink, Leonie L Zeune, Leon WMM Terstappen, Nikolas H Stoecklein, Rui P Neves, Christiane Driemel, Rita Lampignano, Liwen Yang, Hans Neubauer, Tanja Fehm, Johannes C Fischer, Elisabetta Rossi, Mariangela Manicone, Umberto Basso, Piero Marson, Rita Zamarchi, Yohann Loriot, Valerie Lapierre, Vincent Faugeroux, Marianne Oulhen, Françoise Farace, Gemma Fowler, Mariane Sousa Fontes, Berni Ebbs, Maryou Lambros, Mateus Crespo, Penny Flohr and Johann S de Bono 


\section{Abstract}

Frequently, the number of circulating tumor cells (CTC) isolated in $7.5 \mathrm{~mL}$ of blood is too small to reliably determine tumor heterogeneity and to be representative as a 'liquid biopsy'. In the EU FP7 program CTCTrap, we aimed to validate and optimize the recently introduced Diagnostic LeukApheresis (DLA) to screen liters of blood. Here we present the results obtained from 34 metastatic cancer patients subjected to DLA in the participating institutions. $7.5 \mathrm{~mL}$ blood processed with CellSearch was used as 'gold standard' reference. DLAs were obtained from 22 metastatic prostate and 12 metastatic breast cancer patients at four different institutions without any noticeable side effects. DLA samples were prepared and processed with different analysis techniques. Processing DLA using CellSearch resulted in a 0 - 32 fold increase in CTC yield compared to processing $7.5 \mathrm{~mL}$ blood. Filtration of DLA through $5 \mu$ m pores microsieves was accompanied by large CTC losses. Leukocyte depletion of $18 \mathrm{~mL}$ followed by CellSearch yielded an increase of the number of CTC but a relative decrease in yield (37\%) versus CellSearch DLA. In 4 out of 7 patients with O CTC detected in $7.5 \mathrm{~mL}$ of blood, CTC were detected in DLA (range 1 - 4 CTC). The CTC obtained through DLA enables molecular characterization of the tumor. CTC enrichment technologies however still need to be improved to isolate all the CTC present in the DLA. 


\subsection{Introduction}

The presence of circulating tumor cells (CTC) in blood is associated with poor prognosis in patients with metastatic and non-metastatic disease..$^{1-7}$ The numbers of CTC isolated in 7.5 $\mathrm{mL}$ of blood are frequently too low to obtain a 'liquid biopsy' representative for the tumor, determine tumor heterogeneity and assess the optimal treatment strategy. Extrapolation of the CTC frequency distribution in $7.5 \mathrm{~mL}$ of blood from patients with metastatic breast, colon and prostate cancer showed that, probably, all these patients had tumor cells in circulation, but the sample volume was not sufficient to detect them in all patients. ${ }^{8}$ In recent years, numerous assays to detect CTC have been described. EpCAM-based technologies have offered requisites of robustness, reproducibility and cost effectiveness, providing the first in-vitro diagnostic CTC assay. However, one of the major drawbacks in the use of CTC for the selection of personalized therapies in individual patients is that CTC are rare events. It was calculated that at a level of 1,000 in-vivo CTC, there is a probability of 95\% that at least one CTC will be detected in 1 out of 5 samples of $7.5 \mathrm{~mL}$ of blood with the current technologies; below this tumor burden the accuracy of the detection at a time point is limited by the blood volume that can be obtained from a patient. 9.10 One solution to overcome this problem is the use of leukapheresis to obtain the mononuclear cell (MNC) fraction believed to contain the majority of CTC from liters of blood. This procedure introduced by Fisher et al. ${ }^{11}$ was baptized diagnostic leukapheresis (DLA). The concept and feasibility of DLA was demonstrated by processing a small aliquot ( 5\%) of the DLA using the CellSearch ${ }^{\circledR}$ system, which represents the current gold standard for CTC detection. Our first aim was to validate the use of DLA for isolation of CTC in metastatic breast and prostate cancer within the EU FP7 program CTCTrap at multiple centers. Next, we evaluated different technologies to increase the percentage of the DLA that could be processed for the isolation of CTC.

\subsection{Patients and methods}

\subsubsection{Patients}

Twelve patients with metastatic breast cancer were enrolled in the study at the University of hospital Duesseldorf and 22 patients with castration resistant prostate cancer; two at the University hospital of Padova, seven at the Institute Gustave Roussy and 13 at the Royal Marsden hospital. All patients provided written informed consent and the study was approved by the institutional review boards at each participating center. 


\subsubsection{Diagnostic leukapheresis procedure}

Leukapheresis were performed at the clinics in Padova, Villejuif, Duesseldorf and Sutton using the Spectra Optia ${ }^{\circledR}$ (Terumo BCT inc., Lakewood, CO, USA) according to manufacturer's instructions. For DLA, the program of the apheresis device was set to the MNC collection procedure and set at a collection flow rate of $1.0 \mathrm{~mL}$ per minute. Concurrent plasma collection was set to a volume of $0 \mathrm{~mL}$. The objective was to collect a minimum volume of $40 \mathrm{~mL} \mathrm{DLA}$ which was reached in approximately 90 minutes.

\subsubsection{Post DLA sample handling}

Samples were divided into aliquots immediately after the DLA procedure, under sterile conditions. White blood cell (WBC) counts and MNC counts were determined using an automated flow-cytometric based hematology analyzer. For CellSearch ${ }^{\circledR}$ analysis an aliquot of the DLA product containing $2 \times 10^{8} \mathrm{WBC}$ was diluted to a final volume of $8 \mathrm{~mL}$ with CellSearch Circulating Tumor Cell Kit Dilution Buffer (Menarini Silicon Biosystems, Huntingdon Valley, PA, USA) stored at room temperature (RT) and transferred into a CellSave ${ }^{\circledR}$ tube containing

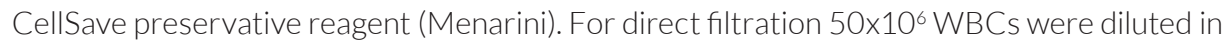
$7.5 \mathrm{~mL}$ dilution buffer and then transferred into a CellSave tube. For RosetteSep ${ }^{\text {TM }}$ (Stemcell Technologies, Vancouver, Canada) $18 \mathrm{~mL}$ of DLA product was transferred to a $50 \mathrm{~mL}$ tube and CellSave preservative reagent from two CellSave tubes was added to the tube. All tubes were kept at RT, at least overnight, until analysis.

\subsubsection{CellSearch sample processing}

CellSave whole blood was run with CellSearch using the CTC kit (Menarini) according to manufacturer's instructions. For the DLA product, containing $2 \times 10^{8} \mathrm{WBC}$, the sample was processed using the CellTracks Autoprep system using the CTC kit. The cartridge from the DLA product was scanned, using the CellTracks analyzer II.

\subsubsection{Filtration}

For filtration, 50×10 $\mathrm{WBC}$ diluted in CellSearch dilution buffer, were filtered using a pump and filtration unit including a microsieve with 5 um pores (VyCAP B.V., Deventer, The Netherlands). The sample was loaded onto the microsieve and a -100 mbar pressure was applied. Filtration was continued until the entire sample passed the microsieve, or for a duration of maximum 10 min. The successfully filtered sample volume was recorded and used to calculate recoveries. After filtration, the microsieve was removed from the filtration unit and was washed once with a PBS/1\% BSA/0.15\% Saponin solution. A permeabilization buffer, containing PBS/1\% BSA/0.15\% Saponin, was added onto the microsieve and was incubated for $15 \mathrm{~min}$ at room 
temperature. Subsequently, a staining solution was added containing anti-CD45-PerCP (Life Technologies, MHCD4531, clone HI30) at a final concentration of 4ug/mL and anti-CKpanNanoParticles 575 (AcZon, clone C11 and AE1/AE3) at a final concentration of 3.5ug/mL in PBS/1\% BSA/0.05\% Saponin. Staining was performed for $15 \mathrm{~min}$ at 370C. After removal of the staining cocktail, the microsieve was washed twice using PBS/BSA 1\%. The sample was then fixed using PBS/formaldehyde 1\% (Sigma, St Louis, USA) for 10 min at room temperature. Removal of the fluid during each of the staining and washing steps was done using a staining holder including a disposable sponge (VyCAP B.V.). Finally, the sieve was mounted using ProLong ${ }^{\circledR}$ Diamond Antifade Mountant with DAPI (ThermoFisher, Carlsblad, CA, USA, P36971) and a custom cut coverslip ( $2 \times 0.85 \mathrm{~cm}^{2}$ custom cut, thickness \#1 0.13-0.16mm) was added to the filter (Menzel-Gläser, Braunschweig, Germany).

\subsubsection{Leukocyte depletion}

Eighteen $\mathrm{mL}$ of DLA was depleted from unwanted white blood cell populations using the RosetteSep CTC Enrichment Cocktail Containing Anti-CD36 (Stemcell Technologies, Catalog\# 15167). First erythrocytes were isolated by centrifugation of two 9 mL EDTA blood tubes from each patient at $800 x g$ for $10 \mathrm{~min}$. The plasma and buffy coat were then removed and the erythrocytes from both tubes were pooled. Erythrocytes were then added to the DLA product to reach a final WBC to erythrocyte ratio of 1:40. Fifty uL of the RosetteSep cocktail was then added for each $1 \mathrm{~mL}$ of sample and incubated for 20 min at RT. After incubation, the sample was diluted with an equal volume of PBS/2\%FBS. The solution was then carefully layered on top of a Ficoll-Paque PLUS density gradient (GE Healthcare, Chalfont St.Giles, UK) and centrifuged at $1200 \mathrm{~g}$ for $20 \mathrm{~min}$ at RT without brake. The enriched cells where then collected and washed by adding 2 volumes of PBS/2\% FBS and centrifuging for 8 min at 300xg. For filtration, cells were resuspended in $9 \mathrm{~mL}$ of $1 \times \mathrm{PBS}$ and filtered through a $5 \mu \mathrm{m}$ microsieve (VyCAP BV) at-100mbar. Staining of the microsieves was performed as described above. For CellSearch analysis after leukocyte depletion $9 \mathrm{~mL}$ of sample was transferred to a conical tube and CellSearch dilution buffer was added to a final volume of $14 \mathrm{~mL}$. This sample was then processed as control within the CellTracks Autoprep system using the CTC kit.

\subsubsection{Scanning}

All CellSearch cartridges, with enriched CTC, were scanned using the CellTracks Analyzer II (Menarini). All microsieves were scanned using an automated fluorescence microscope available at each site. Each system should match the minimal requirements of having a 10x times objective with a minimal numerical aperture of 0.45. In addition, the following filters for fluorescence detection were used: DAPI with excitation 377/50nm, dichroic 409nm LP, 
emission 409nm LP (Spectra Physics Newport, Santa Clara, CA, USA), PE with excitation 543/22nm, dichroic 562nm LP, emission 593/40nm (Spectra Physics Newport, Santa Clara, CA, USA) and PerCP with excitation 435/40nm, dichroic 510nm LP, emission 676/29nm (Spectra Physics Newport, Santa Clara, CA, USA).

\subsubsection{Image analysis}

CellSearch fluorescence images were analyzed according to manufacturer's instructions. The fluorescent images from the microsieves were analyzed using the open-source software ICY. ${ }^{12}$ Operators were asked to annotate every DAPI+, CK+, CD45- event. In addition, raw images of both cartridges and microsieves were analyzed by the open source imaging program ACCEPT. ${ }^{13-15}$ The total number of nucleated events was determined to investigate the number of leukocytes present in the background during image analysis. To improve the detection of nucleated events even in images with crowded areas or images with background artifacts we applied a high-pass Fourier filter to remove the background beforehand. This feature can be used in future versions of ACCEPT to improve image analysis results.

\subsubsection{Statistical analysis}

Statistical analysis was performed using OriginPro 9.1 (OriginLab Corporation, MA, US) using the paired sample t-test.

\subsection{Results}

\subsubsection{CTC in $7.5 \mathrm{~mL}$ of blood versus $200 \times 10^{6}$ cells ( $\left.5 \%\right)$ of DLA product}

DLAs were obtained from 22 metastatic prostate cancer patients and 12 metastatic breast cancer patients at four different European academic medical institutions. Before starting the DLA procedure, $7.5 \mathrm{~mL}$ of whole blood was drawn and processed with the 'gold standard' reference CellSearch ${ }^{\circledR}$ to obtain the CTC counts from whole blood. DLA samples were processed through the analysis techniques shown in figure 6.1 and described in detail in the Standard Operating Procedures (SOP) developed for DLA in the CTCTrap consortium (https:// www.utwente.nl/tnw/mcbp/protocolsandtools/).

In short, $200 \times 10^{6} \mathrm{MNC}$ of the DLA product (on average $3.7 \mathrm{~mL}$ ) were analyzed using CellSearch, $50 \times 10^{6}$ cells were analyzed using filtration and $18 \mathrm{~mL}$ of the DLA product was depleted of its white blood cells, allowing analysis of a larger part of the DLA product, followed by CTC enumeration by either filtration or CellSearch. 


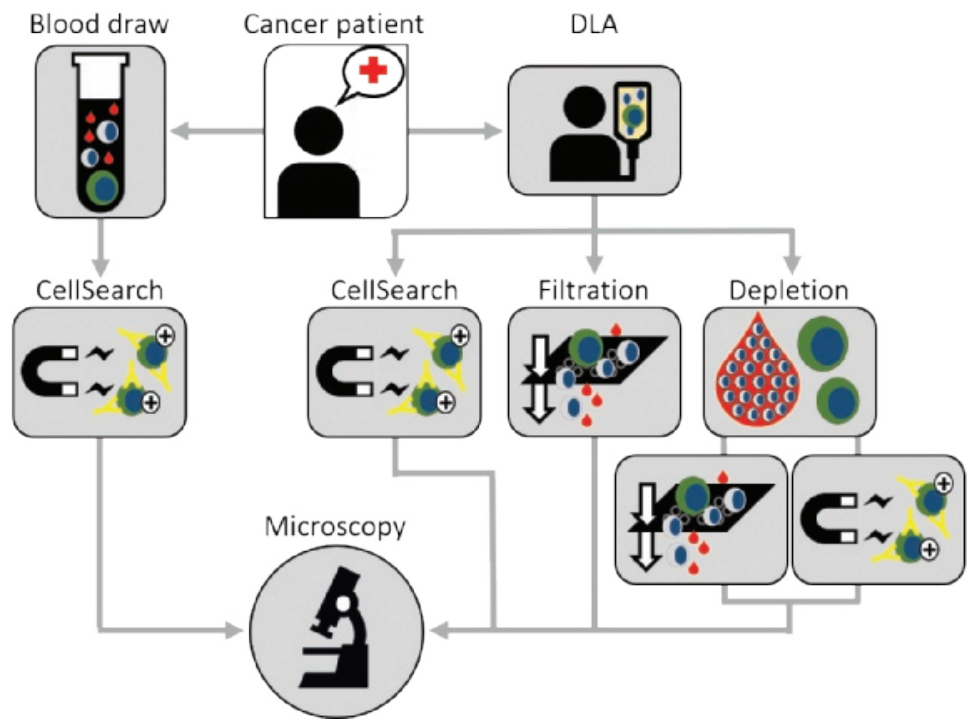

Figure 6.1: Sample workflow. Metastatic cancer patients have undergone DLA for about 90 minutes. Additionally $7.5 \mathrm{~mL}$ whole blood was collected in CellSave tubes. Blood was processed with CellSearch to obtain a CTC count from whole blood. DLA was aliquoted for several analysis technnologies. $200 \times 10^{6}$ cells were processed with CellSearch, $50 \times 10^{6} \mathrm{cells}$ were analyzed using filtration, $18 \mathrm{~mL}$ of DLA product was depleted of leukocytes and then divided into two aliquots to further enrich CTC by filtration or CellSearch. All samples were analyzed for the presence of CTC by fluorescence microscopy.

DLAs from metastatic cancer patients were performed for 90 minutes without any noticeable side effects. DLA products had an average volume of $53 \mathrm{~mL}$ (range $21 \mathrm{~mL}$ - $98 \mathrm{~mL}, \mathrm{SD} 16 \mathrm{~mL}$ )

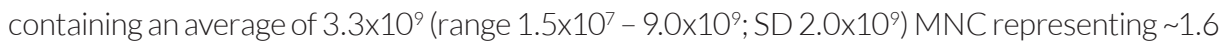
$L$ (range $0.03 \mathrm{~L}-3.5 \mathrm{~L}, \mathrm{SD} 0.7 \mathrm{~L}$ ) of blood. Figure 6.2a illustrates the concentration of MNC per $\mathrm{mL}$ of whole blood and DLA product. The average MNC count in whole blood was $2.0 \times 10^{6} / \mathrm{mL}$ (range $0.3 \times 10^{6} / \mathrm{mL}-4.3 \times 10^{6} / \mathrm{mL}, \mathrm{SD}=0.9 \times 10^{6} / \mathrm{mL}$ ) and in DLA product $64.0 \times 10^{6} / \mathrm{mL}$ (range $0.4 \times 10^{6} / \mathrm{mL}-164.3 \times 10^{6} / \mathrm{mL}, \mathrm{SD}=36.8 \times 10^{6} / \mathrm{mL}$ ). In figure $6.2 \mathrm{~b}$ the ratio of the concentration of MNC in DLA to MNC in blood is shown. The number of CTC in $7.5 \mathrm{~mL}$ of blood ranged from 0 to 324 (mean 67, median 18) and CTC in DLA ranged from 0 to 2913 (mean 362, median 160) resulting in a significant increase in CTC yield $(p=0.003)$. The increase in CTC yield ranged from 0x to 32x (mean 6, median 5). The analyzed DLA volume represented 7 to $212 \mathrm{~mL}$ of blood (mean 98, median 97). In figure 6.3 the absolute number of CTC in $7.5 \mathrm{~mL}$ of peripheral blood and in $200 \times 10^{6} \mathrm{MNC}$ of the DLA product measured by CellSearch is illustrated for each patient. Extrapolation of the number of CTC obtained when the complete DLA volume could have been processed with CellSearch for each patient is also shown in the figure. The complete DLA volume represented 7 to $212 \mathrm{~mL}$ of blood (mean 98, median 97). The entire DLA product would comprise 0 to 9037 CTC (mean 3304, median 2873) or a 0x to 417x increase (mean 104, median 77) compared to $7.5 \mathrm{~mL}$ of blood. 
a

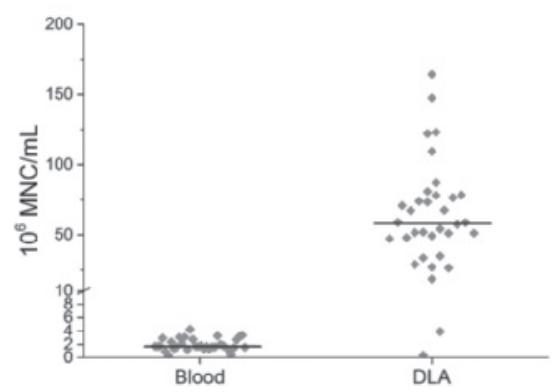

b

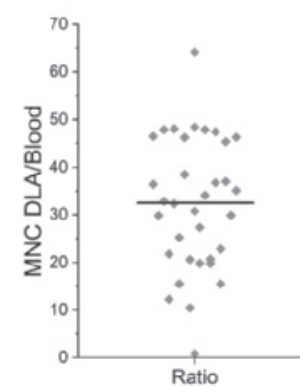

Figure 6.2: a) MNC counts per $\mathrm{mL}$ blood and per $\mathrm{mL}$ of DLA from 34 metastatic cancer patients. The horizontal line represents the median. b) Ratio dot plot showing the ratio of concentration MNC in DLA to MNC in blood, horizontal line is representing the median ratio.

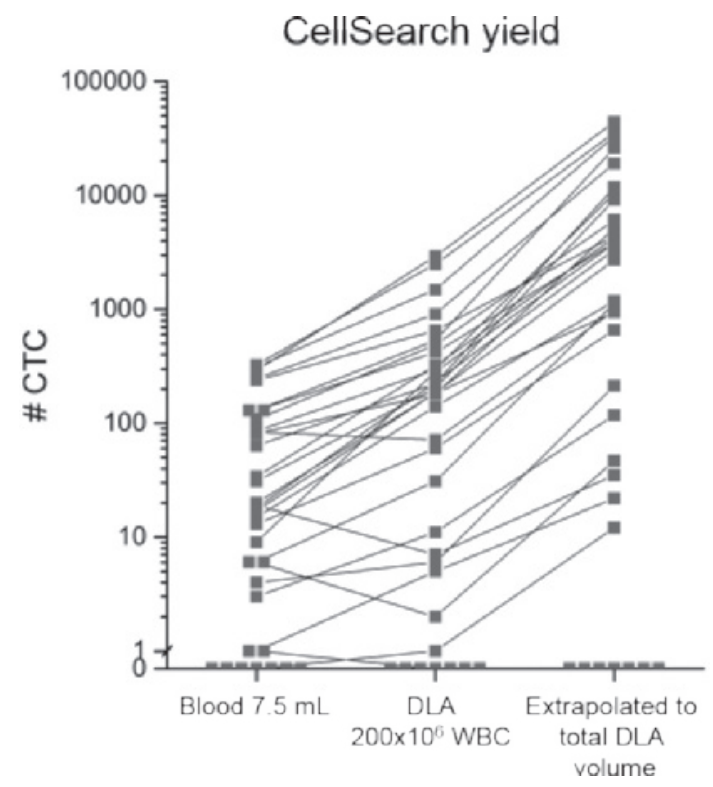

Figure 6.3: Absolute CTC counts in $7.5 \mathrm{~mL}$ of blood, $200 \times 10^{6}$ cells of DLA product processed by CellSearch and the CTC count in the total DLA product by extrapolation of the DLA CTC counts, lines connect measurements from the same patient.

\subsubsection{CTC in $2-18 \mathrm{~mL}(\sim 5-45 \%)$ of DLA product}

The identification of CTC within enriched cell suspensions becomes increasingly more difficult when the number of leukocytes are so large that they are in close proximity to each other. In figure 6.4a representative microscopic images are shown after processing blood by CellSearch (6.4.a 1), after processing DLA with CellSearch (6.4.a 2), after filtration of DLA (6.4.a 3) and after depletion of leukocytes in DLA product followed by either filtration (6.4.a 4) or CellSearch (6.4.a 5). From the images it is clear that identification of CTC in DLA 
product directly processed by CellSearch or filtration is more difficult because of the larger background of leukocytes. To quantify the number of nucleated cells in the images we used the open source imaging program ACCEPT. Gates were set to find all nucleated events by looking at the mean intensity of the DAPI signal and gates for the perimeter and eccentricity were set to identify cell like morphologies. ${ }^{16-18}$ The gate used to define nucleated cells was a DNA mean intensity $>5$, a DNA perimeter $>16$ and a DNA eccentricity $\leq 0.95$. The average number and standard deviation of nucleated cells present after isolation are shown in the top left part of the image. Blood volumes of $7.5 \mathrm{~mL}$ processed with CellSearch had on average 27,513 nucleated events in the background (SD = 6,716; $n=7$ ), DLA products processed with CellSearch had 50,778 nucleated events (SD = 40,486; $n=8$ ), directly filtered DLA exhibited 88,142 nucleated events (SD = 13,338; $n=8$ ), DLAs depleted followed by filtration had 11,929 nucleated events (SD = 3,337; $\mathrm{n}=8$ ) and DLAs depleted followed by CellSearch $3,702$ nucleated events (SD $=1,729 ; n=5)$. The number of CTCs in samples with more than 100,000 WBC in the background is most likely underestimated as they may be obscured by leukocytes. To illustrate the similarities between the morphological characteristics of CTC in blood and DLA, a gallery of images from 4 patients is shown in figure 6.4b.

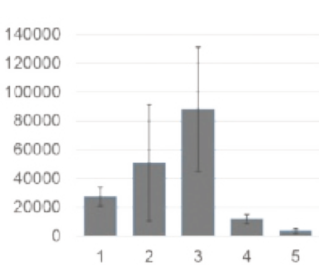

2) DLA $\rightarrow$ CellSearch

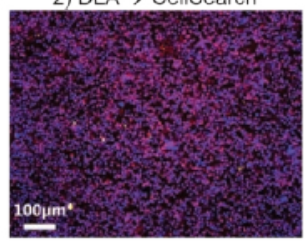

4) DLA Depletion $\rightarrow$ Filtration

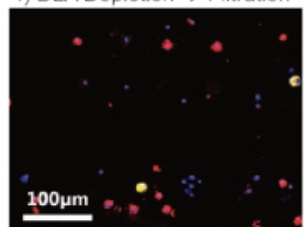

1) Blood $\rightarrow$ CellSearch

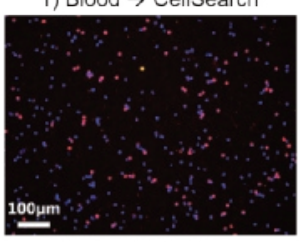

3) DLA $\rightarrow$ Filtration

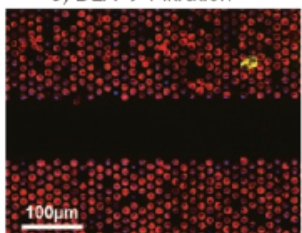

5) DLA Depletion $\rightarrow$ CellSearch

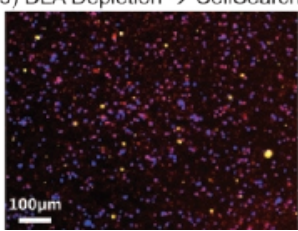

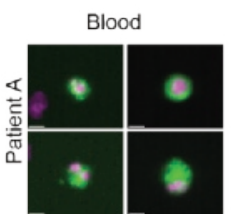
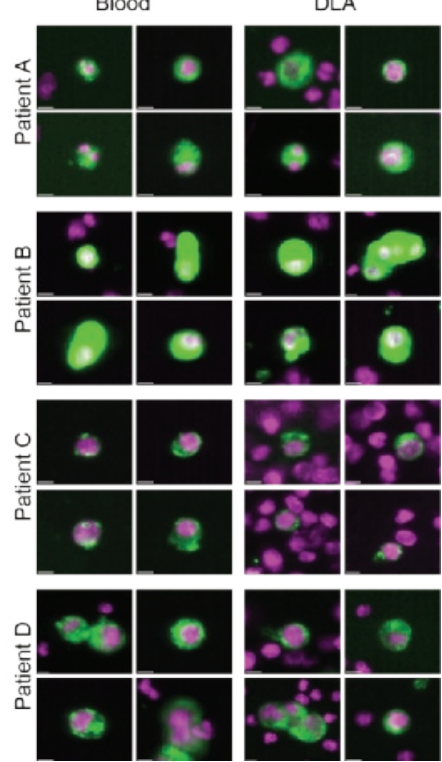

Figure 6.4: a) Typical microscopic images obtained after CTC enrichment and detection with the different techniques. Top left, the average number of nucleated cells in the enriched CTC samples assessed by ACCEPT. b) CellSearch images from CTC detected in both blood and DLA from 4 patients. Cells show similar morphological characteristics. (nucleus = purple, cytokeratin $=$ green $)$ 
Filtration of $50 \times 10^{6} \mathrm{MNC}$ from the DLA in $7.5 \mathrm{~mL}$ of buffer, through $5 \mu \mathrm{m}$-pores microsieves yielded only 0 to $12 \mathrm{CTC}$ (mean $=2$, median $=0, n=16$ ). Leukocyte depletion of $18 \mathrm{~mL}$ of DLA product followed by filtration yielded 0 to 178 CTC (mean 40, median 4, n = 22) not yielding a relative increase compared to analysis of $2 \mathrm{~mL} \mathrm{DLA} \mathrm{product} \mathrm{in} \mathrm{CellSearch.} \mathrm{Leukocyte}$ depletion followed by CellSearch yielded 271 to 1.620 CTC (mean 660, median 484; $n=5$ ) also not yielding a relative increase versus direct analysis of $2 \mathrm{~mL} D L A$ product in CellSearch, but resulted in almost a doubling of absolute CTC numbers (figure 6.5). However, if we use the counts detected in $200 \times 10^{6}$ cells of DLA product and calculated the expected CTC numbers for each of the other DLA analyses techniques we noted relative loss for all other methods.

a

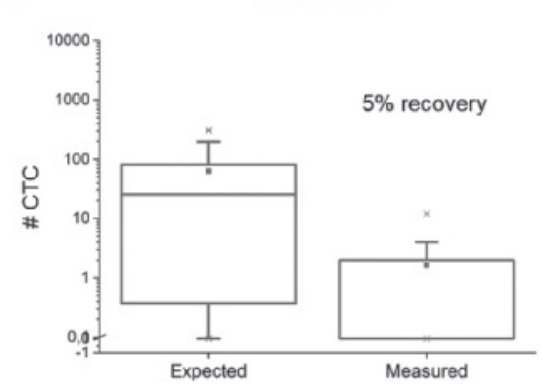

b

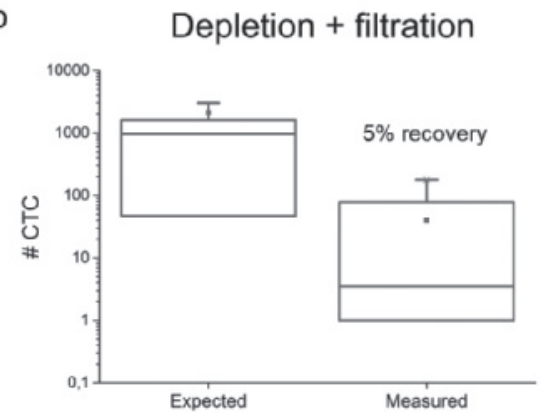

C Depletion + CellSearch

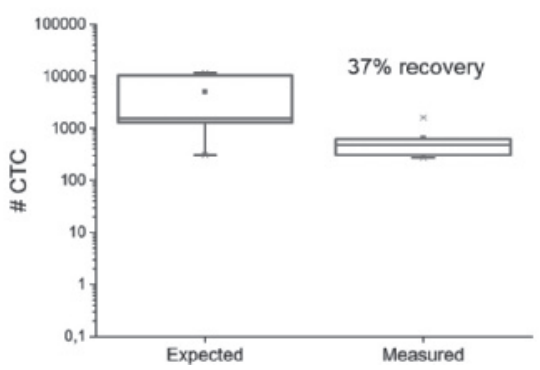

Figure 6.5: Expected number of CTC based on CellSearch CTC count in 200 $10^{6}$ cells of DLA product plotted against the actual measured CTC count for each of the analysis techniques. a) CTC recovery after filtration ( $n=16)$. b) CTC recovery after depletion of DLA product followed by filtration ( $n=22)$. c) CTC recovery of depletion of DLA product followed by CellSearch analysis ( $n=5)$.

\subsubsection{CTC in patients with 0 CTC detected in $7.5 \mathrm{ml}$ of blood}

In 7 patients, O CTC were detected in $7.5 \mathrm{~mL}$ of blood. In 4 out of these 7 patients CTC were detected in the DLA product. In one patient, 1 CTC was detected by processing $2 \mathrm{~mL}$ DLA by CellSearch and in one patient, 1 CTC was detected after leukocyte depletion of $18 \mathrm{~mL}$ of DLA product followed by filtration. In the remaining two patients, 2 and 4 CTC where detected respectively after direct filtration of DLA. 


\subsection{Discussion}

In this European multi-center study we showed that in 34 metastatic cancer patients the DLA procedure was well tolerated and a DLA product could be obtained. The mononuclear blood fraction obtained represented 0.03 - 3.5 liters of blood (mean = 1.6, SD = 0.7 L). In one patient the represented blood volume was only $30 \mathrm{~mL}$ whereas in all other patients, volumes represented $400 \mathrm{~mL}$ or more peripheral blood. Due to the high MNC concentration resulting in high leukocyte-carry-over impeding CTC detection, only around 5\% (200×10 ${ }^{6}$ cells) of the DLA product can be directly processed in a CellSearch run. Processing of $200 \times 10^{6}$ cells with CellSearch can already result in a carryover that is too high for accurate identification of CTC. A simple solution to this problem is to dilute the sample and divide it over multiple cartridges for scanning and image analysis. However, this approach would lead to a practical problem consisting in the availability of empty cartridges.

For a thorough molecular characterization of the tumor an assessment of heterogeneity is important, thereby implying the need for an assessment of the individual cells. A question that cannot be answered is how many molecular characterized tumor cells from how many tumor sites are needed. But we do know that the tumor cells present in the blood can come from a variety of metastatic sites, enabling their direct analysis. Extensive heterogeneity has been observed in CTC that match the findings in the metastatic sites to various degrees. ${ }^{19-21}$ The molecular characterization of single CTC requires technology for their isolation, which can be performed by FACS ${ }^{22,23}$, DEPArray ${ }^{24,25}$, Punch ${ }^{26,27}$ or micromanipulation ${ }^{28}$. However, employing these methods, cell loss is inevitable. Another problem, if only very few cells are available for analysis is that CTCs are frequently in poor condition disabling their further DNA and/or RNA analysis. ${ }^{29}$ Therefore, there is agreement that the more tumor cells are available the better the chance to accurately characterize them. With DLA, the increase in CTC yield after processing 5\% of the DLA product with CellSearch ranged from 0 to 32 fold (mean 6 , median 5) compared to analysis of $7.5 \mathrm{~mL}$ of matched PB. In $23 \%$ of the patients $>100$ CTC were detected in $7.5 \mathrm{~mL}$ of blood and this increased to $53 \%$ of patients in $2 \mathrm{~mL}$ of DLA and to $68 \%$ if all the DLA could have been processed. A lower number may be sufficient for molecular characterization and for example in $59 \%$ of the patients $>10$ CTC were detected in $7.5 \mathrm{~mL}$ of blood and this increased to $65 \%$ of patients in $2 \mathrm{~mL}$ of DLA and to $79 \%$ if all the DLA could have been processed. Molecular characterization and expansion of CTC through in vivo culture in mice is being explored in some of these samples. ${ }^{30,31}$ 


\section{Chapter 6}

Clearly, some improvements have to be made before the use of DLA can become practice in a clinical setting. For example, methodologies for molecular characterization of CTC isolated from DLA need to be standardized. Also, to proceed with molecular characterization, more effective methods need to be established to process the whole DLA product, e.g. processing of 20 CellSearch runs is accompanied by practical and economical limitations. We therefore evaluated other means of CTC enrichment in DLA products. The use of DLA filtration through microsieves was also limited by overwhelming number of leukocytes, which restricted the use of only $1.25 \%$ (50×10 ${ }^{6}$ cells) of the DLA product. Depletion of leukocytes prior to filtration or CellSearch enrichment indeed resulted in a number of leukocytes that could be handled by the image recognition of CTC but the depletion procedure itself was accompanied by CTC losses. The overall number of CTC obtained however increased (figure 6.5) thereby raising the ability to characterize the different tumor cells. We conclude that the use of DLA increases the number of CTC that can be isolated. However, further improvements on CTC enrichment technologies are needed to truly gain advantages of DLA as a means to obtain sufficient CTC for the characterization of the tumor and ultimately to guide therapy. 


\section{References}

1 F. C. Bidard, D. J. Peeters, T. Fehm, F. Nolé, R. GisbertCriado, D. Mavroudis, S. Grisanti, D. Generali, J. A. Garcia-Saenz, J. Stebbing, C. Caldas, P. Gazzaniga, L. Manso, R. Zamarchi, A. F. de Lascoiti, L. De MattosArruda, M. Ignatiadis, R. Lebofsky, S. J. van Laere, F. Meier-Stiegen, M.-T. Sandri, J. Vidal-Martinez, E. Politaki, F. Consoli, A. Bottini, E. Diaz-Rubio, J. Krell, S.-J. Dawson, C. Raimondi, A. Rutten, W. Janni, E. Munzone, V. Carañana, S. Agelaki, C. Almici, L. Dirix, E.-F. Solomayer, L. Zorzino, H. Johannes, J. S. ReisFilho, K. Pantel, J.-Y. Pierga and S. Michiels, Lancet Oncol., 2014, 15, 406-414.

2 S. J. Cohen, C. J. A. Punt, N. Iannotti, B. H. Saidman, K. D. Sabbath, N. Y. Gabrail, J. Picus, M. Morse, E. Mitchell, M. C. Miller, G. V Doyle, H. Tissing, L. W. M. M. Terstappen and N. J. Meropol, J. Clin. Oncol., 2008, 26, 3213-21.

3 J. S. de Bono, H. I. Scher, R. B. Montgomery, C. Parker, M. C. Miller, H. Tissing, G. V Doyle, L. W. W. M. Terstappen, K. J. Pienta and D. Raghavan, Clin. Cancer Res., 2008, 14, 6302-9.

4 M. G. Krebs, R. Sloane, L. Priest, L. Lancashire, J.-M. Hou, A. Greystoke, T. H. Ward, R. Ferraldeschi, A. Hughes, G. Clack, M. Ranson, C. Dive and F. H. Blackhall, J. Clin. Oncol., 2011, 29, 1556-63.

5 T. J. N. Hiltermann, M. M. Pore, A. van den Berg, W. Timens, H. M. Boezen, J. J. W. Liesker, J. H. Schouwink, W. J. A. Wijnands, G. S. M. A. Kerner, F. A. E. Kruyt, H. Tissing, A. G. J. Tibbe, L. W. M. M. Terstappen and H. J. M. Groen, Ann. Oncol., 2012, 23, 2937-2942.

6 W. J. Janni, B. Rack, L. W. M. M. Terstappen, J.-Y. Pierga, F.-A. Taran, T. Fehm, C. Hall, M. R. de Groot, F.-C. Bidard, T. W. P. Friedl, P. A. Fasching, S. Y. Brucker, K. Pantel and A. Lucci, Clin. Cancer Res., 2016, 22, 2583-93.

7 G. van Dalum, G.-J. Stam, L. F. A. Scholten, W. J. B. Mastboom, I. Vermes, A. G. J. Tibbe, M. R. De Groot and L. W. M. M. Terstappen, Int. J. Oncol., 2015, 46, 1361-1368.

8 F. A. W. Coumans, S. T. Ligthart, J. W. Uhr and L. W. M. M. Terstappen, Clin. Cancer Res., 2012, 18, 57115718.

9 A. G. J.Tibbe, M. C. Miller and L.W. M. M. Terstappen, Cytometry. A, 2007, 71, 154-62.
10 N. H. Stoecklein, J. C. Fischer, D. Niederacher and L. W. M. M. Terstappen, Expert Rev. Mol. Diagn., 2016, 16, 147-164.

11 J. C. Fischer, D. Niederacher, S. A. Topp, E. Honisch, S. Schumacher, N. Schmitz, L. Zacarias Föhrding, C. Vay, I. Hoffmann, N. S. Kasprowicz, P. G. Hepp, S. Mohrmann, U. Nitz, A. Stresemann, T. Krahn, T. Henze, E. Griebsch, K. Raba, J. M. Rox, F. Wenzel, C. Sproll, W. Janni, T. Fehm, C. A. Klein, W. T. Knoefel and N. H. Stoecklein, Proc. Natl. Acad. Sci. U. S. A., 2013, 110, 16580-5.

12 F. de Chaumont, S. Dallongeville, N. Chenouard, N. Hervé, S. Pop, T. Provoost, V. Meas-Yedid, P. Pankajakshan, T. Lecomte, Y. Le Montagner, T. Lagache, A. Dufour and J.-C. Olivo-Marin, Nat. Methods, 2012, 9, 690-696.

13 L. L Zeune, https://github.com/LeonieZ/ACCEPT, https://github.com/LeonieZ/ACCEPT, (accessed 18 January 2018).

14 L. Zeune, G. van Dalum, L. W. M. M. Terstappen, S. A. van Gils and C. Brune, SIAM J. Imaging Sci., 2017, 10, 111-146.

15 L. Zeune, G. van Dalum, C. Decraene, C. Proudhon, T. Fehm, H. Neubauer, B. Rack, M. Alunni-Fabbroni, L. W. M. M. Terstappen, S. A. van Gils and C. Brune, PLoS One, 2017, 12, e0186562.

16 A. Nanou, F. A. W. Coumans, G. van Dalum, L. L. Zeune, D. Dolling, W. Onstenk, M. Crespo, M. S. Fontes, P. Rescigno, G. Fowler, P. Flohr, C. Brune, S. Sleijfer, J. S. de Bono and L. W. M. M. Terstappen, Oncotarget, 2018, 9, 19283-19293.

17 S. de Wit, L. L. Zeune and L. W. M. M. Terstappen, in 3rd Advances in Circulating Tumour Cells, Rhodes, 2017.

18 S. de Wit, E. Rosii, E. Heitzer, M. Tamminga, M. Manicone, J. Swennenhuis, R. Vidotto, A. Facchinetti, L. Zeune, E. Schuuring, R. Zamarchi, J. Hilterman, M. Speicher, L. Terstappen and H. Groen, in 3rd Advances in Circulating Tumour Cells, Rhodes, 2017. 
19 S. Meng, D. Tripathy, S. Shete, R. Ashfaq, B. Haley, S. Perkins, P. Beitsch, A. Khan, D. Euhus, C. Osborne, E. Frenkel, S. Hoover, M. Leitch, E. Clifford, E. Vitetta, L. Morrison, D. Herlyn, L. W. M. M. Terstappen, T. Fleming, T. Fehm, T. Tucker, N. Lane, J. Wang and J. Uhr, Proc. Natl. Acad. Sci. U. S. A., 2004, 101, 9393-8.

20 S. Meng, D. Tripathy, S. Shete, R. Ashfaq, H. Saboorian, B. Haley, E. Frenkel, D. Euhus, M. Leitch, C. Osborne, E. Clifford, S. Perkins, P. Beitsch, A. Khan, L. Morrison, D. Herlyn, L. W. M. M. Terstappen, N. Lane, J. Wang and J. Uhr, Proc. Natl. Acad. Sci. U. S. A., 2006, 103, 17361-5.

21 G. Attard, J. F. Swennenhuis, D. Olmos, A. H. M. Reid, E. Vickers, R. A'Hern, R. Levink, F. Coumans, J. Moreira, R. Riisnaes, N. B. Oommen, G. Hawche, C. Jameson, E. Thompson, R. Sipkema, C. P. Carden, C. Parker, D. Dearnaley, S. B. Kaye, C. S. Cooper, A. Molina, M. E. Cox, L. W. M. M. Terstappen and J. S. de Bono, Cancer Res., 2009, 69, 2912-8.

22 R. P. L. Neves, K. Raba, O. Schmidt, E. Honisch, F. Meier-Stiegen, B. Behrens, B. Möhlendick, T. Fehm, H. Neubauer, C. A. Klein, B. Polzer, C. Sproll, J. C. Fischer, D. Niederacher and N. H. Stoecklein, Clin. Chem., 2014, 60, 1290-7.

23 J. F. Swennenhuis, J. Reumers, K. Thys, J. Aerssens and L.W.W. M. M. Terstappen, Genome Med., 2013, 5, 1-11.

24 C. L. Hodgkinson, C. J. Morrow, Y. Li, R. L. Metcalf, D. G. Rothwell, F. Trapani, R. Polanski, D. J. Burt, K. L. Simpson, K. Morris, S. D. Pepper, D. Nonaka, A. Greystoke, P. Kelly, B. Bola, M. G. Krebs, J. Antonello, M. Ayub, S. Faulkner, L. Priest, L. Carter, C. Tate, C. J. Miller, F. Blackhall, G. Brady and C. Dive, Nat. Med., 2014, 20, 897-903.

25 F. De Luca, G. Rotunno, F. Salvianti, F. Galardi, M. Pestrin, S. Gabellini, L. Simi, I. Mancini, A. M. Vannucchi, M. Pazzagli, A. Di Leo and P. Pinzani, Oncotarget, 2016, 7, 26107-19.

26 Y. Yang, H. S. Rho, M. Stevens, A. G. J. J. Tibbe, (Han) J G E Gardeniers, L. W. M. M. Terstappen, H. Gardeniers and L. W. M. M. Terstappen, Lab Chip, 2015, 15, 4331-7.

27 J. F. Swennenhuis, A. G. J. Tibbe, M. Stevens, M. R. Katika, J.van Dalum, H. D. Tong, C. J. M. van Rijn, L. W. M. M. Terstappen, H. Duy Tong, C. J. M. van Rijn and L. W. M. M. Terstappen, Lab Chip, 2015, 15, 3039-46.
28 M. H.D. Neumann, H. Schneck, Y. Decker, S. Schömer, A. Franken, V. Endris, N. Pfarr, W. Weichert, D. Niederacher, T. Fehm and H. Neubauer, Biotechnol. Prog., 2017, 33, 125-132.

29 J. F. Swennenhuis, A. G. J. Tibbe, R. Levink, R. C. J. Sipkema and L. W. M. M. Terstappen, Cytometry. A, 2009, 75, 520-7.

30 M. Lambros, G. Seed, S. Sumanasuriya, V. Gil, M. Crespo, M. Fontes, R. Chandler, N. Mehra, G. Fowler, B. Ebbs, P. Flohr, S. Miranda, W. Wuan, A. Mackay, A. Ferreira, R. Pereira, C. Bertan, I. Figuiredo, R. Riisnaes, D. Nava Rodrigues, A. Sharp, J. Goodall, G. Boysen, S. CArreira, D. Bianchini, P. Rescigno, Z. Zafeiriou, J. Hunt, D. Moloney, L. Hamilton, R. Neves, J. Swennenhuis, K. Andree, N. Stoecklein, L. Terstappen and J. de Bono, Clin. Cancer Res.

31 V. Faugeroux, O. Deas, C. Catelain, E. Pailler, K. Andree, F. Lucibello, E. Alexandrova, J. Judde, N. Stoecklein, J. Scoazec, N. Manaresi, V. Marty, N. Tramalloni, M NgoCamus, C. Nicotra, L. Terstappen, V. Lapierre, K. Fizazi, Y. Loriot and F. Farace, in ACTC, Rhodes, 2017, p. 106. 
Towards a liquid biopsy: DLA increases CTC yields in breast and prostate cancer 

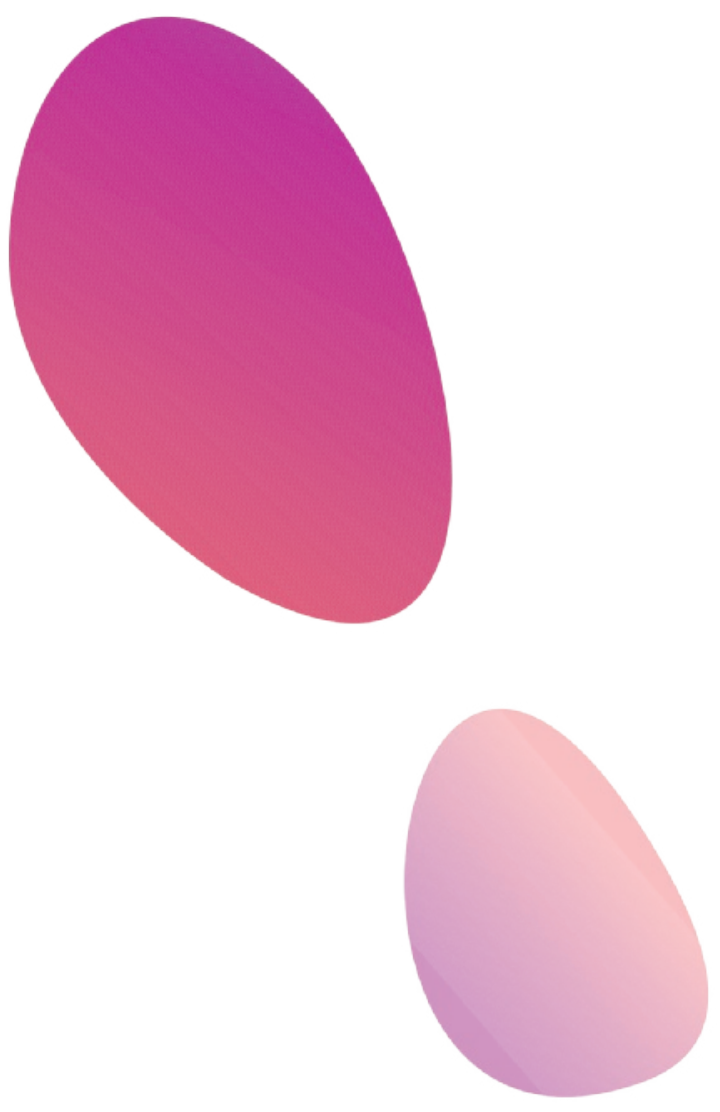


\section{CHAPTER}

\section{Increasing Yield of Circulating Tumor Cells in NSCLC Patients Through Diagnostic Leukapheresis}

Kiki C Andree, Menno Tamminga, Anouk Mentink, Hilda van den Bos, Diana Spiering, Harry JM Groen and Leon WMM Terstappen 


\section{Abstract}

The presence of circulating tumor cells (CTC) in $7.5 \mathrm{~mL}$ of blood from non-small cell lung cancer patients is strongly associated with poor prognosis. The number of patients in which CTC are detected is relatively low. Here we evaluate whether the number of CTC and the number of patients in which CTC can be detected can be increased by the use of Diagnostic LeukApheresis (DLA). In this study 19 patients with stage IV were subjected to DLA and in 6 of these patients the procedure was repeated after the first cycle of therapy. Whole blood was drawn into CellSave ${ }^{\circledR}$ blood collection tubes before and after DLA and processed with CellSearch ${ }^{\circledR}$. From the DLA $2 \times 10^{8}$ mononuclear cells (MNC) was processed directly with CellSearch and $10 \times 10^{8}$ MNC after leukocyte depletion. CTC were detected in 37\% of patients in $7.5 \mathrm{~mL}$ of blood, in 63\% in the DLA aliquot and $89 \%$ in the leukocyte depleted DLA aliquot. In patients with CTC detected the counts ranged from 0 - 35 (mean = 3, SD = 8) in 7.5 $\mathrm{mL}$ of blood $0-39$ (mean = 5, SD = 9) in DLA, and $0-49($ mean = 8, SD = 12) in the leukocyte depleted DLA. No change in peripheral blood CTC count was observed before and after DLA. In 5 out of 6 patients with measurements of CTC before and after initiation of therapy the CTC corresponded with therapy response. Although a significantly larger number of CTC can be obtained through DLA the technologies to isolate CTC from the vast amount of MNC will need to be improved in order to have a sufficient number of cancer cells to represent a biopsy. 


\subsection{Introduction}

The peripheral blood tumor load is directly associated with the amount of time metastatic cancer patients can survive. ${ }^{1-6}$ The number of circulating tumor cells (CTC) can be used as an effective tool to determine the prognosis and monitor the disease, their further characterization also hold the promise to represent a real-time biopsy. In non-small cell lung cancer (NSCLC) current therapeutic strategies are chemotherapy and drugs targeting specific molecular targets and pathways. The number of specific targets is increasing and about a third of NSCLC have drug targets. Since these therapeutic targets are often expressed only on part of the tumor cells the development of tests that can assess the presence of these targets on the individual tumor cells is of utmost importance to guide administration of the drugs. CTC could be a source of tumor material representing also the tumor heterogeneity. For this one however will need a sufficient number of CTC. In NSCLC the numbers of CTC isolated from $7.5 \mathrm{~mL}$ of blood is too low to be representative for the tumor, enable the assessment of tumor heterogeneity and arrive at the optimal treatment strategy. Extrapolation of the CTC frequency distribution in $7.5 \mathrm{~mL}$ of blood from patients with metastatic breast, colon and prostate cancer showed that all these patients had tumor cells in circulation, but the sample volume was not sufficient to detect them. ${ }^{7}$ The same extrapolation approach was used in the CANCER-ID project proposal to determine the blood volume that is needed to obtain a minimum of 10 CTC. The number of 10 CTC was chosen to obtain sufficient confidence that representative information on the tumor can be obtained. For NSCLC patients $12 \%$ has at least 10 CTCs detected in $7.5 \mathrm{~mL}$ of blood, accordingly in $75 \mathrm{~mL}$ of blood this percentage increase to $40 \%$ and in 0.75 liters of blood to $78 \%$. To overcome the volume problem, leukapheresis has been introduced to obtain the mononuclear (MNC) cell fraction of 1 - 5 liters of blood which is believed to contain the majority of CTC. ${ }^{8}$ This procedure was baptized diagnostic leukapheresis (DLA) and feasibility has now been demonstrated in several studies., ${ }^{9,10}$ Today's limitation is that CTC analysis with the CellSearch ${ }^{\circledR}$ system can only be performed on a small aliquot ( $5 \%$ ) of the DLA product.

In the IMI CANCED-ID project the use of DLA is being explored in NSCLC and evaluation of the percentage of NSCLC patients in which a representative liquid biopsy can be obtained through analysis of CTC will be performed. In addition, different technologies will be evaluated and compared to establish technically and clinically validated methodologies, documented in SOPs, which can be used in multi-center clinical trials settings. In order to do so, DLA aliquots of $\sim 2 \times 10^{8}$ MNC ( $2 \%$ of entire DLA product) of NSCLC patients undergoing DLA are send to six sites that process the aliquots using the CellSearch system for CTC enumeration while 
at one site $7.5 \mathrm{~mL}$ of blood taken before and after the DLA procedure is processed on the CellSearch system. The study will continue through 2019. Here we present the data from the first 19 NSCLC patients that underwent DLA at the University Medical Center Groningen (UMCG). In addition to the peripheral blood and $2 \times 10^{8} \mathrm{MNC}$ DLA aliquot for CTC analysis, leukocyte depletion of $9 \mathrm{~mL}$ ( 10\% of entire DLA product) containing around $\sim 10 \times 10^{8} \mathrm{MNC}$ was performed followed by CellSearch analysis to allow processing of a larger portion of the DLA product.

\subsection{Patients and Methods}

\subsubsection{Patients}

Nineteen patients with stage IV metastatic NSCLC were enrolled in this ongoing study at the UMCG. All patients provided written informed consent and the study was approved by the institutional review board of UMCG. Patient characteristics are provided in table 7.1. Blood was collected in CellSave ${ }^{\circledR}$ blood collection tubes (Menarini, Huntingdon Valley, PA, USA) before and after the DLA procedure. Thirteen of the patients had a DLA only before initiation of therapy and six patients before and after the first cycle of therapy.

\subsubsection{Diagnostic leukapheresis procedure}

Leukapheresis were performed using the Spectra Optia ${ }^{\circledR}$ (Terumo BCT inc, Lakewood, CO, USA). For DLA, the program of the apheresis device was set to the MNC collection procedure and set at a collection flow rate of $1.0 \mathrm{~mL}$ per minute. The duration of the procedure, the total blood volume processed, the volume obtained through apheresis is listed in table 7.1.

Table 7.1: Patient and sample information

$\mathrm{N}$

\begin{tabular}{|c|c|c|}
\hline \multicolumn{3}{|l|}{ Gender } \\
\hline Male & 15 & 74 \\
\hline Female & 5 & 26 \\
\hline \multicolumn{3}{|l|}{ Smoking status } \\
\hline Smoking & 10 & 53 \\
\hline Non-smoking & 4 & 21 \\
\hline Unknown & 5 & 26 \\
\hline \multicolumn{3}{|c|}{ ECOG Performance status } \\
\hline$P S=0$ & 13 & 69 \\
\hline$P S=1$ & 5 & 26 \\
\hline$P S=2$ & 1 & 5 \\
\hline
\end{tabular}


Table 7.1: (continued)

\begin{tabular}{lrr} 
& mean & min-max \\
\hline Weight & & $67-105$ \\
$\quad$ Male $(\mathrm{kg})$ & 78 & $73-88$ \\
$\quad$ Female $(\mathrm{kg})$ & & $174-200$ \\
\hline Length & 181 & $165-180$ \\
$\quad$ Male $(\mathrm{cm})$ & 175 & $45-74$ \\
$\quad$ Female $(\mathrm{cm})$ & 61 & $52-130$ \\
\hline Age & 98 & $2195-6671$ \\
\hline Duration of procedure $(\mathrm{min})$ & 4804 & $43-113$ \\
\hline Processed blood volume $(\mathrm{mL})$ & 86 & $67-256$ \\
\hline DLA product volume $(\mathrm{mL})$ & 147 & $0.78-2.99$ \\
\hline DLA WBC concentration $\left(\times 10^{6} / \mathrm{mL}\right)$ & 1.47 & \\
\hline Volume of DLA for CellSearch $(\mathrm{mL})$ & & 68 \\
\hline
\end{tabular}

A $2 \mathrm{~mL}$ DLA aliquot containing $2 \times 10^{8} \mathrm{MNC}$ was diluted to a final volume of $8 \mathrm{~mL}$ with CellSearch Circulating Tumor Cell Kit Dilution Buffer (Menarini Silicon Biosystems, Huntingdon Valley, PA, USA) stored at room temperature (RT) and transferred into a CellSave tube containing CellSave preservative reagent (Menarini). For leukocyte depletion RosetteSep ${ }^{\mathrm{TM}}$ (Stemcell Technologies, Köln, Germany) 9 mL of DLA product ( 1×109 MNC) was transferred to a 50 $\mathrm{mL}$ tube containing CellSave preservative. In addition, an EDTA vacutainer blood collection tube (Becton Dickinson, Etten Leur, The Netherlands) was taken from the patients to provide erythrocytes necessary for leukocyte depletion. All tubes were kept at RT, at least overnight, until analysis.

\subsubsection{CellSearch sample processing}

CellSave whole blood was run with CellTracks Autoprep using the CTC kit (Menarini) according to manufacturer's instructions. To run the DLA product on a CellTracks Autoprep the $8 \mathrm{~mL}$ was centrifuged at $800 \mathrm{~g}$ for 10 minutes and black tape was added at the position of the tube where the red cells in case whole blood is processed is expected. The tube is placed on the system and will detect the black tape as being the position of the red blood cell layer enabling the processing of the DLA product as if it were whole blood.

\subsubsection{Leukocyte depletion}

Nine $\mathrm{mL}$ of DLA was depleted from leukocytes using the RosetteSep CD45 depletion Cocktail (Stemcell Technologies, Catalog\# 15162). First, erythrocytes were isolated by centrifugation of $9 \mathrm{~mL}$ EDTA blood tubes from each patient at $800 \mathrm{~g}$ for $10 \mathrm{~min}$ followed by the removal of the plasma and buffy coat. Erythrocytes were then added to the DLA product to reach a final 
MNC to erythrocyte ratio of 1:40. Fifty uL of the RosetteSep cocktail was then added for each $1 \mathrm{~mL}$ of sample and incubated for 20 min at RT. After incubation, the sample was diluted with an equal volume of PBS/2\%FBS. The solution was then carefully layered on top of a Ficoll-Paque PLUS density gradient (GE Healthcare, Chalfont St.Giles, UK) and centrifuged at $800 \mathrm{~g}$ for 30 min at RT without brake. The enriched cells were collected and washed by adding 2 volumes of PBS/2\% FBS and centrifuging for 8 min at $800 \mathrm{~g}$. For CellSearch analysis after leukocyte depletion, $9 \mathrm{~mL}$ of sample was transferred to a conical tube and CellSearch dilution buffer was added to a final volume of $14 \mathrm{~mL}$. This sample was then processed using CellSearch according manufacturers' instructions. Also here black tape was added to the tube at the position of the RBC for blood samples to mimic this RBC layer.

\subsubsection{Image acquisition and analysis}

All CellSearch cartridges were scanned using the CellTracks Analyzer II (Menarini). The stored images were analyzed with the CellTracks Analyzer software to manual assess the number of CTC as well as by the ACCEPT open source image analysis software to quantify the total number of nucleated events, the number of leukocytes and the number of tumor derived Extracellular vesicles (tdEVs). The following gates were used: for nucleated events DNA mean intensity $>5$, a DNA perimeter $>16$ and a DNA eccentricity $\leq 0.95$; for tdEV, DNA mean intensity $\leq 5$, CK mean intensity $>60$, CK max intensity $>90$, CK eccentricity $\leq 0.8, C K$ size $\leq 150$, CK perimeter $>5$ and CD 45 mean intensity $\leq 5$; for leukocytes (CD45+ cells) DNA mean intensity $>10$, DNA size $>16$, CD 45 mean intensity $>10$ and $C K$ mean intensity $\leq 5 ., 11$

\subsubsection{Single cell isolation}

CellSearch cartridges were stored at $4^{\circ} \mathrm{C}$ for a maximum of 24 hours before further processing. The content of the cartridge was transferred using a Pasteur pipette to a round bottom $5 \mathrm{~mL}$ FACS tube and washed twice with $200 \mu \mathrm{L}$ dilution buffer to ensure removal of the majority of cells from the cartridge. Tube with cells was placed onto a FACS ARIA II (BD Biosciences) equipped with a $375 \mathrm{~nm}, 488 \mathrm{~nm}$ and $633 \mathrm{~nm}$ laser and a single cell deposit unit which was used for single CTC sorting. The instrument was calibrated using CS\&T beads (BD; cat. 641412) before use. Before sorting, the sort gates and the number of cells to be sorted into the 96 wells were set. Cells were sorted into flexible unskirted 96 wells plates (Bio-Rad) containing $5 \mathrm{uL}$ storage buffer (50\% 1x PBS, 7.5\% DMSO and 42.5\% 2x ProFreeze-CMD (Lonza, Breda, The Netherlands)). Plates were centrifuged and cells were stored at $-80^{\circ} \mathrm{C}$ until further processing. 


\subsubsection{CNV analysis}

Pre-amplification-free scWGS library preparation, Illumina sequencing and data analysis was performed according to the protocol described elsewhere. ${ }^{12}$

\subsubsection{Statistical analysis}

Statistical analysis was performed using OriginPro 2017 (OriginLab Corporation, Northampton MA, US) using the paired sample t-test and paired Wilcoxon signed rank test.

\subsection{Results}

\subsubsection{Hematology parameters before and after DLA}

Nineteen patients underwent a diagnostic leukapheresis procedure. The hematocrit $(\mathrm{Ht})$, number of white blood cells (WBC), platelets (Pt), granulocytes (Gran), lymphocytes (Lym) and monocytes (Mon) were determined pre and post apheresis in 19 NSCLC patients and results are shown in figure 7.1. Although all blood parameters show a significant decrease after apheresis ( $p<0.05$ ) no noticeable side effects were observed. These observations are in line with expectations after apheresis and are still within laboratory reference ranges for healthy adults. These blood parameters will return to the values before apheresis depending on blood component ranging from hours uptill weeks. ${ }^{13-15}$

a

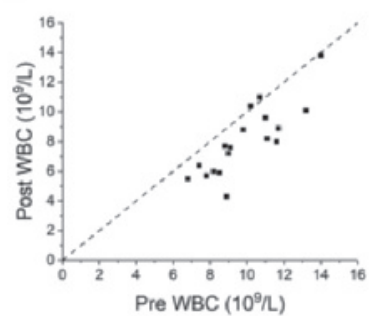

d

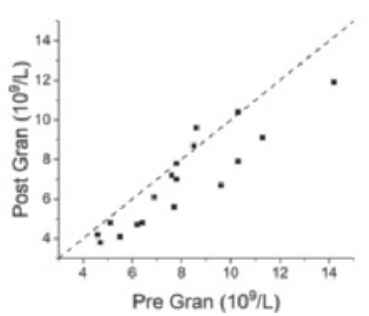

b

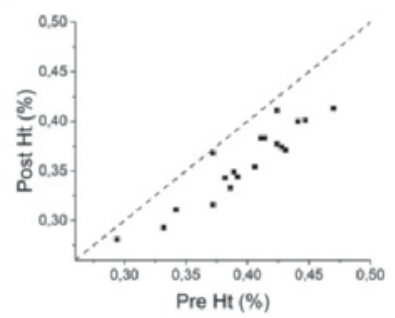

e

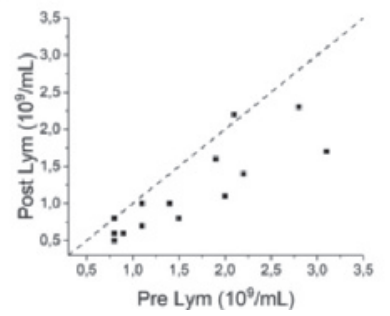

C

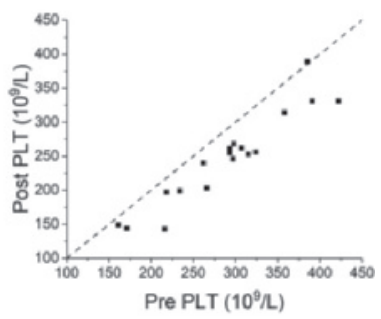

$f$

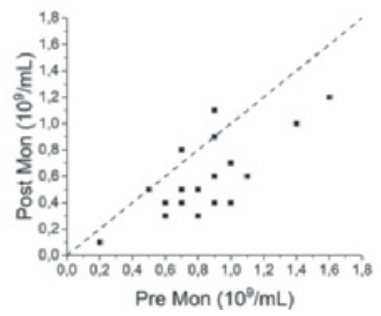

Figure 7.1: Blood composition correlation. Values of several blood components measured in whole blood before and after diagnostic leukapheresis procedure. a) WBC counts b) hematocrit c) platelet counts d) granulocytes e) lymphocytes f) monocytes. 


\subsubsection{CTC in 7.5 mL of blood before and after DLA}

The number of CTC in $7.5 \mathrm{~mL}$ of blood from 19 NSCLC patients was determined before and after the DLA procedure. CTC were detected in $7.5 \mathrm{~mL}$ of blood in 6 out of 19 (26\%) samples before DLA, and 5 out of 19 (21\%) samples after DLA. The correlation in number of CTC before and after the DLA procedure for each of the 19 patients is shown in figure 7.2a. As the CTC numbers are too low to determine whether or not CTC number decreased after DLA we determined the number of tumor derived Extracelluar Vesicles (tdEVs). Figure 7.2b shows the correlation of the number of $t d E V$ before and after DLA. Both the number of CTC $(p>0.34)$ and tdEV ( $p>0.19$ ) show no significant difference before and after DLA procedure.

a

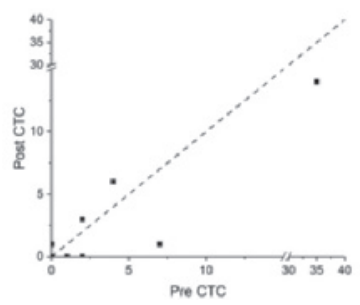

b

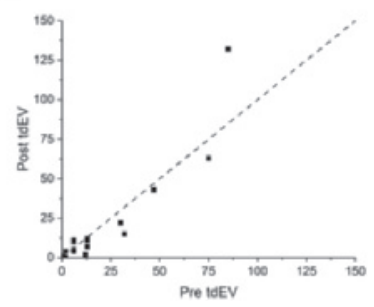

Figure 7.2: The number of CTC (a) and tdEV (b) in blood before and after diagnostic leukapheresis.

\subsubsection{CTC in $\mathbf{7 . 5} \mathrm{mL}$ of blood and $2 \%$ and $10 \%$ aliquot of DLA}

Figure 7.3 shows the number of CTC detected by CellSearch in the two $7.5 \mathrm{~mL}$ whole blood samples and the CellSearch counts in the $2 \times 10^{8}$ cells DLA aliquot (2\%) of DLA representing $\sim 80 \mathrm{~mL}$ of blood and the $9 \mathrm{~mL}$ DLA aliquot (10\%) after leukocyte depletion representing 500 $\mathrm{mL}$ of blood. In $15 \mathrm{~mL}$ of whole blood in 7 out of 19 (37\%) patients one or more CTC were detected. In the 2\% DLA aliquot in 12/19 (63\%) of patients one or more CTC were detected and in the 10\% DLA aliquot in 17/19 (89\%) of patients one or more CTC were detected. In the 7 patients with CTC detected in $15 \mathrm{~mL}$ of blood the fold increase in the 2\% DLA aliquot ranged from 0 - 11 (mean 3.3 which is below the expected five-fold increase in CTC. In the leukocyte depleted DLA aliquot a 27-fold increase in CTC is expected which is not obtained in any of the samples and increase in CTC ranged from 0.1 - 5 (mean 1.9). Still the number of patients in which a CTC could be detected increased significantly (from 7/19 to 17/19). In the figure the samples with no CTC in blood, but with CTC in the DLA or the leukocyte depleted DLA are indicated with green and blue dots respectively. In one patient depicted by red dots in the figure, 7 CTC were detected in one tube and 1 in the other tube, whereas no CTC were detected in the $2 \mathrm{~mL}$ DLA aliquot and only 1 CTC in the leukocyte depleted DLA aliquot. Review of the CTC images showed that all 9 CTC were small in size, exhibited features of apoptosis, but fell within the criteria of a CTC. 


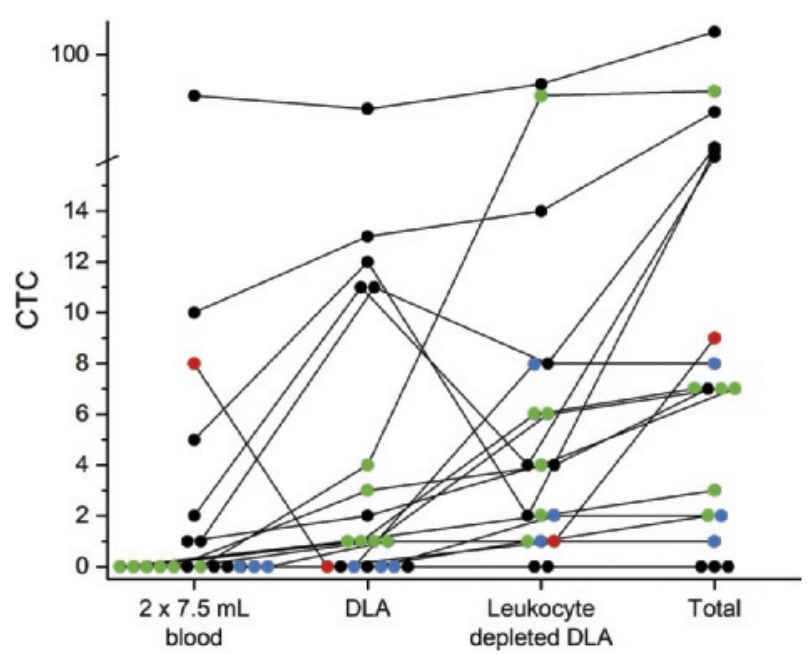

Figure 7.3: CTC counts plotted for each of the samples processed. CTC counts of individual patients are connected by a line. The red color highlights the patient in which CTC were detected in the blood but not in the $2 \mathrm{~mL}$ DLA aliquot. The green color indicated patients in which CTC were not detected in blood, but in $2 \mathrm{~mL}$ DLA aliquot and in blue those with no CTC in blood and $2 \mathrm{ml}$ DLA aliquot but CTC in the 10\% DLA aliquot.

To explore whether the number of CD45+ leukocytes and nucleated cells of unknown origin in the CellSearch cartridges after EpCAM enrichment could explain some of the variable results in CTC yield they were enumerated using ACCEPT and results presented in figure 7.4. The expected number of CTC in the leukocyte depleted DLA was calculated based on the amount of CTC detected in the DLA directly processed by CellSearch. Samples were divided in 3 groups based on their recovery of CTC in the depleted samples. Samples with $<25 \%$ recovery, $25-75 \%$ recovery and $>75 \%$ recovery are indicated in figure 7.4 with respectively orange, blue and green. No clear pattern is observed that could explain the differences in recovery rates.

The number of nucleated cells after processing with CellSearch was similar for peripheral blood and the DLA sample whereas a slightly higher number (not significant) of nucleated cells were present in the leukocyte depleted DLA cartridges. The fraction of nucleated cells in which CD45 could be detected on the surface was relatively larger in the DLA which can be explained by the relatively low fraction of granulocytes in the DLA sample. Expression of CD45 is lower on granulocytes as compared to lymphocytes and is simply not detected by the CellTracks Analyzer II. ${ }^{16}$ The fraction of nucleated cells in which CD45 is detected is lowest in the leukocyte depleted fraction compared to blood or DLA cartridges, which can be explained by the leukocyte depletion prior to processing the DLA as this will deplete the lymphocytes more effectively in addition the CD45 antigen for detection will be less accessible as it was targeted by the depletion. 


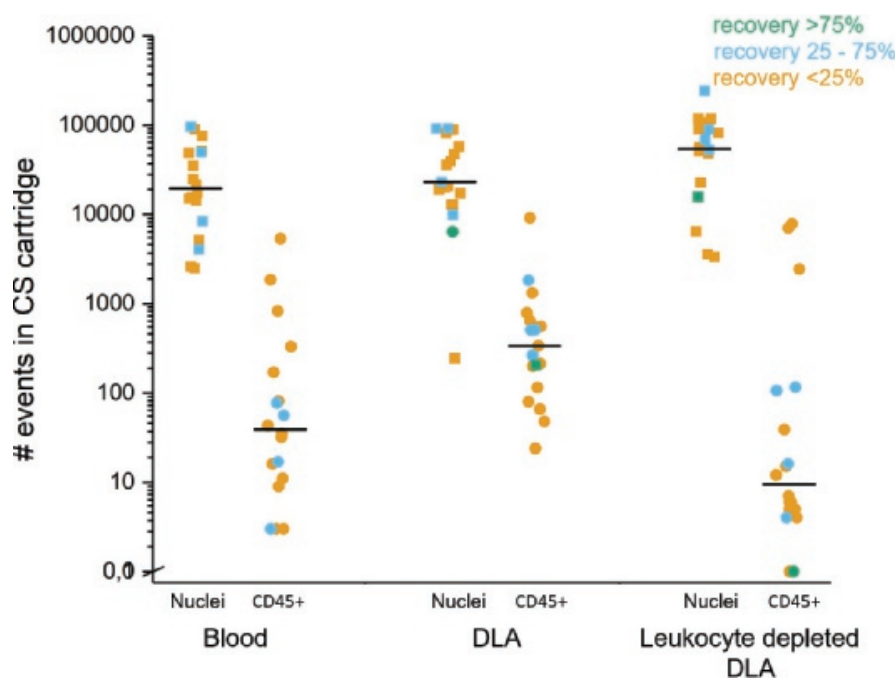

Figure 7.4: Various events in CellSearch cartridges of different sample types. ACCEPT was used to determine the total number of nucleated, and CD45+ events for blood, DLA and leukocyte depleted DLA samples. Recovery CTC rates in the depleted DLA are indicated using colors.

\subsubsection{Molecular confirmation of cancerous origin of CTC}

From one of the patients which had 11 CTC detected in the DLA product, cells were analyzed for genomic aberrations. Eight single cells were sorted and from 4 of these cells the isolated DNA was sufficient to perform Copy Number Variation (CNV) analysis. The CNV profiles of these 4 CTC are shown in figure 7.5. All 4 cells show clear genetic aberration by various kinds of polysomy and confirmed their cancerous origin.

СTC 1

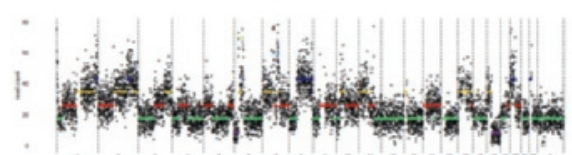

CTC 3

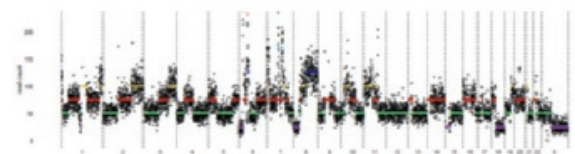

CTC 2

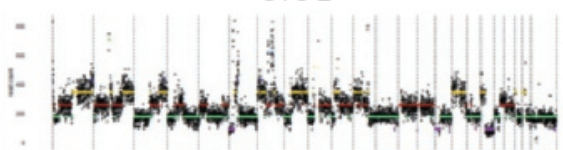

СTC 4

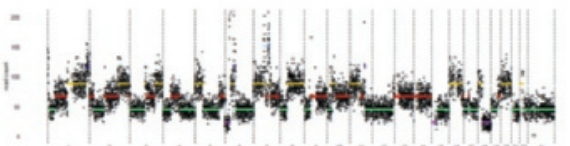

Figure 7.5: CNV profiles of 4 individually sorted cells. All 4 CTC show chromosomal polysomy indicating tumor origin of the cells. 


\subsubsection{CTC before and after initiation of therapy}

In six NSCLC patients DLA was performed before and after initiation of therapy. A follow up procedure would be planned at the time therapy efficacy was evaluate, which is normally around 6 - 12 weeks depending on the given therapy (chemotherapy 6 - 9 weeks, immunotherapy at 6 - 12 weeks and for targeted therapy at 4 - 12 weeks). The after therapy procedures were in general within 5 months after the start of therapy. The number of CTC in the peripheral blood and DLA was determined and added together to obtain a 'total' CTC count, and is shown in figure 7.6. In 4 of the 6 patients the number of CTC decreased after therapy and in two patients CTC were detected after initiation of therapy but not before therapy. Columns are stacked with the amount of CTC found in each sample type. From 4 patients with a CTC decrease, 3 had a partial response and 1 had a complete resection of the tumor. Patient 5 who had an increase of CTC had progressive disease and patient 6 shows an increase in CTC but partial response to therapy. In 5 out of these 6 patients response seems to correlate with CTC counts measured before and after initiation of therapy.

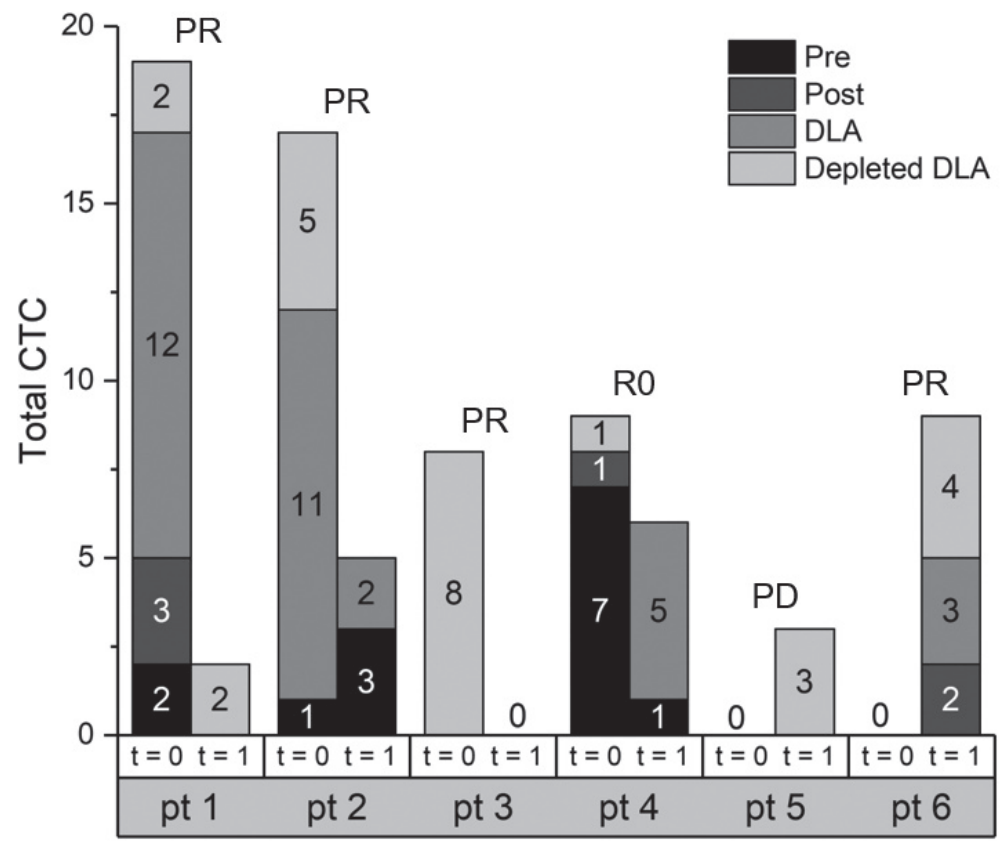

Figure 7.6: Total CTC counts obtained per patient by adding the blood CTC count pre-DLA and post-DLA, the DLA count and the leukocyte depleted CTC counts. This was performed for each of the 6 patients before and after start of treatment. $(n=6)$. Therapy response is indicated above $C T C$ count columns. $P R=$ partial response, $R O=$ complete resection, $\mathrm{PD}=$ progressive disease. 


\subsection{Discussion}

In this ongoing study we showed that in 19 stage IV NSCLC patients the DLA procedure was well tolerated and CTC could be isolated from the DLA product. The mononuclear blood fraction obtained represented $2.2-6.7$ liters of blood (mean $=4.8$ ) resulting in a mean DLA volume of $86 \mathrm{~mL}$ ( $\min =43$, $\max =113$ ). Although the blood composition after the DLA showed a significant decrease of the standard hematologic parameters (figure 7.1) they stayed within the reference range and did not cause any problems. For CTC no such decrease could be observe which was confirmed by the tdEV counts which appear in a higher frequency as compared to CTC. The number of CTC and tdEV in these patients was however to small in this cohort of patients to draw the conclusion that CTC are not decreased through the DLA procedure. Whether or not CTC and tdEV recover faster to their original values as compared to the standard hematology parameters maybe obtained when data from all patients in this study are available.

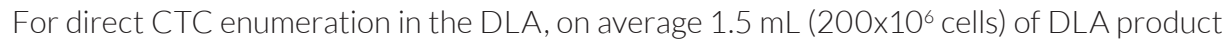
which is around $2 \%$ of the DLA entire product was processed. $200 \times 10^{6}$ was used as the maximum number of cells that could be directly processed in a CellSearch run without overloading the system. This resulted in an increase of 1 or more CTC from 37\% to $63 \%$ of the patients. which increased to $89 \%$ when $9 \mathrm{~mL}$ of DLA product (10\%) was depleted of leukocytes and then processed using CellSearch. Although these findings are encouraging the increase in yield of CTC is disappointing and will need further investigation. From the 7 patients with CTC detected in two aliquots of $7.5 \mathrm{~mL}$ of blood the expected increase in $2 \mathrm{~mL}$ of DLA was 5.3 but only an 3.3 fold increase was found and in the $9 \mathrm{~mL}$ of DLA an increase of 26.6 was expected but only an increase of 1.9 was found. The relatively lower yield in the $9 \mathrm{~mL} D L A$ can likely be contributed to the leukocyte depletion of the DLA as the CellSearch analysis was similar to that of the directly processed DLA. The lower than expected recovery of the CTC from the directly processed DLA samples maybe caused by a loss during the DLA procedure. The Spectra Optia apheresis machine was set such that the majority of granulocytes are not within the collected MNC fraction and as CTC have a very heterogenous morphology and some containing fragmented nuclear material similar to granulocytes a portion may well not be collected in the MNC fraction. On the other hand the very small CTC may also fall outside the MNC collection window. Experiments in which different collection windows are used during the DLA and the subsequent CellSearch analysis of these fractions could address these issues. NSCLC is however not the best disease to address these questions as the relative peripheral tumor load is low and metastatic breast or prostate cancer patients would be better to answer 
these questions. A less likely cause of CTC loss is loss by the CellSearch system as we could not show any relation between recovery and the carry-over of leukocytes and nucleated cells not identified by CD45 or Cytokeratin. Although the leukocyte depletion enabled us to process a large DLA volume the CTC loss is to large and new CTC enrichment procedures will be needed to process the whole DLA volume.

For a thorough, molecular characterization of the tumor an assessment of heterogeneity is important, thereby implying the need for an assessment of the individual cells. A question that cannot be answered is how many molecular characterized tumor cells from how many tumor sites are needed to properly answer this question. For molecular characterization of single CTC, cells were removed from the CellSearch cartridge and sorted by FACS. Cells were then sequenced and CNV analysis was performed. Results from one patient showed chromosomal polysomy indicating cancerous origin of the cells. Molecular characterization cells of other patients yet have to take place.

In six patients DLA was obtained before and after initiation of therapy. Figure 7.6 shows how CTC counts correlate with treatment response in 5 out of these 6 patients. Three patients have partial response and a corresponding decrease in CTC counts. Noteworthy, patient two initially had a partial response which changed to progressive disease right after the second DLA. It might have been that CTC were lower during treatment and were increasing again as disease was becoming progressive. Patient 6 has a partial response but shows an increase in CTC counts which is contradictory.

We conclude that the use of DLA increases the number of patients where CTC are detected and the number of CTC that can be isolated. Processing a larger portion of DLA by leukocyte depletion increases the number of CTC positive patients even more. However, further improvements on CTC enrichment technologies are needed to truly gain advantages of DLA as many CTC are lost during depletion. 


\section{References}

1 S. J. Cohen, C. J. A. Punt, N. lannotti, B. H. Saidman, K. D. Sabbath, N. Y. Gabrail, J. Picus, M. Morse, E. Mitchell, M. C. Miller, G. V Doyle, H. Tissing, L. W. M. M. Terstappen and N. J. Meropol, J. Clin. Oncol., 2008, 26, 3213-3221.

2 M. Cristofanilli, G. T. Budd, M. J. Ellis, A. Stopeck, J. Matera, M. C. Miller, J. M. Reuben, G. V Doyle, W. J. Allard, L. W. M. M. Terstappen and D. F. Hayes, N. Engl. J. Med., 2004, 351, 781-791.

3 J.S. de Bono, H. I. Scher, R. B. Montgomery, C. Parker, M. C. Miller, H. Tissing, G. V Doyle, L. W. W. M. Terstappen, K. J. Pienta and D. Raghavan, Clin. Cancer Res., 2008, 14, 6302-6309.

4 D. F. Hayes, M. Cristofanilli, G. T. Budd, M. J. Ellis, A. Stopeck, M. C. Miller, J. Matera, W. J. Allard, G. V Doyle and L. W. W. M. Terstappen, Clin. Cancer Res., 2006, 12, 4218-24.

5 T. J. N. Hiltermann, M. M. Pore, A. van den Berg, W. Timens, H. M. Boezen, J. J. W. Liesker, J. H. Schouwink, W. J. A. Wijnands, G. S. M. A. Kerner, F. A. E. Kruyt, H. Tissing, A. G. J. Tibbe, L. W. M. M. Terstappen and H. J. M. Groen, Ann. Oncol., 2012, 23, 2937-42.

6 M. G. Krebs, R. Sloane, L. Priest, L. Lancashire, J.-M. Hou, A. Greystoke, T. H. Ward, R. Ferraldeschi, A. Hughes, G. Clack, M. Ranson, C. Dive and F. H. Blackhall, J. Clin. Oncol., 2011, 29, 1556-63.

7 F. A. W. Coumans, S. T. Ligthart, J. W. Uhr and L. W. M. M. Terstappen, Clin. Cancer Res., 2012, 18, 57115718.

8 J. C. Fischer, D. Niederacher, S. A. Topp, E. Honisch, S. Schumacher, N. Schmitz, L. Zacarias Föhrding, C. Vay, I. Hoffmann, N. S. Kasprowicz, P. G. Hepp, S. Mohrmann, U. Nitz, A. Stresemann, T. Krahn, T. Henze, E. Griebsch, K. Raba, J. M. Rox, F. Wenzel, C. Sproll, W. Janni, T. Fehm, C. A. Klein, W. T. Knoefel and N. H. Stoecklein, Proc. Natl. Acad. Sci. U. S. A., 2013, 110, 16580-5.

9 K. C. Andree, A. Mentink, L. L. Zeune, L. W. M. M. Terstappen, N. H. Stoecklein, R. P. Neves, C. Driemel, R. Lampignano, L. Yang, H. Neubauer, T. Fehm, J. C. Fischer, E. Rossi, M. Manicone, U. Basso, P. Marson, R. Zamarchi, Y. Loriot, V. Lapierre, V. Faugeroux, M. Oulhen, F. Farace, G. Fowler, M. Sousa Fontes, B. Ebbs, M. Lambros, M. Crespo, P. Flohr and J. S. de Bono, Int. J. Cancer, 2018, 143, 2584-2591.
10 M. B. Lambros, G. Seed, S. Sumanasuriya, V. Gil, M. Crespo, M. S. Fontes, R. Chandler, N. Mehra, G. Fowler, B. Ebbs, P. R. Flohr, S. Miranda, W. Yuan, A. Mackay, A. Ferreira, R. Pereira, C. Bertan, I. Figueiredo, R. Riisnaes, D. Nava Rodrigues, A. Sharp, J. Goodall, G. Boysen, S. Carreira, D. Bianchini, P. Rescigno, Z. Zafeiriou, J. Hunt, D. Moloney, L. Hamilton, R. P. L. Neves, J. F. Swennenhuis, K. C. Andree, N. H. Stoecklein, L. W. Terstappen and J.S. de Bono, Clin. Cancer Res., 2018 clincanres.0862.2018.

11 A. Nanou, F. A. W. Coumans, G. van Dalum, L. L. Zeune, D. Dolling, W. Onstenk, M. Crespo, M. S. Fontes, P. Rescigno, G. Fowler, P. Flohr, C. Brune, S. Sleijfer, J. S. de Bono, L. W. M. M. Terstappen, A. Nanou, F. A. W. Coumans, G. van Dalum, L. L. Zeune, D. Dolling, W. Onstenk, M. Crespo, M. S. Fontes, P. Rescigno, G. Fowler, P. Flohr, C. Brune, S. Sleijfer, J. S. de Bono and L.W. M. M. Terstappen, Oncotarget, 2018, 9, 19283 19293.

12 H. van den Bos, D. C. J. Spierings, A. Taudt, B. Bakker, D. Porubský, E. Falconer, C. Novoa, N. Halsema, H. G. Kazemier, K. Hoekstra-Wakker, V. Guryev, W. F. A. den Dunnen, F. Foijer, M. Colomé-Tatché, H. W. G. M. Boddeke and P. M. Lansdorp, Genome Biol., 2016, 17 , 116.

13 R. P. Thokala, K. Radhakrishnan, A. Anandan and V. K. Panicker, J. Clin. Diagnostic Res., 2016, 10, EC01ECO4.

14 L. J. Burns, B. R. Logan, P. Chitphakdithai, J. P. Miller, R. Drexler, S. Spellman, G. E. Switzer, J. R. Wingard, C. Anasetti and D. L. Confer, Biol. Blood Marrow Transplant., 2016, 22, 1108-1116.

15 L. J. Dumont, L. Lassahn, P. A. Tomasulo, D. Harpool, S. Pinkard, N. Rugg, J. A. Cancelas, S. Landry, D. R. Ambruso, C. Clementi and R. Schuyler, Blood.

16 S. de Wit, L. Zeune, T. Hiltermann, H. Groen, G. Dalum, L. Terstappen, S. De Wit, L. L. Zeune, T. J. N. Hiltermann, H. J. M. Groen, G. Van Dalum and L. W. M. M. Terstappen, Cancers (Basel)., 2018, 10, 377. 
Increasing Yield of CTC in NSCLC Patients Through DLA 

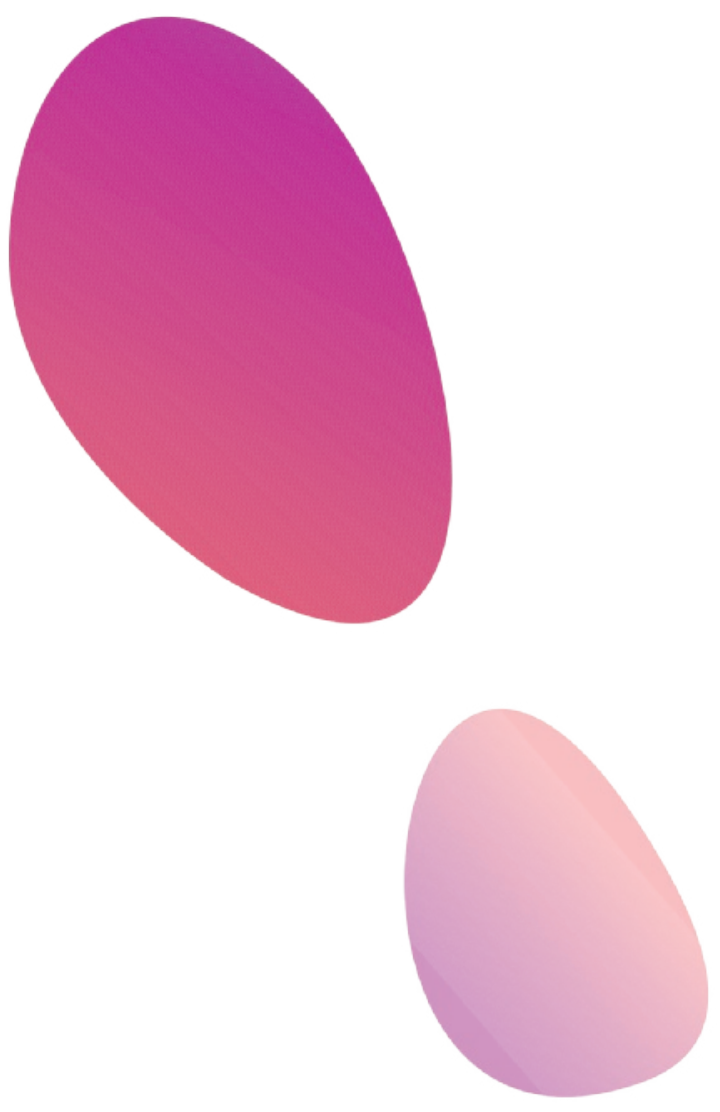


\section{CHAPTER 8}

\section{Conclusions \& Outlook}


Over the last decades, the increasing number of treatment options for patients with metastatic cancer has increased significantly, creating an accompanying need for biomarkers to determine whether the tumor(s) will respond to the intended therapy, to monitor drug efficacy and to anticipate on drug resistance. Ideally, these biomarkers would be obtained by minimal invasive means to allow serial sampling over a longer period of time. Identification and characterization of circulating tumor cells (CTC), to enable molecular analyses of tumor heterogeneity as well as drug responsiveness, may satisfy this need and commonly is referred to as a 'liquid biopsy'. The current standard for CTC detection is the FDA cleared CellSearch system. CellSearch captures CTC, from $7.5 \mathrm{~mL}$ of whole blood, based on their expression of the EpCAM antigen. CTC are then stained using DAPI (nucleus), anti-cytokeratin's and anti-CD45 (leukocytes). All DAPI+, CK+ and CD45- events which are at least 4 $\mu \mathrm{m}$ in size are enumerated as CTC. However, the number of CTC that are detected with the CellCearch system in patients with metastatic carcinomas is in most cases too small to reliably determine heterogeneity and to be representative as a 'liquid biopsy'. As previous studies ${ }^{1,2}$ predicted that sampling more blood, up to $7.5 \mathrm{~L}$, would result in detecting CTC in all metastatic cancer patients with an almost 95\% probability, approaches to analyze larger blood volumes are therefore of utmost importance.

\section{CTC isolation and characterization}

Approaches to isolate CTC from large blood volumes were attempt in chapter 5. Here a therapeutic apheresis device (CTCTrap) was developed and evaluated. Goal of the CTCTrap device was to capture CTC and then reintroduce the blood depleted of tumor cells back into the body with the promise to obtain CTC in all metastatic cancer patients. The development took place within the CTCTrap consortium were universities, research institutions and small and medium enterprises (SMEs) were linked in a joint effort to use therapeutic apheresis (TA), for the collection of CTC from peripheral blood in cancer patients, working towards answering the need for higher CTC numbers. Results after evaluation of the CTCTrap device indicated that the use of the device is not suitable for processing large volumes. It was therefore decided to continue using alternative techniques. Diagnostic LeukApheresis (DLA) was introduced to increase the amount of blood that can be analyzed. Using leukapheresis 1 - $5 \mathrm{~L}$ of blood can be processed and CTC can be extracted from this volume. Several technologies where evaluated to isolate CTC from DLA products. This resulted in the development of a leukocyte depletion protocol based on the commercially available RosetteSep CTC enrichment kit. Leukocyte depletion using RosetteSep was, next to CellSearch and filtration using VyCAP microsieves, evaluated as the most promising method to isolate CTC from large volumes with large cell numbers. 
In chapter 6 and chapter 7 the workflows as developed in chapter 5 were applied and evaluated in multi-center studies using both blood and DLA product from metastatic breast, prostate and non-small cell lung (NSCLC) cancer patients. Results showed that the use of DLA, compared to blood, results in successful detection of higher CTC numbers in patients with metastatic disease and increasing the percentage of patients were CTC can be detected. To be more specific, in metastatic breast and prostate cancer, the majority of patients have CTC in $7.5 \mathrm{~mL}$ of blood using CellSearch. Big advantage here is that by using DLA the amount of CTC could be increased with an average of 6 -fold using the same CellSearch test. This in contrast to NSCLC patients, were only $37 \%$ of the patients have CTC in $7.5 \mathrm{~mL}$ of blood according to CellSearch. This percentage could be increased to 63\% when processing DLA using CellSearch and even up to $89 \%$ when using leukocyte depletion.

Biggest challenge here is processing the large amount of DLA volume and the high cell numbers that come with it. Conventional CTC enumeration technologies (i.e. CellSearch) are only able to process a small fraction $(\sim 5 \% / 2 \mathrm{~mL})$ of an entire DLA product. We introduced a combination of CD45 depletion followed by CellSearch analysis allowing the processing of larger amounts of DLA product. Though we were able to process 9 - $18 \mathrm{~mL}$ of DLA product using this combination of techniques, steps have to be made to be able to process an entire DLA volume ( $60 \mathrm{~mL})$. In theory an entire DLA sample could be processed using RosetteSep leukocyte depletion followed by CellSearch. The need for sufficient red blood cells (RBC) amounts for successful rosette formation could be fulfilled by adding donor RBC or drawing additional RBC from the patient. However, results also indicate that a considerable amount of CTC are lost during RosetteSep depletion and therefore other approached should be pursued.

One of the approaches, to be able to processes an entire DLA volume, could be the in chapter 2 introduced antibody functionalized glass slides to capture CTC. The affinity and binding efficacy of four different anti-EpCAM antibodies was shown. This approach was continued in chapter 3 were microfluidic chips with a functionalized surface were used to isolate cells from blood. Big advantage here is the dynamic set-up used where the sample volume can change and new sample can be added continuously. This in contrast to, for example the CellSearch system where static conditions limit to processing only a fixed volume. In the set-up as presented in chapter 3 capacity is limited to processing $7.5 \mu \mathrm{L} / \mathrm{min}$. This however can be scaled up by stacking multiple glass chips or running several chips in parallel, allowing the processing of larger volumes within the same time frame. 
Another approach to process an entire DLA product could be by the re-use of EpCAMferrofluids. Work has started on a novel technology which enables the enrichment of CTC from large sample volumes. The technology is based on the ability to re-use antibody labelled ferrofluids after immunomagnetic separation. The proposed workflow would look like this: ferrofluids targeting CTC are added together with a first aliquot of DLA sample to a reaction tube and is incubated. Magnetic separation then separates the ferrofluids and the captured cells from the unwanted unbound cells. The unbound fraction of the sample is aspirated and removed. The next sample aliquot can now be added to the tube, and the ferrofluids and already captured cells will be resuspended into the new sample aliquot. Incubation allows the ferrofluids to bind the CTC in the new aliquot. The tube can now be placed against a magnet for magnetic separation of the ferrofluids along with the captured cells from the first, but now also from the second aliquot. The process can be repeated until the complete sample volume has been processed. As the relative amount of ferrofluids that actually bind to the rare cancer cells is neglectable, practically all ferrofluid is unbound and can be re-used. Proof of principle experiments of the technology have been successfully conducted. Biggest challenge here is the binding of leukocytes to the ferrofluids and the aggregation of ferrofluids diminishing the amount of unused ferrofluids which might affect the efficacy of tumor cells capture after several rounds of re-using the ferrofluids. Therefore the development of the ferrofluids, with high affinity for tumor cells, low a specific binding and no aggregation after magnetic separation and resuspension is something that needs extensive dedication.

In this thesis and other studies ${ }^{3}$ it has been shown that CTC counts can be increased in metastatic cancer patients by using DLA as sample material. The question remains if the same is true for non-metastatic patients. The next step will be to confirm whether the use of DLA can be useful in early detection of metastatic disease. If this holds true the use of a liquid biopsy during the whole course of the disease becomes more realistic. Repeated sampling during the course of disease can help guiding therapy and in the end lead to the possibility to apply a therapy to the individual patient (personalized medicine). To do so, response of therapy to the CTC need to be measured and molecular characterization of tumor cells is necessary to determined therapy targets and to monitor molecular changes and tumor heterogeneity over time.

In chapter 4 we used self-seeding microwell chips to isolate individual viable circulating tumor cells. This microwell chips can be used to isolate single cells from an enriched sample after which DNA or RNA can be isolated and analyzed. The workflow for CTC isolation followed by DNA analysis using the microwell ships has been shown before ${ }^{4}$. DNA analysis 
can be used to determine mutations or copy number variations within the genome, thereby revealing potential treatment targets. Currently the development of a workflow for single CTC isolation followed by single-cell RNA sequencing is ongoing which would be helpful in mapping genotypes to phenotypes. In addition, single-cell RNA analysis will facilitate the discovery of novel transcripts, identification of alternatively spliced genes, and detection of allele-specific expression. This might help researchers to discover new and potentially unexpected biological processes and uncover regulatory relationships between genes. The use of DLA to facilitate the capture of large numbers of CTC noninvasively allows for the deconvolution of intrapatient heterogeneity and clonal evolution (Lambros at al. $)^{5}$ This all will help researchers to get a better understanding of cancer which then can help in the development of new treatment options.

The availability of viable tumor cells could significantly improve the disease management of cancer patients and makes personalized medicine one step closer. Drug screening for the identification of compounds with anticancer activity is commonly performed using cultured cell lines. Ideally drug screening should be implemented on patient derived tumor material to define the optimal treatment strategy. Patient-derived tumor xenograft (PDX) models are increasingly used in translational cancer research. These models are useful for drug screening, biomarker development, and the preclinical evaluation of personalized medicine strategies. ${ }^{6}$ These PDX models in mice are often generated using fresh primary or metastatic cancer cells. Recently, the use of CTC to generate PDX models are described and are beginning to assist personalized therapy approaches for example in in $\mathrm{NSCLC}^{7}$ and prostate ${ }^{8}$ cancer. In chapter 4 we showed an approach to isolate viable CTC from blood. The use of these microwells could be combined with drug screening on individual cells inside the wells. Not only could, for example, the influence of cancer drugs on cell viability be monitored but also cell secretion products could be measured. Next to identification of aberrations on the DNA and RNA level of cancer cells, characterization of the protein level is of utmost importance. Tumorspecific markers are usually expressed at much higher levels in cancer cells compared with normal cells, and they are specific to certain tumor types. HER2 and epidermal growth factor receptor (EGFR) are good examples of tumor-associated markers that are also important in the context of targeted therapies. Tissue-specific markers, such as prostate-specific antigen (PSA) for prostate cancer and mammaglobin for breast cancer, have a high specificity but can be downregulated during dedifferentiation of tumor cells. Cell product secretion from cells inside microwells by surface plasmon resonance imaging was shown ${ }^{9,10}$ and ideally, work on this can be continued to allow the same for measurement of the secretome of cancer cells. Other groups now have shown the isolation of viable CTC from DLA products. ${ }^{11}$ Culture of 
these viable cells would allow functional and molecular analysis. Chances of having a successful culture increase with the amount of starting cells. DLA product comprising high CTC counts will therefore be a promising source of material for successful cultures. The increase in CTC counts in chapter 6 and unpublished CTC counts from other groups show that using DLA in especially prostate cancer can provide up to 100.000 CTC per DLA product per patient are promising and showing the true value of using DLA. With these extraordinary cell numbers compared with what can be detected using conventional methods using $7.5 \mathrm{~mL}$ of blood the chances of personalized medicine is becoming much closer. These high cell numbers might provide the opportunity to replace the conventional tissue biopsy, which comes with many disadvantages. Tissue biopsies are more invasive for the patients, sometimes tumor sites are not accessible for a biopsy and more importantly a tissue biopsy might only represent part of the tumor and may not be representative for the entire cancer, especially in case of metastasis. These problems could be answered by the use of DLA. It can be concluded that the source of sufficient CTC material is there, only technologies to enrich these CTC from an entire DLA product have to be further developed and subsequently technologies to perform the right analysis have to be further established.

\section{Alternatives}

An emerging field next to the very rare CTC are so called tumor derived extracellular vesicles (tdEVs). tdEVs, secreted by tumor cells into the extracellular environment, include exosomes, microvesicles, and apoptotic bodies. Their size ranges from approximately $40 \mathrm{~nm}$ to a few $\mu \mathrm{m}$ in size. The growing interest for $\mathrm{tdEV}$ comes from the fact that these vesicles contain a variety of molecules including signal peptides, mRNAs, proteins, and lipids and are involved in local and systemic cell communication, they can be detected in blood and might hold information about the tumor. Recent studies showed that tdEV are significantly increased in castration resistant prostate cancer and are correlated with outcome. ${ }^{12}$ In addition to recent data from our group shows the same metastatic breast, colorectal and NSCLC patients. ${ }^{13}$ Where large tdEVs, which were isolated along with CTC using CellSearch, are a prognostic biomarker. They can be found in frequencies an order of magnitude higher than CTC. The use of tdEVs could therefore be an answer or alternative to the use of DLA for those patients were CTC counts are low or absent in blood. Where the use of DLA provides an increase of CTC counts compared to whole blood, tdEVs do provide information in blood samples lacking sufficient CTC material. These tdEVs could therefore be very well used as alternative to CTC. The question remains however if sufficient information can be subtracted from these tdEVs that represent the tumor and could thereby help guide therapy. 
Next to CTC and tdEV, the use of other biomarker are being pursued. For example cell free circulating tumor DNA (ctDNA), plasma RNA or methylation of cell free DNA. ${ }^{14}$ Elevated concentrations of ctDNA fragments have been found in blood plasma of patients with various cancer types and is associated with unfavorable outcome in some clinical studies. In addition, targeted approaches can be used to analyze single nucleotide mutations or chromosomal rearrangements. ${ }^{14,15}$ These technologies can provide valuable knowledge on the tumor characteristics, also in cases where no CTC can be isolated. Disadvantage of these alternative biomarkers might that they only reflect a part of the disease and don't provide the full story.

\section{Future perspective}

In an ideal situation, one would continuously collect CTC in vivo directly from a peripheral vein. In this way CTC can be collected from a whole blood volume. Even repeated collection of CTC from the same volume could be achieved. A technology like this could potentially be used to analyze large numbers of CTC to facilitate translation of analytical information into future clinical decisions. Very recently, first attempts towards such a device were made by a group from the University of Michigan ${ }^{16}$. They described an in vivo indwelling intravascular aphaeretic CTC isolation system to continuously collect CTC directly from a peripheral vein. After CTC collection the system returns the remaining blood products back into the patient. More specifically, the CTC are being captured on a herringbone shaped chip with a highdensity anti-EpCAM antibody layer on the surface to capture the CTC.

The re-use of ferrofluids for CTC capture as mentioned earlier is a technology which could in theory be used in such a fashion as well. The ferrofluids can be used to deplete CTC continuously from a cancer patient's blood. This could be achieved by creating a device where blood from a patient is entering the device, blood and ferrofluids are mixed after tumor cells bound to the ferrofluids they are magnetically separated from the blood. The blood depleted of tumor cells will re-enter the patient and a new blood fraction from the patient is entering the device to be processed. This could be a continuous process in a wearable device. The simplicity and the limited size of the technology makes it possible to wear it on your body. This creates the possibility for a 'cancer-watch' that continuously samples blood on the presence of the tumor cells. This allows to monitor individuals for the recurrence of cancer that were previously treated but more interesting it allows screening of healthy individuals as well. This ultimate goal will of course require extensive product development, approvals, clinical demonstrations. 


\section{Chapter 8}

Once there would be access to such a device, the amount of tumor cells one would be able to get access to would likely provide sufficient information on the entire cancer and its heterogeneity. The available technologies for (single) cell characterization like analysis of the DNA, RNA or secretome of cells could help guide therapy. Maybe even more important, in case of non-metastatic disease such a device might help in early diagnosis by detection of CTC, indicating the presence of cancer in the body where traditional imaging technologies like (PET, CT scan) or lab blood test are unable to detect. This all would lead to better cancer diagnosis, patients care and reduction in healthcare costs. 


\section{References}

1 F. A. W. Coumans, S. T. Ligthart, J. W. Uhr and L. W. 8 M. M. Terstappen, Clin. Cancer Res., 2012, 18, 57115718.

2 N. H. Stoecklein, J. C. Fischer, D. Niederacher and L. W. M. M. Terstappen, Expert Rev. Mol. Diagn., 2016, 16, 147-164.

3 J. C. Fischer, D. Niederacher, S. A. Topp, E. Honisch, S. Schumacher, N. Schmitz, L. Zacarias Föhrding, C. Vay, I. Hoffmann, N. S. Kasprowicz, P. G. Hepp, S. Mohrmann, U. Nitz, A. Stresemann, T. Krahn, T. Henze, E. Griebsch, K. Raba, J. M. Rox, F. Wenzel, C. Sproll, W. Janni, T. Fehm, C. A. Klein, W. T. Knoefel and N. H. Stoecklein, Proc. Natl. Acad. Sci. U. S. A., 2013, 110, 16580-5.

4 J. F. Swennenhuis, A. G. J. Tibbe, M. Stevens, M. R. Katika, J.van Dalum, H. D. Tong, C. J. M. van Rijn, L. W. M. M. Terstappen, H. Duy Tong, C. J. M. van Rijn and L. W. M. M. Terstappen, Lab Chip, 2015, 15, 3039-46.

5 M. B. Lambros, G. Seed, S. Sumanasuriya, V. Gil, M. Crespo, M. Fontes, R. Chandler, N. Mehra, G. Fowler, B. Ebbs, P. Flohr, S. Miranda, W. Yuan, A. Mackay, A. Ferreira, R. Pereira, C. Bertan, I. Figueiredo, R. Riisnaes, D. N. Rodrigues, A. Sharp, J. Goodall, G. Boysen, S. Carreira, D. Bianchini, P. Rescigno, Z. Zafeiriou, J. Hunt, D. Moloney, L. Hamilton, R. P. Neves, J. Swennenhuis, K. Andree, N. H. Stoecklein, L.W. M. M. Terstappen and J.S. de Bono, Clin. Cancer Res., 2018, 24, 5635-5644.

6 M. Hidalgo, F. Amant, A. V Biankin, E. Budinská, A. T. Byrne, C. Caldas, R. B. Clarke, S. de Jong, J. Jonkers, G. M. Mælandsmo, S. Roman-Roman, J. Seoane, L. Trusolino and A. Villanueva, Cancer Discov., 2014, 4, 998-1013.

7 A. Lallo, M. W. Schenk, K. K. Frese, F. Blackhall and C. Dive, Transl. lung cancer Res., 2017, 6, 397-408.
V. Faugeroux, O. Deas, C. Catelain, E. Pailler, K. Andree, F. Lucibello, E. Alexandrova, J. Judde, N. Stoecklein, J. Scoazec, N. Manaresi, V. Marty, N. Tramalloni, M NgoCamus, C. Nicotra, L. Terstappen, V. Lapierre, K. Fizazi, Y. Loriot and F. Farace, in ACTC, Rhodes, 2017, p. 106.

9 F. Abali, M. Stevens, A. G. J. Tibbe, L. W. M. M. Terstappen, P. N. van der Velde and R. B. M. Schasfoort, Anal. Biochem., 2017, 531, 45-47.

10 F. Abali, J. Broekmaat, A. Tibbe, R. B. M. Schasfoort, L. Zeune and L. W. M. M. Terstappen, Lab Chip, 2019, DOI:10.1039/c9lc00100j.

11 A. Franken, C. Driemel, B. Behrens, F. Meier-Stiegen, V. Endris, A. Stenzinger, D. Niederacher, J. C. Fischer, N. H. Stoecklein, E. Ruckhaeberle, T. Fehm and H. Neubauer, Clin. Chem., 2019, 65, 549-558.

12 A. Nanou, F.A. W. Coumans, G.van Dalum, L. L. Zeune, D. Dolling, W. Onstenk, M. Crespo, M. S. Fontes, P. Rescigno, G. Fowler, P. Flohr, C. Brune, S. Sleijfer, J. S. de Bono and L. W. M. M. Terstappen, Oncotarget, 2018, 9, 19283-19293.

13 A. Nanou, L. L. Zeune, S. de Wit, C. M. Miller, C. J. A. Punt, H. J. M. Groen, D. F. Hayes, J. S. de Bono and L. W. M. Terstappen, in AACR Annual Meeting, Atlanta, 2019.

14 S. Perakis and M. R. Speicher, BMC Med., 2017, 15, 75.

15 K. Pantel and C. Alix-Panabieres, Cancer Res., 2013, 73, 6384-6388.

16 T. H. Kim, Y. Wang, C. R. Oliver, D. H. Thamm, L. Cooling, C. Paoletti, K. J. Smith, S. Nagrath and D. F. Hayes, Nat. Commun., 2019, 10, 1478. 

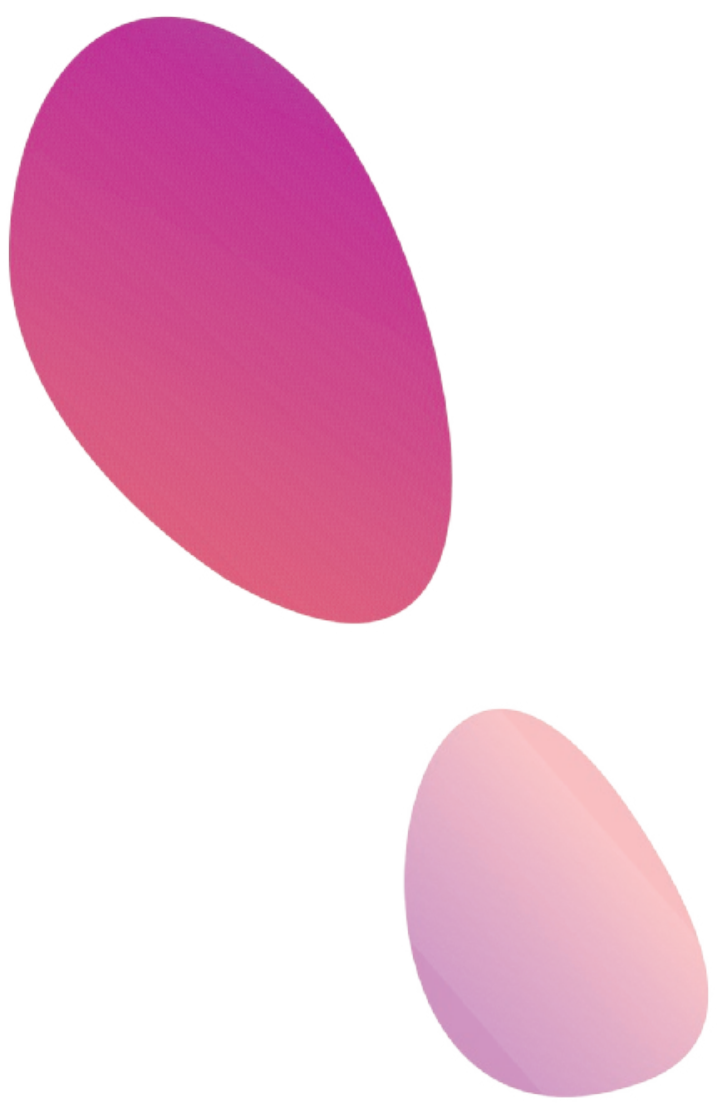
APPENDICES 


\section{Summary}

Cancer is one of the leading causes of death worldwide. For adequate and effective treatment a correct cancer diagnosis is essential. Traditionally, this is done by means of imaging (e.g. ultrasound, CT, MRI scan) and lab tests followed by confirmation through a biopsy of the tumor. Next to these traditional methods, circulating tumor cells can be isolated from blood and used as a liquid biopsy providing a source of information on the tumor characteristics. Circulating tumor cells (CTC) are cells that shed from a tumor site, enter the bloodstream, spread through the body and can form metastases at distant sites. CTC have important prognostic and therapeutic implications but as their numbers are very small, detection is very difficult. CTC are found in frequencies in the order of 1 - 10 CTC per $\mathrm{mL}$ of whole blood in patients with metastatic disease. For comparison, $1 \mathrm{~mL}$ of blood contains around 5 million white blood cells and around 5 billion red blood cells. Current technologies, like CellSearch, usually isolate CTC from $7.5 \mathrm{~mL}$ of blood. Big advantage over traditional tissue biopsies, where often surgery is required, is that sampling blood for CTC isolation is less invasive and can be done repeatedly thereby allowing a source of real-time information during the course of disease. However, in many patients non or very few CTC are detected in $7.5 \mathrm{~mL}$ but predictions suggest that all patients including those who do not have detectable CTC have at least 1 CTC in 5 L of blood. Increasing the processed blood volume would theoretically lead to an overall higher yield of CTC providing a sufficient source of tumor material.

In this dissertation we investigated techniques allowing for the isolation and characterization of CTC from large volumes of blood which would be very beneficial for realizing a successful real-time liquid biopsy.

First, we looked into techniques where antibody functionalized surfaces, targeting CTC, are used to capture tumor cells from blood. For this, the affinity and epitope binding competition of 4 different a-EpCAM antibodies were measured. Next, the optimal antibody and set-up conditions were determined to capture cells on these surfaces and the successful capture of tumor cells from blood was shown. The advantage is that this approach allows us to flow blood, rather than using static conditions, making it possible to process larger volumes.

To characterize tumor cells isolated from blood we developed and evaluated a method using self-seeding microwells to obtain single CTC and assess their potential to proliferate. Using this method we were able to isolate and detect viable CTC from patient blood samples. 
Next, within the CTCTrap consortium we investigated the use of a therapeutic apheresis, for the collection of CTC from peripheral blood in cancer patients. The goal within this consortium was to develop a new apheresis column to capture CTC and then reintroduce the blood depleted of tumor cells back into the body with the promise to obtain CTC in all metastatic cancer patients. Unfortunately, the device developed in this project showed a very low recovery of tumor cells and a high carryover of leukocytes in the processed samples, resulting in no enrichment of tumor cells. Alternatively, the use of diagnostic leukapheresis (DLA) was introduced. During DLA mononuclear cells, including CTC, are isolated from patient blood, which results in a product of approximately $60 \mathrm{~mL}$ which holds the cells of $2 \mathrm{~L}$ of blood. This approach allows us to process liters of blood. Various approaches were pursued to process these large blood volumes from leukapheresis products as current technologies can only process a small portion. This resulted in the development of a leukocyte depletion protocol based on the commercially available RosetteSep kit for the isolation of CTC from large volumes.

The use of DLA and the protocols developed to isolate CTC from large volumes were evaluated in 2 patient studies. In the first study 34 metastatic breast and prostate cancer patients underwent a DLA procedure to obtain a large blood volume. In addition $7.5 \mathrm{~mL}$ from a standard blood draw was processed as a golden standard for CTC enumeration. Using DLA instead of blood, for the enumeration of CTC, resulted in a 0 - 32 fold increase in CTC yield. When using the developed depletion protocol to process a large volume of DLA product the yield was even higher. In the second study we evaluated whether the number of CTC, and the number of patients in which CTC are detected can be increased by the use of DLA in non-small cell lung cancer. The number of non-small cell lung cancer patients in which CTC are detected is relatively low compared to other cancers. CTC were detected in $37 \%$ of patients in $7.5 \mathrm{~mL}$ of blood, in 63\% in a small DLA aliquot and $89 \%$ in a larger leukocyte depleted DLA aliquot.

We show that a significantly larger number of CTC can be obtained by processing a large blood volume through DLA. Although, the technologies to isolate CTC from the vast amount of mononuclear cells in DLA will need to be improved as during processing of the sample part of the CTC get lost. Processing large volumes while recovering the majority of tumor cells stays a challenge which has to be overcome in order to have a sufficient number of tumor cells to represent a biopsy. 


\section{Samenvatting}

Kanker is wereldwijd een van de belangrijkste doodsoorzaken. Voor een adequate en effectieve behandeling is een correcte diagnose cruciaal. Traditioneel gezien wordt dit gedaan doormiddel van het in beeld brengen van de tumor (met behulp van: CT-scan, MRI, of een echo), lab testen en door bevestiging doormiddel van het nemen van een biopt van de tumor. Naast deze traditionele methoden kunnen er ook circulerende tumor cellen (CTC) uit het bloed geïsoleerd worden. Deze cellen kunnen gebruikt worden als een vloeibare biopt waarbij ze dienen als een bron van informatie over de tumor eigenschappen. Circulerende tumor cellen raken los van een primaire tumor, komen in de bloedbaan terecht, verspreiden zich en kunnen vervolgens elders in het lichaam uitzaaiingen veroorzaken. CTC hebben een belangrijke prognostische en therapeutische waarde, echter komen ze in kleine hoeveelheden voor waardoor het moeilijk is ze te detecteren. Ter vergelijking, $1 \mathrm{~mL}$ bloed bevat ongeveer 5 miljoen witte bloedcellen en 5 miljard rode bloedcellen. CTC komen voor in de orde van 1 - 10 CTC per mL bloed in patiënten met uitgezaaide kanker. Huidige technologieën, zoals CellSearch, maken gebruik van 7,5 mL bloed waar de CTC uit geïsoleerd worden. Het grote voordeel ten opzichte van een traditionele biopsie, waar vaak een operatie voor nodig is, is dat bloed makkelijk afgenomen kan worden wat minder belastend is voor de patiënt. Ook kan dit herhaaldelijk gedaan worden waardoor er op elk tijdsmoment een bron van informatie over de ziekte beschikbaar is. Echter worden er in veel patiënten niet of nauwelijks CTC in 7,5 mL bloed gedetecteerd. Voorspellingen laten daarentegen zien dat alle kanker patiënten ten minste 1 detecteerbare CTC hebben in 5 liter bloed. Door het vergroten van het te verwerken bloed volume zou in theorie een hogere opbrengst van CTC moeten plaatsvinden wat zou zorgen voor voldoende beschikbaar tumor materiaal in al deze patiënten.

In dit proefschrift onderzoeken we technieken voor het isoleren en karakteriseren van tumor cellen uit grote volumes bloed wat erg gunstig zou zijn voor het realiseren van een real-time vloeibare biopsie.

Allereerst hebben we gekeken naar het gebruik van antilichaam gefunctionaliseerde oppervlakten, welke gericht zijn tegen CTC, om zo tumor cellen uit bloed te vangen. Hiervoor hebben we van 4 verschillende antilichamen de affiniteit en de onderlinge epitoop binding competitie gemeten. Vervolgens hebben we de optimale voorwaarden voor de antilichamen en de gebruikte opstelling bepaald om tumor cellen te kunnen vangen. Het vangen van tumor cellen uit bloed op deze speciale oppervlakten hebben we succesvol gedemonstreerd. Het voordeel van deze werkwijze is dat we gebruik maken van het stromen van bloed waardoor 
we grotere volumes kunnen verwerken dan wanneer een statische vaste hoeveelheid bloed gebruikt zou worden.

Hierna is er binnen het CTCTrap consortium onderzoek gedaan naar het gebruik van therapeutische aferese voor het verzamelen van CTC uit het bloed van kanker patiënten. Binnen dit consortium was het doel om een nieuw soort aferese kolom te ontwikkelen waarmee CTC uit het bloed van kanker patiënten gevangen worden, waarna dit bloed zonder de tumor cellen terug de patiënt in gaat. Het apparaat dat ontwikkeld werd binnen dit project herwon echter erg weinig tumor cellen en ook werden er veel witte bloedcellen mee gevangen wat betekende dat er eigenlijk geen verrijking van tumor cellen plaats vond. Als alternatief werd het gebruik van een zogenaamde diagnostische leukaferese geïntroduceerd (DLA). Tijdens een DLA-procedure worden alle mononucleaire cellen, inclusief CTC, uit het bloed van een patiënt geïsoleerd. Dit resulteert in een product van ongeveer $60 \mathrm{~mL}$ waar de cellen uit $2 \mathrm{~L}$ bloed in verzameld zijn. Deze aanpak maakt het mogelijk om liters bloed te verwerken, zonder dat het belastend is voor de patiënt. Verschillende aanpakken voor het verwerken van deze volumes zijn getest omdat huidige bestaande technieken enkel in staat zijn om een kleine fractie van dit DLA-product te verwerken. Dit heeft geresulteerd in de ontwikkeling van een leukocyten depletie protocol, gebaseerd op de commercieel verkrijgbare RosetteSep kit, voor het isoleren van CTC uit grote volumes.

Het gebruik van DLA en de ontwikkelde protocollen voor het isoleren van CTC uit grote volumes zijn geëvalueerd in twee patiënten studies. In de eerste studie ondergingen 34 patiënten met uitgezaaide borst of prostaat kanker een DLA procedure, om zo een groot bloed volume te verkrijgen. Daarnaast werd er ook $7,5 \mathrm{~mL}$ bloed geanalyseerd, wat verkregen werd door middel van een standaard bloed afname, en wat fungeerde als 'gouden standaard' voor het tellen van CTC. Door gebruik te maken van DLA in plaatst van bloed voor het tellen van CTC werd er een 0 - 32 voudige vermeerdering van tumor cellen gevonden. Wanneer het ontwikkelde depletie protocol gebruikt werd voor het verwerken van grote hoeveelheden DLA-product werd de opbrengst van CTC nog hoger. In de tweede studie hebben we gekeken of de hoeveelheid CTC en het aantal patiënten waarin we CTC vinden verhoogd kan worden met behulp van DLA in patiënten met niet-kleincellige longkanker. Het aantal niet-kleincellige longkankerpatiënten waarbij CTC in het bloed gevonden worden is relatief laag vergeleken met andere kanker soorten. In deze studie werden CTC gedetecteerd in bloed bij 37\% van de patiënten, in een kleine fractie van het DLA product bij 63\% van de patiënten en in $89 \%$ wanneer we een grote hoeveelheid DLA-product verwerkten met behulp van het leukocyten depletie protocol. 
We hebben laten zien dat door het verwerken van een groot bloed volume door middel van DLA een significant grotere hoeveelheid CTC verkregen kan worden. Echter, de technologieën die gebruikt worden voor het isoleren CTC vanuit de grote hoeveelheid mononucleaire cellen die zich in een DLA-product bevinden kunnen verbetering gebruiken. Tijdens het verwerken van deze samples gaat een deel van de tumor cellen verloren. Het verwerken van deze grote volumes, waarbij we tegelijkertijd de meerderheid van de tumor cellen behouden blijft een uitdaging welke overwonnen dient te worden om voldoende tumor cellen te verkrijgen om representatief te zijn als biopt. 


\section{List of Publications}

\section{Journal Publications}

Tumor Cell Capture from Blood by Flowing across Antibody-Coated Surfaces

K.C. Andree, A. Mentink, A.T. Nguyen, P Goldsteen, G van Dalum, J.J. Broekmaat, C.J.M van Rijn, L.W.M.M. Terstappen

Lab on a Chip, 2019 Mar 13;19(6):1006-1012

Self-Seeding Microwells to Isolate and Assess the Viability of Single Circulating Tumor Cells

K.C. Andree, F. Abali, L. Oomens, F. Passanha, J.J. Broekmaat, J. Kraan, P. Mendelaar, S. Sleijfer, L.W.M.M. Terstappen

International Journal of Molecular Sciences. 2019, 20 (3):477

EpCAM ${ }^{\text {high }}$ and EpCAM low Circulating Tumor Cells in Metastatic Prostate and Breast Cancer Patients S. de Wit, M. Manicone, E. Rossi, R. Lampignano, L. Yang, B. Zill, A. Rengel-Puertas, M. Ouhlen, M. Crespo, A.M.S. Berghuis, K.C. Andree, R. Vidotto, E.K. Trapp, M. Tzschaschel, E. Colomba, G. Fowler, P. Flohr, P. Rescigno, M.S. Fontes, R. Zamarchi, T. Fehm, H. Neubauer, B. Rack, M. Alunni-Fabbroni, F. Farace, J. De Bono, MJ. IJzerman, L.W.M.M. Terstappen

Oncotarget. 2018, 9 (86):35705-16

Single-Cell Analyses of Prostate Cancer Liquid Biopsies Acquired by Apheresis

M.B.K. Lambros, G. Seed, S. Sumanasuriya, V. Gil, M. Crespo, M. Sousa Fontes, R. Chandler, N. Mehra, G. Fowler, B. Ebbs, P. Flohr, S. Miranda, W. Yuan, A. Mackay, A. Ferreira, R. Pereira, C. Bertan, I. Figueiredo, R. Riisnaes, D. N. Rodrigues, A. Sharp, J. Goodall, G. Boysen, S. Carreira, D. Bianchini, P. Rescigno, Z. Zafeiriou, J. Hunt, D. Moloney, L. Hamilton, R.P. Neves, J.S. Swennenhuis, K.C. Andree, N.H. Stoecklein, L.W.M.M. Terstappen, J.S. de Bono

Clinical Cancer Research. 2018, August, clincanres.0862.2018

Toward a Real Liquid Biopsy in Metastatic Breast and Prostate Cancer: Diagnostic LeukApheresis Increases CTC Yields in a European Prospective Multicenter Study (CTCTrap)

K.C. Andree, A. Mentink, L.L. Zeune, L.W.M.M. Terstappen, N.H. Stoecklein, R.P. Neves, C. Driemel, R. Lampignano, L. Yang, H. Neubauer, T. Fehm, J.C. Fischer, E. Rossi, M. Manicone, U. Basso, P. Marson, R. Zamarchi, Y. Loriot, V. Lapierre, V. Faugeroux, M. Oulhen, F. Farace, G. Fowler, M. Sousa Fontes, B. Ebbs, M. Lambros, M. Crespo, P. Flohr, J.S. de Bono International Journal of Cancer. 2018, 143 (10):2584-91 
In Vivo Imaging of Antileukemic Drug Asparaginase Reveals a Rapid Macrophage-Mediated Clearance from the Bone Marrow

L.T. van der Meer, S.Y.A. Terry, D.S. van Ingen Schenau, K.C. Andree, G.M. Franssen, D.M. Roeleveld, J.M. Metselaar, T. Reinheckel, P.M. Hoogerbrugge, O.C. Boerman, F.N. van Leeuwen Journal of Nuclear Medicine. 2017, 58 (2):214-20

Capture of Tumor Cells on Anti-EpCAM-Functionalized Poly(acrylic Acid)-Coated Surfaces

K.C. Andree, A.M.C. Barradas, A.T. Nguyen, A. Mentink, I. Stojanovic, J. Baggerman, J. van Dalum, C.J.M. van Rijn, L.W.M.M. Terstappen

ACS Applied Materials \& Interfaces. 2016, 8 (23):14349-56

Interpolation Method for Accurate Affinity Ranking of Arrayed Ligand-Analyte Interactions

R.B.M.Schasfoort, K.C.Andree, P.N.van der Velde, A.van der Kooi, I.Stojanović, L.W.M.M. Terstappen Analytical Biochemistry. 2016, 500 (February):21-23.

Challenges in Circulating Tumor Cell Detection by the CellSearch System

K.C. Andree, G. van Dalum, L.W.M.M. Terstappen

Molecular Oncology. 2016, 10 (3):395-407

\section{Conference contributions}

\section{Oral presentations}

Circulating Tumor Cells in Diagnostic LeukApheresis Products

DCC-Net Retreat. October 12 2018, Nettetal Germany

Comparison of CTC Enrichment Technologies on DLA

CTC DLA workshop. March 28 2018, Düsseldorf Germany

Isolation and Characterization of CTC in Diagnostic LeukApheresis

3rd Cancer-ID General Assembly Meeting. October 4-7 2017, Rhodos Greece

Circulating Tumor Cells a Real Time Liquid Biopsy

MIRA day. November 3 2016, Enschede Netherlands

Isolation of CTC from DLA

CTCTrap Meeting. 25-26 2016 August, London United Kingdom 
Appendices

Tumor Cell Detection in Diagnostic Leukapheresis

2nd Cancer-ID General Assembly Meeting. March 21-22, 2016, Hamburg Germany

Leukocyte Depletion followed by CTC Detection

Consortium Progress Meeting CTCTrap. September 8-9 2015, Tallin Estonia

Depletion of Leukocytes

DLA workshop. May 19 2015, Düsseldorf Germany

CTC TRAP Update

Annual CTCTrap meeting. September 22-24 2014, Padova Italy

\section{Posters/Abstracts}

Circulating tumor cells in the peripheral blood and leukapheresis product of non-small cell lung cancer patients

K.C. Andree, M. Tamminga, A. Mentink1, T.J.N. Hilterman, H.J.M. Groen, L.W.M.M. Terstappen

ISMRC. 3-5 May 2018, Montpellier France

Self-Seeding Microwells to Isolate and Expand Single Cells

K.C. Andree, F. Abali, J.F. Swennenhuis, F. Passanha, L. Oomens, M. Stevens, J.J Broekmaat, L.W.M.M. Terstappen

ISMRC. 3-5 May 2018, Montpellier France

Leukocyte depletion using ferrofluids to enrich circulating tumor cells

A. Mentink, K. C. Andree, S.D. Brockhuis, L.W.M.M. Terstappen

ISMRC. 3-5 2018, Montpellier France

Circulating Tumor Cells in the Peripheral Blood and Leukapheresis Product of Non-Small Cell Lung Cancer Patients

K.C. Andree, M. Tamminga, A. Mentink, T.J.N. Hilterman, H.J.M. Groen, L.W.M.M. Terstappen AACR. April 2018, Chicago United States 
Tumor cell capture from blood by flowing across antibody-coated surfaces

K.C. Andree, A. Mentink, A. T. Nguyen, G. van Dalum, J. J. Broekmaat, P. Goldsteen, C.J.M. van Rijn, L.W.M.M. Terstappen

ACTC 2017. October 4-7 2017, Rhodos Greece

Establishment and characterization of a circulating tumor cell-derived xenograft in prostate cancer V. Faugeroux, O. Deas, C. Catelain, E. Pailler, K. C. Andree, F. Lucibello, K. Alexandrova, J.G. Judde, N.H. Stoecklein, J. Scoazec, N. Manaresi, V. Marty, D. Tramalloni, M.N. Camus, C. Nicotra, L.W.M.M. Terstappen, V. Lapierre, K. Fizazi, Y. Loriot, F. Farace

ACTC 2017. October 4-7 2017, Rhodos Greece

Leukocyte depletion using ferrofluids to enrich circulating tumor cells

A. Mentink, K.C. Andree, F. al Makindji, G. van Dalum, L.W.M.M. Terstappen

ACTC 2017. October 4-7 2017, Rhodos Greece

Evaluating the consensus in circulating tumor cell scoring

L.L. Zeune, S. Mutter-de Wit, G. van Dalum, K.C. Andree, J.F. Swennenhuis, A. Mentink, A. Nanou, A. Enciso Martinez, L.W.M.M. Terstappen

ACTC 2017. October 4-7 2017, Rhodos Greece

Diagnostic LeukApheresis Results in a Significant Increase in CTC Yield in Metastatic Breast and Prostate Cancer

K.C. Andree, A. Mentink, J.F. Swennenhuis, L.W.M.M. Terstappen, N.H. Stoecklein, R.P. Neves, R. Lampignano, H. Neubauer, T. Fehm, J.C. Fischer, E. Rossi, M. Manicone, U. Basso, P. Marson, R. Zamarchi, Y. Loriot, V. Lapierre, V. Faugeroux, M. Oulhen, F. Farace, G. Fowler, M. Sousa Fontes, B. Ebbs, M. Lambros, M. Crespo, P. Flohr, J.S. de Bono AACR. April 2017, Washington United States

Self-Seeding Microwells to Isolate and Expand Single Circulating Tumor Cells J.F. Swennenhuis, K.C Andree, F. Abali, F. Passanha, J.J Broekmaat, M. Stevens, C.J.M. van Rijn, L.W.M.M. Terstappen

AACR. April 2017, Washington United States 
Diagnostic Leukapheresis (DLA): Molecular Characterization and Organoid Culture of Circulating Tumor Cells (CTC) from Metastatic Castration Resistant Prostate Cancer (mCRPC)

M.B. Lambros, V.S. Gil, M. Crespo, M.S. Fontes, N. Mehra, R.P Neves, G. Folwer, B. Ebbs, P. Flohr, G. Seed, W. Yuan, J. Hunt, D. Moloney, D. Ayanda, J.F. Swennenhuis, K.C. Andree, S. Sumanasuriya, P. Rescigno, Z. Zafeiriou, J. Mateo, D. Bianchini, N.H Stoecklein, L.W.M.M. Terstappen, G. Boysen, J. S. de Bono

AACR. April 2017, Washington United States

The Isolation of Circulating Tumor Cells from Diagnostic LeukApheresis

K.C. Andree, A. Mentink, M Scholz, R. Kirchner, R. P. Neves, C. Driemel, R. Lampignano, H Neubauer, D Niederacher, T Fehm, W. T. Knoefel, J. C. Fischer, N.H. Stoecklein, L.W.M.M. Terstappen

AACR. April 2016, New Orleans United States

Isolation of Circulating Tumor Cells from Diagnostic Leukapheresis

K.C. Andree, A. Mentink, M. Scholz, R. Kirchner, R.P. Neves, C. Driemel, R. Lampignano, H. Neubauer, D. Niederacher, J. C. Fischer, N.H. Stoecklein, L.W.M.M. Terstappen

EMTRAIN PhD Workshop. 2016 Bayer, Berlin Germany

Standardization of technologies for CTC, ctDNA and miRNA enrichment, isolation and analysis for liquid biopsies during the first year of IMI'S CANCER-ID.

T. Schlange, N.H. Stoecklein, R.P. Neves, S. Pleier, Sabrina Bender, N. Brychta, M.V. LuetkeEversloh, K.C. Andree, L.W.M.M. Terstappen, T. Krahn

AACR. April 2016, New Orleans United States 


\section{Acknowledgments}

Here we go, the most read part of this book, and the opportunity for me to say thanks to a lot of people.

After 4, almost 5 years, this book is finally finished and I have met and worked together with many people along the way. First of all, I would like to thank my promotor, Leon Terstappen. Thank you for giving me a PhD position where I got the opportunity to work on techniques to isolate CTC from large volumes. The fact that this work was done within European consortia for me was of great value. Thank you for the monthly meetings that we had. Quite often I entered these meetings not sure or confident about my results or progress but your view and input were always very uplifting. Also, I really appreciate your goal oriented approach, especially at the end of my PhD track, when 4 years were over and only writing the book was left, this was very helpful in finishing things.

Dear committee members, prof. Nikolas Stoecklein, prof. John Martens, prof. Han Zuilhof, prof. Marcel Karperien and prof. Pascal Jonkheijm, thank you for accepting being part of my committee and taking the effort to review my thesis.

My Paranymphs, Anouk and Michiel. I am very happy to have the both of you at my side during my defense. Anouk we worked extensively together on finding a way to isolate CTC from DLA and were lucky to attend many consortium meeting and conferences together to present the progress. In addition, we processed and analyzed dozens and dozens of patient samples. I think it wouldn't have been that much fun without you and I really appreciate the amount of support you have given me. Michiel, I think you are one of persons I know the longest within MCBP and I enjoyed working on a shared project the last couple of months. I really appreciate your humor, your matter of fact attitude, fun conversations but also valued discussing experiments with you. Good luck with your own PhD, let those ferrofluids get them!

During my PhD I was fortunate to collaborate with many international colleagues throughout Europe. I would like to thank everyone I collaborated with within the CTCTrap and CANCERID consortium. Special thanks goes to the people in Dusseldorf, Nick, Rui, Christiane for always giving me a warm welcome and the nice projects we worked on together. I also like to thank Menno and Harry from the UMCG. Thanks a lot for the nice collaboration! 
Then the MCBP group which has many different personalities all complementing each other, creating an exquisite atmosphere to work in. The 'Roomies' from the most gezellig office in Carre: CR4.435. Sanne, Barbara, Guus, Yoon, Agustin and Andrea, thank you for all the small talks, laughs, work discussions, gossiping, fun, Tony's Chocolonely, but also the moments of silence when someone had a deadline and really needed to stay focused. Knowing to have such nice office mates made going to work even more fun!

Ingrid thank you for the Monday morning coffees (and later not Mondays anymore but Tuesdays or any other week day) to catch up on the weekend, discuss the performance of Heracles and always being there for a chat. Christian, thank you for your support and fixing many things, often you just showing up already was enough for a broken system to start working again! Joost S. your enthusiasm, work spirit, optimism has always been very inspiring. Leonie, it was great having many awesome conference trips together, especially traveling to Washington! Pepijn, Cheers!, onto the next Whiskey fair. Dodo, I think it is great having a chemist like you around, I have learned a lot! and I love your eagerness to keep learning new things. Joost vD, you are the fact man, always knows something about anything. Afroditi, thank you for being the ultimate worldwide restaurant guide. Cees, Aufried, Richard, Ivan, Frank, Markus, Hoon, Xichen, Fikri, Narges, thank you for being great colleagues!

Team VyCAP, Arjan, Joska, Lisa, Michiel and Joris, coffee breaks are just a bit more fun when you are around!

Over the last four years I got the opportunity to guide many bachelor and master students and they all contributed to greater of lesser extent to this book. Johan, Tanja, Yvonne, Fadi, Birgit, Pien, Rick and Fiona thanks a lot!

The Mexico crew, Agustin, Afroditi, Linda, Leonie and Lisa, thank you for contributing and for being part of this amazing trip including: despacito, mole, grasshoppers, tortilla's, a luxurious camp, hawler monkeys, cenotes, tequila, mariachi and many toilet visits. This really was a nice break during 4 years of hard work, it was great traveling with you!

Voor het zorgen voor ontspanning naast het harde werk wil ik al mijn vrienden bedanken. Een aantal in het bijzonder. Esil, dankje voor alle gezellige uitjes, lekkere etentjes en het kunnen delen van ervaringen als PhD student! Does en Krek, partypoppers, champagne, high beers, casinos, naar de ratten, op de boot, skeer en vooral pak ze! Dank voor oneindig veel plezier! Yoon and Hoon, thank you for becoming such great friends. 
Familie en schoonfamilie dank voor jullie support. Deick, bedankt! Speciaal voor je hulp bij wat Matlab werk ;). En je hoeft nu niet meer te vragen: 'ben je al een keer klaar?' Mijn ouders, dank voor jullie onvoorwaardelijke steun en fijn om te weten hoe trots jullie zijn. Dankzij jullie ben ik zover gekomen.

Lieve Niels, jij bent mijn steun en toeverlaat. Dankje voor het delen van blijdschap, enthousiasme maar ook voor het wegnemen van frustraties en stress gedurende 4 jaar PhD. Met jou is alles leuker. Dank dat je er altijd voor me bent!

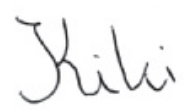



